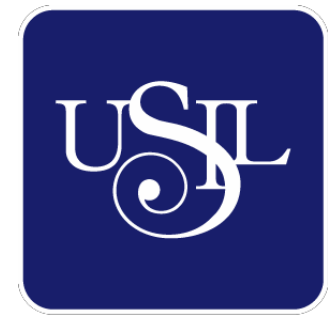

UNIVERSIDAD

SAN IGNACIO

DE LOYOLA

\title{
ESCUELA DE POSTGRADO \\ LA LÍNEA DE FIBROCEMENTO EN ETERNIT: UNA PROPUESTA DE CRECIMIENTO SOSTENIDO
}

Trabajo de Investigación para optar el grado de:

MIGUEL ANGEL CORONADO CAMAC

Maestro en Ciencias Empresariales con Mención en Gestión de Proyectos

LUIS PEREZ ARANGURI

Maestro en Ciencias Empresariales con Mención en Gestión de Proyectos

MAYRA ALEJANDRA RAMOS ORBEGOSO

Maestro en Ciencias Empresariales con Mención en Gestión del Capital Humano

DANNY PAOLO VICTORIO BLAS

Maestro en Ciencias Empresariales con Mención en Gestión Comercial

Asesor:

Dr. Edmundo Rafael Casavilca Maldonado

$$
\text { Lima - Perú }
$$

2020 


\section{Resumen Ejecutivo}

El 74\% de la población en el Perú requiere un mejoramiento en sus viviendas, el déficit es principalmente de orden cualitativo. Las paredes interiores y exteriores de las viviendas en el país suelen ser construidas en más del $80 \%$ con materiales de ladrillo, bloque de cemento, adobe o tapia; sin embargo, por el alto costo y tiempo de construcción se buscan otras alternativas que carecen de respaldo técnico. Inclusive en situaciones de emergencia, las viviendas temporales que se escogen no son las adecuadas alargando el sufrimiento de los afectados.

Eternit produce una alternativa confiable, ya que es una empresa líder inmersa en el rubro de la construcción de edificaciones en los segmentos de vivienda, institucional, educación, salud e industrial. Tiene dos unidades de negocio la de polietileno y la de fibrocemento. Los productos de fibrocemento son incombustibles, mantienen las temperaturas ambientales, aíslan los sonidos, tienen una dureza adecuada y son de fácil instalación con un costo menor, por lo que se presentan como una alternativa. Asimismo, la empresa tiene un $20 \%$ de capacidad ociosa en su unidad de negocio de fibrocemento, donde el déficit de producción se encuentra en las planchas planas de fibrocemento en un 59\% de utilización, a diferencia de las planchas onduladas cuyo porcentaje de utilización llega al 90\%, es decir, se identifica una oportunidad de incrementar la participación en el mercado logrando disminuir el costo marginal del producto y aumentar las utilidades de la compañía en su totalidad.

El presente trabajo de Tesis plantea un Plan estratégico que incluye desarrollar el mercado difundiendo los beneficios del producto. Asimismo, se reconoce como mercado potencial al estado por los programas de vivienda que tienen. Propone alianzas estratégicas con centros comerciales de mayor venta, la capacitación al personal encargado de la fabricación teniendo en cuenta que son el primer agente difusor; ofrecer un plan de línea de carrera y reestructurar las 
bandas salariales de acuerdo a dicho plan. Estas acciones realizadas dan como resultado el incremento del $4 \%$ en venta de la unidad de negocio de fibrocemento sostenible en los próximos 5 años.

Palabras Clave: Plan estrategico, construcción, fibrocemento, planeamiento, vivienda, planchas planas

\begin{abstract}
$74 \%$ of the population in Peru requires an improvement in their homes, the deficit is mainly of a qualitative nature. The interior and exterior walls of homes in the country are usually built in more than $80 \%$ with brick, cement block, adobe or brick materials; however, due to the high cost and construction time, other alternatives are sought that lack technical support. Even in emergency situations, the temporary homes chosen are not adequate, lengthening the suffering of those affected.

Eternit produces a reliable alternative, since it is a leading company immersed in the field of construction of buildings in the housing, institutional, education, health and industrial segments. It has two business units: polyethylene and fiber cement. Fiber cement products are fireproof, maintain ambient temperatures, isolate sounds, have adequate hardness and are easy to install at a lower cost, so they are presented as an alternative. Likewise, the company has $20 \%$ idle capacity in its fiber cement business unit, where the production deficit is found in flat fiber cement plates at $59 \%$ utilization, unlike corrugated plates whose utilization percentage reaches to $90 \%$, that is, an opportunity to increase market share is identified, reducing the marginal cost of the product and increasing the company's profits as a whole.
\end{abstract}


The present work of Thesis proposes a Strategic Plan that includes developing the market spreading the benefits of the product. Also, the state is recognized as a potential market for the housing programs they have. It proposes strategic alliances with the best-selling shopping centers, training the personnel in charge of manufacturing, bearing in mind that they are the first disseminating agent; offer a career line plan and restructure salary bands according to said plan. These actions carried out result in a $4 \%$ increase in the sale of the sustainable fiber cement business unit in the next 5 years.

Keywords: Strategic plan, construction, fiber cement, planning, housing, flat sheets 


\section{Tabla de contenido}

Resumen Ejecutivo .............................................................................................. I

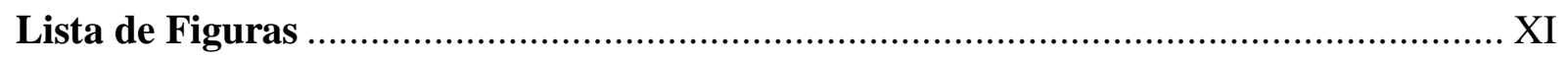

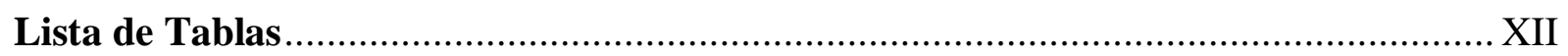

Capítulo I. Generalidades .............................................................................

1.1. Antecedentes ...................................................................................

1.1.1. Fibrocemento .............................................................................

1.1.2. Polietileno .......................................................................................

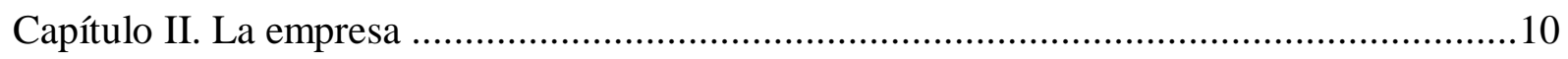

2.1. Antecedentes de la empresa .................................................................. 10

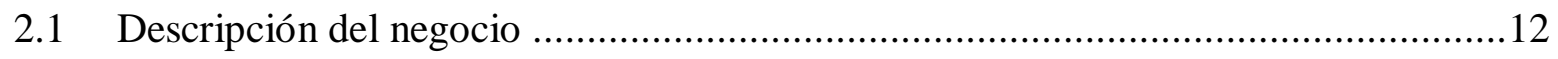

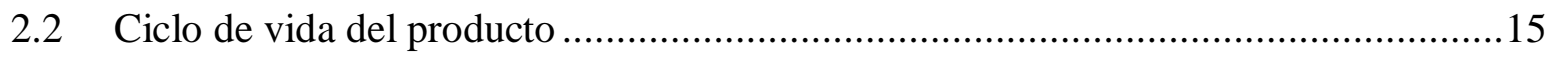

2.3 Estructura organizacional actual de la empresa ....................................... 17

2.4 Situación de Mercado y Financiera actual de la Industria ..................................22

Capítulo III: Formulación de visión, misión y valores de la empresa.................................24

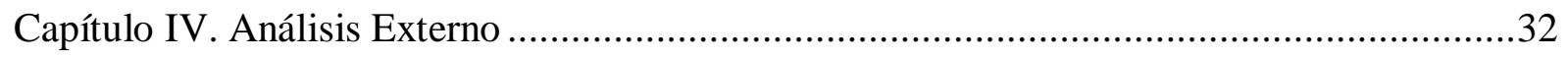

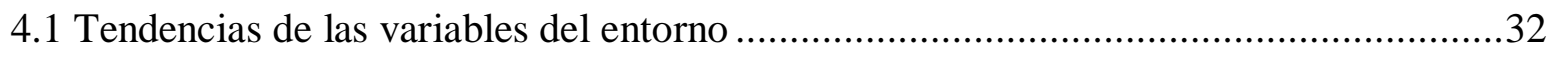


4.1.1 Análisis Político - Gubernamental ............................................................. 32

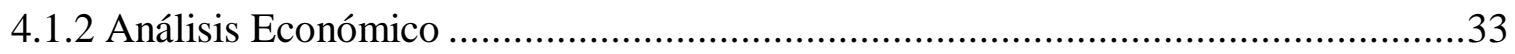

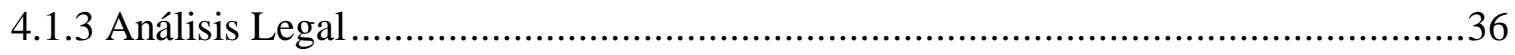

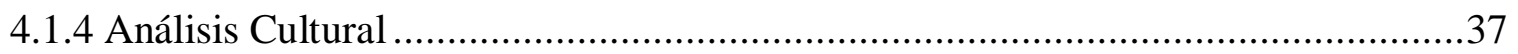

4.1.5 Análisis Tecnológico .........................................................................41

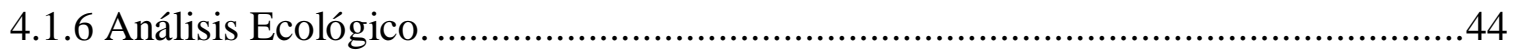

4.2 Impacto en clientes / proveedores de cada una de las variables del entorno.................45

4.2.1 Análisis Político Gubernamental ....................................................................45

4.2.2 Análisis Económico ................................................................................45

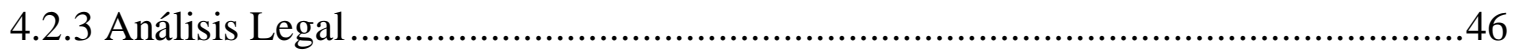

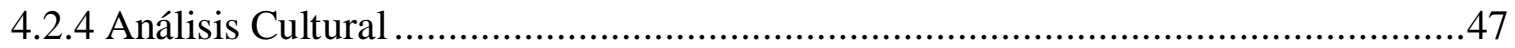

4.2.5 Análisis Tecnológico .................................................................4

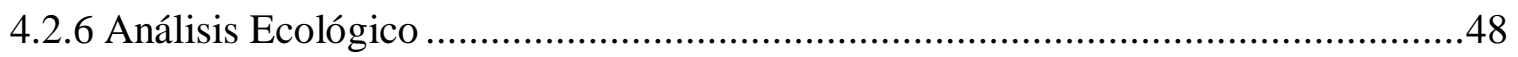

4.3 Efecto en la empresa de cada una de las variables del entorno. ..............................48

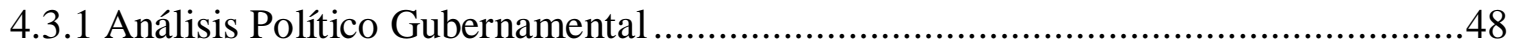

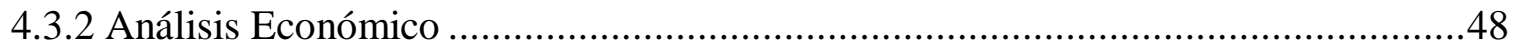

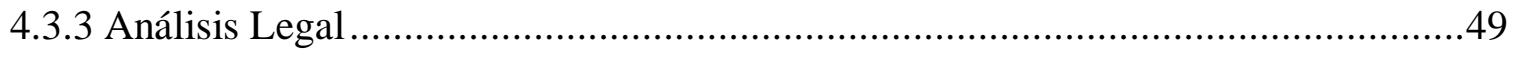

4.3.4 Análisis Cultural .................................................................................49

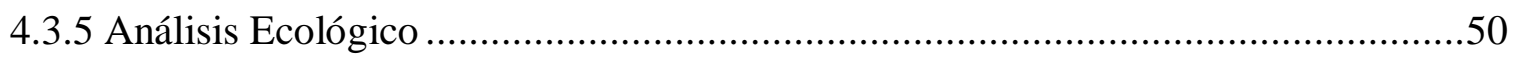

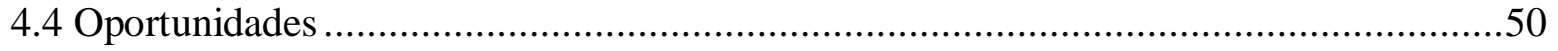


4.4.1 Oportunidades de la unidad de negocio de fibrocemento de Eternit. .50

4.5. Matriz de evaluación de los factores externos EFE .51

Capítulo V. Análisis Interno .58

5.1 Descripción de la Cadena de Valor ..............................................................58

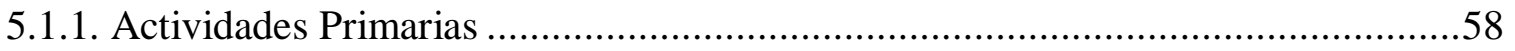

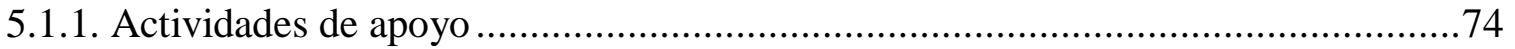

5.2 Indicadores de cada una de las actividades de la cadena de valor ..........................81

5.3 Benchmarking y Comparación con los líderes de la Industria................................86

5.4 Competencias de la Empresa ................................................................ 87

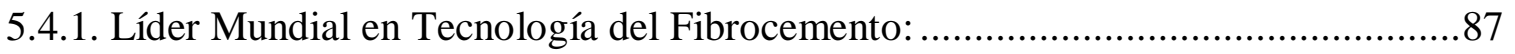

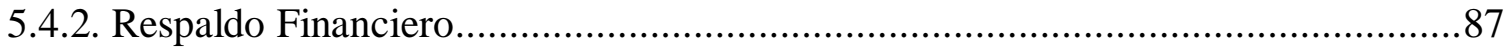

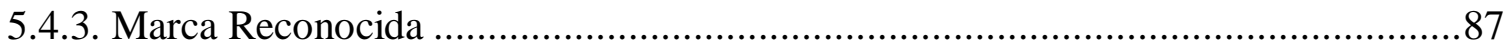

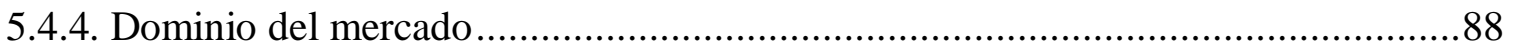

5.4.5. Variedad de productos y flexibilidad en productos y proyectos: .........................88

5.5 Identificación de la ventaja competitiva de la empresa .....................................89

5.6 Matriz de evaluación de los factores internos:...........................................91

Capítulo VI. Análisis de la Industria ...................................................................97

6.1 Descripción del Mercado (demanda) e Industria (oferta) .................................97

6.2 Descripción las cinco fuerzas competitivas de la industria .................................98

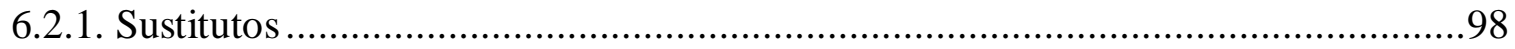


6.2.3. Clientes. 102

6.2.4. Proveedores .105

6.2.5. Competencia en el mismo sector.

6.3 Matriz de atractividad de cada una de las cinco fuerzas.................................... 110

6.4 Análisis del Grado de atractividad de la industria......................................... 111

6.4.1. Amenaza de Productos Sustitutos ................................................................. 112

6.4.2. Amenaza de Entrada de Nuevos Competidores Potenciales ............................. 112

6.4.3. Poder de Negociación de los Clientes...................................................... 113

6.4.4. Poder de Negociación de Proveedores....................................................... 114

6.4.5. Rivalidad entre Competidores de la Industria ............................................. 115

6.5 Matriz de Perfil Competitivo MPC ........................................................... 115

Capítulo VII: Formulación de los objetivos y diseño de las estrategias.............................119

7.1 Objetivos Estratégicos .................................................................... 119

7.2 Diseño y formulación de estrategias......................................................... 119

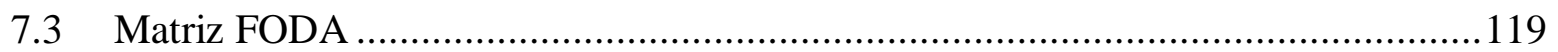

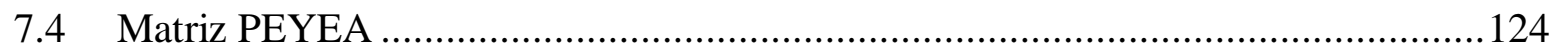

7.5 Matriz Interna - Externa ................................................................. 128

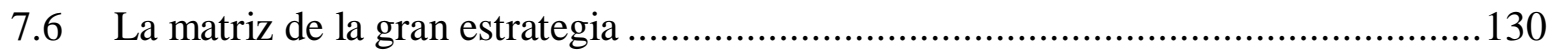

7.7 Resumen de las Estrategias Formuladas .................................................. 133 
Capítulo VIII. Selección de la Estrategia.

8.1 Método factores estratégicos claves

8.1.1. Criterios de selección

8.1.2. Matriz de selección

8.2 Matriz de planeación estratégica cuantitativa (MPEC) del plan de negocios.

8.3 Descripción de estrategia seleccionada

8.4 Descripción de estrategia contingente

Capítulo IX. Implementación de la Estrategia

9.1 Objetivos específicos según el Mapa de Estrategia.

9.2 Indicadores para cada uno de los Objetivos Específicos

9.3 Metas para cada uno de los Objetivos Específicos

9.4 Iniciativas (acciones a llevar a cabo para cado uno de los objetivos específicos),

Estrategias, Programas, Políticas, Reglas, Procedimiento

9.5 Responsable de cada una de las iniciativas

9.6 Presupuesto de cada una de las iniciativas.

Capítulo X: Evaluación financiera de la empresa

10.1 Proyección de estados financieros (situación actual y situación con la nueva estrategia) 157

10.2 Estado de resultados - situación actual 157

10.3 Balance General - situación actual. 161 
10.4 Flujo de efectivo - situación actual ¡Error! Marcador no definido.

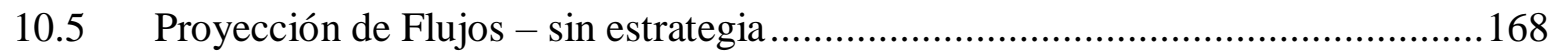

10.6 Proyección de Flujos y Estado de Ganancias y Pérdidas - con estrategia .............170

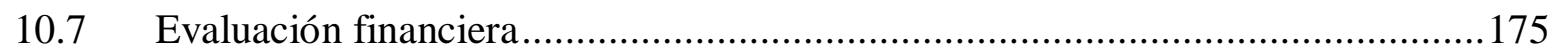

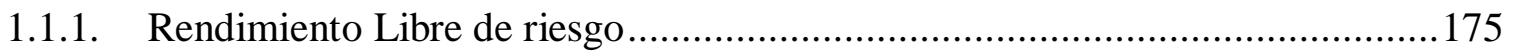

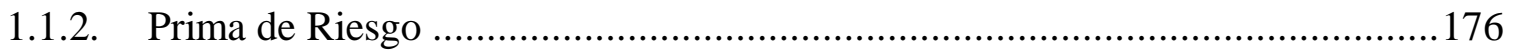

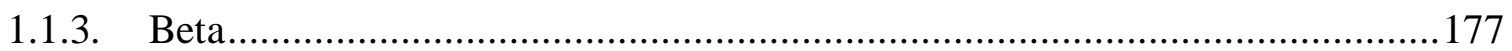

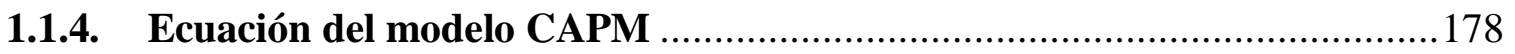

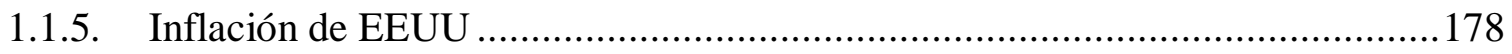

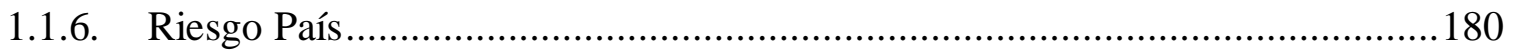

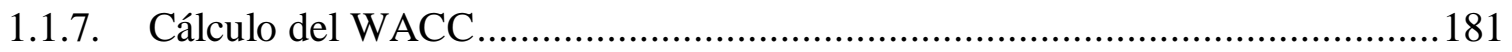

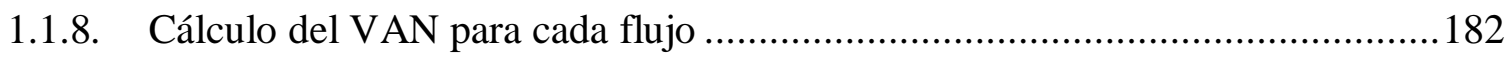

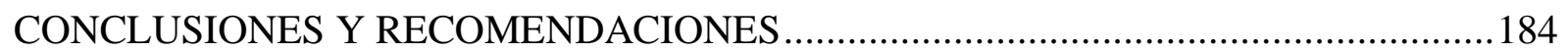




\section{Lista de Figuras}

Figura 1. Volumen de Ventas por año .......................................................................

Figura 2. Línea de tiempo de la evolución de Fabrica Peruana de Eternit ............................11

Figura 3. Unidades de Negocio Eternit............................................................... 12

Figura 4. Etapas del ciclo de la vida.............................................................. 15

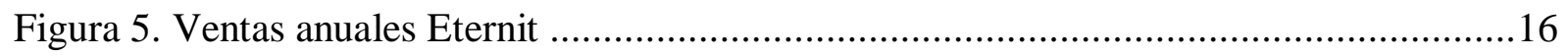

Figura 8. Organigrama Unidad de Negocio Fibrocemento .......................................... 18

Figura 9. Ventas en MM de soles .............................................................................22

Figura 10. Crecimiento económico anual en Latinoamérica. ...........................................34

Figura 11. PBI países de América Latina 1S2017...................................................35

Figura 12. Pilares del Crecimiento Económico (2018) ................................................36

Figura 13. Viviendas según su material constructivo.................................................38

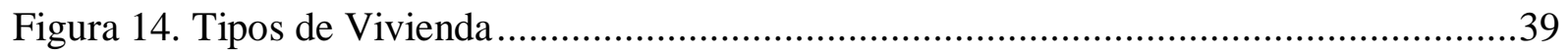

Figura 15. Tipo de Material de la Vivienda ............................................................. 40

Figura 16. Sedes por construir Panamericanos ........................................................55

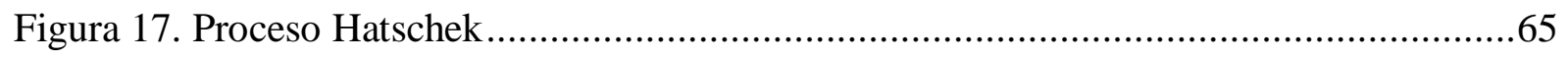

Figura 18. Organigrama Gerencia Comercial .........................................................69

Figura 19. Organigrama Gerencia de Marketing ........................................................ 71

Figura 20. Organigrama Gerencia de Finanzas ....................................................... 73

Figura 21. Organigrama Recursos Humanos ..........................................................75

Figura 22. Participación de Mercado y Comparación con competencia directa .....................88 


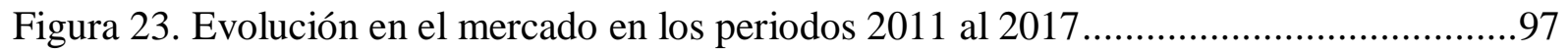

Figura 24. Participación de Mercado 2011 al 2017.......................................................98

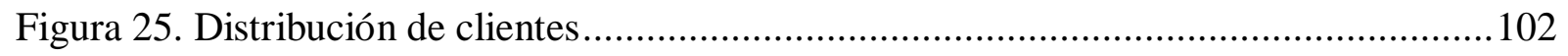

Figura 26. Tiendas Maestro en Perú en Línea de Tiempo. ............................................... 104

Figura 27. Ventas y EBITDA UNACEM ................................................................ 107

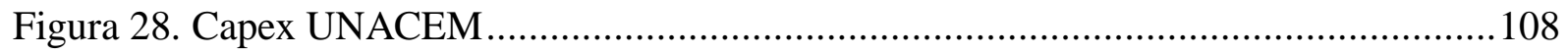

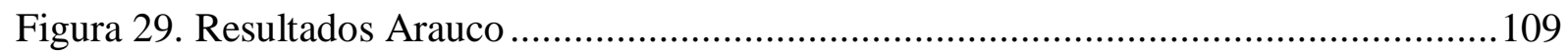

Figura 30. Resultado de la matriz PEYEA ............................................................. 127

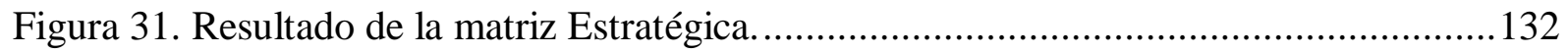

Figura 32. Mapa de estrategia ETERNIT ........................................................ 144

\section{Lista de Tablas}

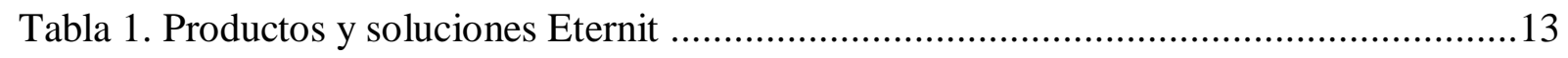

Tabla 2. Criterios de Evaluación de la Visión................................................................25

Tabla 3. Análisis de la misión de la Empresa ..........................................................28

Tabla 4. Alineamiento Estratégico Visión, Misión, Valores ...............................................31

Tabla 5. Oportunidades Eternit (Unidad de negocio de fibrocemento)..............................51

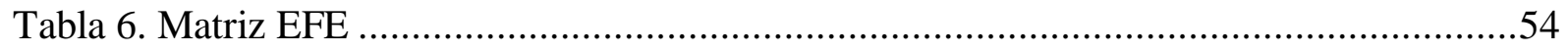

Tabla 7. Benchmarking Principales competidores ................................................... 86

Tabla 8. Ventaja Competitiva .............................................................................. 90

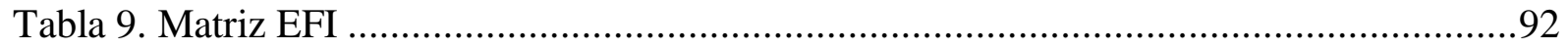

Tabla 10. Comparativo características de planchas de Fibrocemento vs Sustitutos. ............. 100

Tabla 11. Comparativo Precios Fibrocemento vs Sustitutos ........................................... 100 


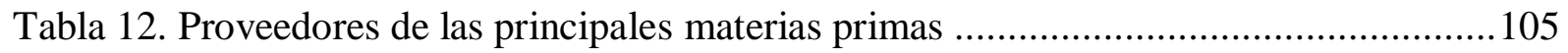

Tabla 13. Matriz de atractividad de las Cinco Fuerzas Competitivas ....................................110

Tabla 14. Matriz del Perfil Competitivo de la unidad de fibrocemento de Eternit ................117

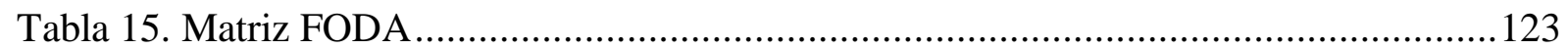

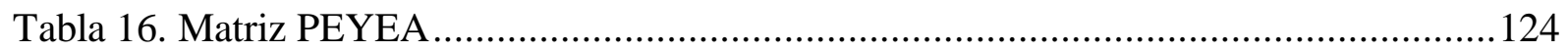

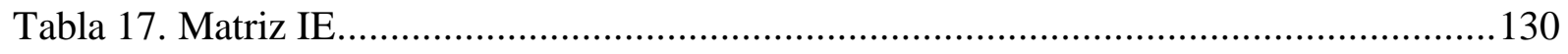

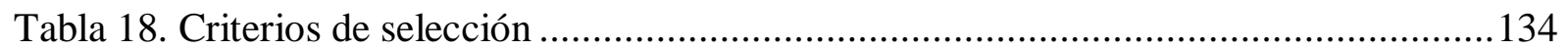

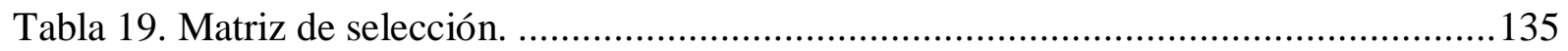

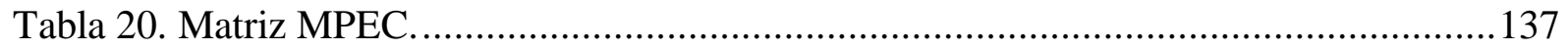

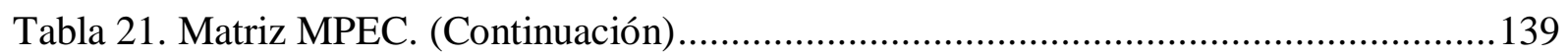

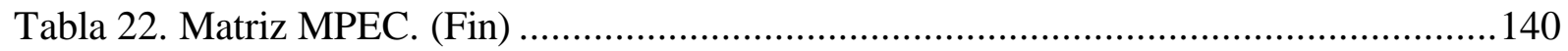

Tabla 24. Indicadores de medición para cada objetivo específico .........................................146

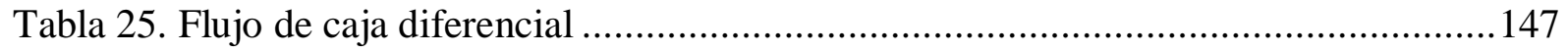

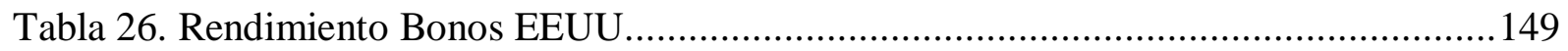

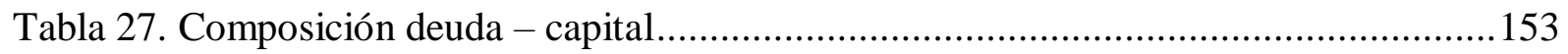

Tabla 28. Presupuesto por cada una de las iniciativas ........................................................156

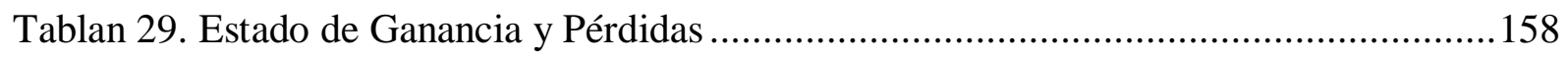

Tabla 31. Estado de Ganancias y Pérdidas - Análisis Horizontal...........................................160

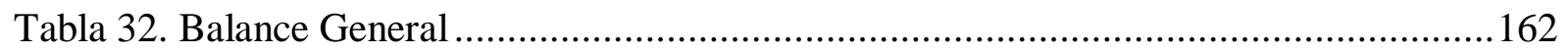

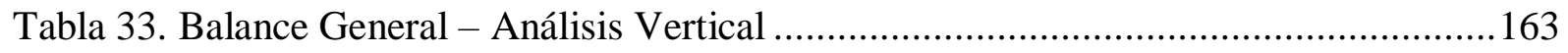

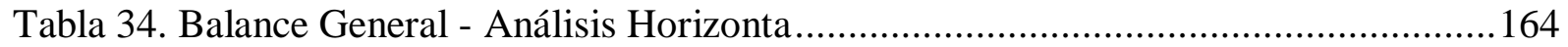

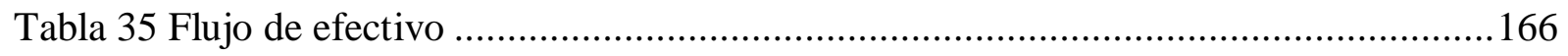

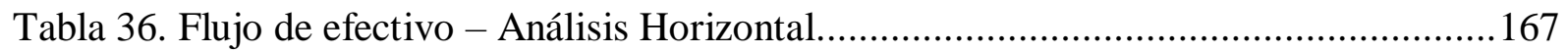


Tabla 37. Proyección de flujo de caja proyectado sin estrategia 169

Tabla 38. Proyección de flujo de caja proyectado con estrategia 172

Tabla 39. Proyección de flujo de caja proyectado con estrategia

Tabla 42. Retornos anuales / rendimientos históricos: 176

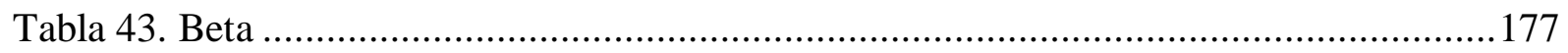

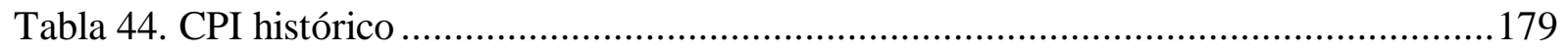

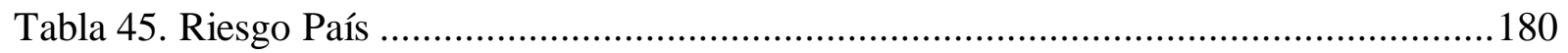

Tabla 47. Cálculo del VAN para cada flujo (en miles de nuevos soles) ............................ 182 


\section{Capítulo I. Generalidades}

\subsection{Antecedentes}

La empresa Eternit, perteneciente al grupo Etex, tiene más 77 años en el mercado. Su giro de negocio es el desarrollo y fabricación de materiales de fibrocemento y polietileno que se utilizan en la construcción de viviendas, instituciones de salud, educación, comercial e industrias.

Las unidades de negocio de Eternit:

\subsubsection{Fibrocemento}

La unidad de negocio de Fibrocemento cuenta con 3 líneas de Producción diferenciadas:

a) Planchas Planas de Fibrocemento: Son Placas de mezcla de cemento, fibra celulosa, sílice, agua al igual que agregados naturales y fabricada mediante un proceso de autoclave (alta presión, temperatura y humedad) que le brinda una gran estabilidad dimensional y alta resistencia. Aplicaciones:

- Paredes económicas

- Cielo rasos y aleros (sellado)

- $\quad$ Paredes exteriores de poca altura

- $\quad$ Paredes interiores - zonas de impacto y zonas húmedas (sellado)

- $\quad$ Paredes exteriores (sellado)

- $\quad$ Paredes exteriores - base para techos (sellado)

b) Techos (Roofing) o Planchas Onduladas: Techos de fibrocemento de alta resistencia y durabilidad. Adecuados para cualquier condición Climática, resisten humedad, intensas lluvias, nieve o granizo. 
c) Techos decorativos: La Teja Andina es una plancha decorativa de fibrocemento que por sus características dimensionales y de peso, son cubiertas para uso domésticos y obras de especificación.

\subsubsection{Polietileno}

Dedicada a la fabricación de tanques y cisternas para almacenamiento de agua, así como biodigestores.

Etex está posicionado en más de 40 países, llegando a tener 17.000 empleados. En Perú, Eternit tiene 2 plantas, siendo la más relevante la situada en el Cercado Lima por el tamaño y alta calidad de producción, asimismo, tiene la sede Chiclayo la cual se inauguró en el 2014.

Por ser del rubro de construcción, la caída en los últimos años del sector ha sido de consideración, ya que se acumuló el año pasado un decrecimiento de 3.15\%, aunque se espera una recuperación en su demanda y en su sector, vinculada con las obras para la reconstrucción en la segunda mitad del año, informó el Banco Central de Reserva. (Gestión, 2017, párr. 2).

El panorama interno, tanto económico como político, durante el año 2016 y el 2017 sigue la misma tendencia, es decir, no ha sido favorable para el desarrollo del sector construcción en el país. Además, de acuerdo a lo indicado por el INEI (2017), el sector de construcción ha visto una desaceleración en departamentos como Ayacucho (-17.4), San Martin (-13.4), Ancash (-9.1), Cusco (-8.9) y Piura (-8.5), sobre todo el último año. Siendo muchos de los mencionados lugares claves para la demanda del producto de cemento y sus derivados. "El déficit habitacional en Lima Metropolitana, que comprende 43 distritos, alcanzó las 612 mil 464 unidades de vivienda el 2016" (HD Group, 2017).

El déficit habitacional al que se hace referencia, se puede entender de dos maneras, el cualitativo y el cuantitativo. 
a) Cuantitativo. El déficit cuantitativo corresponde a viviendas que necesitan ser reemplazadas para satisfacer los siguientes puntos; primero la necesidad de hogares secundarios que aspiran a comprar una vivienda; y segundo, para reponer viviendas que no son adecuadas para habitarlas, o porque además en ella viven dos o más hogares. Del total del déficit señalado anteriormente, 251,942 viviendas corresponden al déficit cuantitativo, que porcentualmente representa el $41.1 \%$.

b) Cualitativo. El déficit cualitativo corresponde a viviendas existentes con deficiencias en la calidad del material de construcción, hacinamiento y acceso a los principales servicios básicos como el agua potable, electricidad y desagüe. Del déficit diferencial 360,522 unidades habitacionales corresponden al déficit cualitativo que porcentualmente representa el 59\%.

\section{Definición del Problema u Oportunidad.}

De acuerdo al comportamiento comercial y financiero de las unidades de negocio de la empresa Eternit, se ha podido identificar que la unidad de negocio de fibrocemento tiene un nivel de utilización de solo el 82\%, por debajo en comparación con las otras filiales del grupo que se encuentran por encima del 95\%; y dada la demanda incremental de este producto, esto representa una oportunidad para la empresa, por eso se considera importante diseñar un plan estratégico en la unidad de negocio de fibrocemento.

La poca actividad de la demanda interna y la baja de inversión del sector público y privado; afectaron los volúmenes de venta de los principales productos que generó la empresa durante el 2016. A raíz del anunciado Fenómeno del Niño en el último trimestre del 2015, se pudo advertir una demanda importante de techos; sin embargo, el volumen de ventas no fue el esperado, decreció en un $26 \%$. 
Es así como, diferentes materiales de construcción registraron una conducta negativa con respecto al volumen de ventas. Por ejemplo, la teja andina tuvo una caída en el volumen de ventas de -3\%; influenciado principalmente por la menor inversión de los gobiernos regionales y municipales.

Asimismo, en Eternit la producción de planchas planas de fibrocemento tiene actualmente una utilización de solo el 59\% de su capacidad, mientras que la producción de planchas onduladas se encuentra a más del $95 \%$ de la capacidad

Con respecto a la línea planchas planas de fibrocemento, experimentó un crecimiento de 3\% respecto al año 2015, ya que el desarrollo de importantes proyectos dentro del sector salud y comercio fueron especificados con la marca de la empresa, lo cual apoyó en que no se viera afectado como los otros.

Todo lo mencionado en la coyuntura nacional sobre su lento crecimiento y desaceleración, nos lleva a la necesidad de fortalecer la unidad de negocio de fibrocemento de Eternit, de tal modo que suponga obtener mayores niveles de rentabilidad durante los próximos 10 años y un crecimiento sostenido a mediano y largo plazo.

\section{Justificación del Plan Estratégico.}

Considerando los decrecimientos de ventas en la unidad de negocio de Fibrocemento y viendo el potencial del $18 \%$ de capacidad sin utilizar, resulta importante realizar un plan estratégico que nos permita aprovechar esta oportunidad y afrontar el decrecimiento en las ventas de algunas líneas de productos por la coyuntura actual del mercado e incrementar los niveles de contribución a la empresa en su totalidad, teniendo en cuenta que esta unidad de negocio representa el 90\% de participación dentro de la empresa. 
Justificación práctica. La presente investigación aportará a la literatura científica nuevas formas de implementar un plan estratégico para fortalecer la unidad de negocios de fibrocemento de Eternit, permitiendo un crecimiento del negocio y aporte a la empresa en su conjunto; demostrándose su impacto financiero y comercial.

\section{Justificación social.}

Actualmente existe un déficit de vivienda en el país que puede ser cubierto con sistemas de vivienda económicos y/o temporales para situaciones de emergencia, como el presentado durante el año 2017 denominado el fenómeno del niño costero. Estos sistemas de vivienda se presentan como una alternativa para el trabajo social gubernamental. Asimismo, según Cámara Peruana de la Construcción (CAPECO, 2017,), el 70\% de las viviendas y edificios construidos en Lima son informales o no cumplen con la Norma Técnica de Edificaciones. De acuerdo con la Publicación del Diario el Comercio del 8 de octubre del 2017, una de las razones es el desabastecimiento y altos costos de materiales adecuados como el Ladrillo, el cual en muchas ocasiones se usa de manera inadecuada en la Mayoría de las edificaciones. En este Sentido el fibrocemento constituye una alternativa para cumplir con los reglamentos de construcción del país.

\section{Justificación ambiental.}

Este material tiene un ciclo de vida de alrededor de 25 a 30 años de duración, y es reciclable para la producción del mismo producto o relleno en construcciones Civiles.

Justificación comercial. El Fibrocemento pasó de ser una solución a diferentes procesos en la construcción desde su invención en los años 1900 hasta 1990, y se convirtió en un producto cuestionado por el uso de asbesto, cuyo uso fue prohibido por el riesgo cancerígeno que presentaba. Desde entonces el Fibrocemento ha variado su composición y reemplazado el asbesto por materiales como la celulosa o fibra natural y la fibra sintética. Este factor ha influido 
en la percepción del país respecto a este producto, sumado a la poca difusión comercial. La preferencia del mercado peruano por tanto permanece en los materiales en base a ladrillo y concreto armado. El mercado de la construcción no es ajeno a esta preferencia, pues se debe al usuario final quien condiciona el tipo de material a utilizar.

Esta preferencia del mercado genera que la demanda de este tipo de productos sea muy baja con respecto a la capacidad de producción con la que se cuenta, específicamente en la unidad de negocio de fibrocemento. Este trabajo permite identificar las variables que impulsan las

preferencias del consumidor al uso de material noble y no pensar en la alternativa del

Fibrocemento, y plantear las estrategias que nos permitan cambiar estas preferencias y llevarlas a la de nuestro producto.

\section{Justificación Financiera.}

De acuerdo con lo expuesto, si logramos cambiar las preferencias del consumidor a fibrocemento, tenemos la oportunidad de fortalecer la unidad de negocio haciendo uso del $100 \%$ de la capacidad de producción, que nos permitirá la reducción de costos y mayor competitividad en el mercado, logrando incrementar los márgenes de la compañía.

Eternit cuenta actualmente con el 95\% de Market Share, sin embargo, existe una oportunidad de venta del $20 \%$ de las ventas actuales de acuerdo con su capacidad de producción actual. Es decir $4 \mathrm{MM}$ de $\mathrm{m} 2 \mathrm{n}$ con un ingreso en ventas aproximado de 25MM de soles. 


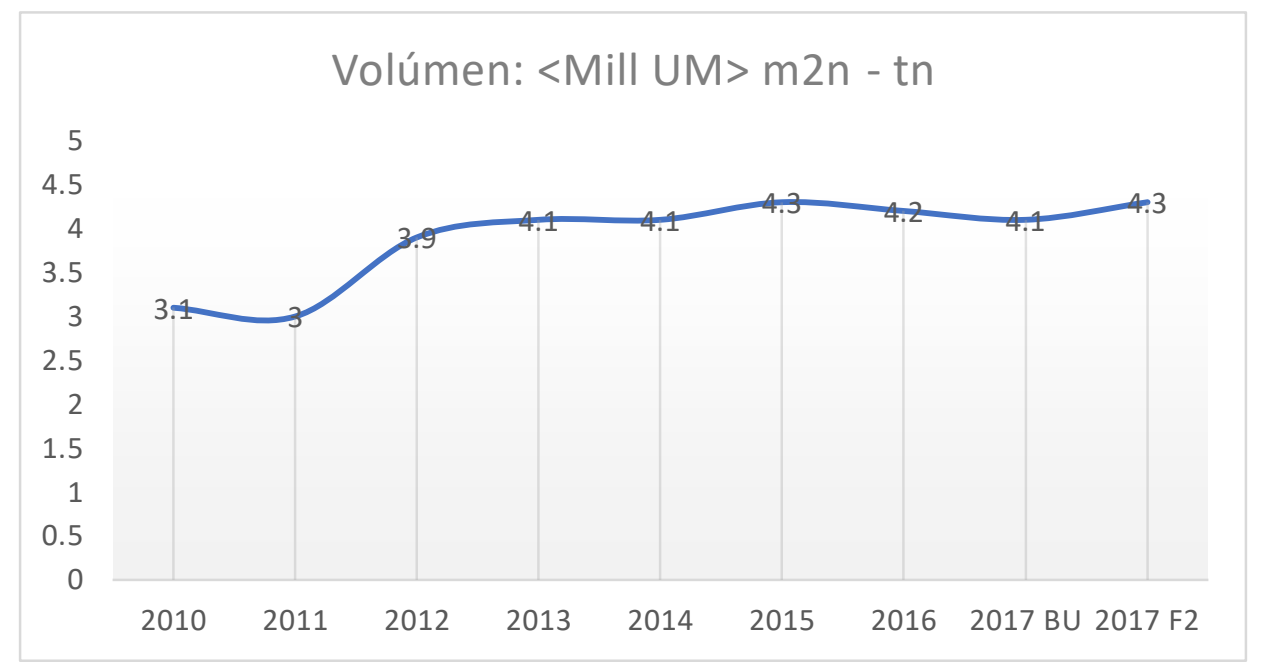

Figura 1. Volumen de Ventas por año

Fuente: Elaboración propia

Factores de Diferenciación y Posicionamiento.

Factores de Diferenciación

"Construye un lugar seguro para tu familia cuidando el medio ambiente"

\section{Factores de Posicionamiento}

Considerando que el factor de diferenciación se enfoca en el cuidado tanto de la familia como del medio ambiente, se considera conveniente establecer los siguientes factores de posicionamiento para reforzarlo:

a) El fibrocemento es un material que brinda menor posibilidad de causar daño ante un sismo; debido al menor espesor en comparación de la pared de concreto.

b) El fibrocemento es un producto incombustible.

c) El fibrocemento es un aislante térmico y acústico.

d) El fibrocemento tiene la dureza adecuada 
e) El fibrocemento se puede instalar y recubrir fácilmente

f) Los fibrocementos aportan a la sustentabilidad del planeta, el impacto en la huella de carbono es menor en construcción de concreto.

\section{Objetivo General y Objetivos Específicos}

\section{Objetivo General.}

De acuerdo con la información obtenida por la empresa, se considera conveniente definir como objetivo general el siguiente:

"Elaborar un Plan estratégico que permita a la compañía mantener los márgenes de utilidad y el market share actual."

Objetivos Específicos.

a) Analizar el alineamiento estratégico de la Misión, Visión y valores de la empresa. para evaluar su direccionamiento con los objetivos estratégicos.

b) Analizar la situación de la empresa mediante matrices de gestión con información de expertos, directivos, información interna y de mercado.

c) Formular los objetivos y diseñar las estrategias con la información obtenida del análisis de la empresa, para seleccionar la mejor estrategia que permita lograr el objetivo general.

d) Elaborar el análisis financiero de la estrategia seleccionada para determinar el rendimiento económico y financiero y detallar el plan de implementación.

\section{Alcances y Limitaciones.}

Alcances.

a) Para la elaboración del plan estratégico se tomará la información hasta diciembre 2017 para el análisis interno y externo. 
b) El plan estratégico abarca desde el año 2018 - 2023.

c) El alcance geográfico será a nivel Lima Metropolitana.

d) El presente planeamiento estratégico abarca la unidad de negocio de fibrocemento.

e) Se realizará visitas a la planta de Eternit y se realizarán entrevistas por competencias a los jefes y expertos de la planta.

f) Asimismo, utilizaremos información primaria y virtual para enriquecer la investigación.

g) Contamos con información internacional confiable, la cual utilizaremos como referencia para poder replicarla referente al impacto social y económico.

\section{Limitaciones.}

a) El plan estratégico de la unidad de negocio de fibrocemento solo se podrá desarrollar a nivel de Lima Metropolitana. 


\section{Capítulo II. La empresa}

\subsection{Antecedentes de la empresa}

Fábrica Peruana Eternit S.A, fue constituida en abril de 1940 por empresarios belgas y

peruanos, miembros fundadores Sr. German Aguirre U., Dr. Pablo Carriquiry M., Sr. Jean Emsens.

Eternit es una compañía que tiene como giro de negocio la producción y comercialización de materiales de construcción principalmente a base de fibrocemento y la mayoría de sus productos se comercializan bajo la marca Superboard (Memoria de Fábrica Peruana de Eternit, 2012). Eternit cuenta con 3 plantas a Nivel Nacional:

a) Planta Lima.

b) Planta Chiclayo

Lima es la planta más emblemática de Eternit; la cual se encuentra en el Cercado de Lima, esta fue inaugurada en el año 1940. Las unidades de negocio que están instaladas en esta sede son las de fibrocemento y tanques de polietileno. Dentro de la unidad de fibrocemento se fabrican la teja andina decorativa, las planchas planas y planchas onduladas. Por otro lado, también producen cisternas y biodigestores de la unidad de tanques de polietileno.

Con miras de descentralizar el negocio se inaugura la primera planta a las afueras de la capital en el año 2000, en Chiclayo, con el fin de optimizar los tiempos de atención y entrega de los productos para los clientes en el Norte del país. Los tanques de polietileno domésticos se fabrican en esta planta. 

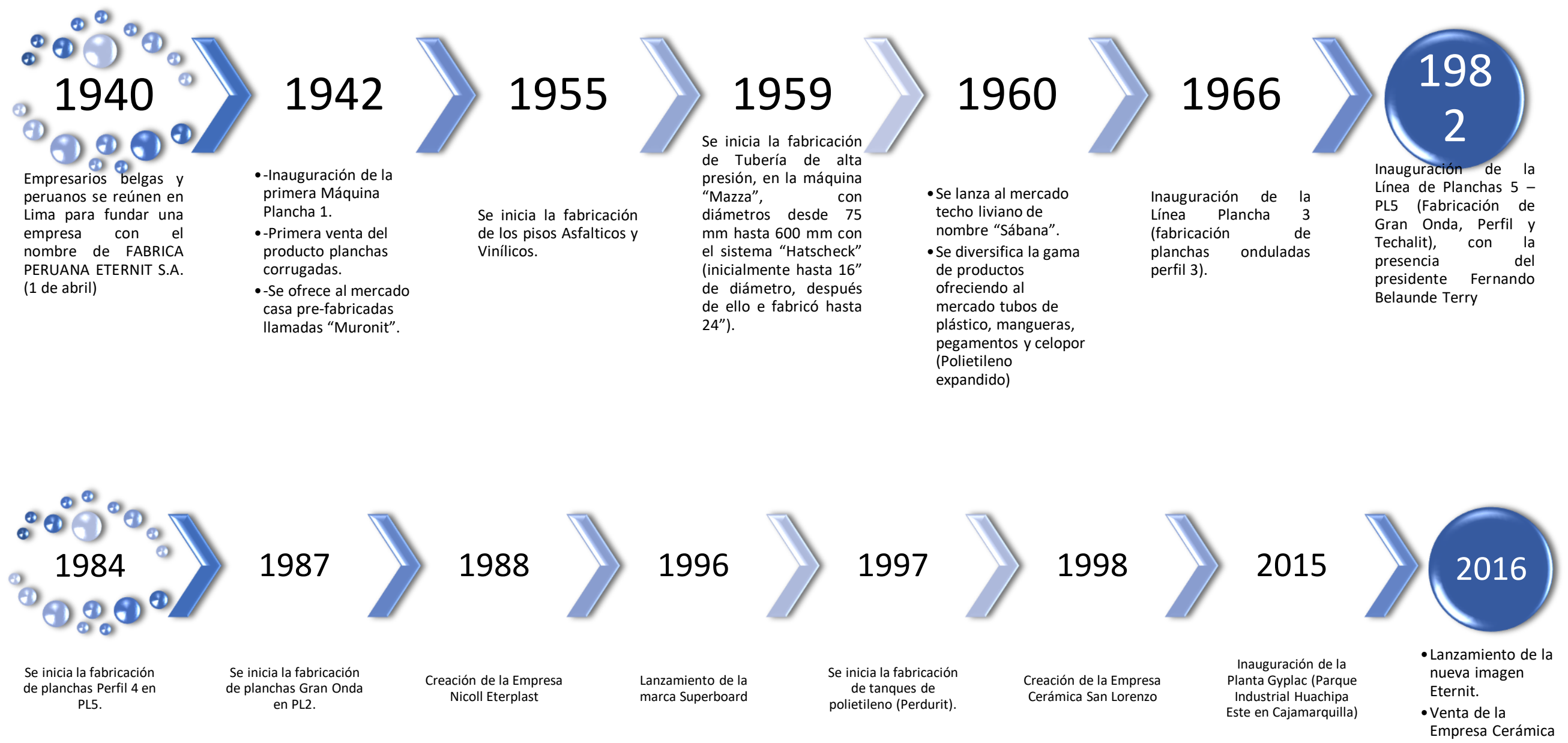

Figura 2. Línea de tiempo de la evolución de Fabrica Peruana de Eternit

Fuente: Elaboración propia 


\subsection{Descripción del negocio}

La empresa Eternit es considerada líder en el mercado, tiene como giro de negocio el desarrollo y fabricación de materiales de fibrocemento y polietileno. Estos materiales se utilizan para construir tanto en sectores de vivienda, comercial, institucional, educación, salud e industria edificaciones. Eternit tiene más de 77 años en el mercado pertenece al grupo Etex el cual cuenta con 100 empresas especializadas en el rubro de la construcción ubicadas en 40 países del mundo contando con más de 17.000 empleados, de los cuales el 20\% se encuentran en Perú.

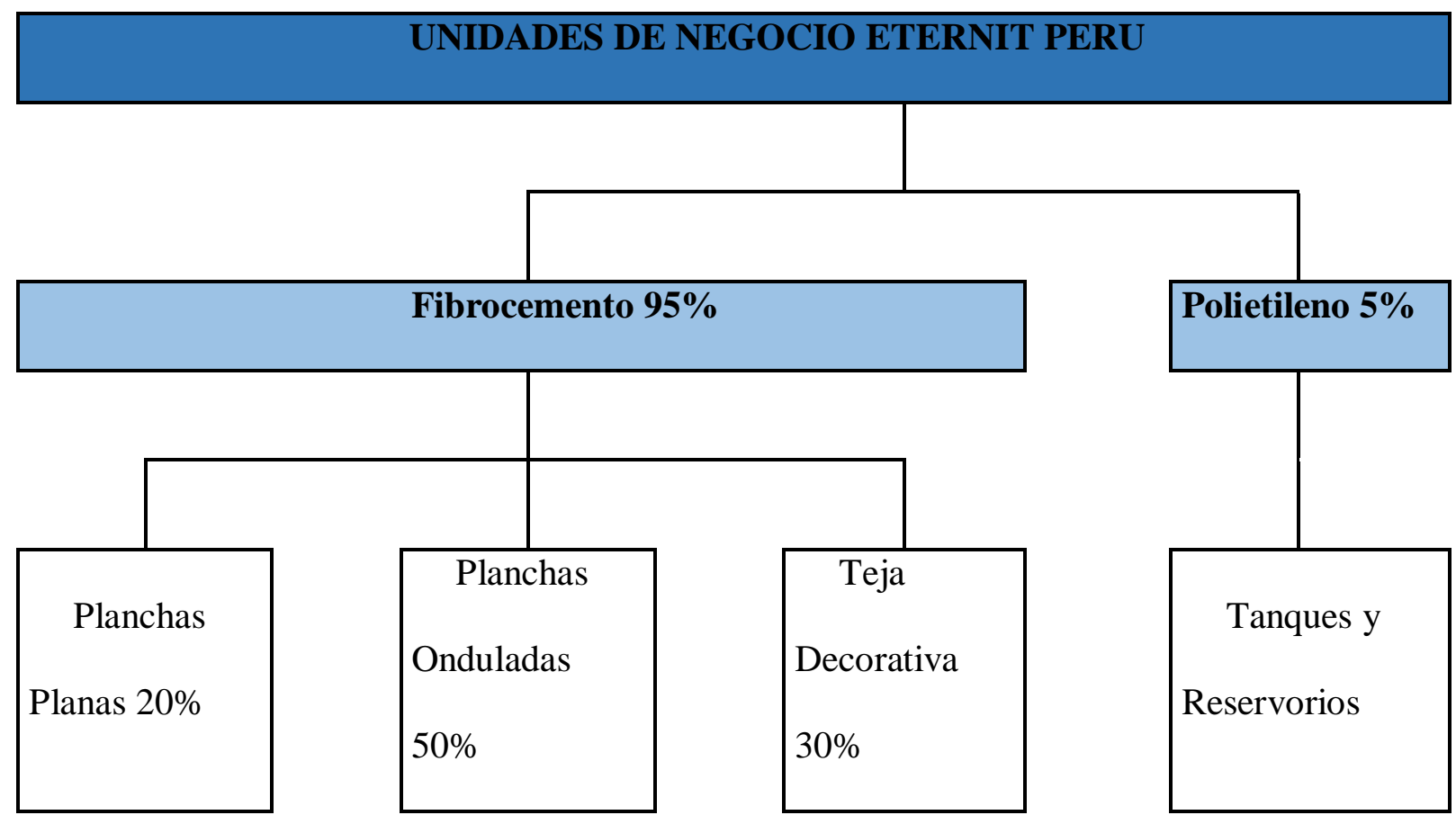

Figura 3. Unidades de Negocio Eternit 
Los productos y soluciones que brindan se describen en la tabla 1.

Tabla 1. Productos y soluciones Eternit

\begin{tabular}{|c|c|c|c|c|}
\hline ITEM & PRODUCTO & FOTO & DESCRIPCION & USO \\
\hline 1 & $\begin{array}{c}\text { Techos } \\
\text { Ondulados }\end{array}$ & & $\begin{array}{l}\text { Techos de } \\
\text { fibrocemento de alta } \\
\text { resistencia y } \\
\text { durabilidad. } \\
\text { Adecuados para } \\
\text { cualquier condición } \\
\text { climática, resisten } \\
\text { humedad, intensas } \\
\text { lluvias, nieve o } \\
\text { granizo. }\end{array}$ & $\begin{array}{l} \\
\text { - Coberturas } \\
\text { para techos } \\
\text { industriales, } \\
\text { edifícios, } \\
\text { casas. }\end{array}$ \\
\hline 2 & $\begin{array}{l}\text { Planchas } \\
\text { Planas }\end{array}$ & & $\begin{array}{l}\text { Placas de una } \\
\text { mezcla de cemento, } \\
\text { fibra celulosa, sílice, } \\
\text { agua al igual que } \\
\text { agregados naturales } \\
\text { y fabricados } \\
\text { mediante un proceso } \\
\text { de autoclave (alta }\end{array}$ & $\begin{array}{l}\text { - Cielo rasos } \\
\text { y aleros } \\
\text { (sellado) } \\
\text { - Paredes } \\
\text { exteriores } \\
\text { de poca } \\
\text { altura. } \\
\text { - Paredes } \\
\text { interiores }\end{array}$ \\
\hline
\end{tabular}




\begin{tabular}{|l|l|l|} 
& presión, temperatura & - Paredes \\
& y humedad) & exteriores \\
\hline
\end{tabular}

\begin{tabular}{|c|c|c|c|c|}
\hline ITEM & PRODUCTO & FOTO & DESCRIPCION & USO \\
\hline 3 & $\begin{array}{c}\text { Techos } \\
\text { Decorativos }\end{array}$ & & $\begin{array}{l}\text { La teja andina } \\
\text { es una plancha } \\
\text { decorativa de } \\
\text { fibrocemento que } \\
\text { por sus } \\
\text { características } \\
\text { dimensionales y } \\
\text { de peso, son } \\
\text { cubiertas para uso } \\
\text { domésticos y } \\
\text { obras de } \\
\text { especificación. }\end{array}$ & $\begin{array}{l}\text { Coberturas } \\
\text { Decorativas para } \\
\text { techos Edificios, } \\
\text { casas, etc. }\end{array}$ \\
\hline 4 & Polietileno & eternit eterni & $\begin{array}{l}\text { Son tanques y } \\
\text { cisternas a base de } \\
\text { polietileno }\end{array}$ & $\begin{array}{l}\text { Almacenamient } \\
\text { o de agua potable y } \\
\text { químicos } \\
\text { industriales. }\end{array}$ \\
\hline
\end{tabular}

Fuente: Elaboración propia 


\subsection{Ciclo de vida del producto}

De acuerdo con Kotler \& Armstrong (2003), el ciclo de vida de un producto muestra el "curso de las ventas y utilidades a lo largo de su existencia”, esta teoría establece cinco etapas bastante marcadas, las cuales se pueden observar en la figura 3 y son:

a) Desarrollo de producto, cuando hablamos de un producto completamente nuevo

b) Introducción, cuando un producto es lanzado al mercado y las ventas van creciendo muy lentamente

c) Crecimiento, cuando el producto ha sido aceptado por el mercado y las ventas crecen rápidamente.

d) Madurez, el producto se encuentra posicionado y aceptado, el crecimiento de la etapa anterior se contrae y se busca mantenerse la posición del mercado.

e) Declive, cuando las ventas del producto caen y se debe decidir si el producto se reinventa o sale del mercado.

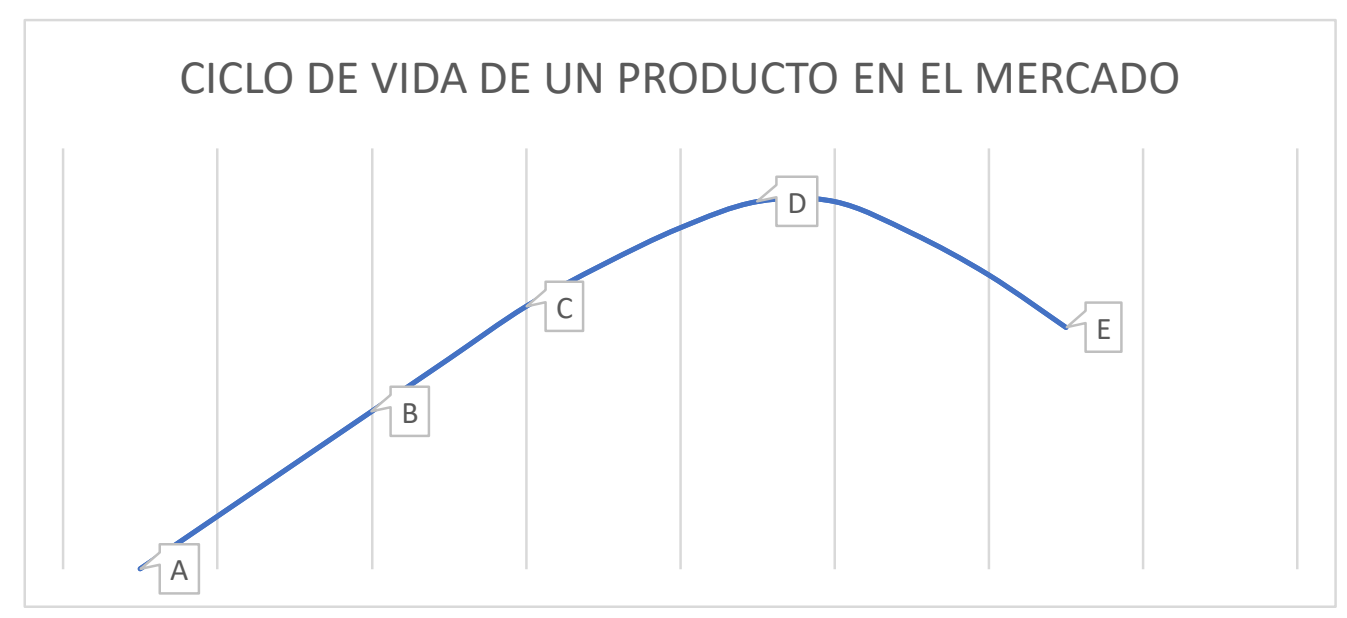

Figura 4. Etapas del ciclo de la vida.

Para el análisis de ciclo de vida del producto hemos detallado la evolución de ventas de la empresa en su unidad de negocio de fibrocemento y la proyección estimada para los próximos 5 
años. Se espera crecer un 15\% al 2023 con las inversiones proyectadas. Esta información nos lleva a pensar que los productos de fibrocemento en el País están en su etapa de crecimiento llegando a la etapa de consolidación

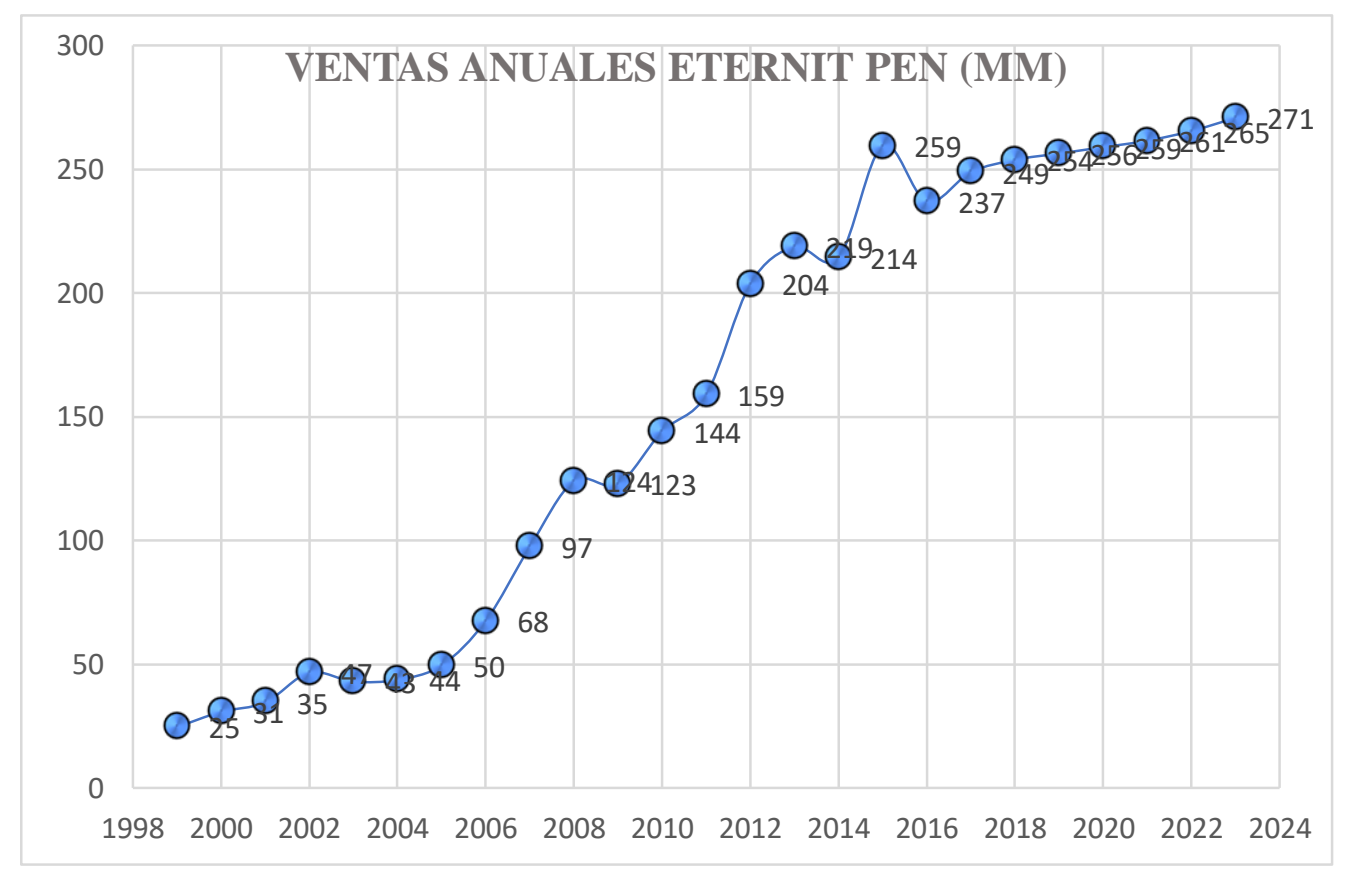

Figura 5. Ventas anuales Eternit

Fuente: Elaboración propia

Asimismo, podemos observar la evolución del consumo en MMm2n (Figura 6), la participación mercado (Fig. 7), y las ventas de Eternit de fibrocemento, convirtiéndose en una gran oportunidad, mostrándonos que nos encontramos en una etapa de introducción para este producto específico dentro de un ciclo de vida. 


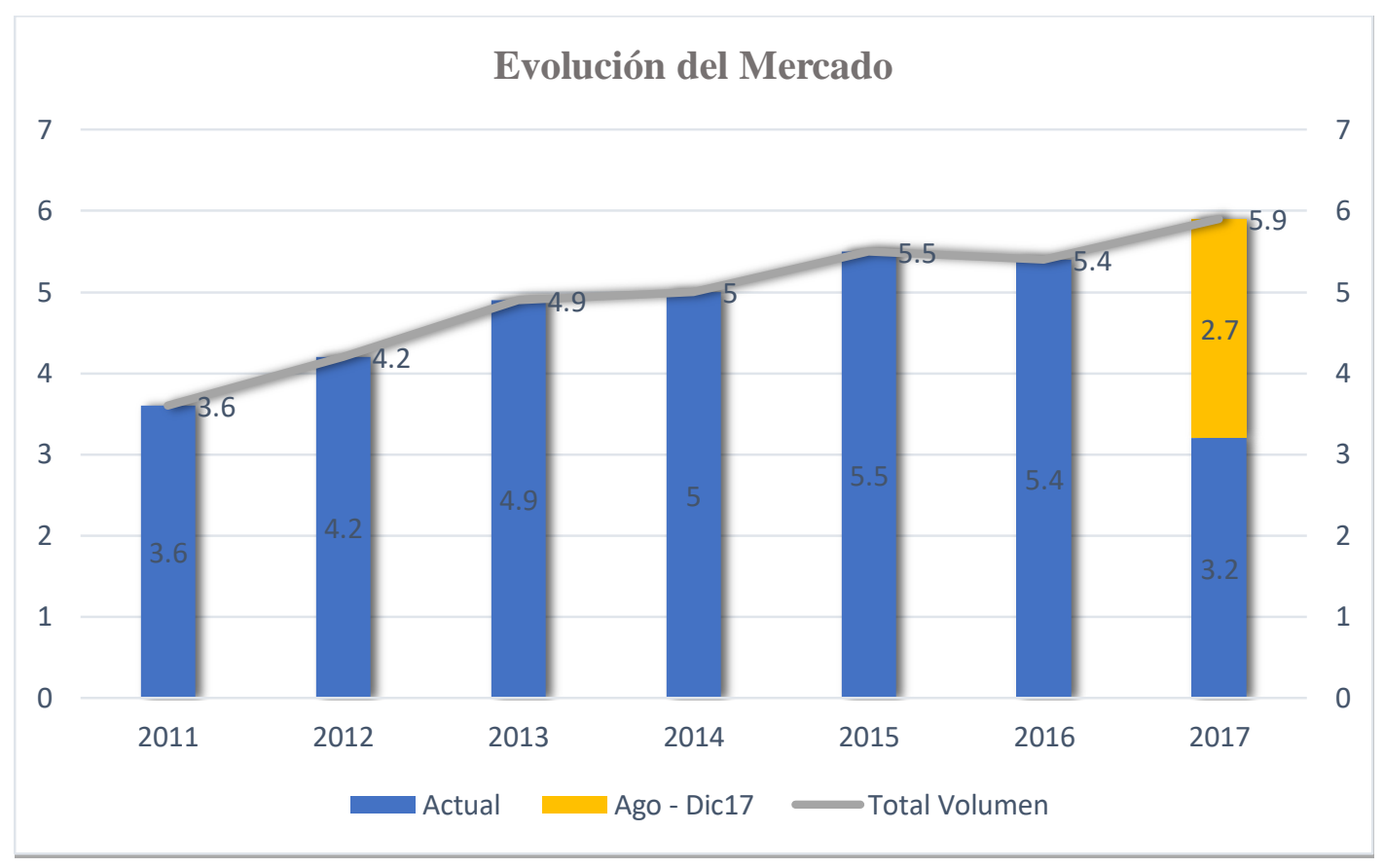

Figura 6. Evolución en el mercado en los periodos 2011 al 2017

Fuente: Elaboración propia

Participación del Mercado 2017

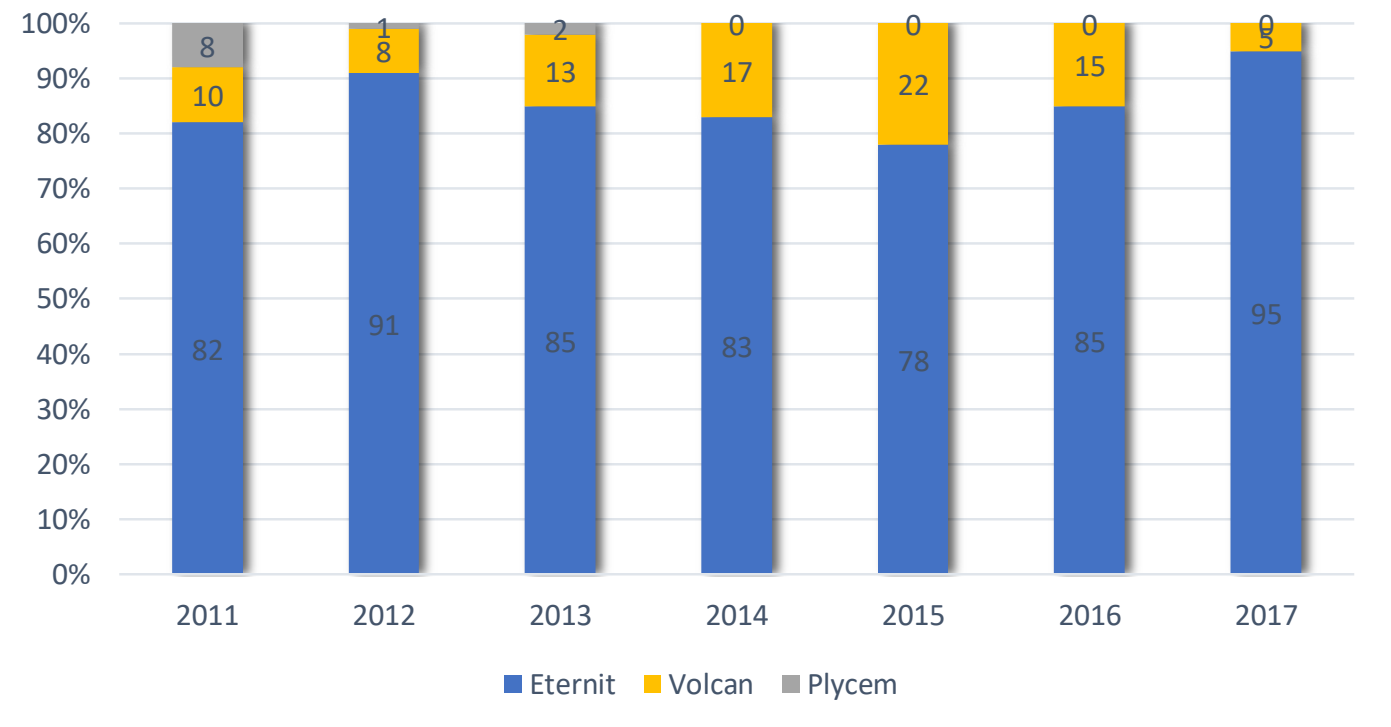

\subsection{Estructura organizacional actual de la empresa}

La unidad de negocio de fibrocemento está estructurada de la siguiente manera:

Figura 7. Participación de Mercado 2011 al 2017

Fuente: Elaboración propia 


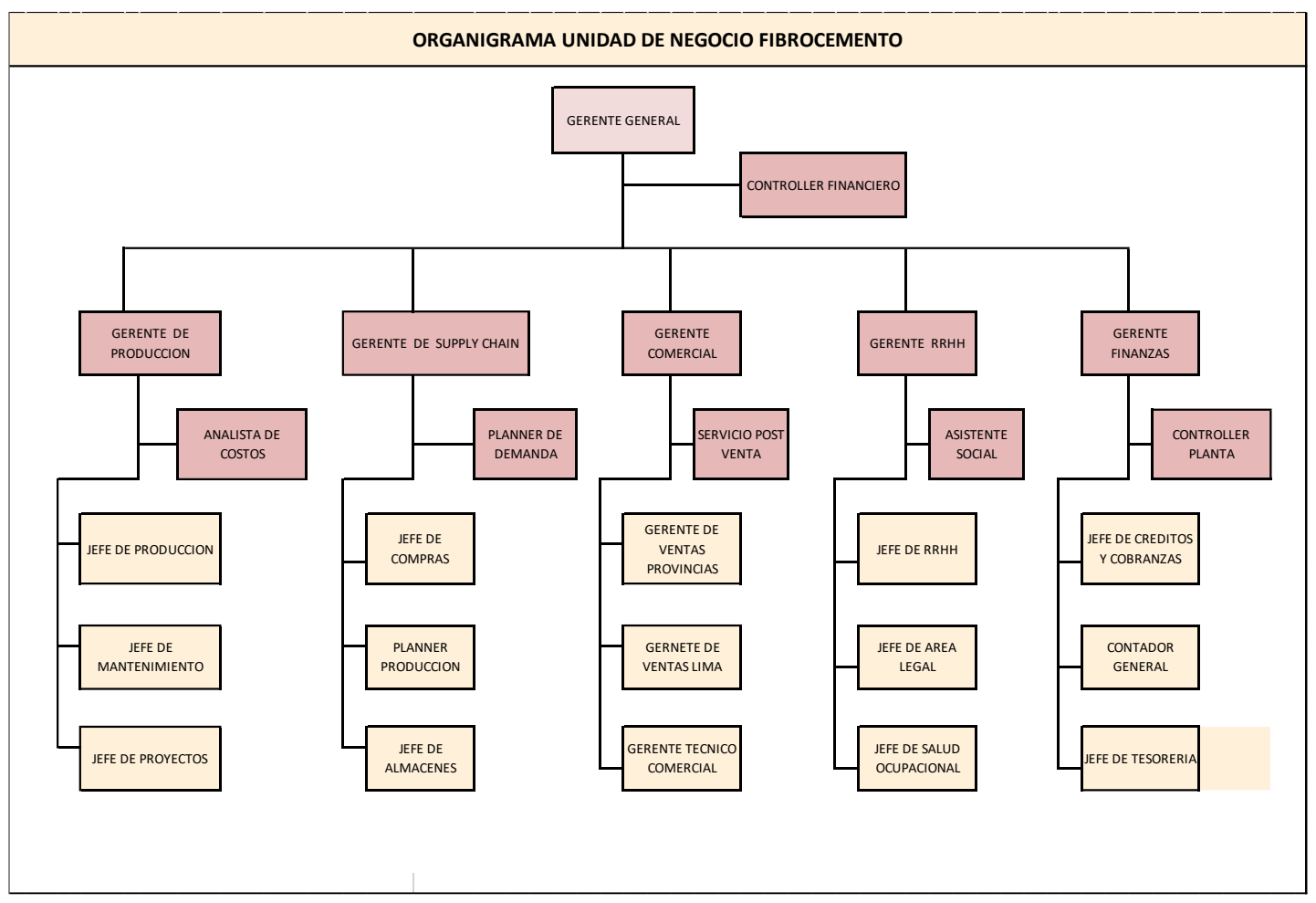

Figura 6. Organigrama Unidad de Negocio Fibrocemento

Fuente: Elaboración propia

Analizando la estructura actual de la unidad de negocio de fibrocemento, podemos ver que tiene una estructura funcional.

Tomando en cuenta los conceptos de Mintzberg en su libro "El Proceso estratégico" haremos un análisis de la estructura actual:

a) Ápice estratégico: Administrador de todo el Sistema. Vemos que la estructura cuenta con un Gerente General para la planta de fibrocemento en Perú, así como gerentes funcionales para cada área estratégica de la unidad de negocio. Asimismo, siendo Eternit una empresa de manufactura, la estructura funcional está alineada para este tipo de organizaciones.

b) Núcleo de operaciones: Siendo Eternit una empresa de manufactura cuenta con un grupo de trabajadores con años de experiencia en la operación de equipos de manufactura de productos de fibrocemento. 
c) Tecnoestructura: Dentro de su organigrama observamos personal de analistas y coordinación quienes planean la producción diaria y generan las coordinaciones y son el nexo con las diferentes áreas. (Analista de costos, Planner de Producción, Coordinador de Producción).

d) Personal de Apoyo: Siendo una empresa con más de 600 trabajadores, cuenta con equipos de trabajo para asesoría legal, comedor, evaluaciones de salud y asistencia social, que representan el staff de apoyo dentro de la organización.

e) Línea Intermedia: la magnitud de la empresa demanda una línea intermedia entre la que se encuentra Gerentes y jefes que permiten una mejor gestión dado el tamaño de la compañía.

f) Ideología: Eternit tiene una cultura clara expresada en sus valores y alineados a su Misión y Visión.

Concluyendo que la estructura organizacional de Eternit cumple con las seis partes básicas de la organización, ahora analizaremos los parámetros fundamentales del diseño de una estructura, esto se refiere al diseño de las posiciones individuales de la organización:

a) La especialización del trabajo: referido al número de tareas de un determinado puesto y el control sobre ellas. En Eternit se cuenta con personal obrero especializado en operación de máquinas específicas, siendo esto un puesto especializado horizontal. A su vez cuenta con ayudantes con puestos verticales llamados multifuncionales, y que apoyan en diversas labores.

b) La capacitación: Referido a la instrucción del personal para el desempeño de su trabajo, la empresa mantiene una política de inducción y capacitación a personal nuevo, y personal en nuevos roles y funciones, además de la formalización de los puestos a través de la entrega de los manuales y registro de capacitaciones. 
c) La agrupación de unidades: De acuerdo con el organigrama, están claramente agrupadas las unidades de la compañía, separando producción, de compras y abastecimiento, finanzas, recursos humanos, comercial y dentro de ellas mismas grupos por líneas de producción o procesos específicos.

d) La formalización del comportamiento: Eternit cuenta con certificación ISO 9001, ISO 14001 Y OSHAS 18000, donde se especifica el detalle de los procesos, y los procedimientos de operación para cada uno de ellos. Esto incluye, descripciones de puesto, reglamentos internos, manual de funciones, que garantizan este punto del diseño.

e) Los sistemas de planeación y control: La estructura muestra claramente que se tiene grupos funcionales dedicados a la planeación y control de los procesos, entre ellos el control de las especificaciones de producto, a través del área de calidad y la secuencia de producción o procesos, a través del planeamiento de la producción alineada a la demanda comercial, esto como ejemplo a las demás unidades de la compañía.

Esto muestra que la estructura actual se alinea a los fundamentos de diseño. Ahora haremos un análisis en cuanto a las ventajas y desventajas de una estructura funcional, analizaremos si la estructura es la adecuada para la organización y si se toman las acciones y prevenciones para minimizar los impactos de las desventajas naturales de una estructura funcional.

\section{a) Ventajas de una estructura funcional}

- Se aplica para organizaciones de manufactura

- Proporciona especialización a los diversos roles

- Permite mejor supervisión técnica dada la especialización que se tiene en esta estructura

- La comunicación es más directa y eficiente 
Esto nos muestra que la estructura funcional y sus ventajas se adecuan al tipo de organización de Eternit.

\section{b) Desventajas de una estructura funcional}

- Subordinación múltiple: Esta desventaja está controlada con la claridad en roles y funciones establecidos en las capacitaciones y en general en los sistemas de gestión.

- Tendencia a la competencia entre los especialistas: Este nos es un tema crítico para la compañía, dado que se tiene establecido una política salarial y de crecimiento, así como capacitaciones establecidas, además que los roles, responsabilidades y funciones de las especialistas son claras y bien difundidas.

Podemos concluir que la Estructura de Eternit se muestra adecuada para la situación actual de la Empresa, y sus objetivos alineados al tipo de industria en que se desenvuelve.

Sin embargo, el plan estratégico evaluará si requerirá cambios o ajustes para las estrategias y nuevos objetivos que se definirán en este documento.

Asimismo, esta organización viene soportada por una estructura global del grupo Etex 


\subsection{Situación de Mercado y Financiera actual de la Industria}

Participación del mercado de la unidad de negocio de fibrocemento.

\begin{tabular}{|c|c|c|c|c|c|c|c|}
\hline \multicolumn{8}{|c|}{ Ventas en MM PEN } \\
\hline & 2011 & 2012 & 2013 & 2014 & 2015 & 2016 & 2017 \\
\hline Eternit & 159 & 204 & 219 & 214 & 259 & 237 & 249 \\
\hline Volcán & 19 & 18 & 33 & 44 & 73 & 42 & 13 \\
\hline Plycem & 16 & 2 & 5 & & & & \\
\hline $\begin{array}{c}\text { Total } \\
\text { Mercado }\end{array}$ & 194 & 224 & 258 & 258 & 332 & 279 & 262 \\
\hline Participación & $82 \%$ & $91 \%$ & $85 \%$ & $83 \%$ & $78 \%$ & $85 \%$ & $95 \%$ \\
\hline $\begin{array}{l}\text { Var \% - } \\
\text { Eternit } \\
\text { Var \% - }\end{array}$ & & $28 \%$ & $7 \%$ & $-2 \%$ & $21 \%$ & $-8 \%$ & $5 \%$ \\
\hline Mercado & & $16 \%$ & $15 \%$ & $0 \%$ & $29 \%$ & $16 \%$ & $-6 \%$ \\
\hline
\end{tabular}

Figura 7. Ventas en MM de soles

Fuente: Elaboración propia

El mercado de fibrocemento tuvo un crecimiento bueno del 2011 al 2015, luego viene presentando una caída desde el 2016, esto se ve reflejado en el sector de la construcción donde el PBI tuvo una caída en $3.1 \%$, la cual se debe a la baja inversión privada como pública. En el sector privado, los proyectos mineros en construcción fueron de mucha menor envergadura que en años anteriores y los proyectos de infraestructura de APP se retrasaron por problemas de expropiaciones de terrenos e interferencias. En el sector público, el nuevo gobierno implementó un ajuste en sus gastos para cumplir con la meta de déficit fiscal (Memoria Anual Fábrica Peruana de Eternit, 2016).

Asimismo, podemos observar los esfuerzos de Eternit por mantener un crecimiento a pesar de la caída del sector con ventas superiores a los 200MM de soles anuales. Se tiene una oportunidad de crecimiento en sector considerando que el consumo per cápita de 
fibrocemento en el Perú es de $0.3 \mathrm{~m} 2$ por habitante (10 millones de $\mathrm{m} 2$ de consumo al año), una cifra por debajo de países de la región como Chile (con un consumo de $3 \mathrm{~m} 2$ por habitante) o naciones de Europa donde se sobrepasa los $5 \mathrm{~m} 2$ por habitante. Esto demuestra que el país tiene un gran nicho por explotar. 


\section{Capítulo III: Formulación de visión, misión y valores de la empresa.}

La misión, visión y valores están definidos para una empresa y no específicamente para cada unidad y este es el caso de ETERNIT, por esta razón y para los fines prácticos del presenta plan estratégico, hemos considerado que la misión, visión y valores de la empresa son aplicables específicamente a la unidad y serán analizados de esa manera.

\section{Visión de la Empresa}

La visión de una Organización es la definición deseada de su futuro, responde a la Pregunta ¿qué queremos llegar a ser? (D’Allessio). Una Visión Estratégica indica las aspiraciones de la administración para la organización, proporcionando una vista panorámica de "en que negocios deseamos estar, hacia donde nos dirigimos y la clase de compañía que estamos tratando de crear" (Thompson Strickland, 2018, p. 40).

A continuación, haremos una evaluación de la Visión de Eternit

\section{Visión actual de la Empresa}

La Visión actual de Eternit es:

“Eternit se esfuerza por ser el líder innovador en soluciones de construcción sostenibles y asequibles".

\section{Análisis de la Visión actual de la Empresa}

De acuerdo con Fernando D'Alessio (2018) haremos una evaluación con los 9 aspectos que debe tener una Visión bien definida: 
Tabla 2. Criterios de Evaluación de la Visión

\begin{tabular}{|c|c|c|c|}
\hline ITEM & $\begin{array}{l}\text { CRITERIOS } \\
\text { DE } \\
\text { EVALUACION }\end{array}$ & DEFINICION & EVALUACION DE LA VISION \\
\hline 1 & $\begin{array}{l}\text { Ideología } \\
\text { Central }\end{array}$ & \begin{tabular}{l}
\multicolumn{1}{c}{ La ideología } \\
Central está formada \\
por un propósito \\
Central y por los \\
valores centrales que \\
constituyen las bases \\
fundamentales y \\
duraderas de la \\
organización.
\end{tabular} & $\begin{array}{l}\text { - La ideología Central de la Compañía } \\
\text { es Brindar soluciones de Construcción } \\
\text { sostenibles y asequibles para las } \\
\text { personas }\end{array}$ \\
\hline 2 & $\begin{array}{l}\text { Visión de } \\
\text { Futuro }\end{array}$ & $\begin{array}{l}\text { ¿Qué queremos } \\
\text { llegar a ser? }\end{array}$ & $\begin{array}{l}\text { • Eternit aspira y se esfuerza en ser el } \\
\text { líder Innovador en soluciones de } \\
\text { Construcción. }\end{array}$ \\
\hline 3 & $\begin{array}{l}\text { Característi } \\
\text { cas de la } \\
\text { Visión } \\
\end{array}$ & $\begin{array}{l}\quad \text { Aspectos } \\
\text { adicionales que debe } \\
\text { tener una Visión } \\
\end{array}$ & $\begin{array}{l}\text { - Se detalla el análisis de cada } \\
\text { característica. }\end{array}$ \\
\hline & \multicolumn{2}{|c|}{ 3.1. Simple, clara y comprensible } & $\begin{array}{l}\text { - La visión cumple con ser simple, } \\
\text { clara y comprensible. }\end{array}$ \\
\hline & \multirow{3}{*}{\multicolumn{2}{|c|}{$\begin{array}{l}\text { 3.2. Ambiciosa, convincente y } \\
\text { realista }\end{array}$}} & $\begin{array}{l}\text { - Es ambiciosa dado que la industria } \\
\text { de la construcción está exigiendo nuevos } \\
\text { desafíos de sustentabilidad, y materiales } \\
\text { amigables con el ambiente. }\end{array}$ \\
\hline & & & $\begin{array}{l}\text { - Es convincente por que tiene la } \\
\text { tecnología el respaldo y la exigencia del } \\
\text { mercado }\end{array}$ \\
\hline & & & $\begin{array}{l}\text { - Realista porque hoy la compañía es } \\
\text { un líder mundial. }\end{array}$ \\
\hline & \multicolumn{2}{|c|}{$\begin{array}{l}\text { 3.3. Definida en un horizonte de } \\
\text { tiempo }\end{array}$} & $\begin{array}{l}\text { - No está definida en un horizonte de } \\
\text { tiempo, }\end{array}$ \\
\hline & \multicolumn{2}{|c|}{$\begin{array}{l}\text { 3.4. Proyectada a un alcance } \\
\text { Geográfico }\end{array}$} & $\begin{array}{l}\text { - No es explicita, sin embargo, la } \\
\text { Visión está alineada a la del Grupo al } \\
\text { que pertenece, y se entiende que es en } \\
\text { todas las operaciones en el mundo y en } \\
\text { el caso de Eternit para el Perú. }\end{array}$ \\
\hline & \multicolumn{2}{|c|}{ 3.5. Conocida por todos } & $\begin{array}{l}\text { - La Visión de la Compañía es } \\
\text { difundida a todos los niveles, a través de } \\
\text { inducciones, publicaciones. }\end{array}$ \\
\hline
\end{tabular}




\begin{tabular}{|c|c|}
$\begin{array}{c}3.5 \text { Expresada de tal manera que } \\
\text { permita crear un sentido de Urgencia }\end{array}$ & $\begin{array}{l}\text { - Lo innovador, sostenible y asequible } \\
\text { muestra un sentido de urgencia por lo } \\
\text { que la industria y el mercado cambiante, } \\
\text { exigen en estos puntos a todo el negocio. }\end{array}$ \\
\hline $\begin{array}{c}\text { 3.6. Idea clara desarrollada de } \\
\text { adonde desea ir la organización }\end{array}$ & $\begin{array}{l}\text { Está claro dónde quiere estar en el } \\
\text { líder. }\end{array}$ \\
\hline
\end{tabular}

Fuente: Elaboración propia

\section{Visión Propuesta}

De acuerdo con lo evaluado la visión de Eternit (unidad de negocio de fibrocemento) cumple con 7 de los criterios de evaluación de una Visión bien definida. Respecto a la proyección geográfica es implícito en todos los negocios del Grupo, lo cual es reforzado en la difusión de esta en la compañía. No define un horizonte de tiempo, sin embargo, muchas organizaciones en la actualidad no incluyen el horizonte de tiempo en su declaración de Visión alineado a los criterios de hacerla simple, teniendo en cuenta que el horizonte implícito de una Visión es de largo plazo y por lo tanto mayor a 2 años.

A continuación, algunos ejemplos de Visión de empresas líderes en el mundo

\section{a) Chevron:}

"Ser la compañía de energía global más admirada por su gente, socios y por su desempeño”

\section{b) Plycem}

"Ser el proveedor preferido de la industria de la construcción"

\section{c) Lan}

"Ser una de las 10 mejores aerolíneas del mundo"

\section{d) Nestle}


"Evolucionar de una respetada y confiable compañía de alimentos a una respetada y confiable compañía de alimentos, nutrición, salud y bienestar"

Por tanto, la Visión de Eternit (unidad de negocio de fibrocemento) puede mantenerse y ser simple:

"Ser el líder innovador en soluciones de construcción sostenibles y asequibles".

\section{Misión de la Empresa}

La declaración de la Misión es la expresión perdurable del propósito que distingue a una organización de otras empresas similares, es la declaración de la "razón de ser" de una organización, y la respuesta a la pregunta fundamental ¿Cuál es nuestro negocio”? Una declaración de Misión clara es esencial para establecer los objetivos y formular estrategias de manera efectiva. (David, 2003).

A continuación, haremos una evaluación de la Misión de la Compañía.

\section{Misión actual de la Empresa}

La Misión actual de Eternit (Unidad de negocio de fibrocemento) es:

"Brindar productos y soluciones en la actividad de la construcción, que mejoren la calidad de vida de los usuarios, manteniendo un espíritu de mejoramiento continuo en nuestra organización”

\section{Análisis de la Misión actual de la Empresa}

De acuerdo con David (2003) haremos una evaluación con los 9 componentes que debe tener una Misión bien definida: 
Tabla 3. Análisis de la misión de la Empresa

\begin{tabular}{|c|c|c|c|}
\hline ITEM & $\begin{array}{l}\text { COMPONENTES } \\
\text { DE LA MISION }\end{array}$ & DEFINICION & $\begin{array}{c}\text { EVALUACION DE LA } \\
\text { MISION }\end{array}$ \\
\hline 1 & Clientes & $\begin{array}{c}\text { Quienes son los } \\
\text { clientes de la Empresa }\end{array}$ & $\begin{array}{l}\quad \text { No especifica quienes } \\
\text { son sus Clientes, solo la } \\
\text { Industria a la que pertenece }\end{array}$ \\
\hline 2 & $\begin{array}{l}\text { Productos o } \\
\text { Servicios }\end{array}$ & $\begin{array}{l}\quad \text { Cuáles son los } \\
\text { principales productos o } \\
\text { servicios que ofrece la } \\
\text { Empresa }\end{array}$ & $\begin{array}{l}\text { Es muy general solo } \\
\text { habla de Productos y } \\
\text { Servicios }\end{array}$ \\
\hline 3 & Mercados & $\begin{array}{l}\text { En términos } \\
\text { Geográficos ¿en dónde } \\
\text { compite la Empresa? }\end{array}$ & $\begin{array}{l}\text { No especifica ni } \\
\text { menciona una zona } \\
\text { Geográfica }\end{array}$ \\
\hline 4 & Tecnologías & $\begin{array}{l}\quad \text { ¿La empresa está } \\
\text { actualizada desde el } \\
\text { punto de vista } \\
\text { Tecnológico? }\end{array}$ & $\begin{array}{l}\text { La declaración actual no } \\
\text { menciona o incluye temas } \\
\text { tecnológicos. }\end{array}$ \\
\hline 5 & $\begin{array}{l}\text { Objetivos de la } \\
\text { Organización }\end{array}$ & $\begin{array}{l}\quad \text { ¿La empresa está } \\
\text { comprometida con el } \\
\text { crecimiento y la solidez } \\
\text { Financiera? }\end{array}$ & $\begin{array}{c}\text { Hace hincapié en el } \\
\text { Mejoramiento Continuo. }\end{array}$ \\
\hline 6 & $\begin{array}{l}\text { Filosofía de la } \\
\text { Organización }\end{array}$ & $\begin{array}{l}\qquad \text { ¿Cuáles son las } \\
\text { creencias, valores, } \\
\text { aspiraciones y } \\
\text { prioridades éticas básicas } \\
\text { de la Empresa? }\end{array}$ & $\begin{array}{l}\text { No Menciona ninguno de } \\
\text { los valores de la compañía. }\end{array}$ \\
\hline 7 & $\begin{array}{l}\text { Auto concepto de } \\
\text { la organización }\end{array}$ & $\begin{array}{l}\quad \text { ¿Cuál es la } \\
\text { competencia distintiva o } \\
\text { la ventaja competitiva de } \\
\text { la Empresa? }\end{array}$ & $\begin{array}{l}\text { La declaración actual no } \\
\text { menciona o incluye las } \\
\text { ventajas competitivas. }\end{array}$ \\
\hline 8 & $\begin{array}{l}\text { Preocupación por } \\
\text { la Imagen Publica }\end{array}$ & $\begin{array}{l}\text { La empresa responde } \\
\text { a las preocupaciones } \\
\text { sociales, comunitarias y } \\
\text { ambientales }\end{array}$ & $\begin{array}{l}\text { Solo enfoca su } \\
\text { declaración en mejorar la } \\
\text { vida de los usuarios, no } \\
\text { hace énfasis en lo social o } \\
\text { ambiental. }\end{array}$ \\
\hline 9 & $\begin{array}{l}\text { Preocupación por } \\
\text { los empleados }\end{array}$ & $\begin{array}{l}\quad \text { ¿Los empleados son } \\
\text { un activo valioso para la } \\
\text { Compañía? }\end{array}$ & $\begin{array}{l}\text { La declaración actual no } \\
\text { enfoca su Misión en sus } \\
\text { empleados. }\end{array}$ \\
\hline
\end{tabular}

Fuente: Elaboración propia 


\section{Misión Propuesta:}

Del análisis de la Misión vemos como no cumple con los componentes requeridos para una buena declaración de la Misión. Por lo tanto, a continuación, detallamos la Misión Propuesta:

"El mundo de hoy tiene mucha demanda de construcción; por ello estamos en un viaje para proporcionar soluciones en la actividad de la construcción; técnica y estéticamente superiores que se ajusten a las necesidades de las personas y les permiten vivir en un lugar seguro, sostenible e inspirador".

\section{Valores de la Empresa}

Los valores guiaran el camino hacia nuestras metas de crecimiento, excelencia y desarrollo personal.

\section{Valores Actuales de la Empresa:}

- Conexión y cuidado:

Desarrollar a las personas y construir relaciones y redes solidas

\section{- Pasión por la excelencia}

Hacer las cosas bien y disfrutar al superarnos

\section{- Pioneros en Liderar}

Impulsar cambios que aportan valor

Análisis de los Valores Actuales de la Empresa (unidad de negocio de fibrocemento):

\section{- Conexión y cuidado:}

Este valor tiene que ver con crear relaciones más significativas, como recordar a un colega el uso de sus implementos de seguridad, o de atender bien a un cliente. Significa también 
desarrollar a las personas adecuadas a través de una cultura que promueva la innovación, el desempeño y el crecimiento.

- Pasión por la excelencia

Este valor significa ir más allá, dar la milla extra, sugiriendo una mejor forma de realizar las cosas, un proceso o un mejor servicio al cliente.

\section{- Pioneros en Liderar}

Este valor conduce a mejorar continuamente, innovando un producto o servicio, un sistema o aplicación, o la proactividad para lidera nuevos proyectos.

\section{Valores Propuestos:}

Los valores se muestran alineados a la Visión actual y la Misión propuesta, por lo tanto, consideramos que deben mantenerse. Sin embargo, consideramos que debe agregarse un valor relacionado al compromiso con el ambiente y la sociedad. Nuevo Valor:

\section{- Operaciones Sustentables}

Este valor conduce a operar con respeto y profesionalismo pensando en cuidar nuestro entorno, amigables con el medio ambiente, y la sociedad que nos rodea.

\section{Alineamiento estratégico visión, misión y valores}


Tabla 4. Alineamiento Estratégico Visión, Misión, Valores

\begin{tabular}{|c|c|c|}
\hline \multirow[b]{3}{*}{ VALORES } & \multicolumn{2}{|r|}{ ALINEACION } \\
\hline & VISION & MISION \\
\hline & $\begin{array}{l}\quad \text { "Ser el líder } \\
\text { innovador en } \\
\text { soluciones de } \\
\text { construcción } \\
\text { sostenibles y } \\
\text { asequibles". }\end{array}$ & $\begin{array}{l}\text { "EI mundo de hoy tiene mucha } \\
\text { demanda de construcción. Estamos en } \\
\text { un viaje para proporcionar materiales } \\
\text { de construcción técnica y estéticamente } \\
\text { superiores que se ajusten a las } \\
\text { necesidades de las personas y les } \\
\text { permiten vivir en un lugar seguro, } \\
\text { sostenible e inspirador". }\end{array}$ \\
\hline $\begin{array}{l}\text { Conexión y } \\
\text { cuidado: }\end{array}$ & \multicolumn{2}{|c|}{$\begin{array}{l}\text { El cuidar y desarrollar a su personal es un valor que los llevara a } \\
\text { la innovación, y alinearnos al compromiso de su gente para que esta } \\
\text { innovación sea sostenible, segura e inspiradora }\end{array}$} \\
\hline $\begin{array}{l}\text { Pasión por } \\
\text { la excelencia: }\end{array}$ & \multicolumn{2}{|c|}{$\begin{array}{l}\text { Esforzarse cada día más, y dar todo por una compañía, es clave } \\
\text { para conseguir el liderazgo a través de desarrollar procesos } \\
\text { coherentes con lo que requiere el mercado de la construcción }\end{array}$} \\
\hline $\begin{array}{l}\text { Pioneros en } \\
\text { Liderar: }\end{array}$ & \multicolumn{2}{|c|}{$\begin{array}{l}\text { Enfocarse en la mejora continua, y en la constante innovación de } \\
\text { productos, permitirá lograr productos superiores, asequibles y } \\
\text { sostenibles }\end{array}$} \\
\hline $\begin{array}{l}\text { Operaciones } \\
\text { Sustentables: }\end{array}$ & \multicolumn{2}{|c|}{$\begin{array}{l}\text { Desarrollar y mantener procesos ambientalmente correctos, es la } \\
\text { herramienta que permite ser consecuentes con desarrollar } \\
\text { soluciones que permitan vivir en un lugar mejor, seguro, sostenible e } \\
\text { inspirador }\end{array}$} \\
\hline
\end{tabular}

Fuente: Elaboración propia 


\section{Capítulo IV. Análisis Externo}

\subsection{Tendencias de las variables del entorno}

\subsubsection{Análisis Político - Gubernamental}

En el territorio nacional encontramos al electo presidente Pedro Pablo Kuczynski, luego de unas elecciones accidentadas por cambios en las leyes de partido en últimas instancias tras las salidas de los candidatos Julio Guzmán y Cesar Acuña. La candidata Keiko Fujimori pese a haber quedado en segundo lugar, logró como partido la mayoría de los congresistas teniendo desde esta perspectiva mayor opción de tomar decisiones, inclusive más que el mismo presidente por la mayoría de los integrantes dentro del Congreso de la República.

A pesar de las diferencias, el Congreso apoyó inicialmente al Estado en el objetivo de combatir el desmesurado aumento de inseguridad ciudadana, reactivar la economía en un año marcado por la desaceleración y fomentar la formalización del empleo.

Al cierre del 2016 estuvo caracterizado por un claro debilitamiento en el aumento de las ventas locales. Esto se explicó, en parte, por la reducción del gasto público decretado en el cuarto trimestre para poder cumplir con la meta de déficit fiscal (3\% del PBI). Este debilitamiento impactó negativamente en la confianza de los empresarios y consumidores, así como en la aprobación presidencial. En este contexto, el nuevo gobierno anunció una serie de medidas orientadas a desburocratizar los trámites con el Estado, agilizar la inversión pública y la inversión concesionada, y a mejorar la calidad regulatoria de las normas.

Los casos de corrupción de Carlos Moreno beneficiado económicamente con convenios ente el Sistema Integral de Salud (SIS) y clínicas privadas; Mariano Gonzales Ministro de defensa favoreciendo a su pareja; el caso Chincheros cuya adenda al contrato fue denunciada por ser en extremo lesiva al interés público, y el caso Odebrecht donde se ha vinculado a una serie de 
Políticos por irregularidades en las licitaciones del estado con este Empresa, el caso ha involucrado a los expresidente Ollanta Humala, Toledo y al actual Presidente Pedro Pablo Kuckinsky. Todos estos casos de corrupción han dejado un clima político bien complicado para empresas de construcción que dependen de proyectos de inversión pública, que son los principales clientes de la línea de fibrocemento.

Todo este entorno político de incertidumbre se traduce en inestabilidad y por ende merma la capacidad de inversión, específicamente en infraestructura, construcción, etc. Por tal razón esta situación política tendría un efecto sobre la unidad de fibrocemento de eternit, siendo un insumo del sector construcción.

\subsubsection{Análisis Económico}

La economía global se proyecta favorables en los próximos años gracias a que los precios de productos primarios se mantienen, brindando de esta manera estabilidad a los mercados que están en crecimiento y da soporte para condiciones financieros a nivel global donde la demanda se sigue recuperando.

Todo lo mencionado ayuda a que aumente la economía del Perú en unos 0,3 puntos porcentuales (p.p.), diferenciando lo sucedido entre los años 2012 al 2016 donde nos encontrábamos en un promedio negativo del -0,5 p.p. Para que se logre lo mencionado, es importante afrontar las incertidumbres generadas en la política; sobre todo las que suceden en países de alto potencial mundial como es Estados Unidos, ya que podría solo aumentar en un 0,2 p.p. 


\begin{tabular}{|c|c|c|c|c|c|c|c|c|c|c|}
\hline & \multirow{2}{*}{$2012-2016$} & \multirow{2}{*}{2017} & \multicolumn{4}{|c|}{ IAPM -Abril 2017} & \multicolumn{4}{|c|}{ MMM 2018 -2021 } \\
\hline & & & 2018 & 2019 & 2020 & 2021 & 2018 & 2019 & 2020 & 2021 \\
\hline Mundo & 3.4 & 3.5 & 3.6 & 3.7 & 3.7 & 3.7 & 3.6 & 3.7 & 3.7 & 3.7 \\
\hline Economias Avanzadas & 1.7 & 2.0 & 2.0 & 1.9 & 1.7 & 1.7 & 2.0 & 1.9 & 1.8 & 1.8 \\
\hline Estados Unidos & 2.1 & 2.0 & 2.5 & 2.1 & 1.8 & 1.7 & 2.3 & 2.1 & 2.0 & 2.0 \\
\hline Zona Euro & 0.8 & 1.9 & 1.6 & 1.6 & 1.5 & 1.5 & 1.7 & 1.6 & 1.6 & 1.6 \\
\hline Japon & 1.2 & 1.4 & 0.6 & 0.8 & 0.2 & 0.7 & 1.0 & 1.0 & 1.0 & 1.0 \\
\hline Economias Emergentes y en Desarrollo & 4.7 & 4.5 & 4.8 & 4.9 & 4.9 & 5.0 & 4.8 & 4.9 & 4.9 & 4.9 \\
\hline China & 7.3 & 6.6 & 6.2 & 6.0 & 5.9 & 5.8 & 6.2 & 6.0 & 5.9 & 5.8 \\
\hline India & 6.8 & 7.2 & 7.7 & 7.8 & 7.9 & 8.1 & 7.4 & 7.5 & 7.5 & 7.5 \\
\hline America Latina y el Caribe & 1.2 & 1.0 & 2.0 & 2.5 & 2.6 & 2.7 & 1.8 & 2.2 & 2.4 & 2.4 \\
\hline Argentina & -0.2 & 1.2 & 2.3 & 2.5 & 3.0 & 3.2 & 2.1 & 3.0 & 3.5 & 3.5 \\
\hline Brasil & -0.4 & 0.1 & 1.7 & 2.0 & 2.0 & 2.0 & 1.5 & 1.7 & 2.0 & 2.0 \\
\hline Chile & 3.0 & 1.4 & 2.3 & 2.7 & 2.9 & 3.1 & 1.8 & 2.0 & 2.0 & 2.0 \\
\hline Colombia & 3.7 & 1.8 & 3.0 & 3.6 & 3.6 & 3.6 & 2.3 & 2.5 & 2.7 & 2.7 \\
\hline Mexico & 2.5 & 2.0 & 2.0 & 2.7 & 2.7 & 2.7 & 2.0 & 2.0 & 2.2 & 2.2 \\
\hline PBI Socios Comerciales & 3.4 & 3.2 & 3.3 & 3.2 & 3.2 & 3.1 & 3.2 & 3.2 & 3.2 & 3.2 \\
\hline
\end{tabular}

Figura 8. Crecimiento económico anual en Latinoamérica.

Fuente: Proyecciones MEF, FMI.

En el análisis global la economía en el Perú se mantiene favorable, es decir, que en América Latina se espera un crecimiento de $1.0 \%$ en el 2017 y $1.8 \%$ en el 2018 y esto se debe a la estabilidad de condiciones económicas en Brasil y Argentina.

El fenómeno del niño costero y los casos de corrupción de Odebrecht develados se identifican como los 2 motivos principales por los que en el primer semestre del año 2017 el Perú tuvo un crecimiento de solo 2,3\%. Debido a la paralización de los proyectos liderados por Odebrecht no se realizaron inversiones privadas como el año anterior. Estos sucesos afectan los cultivos como la formalización de trabajos, lo cual significa menor ingreso en la canasta familiar.

En el siguiente cuadro podemos visualizar el crecimiento en el primer trimestre del año 2017 de los países latinoamericanos, identificando que el Perú a pesar de los problemas mencionados, mantiene el más alto crecimiento. EL promedio en general de crecimiento es del 1,0\% aproximadamente. 


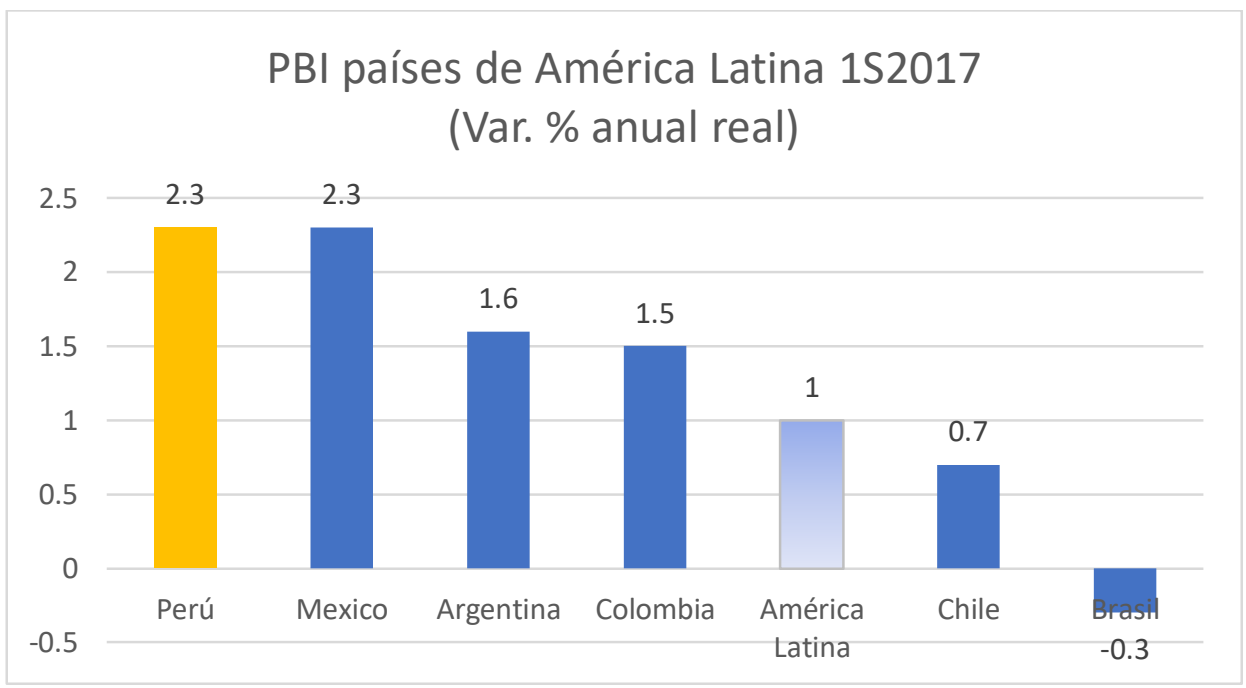

Figura 9. PBI países de América Latina 1S2017.

Fuente: Latín Focus Consensus Forecast - Agosto 2017, MEF.

Por otro lado, otro indicador económico que afectaría a la unidad de fibrocemento de eternit, considerando que el sector construcción está ligado fuertemente a la inversión, sería la evolución de la tasa de interés, la cual ha disminuido comparándose al mismo periodo en el año anterior, llegando a disminuir de $4.25 \%$ en diciembre del 2016 a 3.25\% a diciembre del 2017.

Así también, otro indicador que puede explicar la situación económica nacional es la inflación, la que se ha reducido de $3.2 \%$ a 1.4\%, lo que demuestra cierta estabilización de la economía.

El gasto público en el Perú aumento su ritmo de crecimiento de 2,8\% en el 2017 a 4,0\% en el 2018 debido a un mayor impulso fiscal orientado a la ejecución del plan de reconstrucción y los Juegos Panamericanos; a esto se sumará una recuperación gradual de la inversión privada, en un contexto de altos precios de metales, recuperación de la demanda interna (especialmente, pública), avance de importantes proyectos de infraestructura (con un marco más ágil para la obtención de predios) e implementación de medidas para promover la inversión minera y de hidrocarburos. Con ello, se reiniciará el círculo virtuoso de mayor inversión, empleo y consumo. 


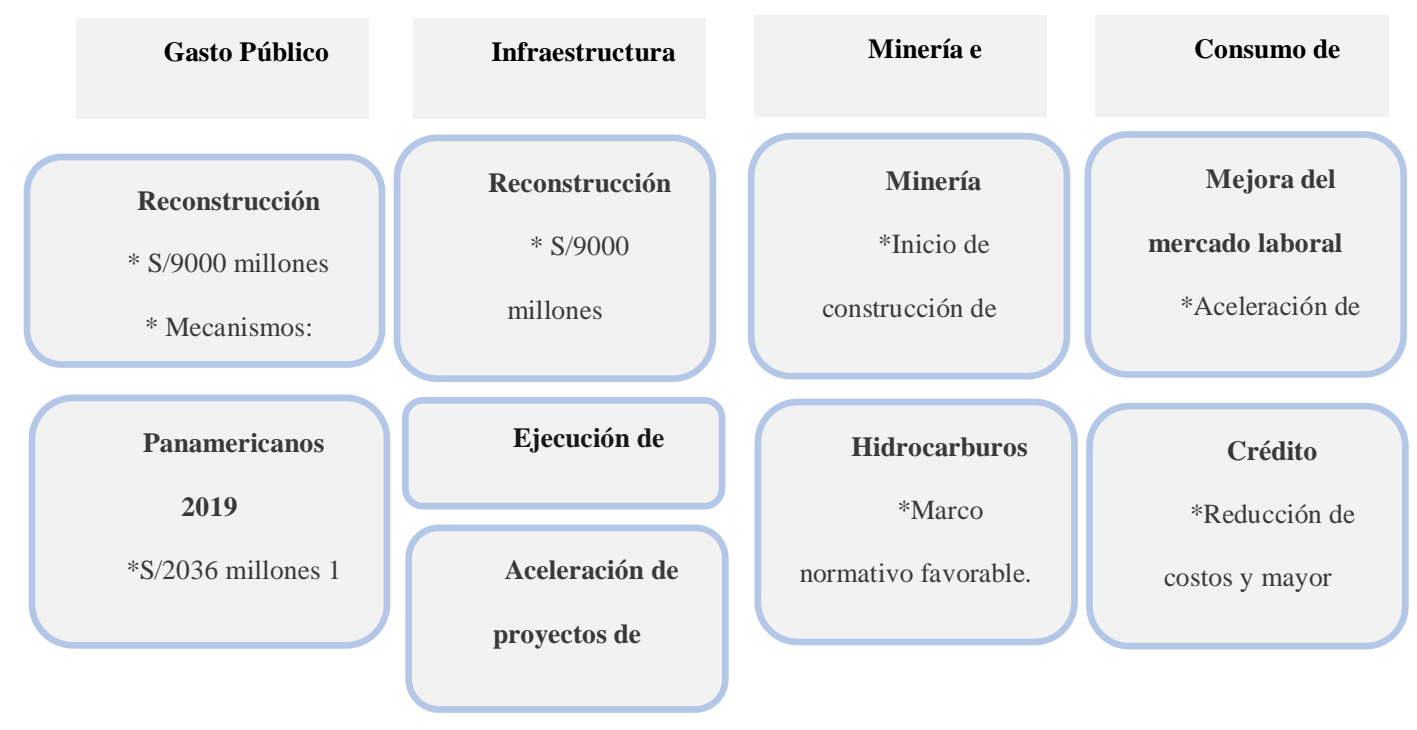

Figura 10. Pilares del Crecimiento Económico (2018)

1/ Incluye S/1367 millones de gasto corriente e inversión para la construcción de las sedes y S/ 669 millones de obras complementarias.

Fuente: MEF

\subsubsection{Análisis Legal}

Entre las principales leyes que se analizara:

a. Ley $\mathrm{N}^{\circ} 30425$ - Retiro del $95.5 \%$ del fondo AFP

Ley que modifica el texto único ordenado de la ley, aprobado por el decreto supremo 05497-ef, y que amplía la vigencia del régimen especial de jubilación anticipada, el cual permite el retiro del $95.5 \%$ del fondo de AFP.

b. Ley $\mathrm{N}^{\circ} 30478$ - Disposición del 25\% AFP para compra de un primer inmueble Ley que establece que los afiliados al Sistema Privado de Pensiones podrán disponer de hasta el 25\% del fondo acumulado en su Cuenta Individual de Capitalización de aportes obligatorios para pagar la cuota inicial para la compra de un primer inmueble, siempre que se 
trate de un crédito hipotecario, o amortizar un crédito hipotecario que haya sido utilizado para la compra de un primer inmueble, en ambos casos otorgado por una entidad del sistema financiero.

c. Ley $\mathrm{N}^{\circ} 30556$ - Reconstrucción con cambios

Ley que aprueba disposiciones de carácter extraordinario para las intervenciones del gobierno nacional frente a desastres y que dispone la creación de la autoridad para la reconstrucción con cambios. Que implica una inversión de 23 mil millones de soles y que generará 150 mil nuevos empleos formales. El plan tiene como objetivos esenciales, uno: mostrar las infraestructuras y actividades que van a ser desarrolladas en los siguientes tres años. Dos, una evaluación de qué gobiernos regionales, qué gobiernos locales y qué sectores van a ejecutar los proyectos allí incluidos; tres: quiénes son los que van a recibir esas obras, es decir

quién se va a encargar de la operación y mantenimiento; y cuatro: cuales son las modalidades de ejecución del plan".

Todas estas normativas, al afectar directa o indirectamente el mercado inmobiliario, afectan al sector construcción, específicamente al mercado de materiales de construcción en donde Eternit y la unidad de fibrocemento actualmente se encuentran.

\subsubsection{Análisis Cultural}

a. Materiales usados para las paredes de las viviendas a nivel nacional

Según el INEI los materiales más usados para las paredes de las viviendas son el ladrillo o bloque de cemento y el adobe, teniendo en cuenta que el predominante en la zona urbana es el ladrillo o bloque de cemento y en la zona rural el adobe. 


\begin{tabular}{|c|c|c|c|c|c|c|}
\hline \multicolumn{7}{|c|}{$\begin{array}{r}\text { VIVIENDAS PARTICULARES SEGÚ } \\
\text { PAREDES Y AEREA } \\
\text { (Porcentaje del total de viviendas particulares) }\end{array}$} \\
\hline $\begin{array}{l}\text { Material predominante en las paredes } \\
\text { exteriores / area de residencia }\end{array}$ & 2010 & 2011 & 2012 & 2013 & 2014 & 2015 \\
\hline Total & 100 & 100 & 100 & 100 & 100 & 100 \\
\hline Ladrillo o bloque de cemento & 51.4 & 50.6 & 51.5 & 52.2 & 51.7 & 51.7 \\
\hline Piedra con cal o cemento & 0.7 & 0.7 & 0.8 & 0.7 & 0.6 & 0.6 \\
\hline Adobe & 34.2 & 34.4 & 34.1 & 33.6 & 34.3 & 33.5 \\
\hline Quincha & 1.7 & 1.8 & 1.8 & 1.8 & 1.6 & 1.7 \\
\hline Piedra con barro & 0.9 & 1 & 1 & 0.9 & 0.9 & 0.8 \\
\hline Madera & 6.1 & 6.9 & 7 & 7.6 & 7.7 & 8.5 \\
\hline Estera & 0.6 & 0.7 & 0.4 & 0.4 & 0.4 & 0.4 \\
\hline Otro material & 4.4 & 3.9 & 3.4 & 2.8 & 2.8 & 2.8 \\
\hline Urbana & 100 & 100 & 100 & 100 & 100 & 100 \\
\hline Ladrillo o bloque de cemento & 67.4 & 66.2 & 67 & 67.2 & 66.4 & 66 \\
\hline Piedra con cal o cemento & 0.9 & 0.8 & 1 & 0.8 & 0.7 & 0.7 \\
\hline Adobe & 20.5 & 21.1 & 20.8 & 20.9 & 21.8 & 21.1 \\
\hline Quincha & 1.5 & 1.7 & 1.8 & 1.8 & 1.6 & 1.7 \\
\hline Piedra con barro & 0.2 & 0.2 & 0.1 & 0.1 & 0.1 & 0.1 \\
\hline Madera & 4.8 & 5.7 & 5.8 & 6.3 & 6.5 & 7.5 \\
\hline Estera & 0.5 & 0.8 & 0.4 & 0.4 & 0.5 & 0.4 \\
\hline Otro material & 4.2 & 3.5 & 3.1 & 2.5 & 2.4 & 2.5 \\
\hline Rural & 100 & 100 & 100 & 100 & 100 & 100 \\
\hline Ladrillo o bloque de cemento & 5.8 & 6.3 & 6.2 & 6.9 & 7.3 & 7.3 \\
\hline Piedra con cal o cemento & 0.2 & 0.3 & 0.2 & 0.4 & 0.3 & 0.4 \\
\hline Adobe & 73.4 & 72.2 & 72.9 & 72.3 & 72.2 & 72.5 \\
\hline Quincha & 2.2 & 2 & 1.7 & 1.8 & 1.6 & 1.5 \\
\hline Piedra con barro & 3.1 & 3.4 & 3.7 & 3.2 & 3.3 & 2.9 \\
\hline Madera & 9.9 & 10.5 & 10.7 & 11.4 & 11.3 & 11.5 \\
\hline Estera & 0.5 & 0.4 & 0.4 & 0.4 & 0.3 & 0.3 \\
\hline Otro material & 4.9 & 4.9 & 4.2 & 3.6 & 3.7 & 3.6 \\
\hline
\end{tabular}

Figura 11. Viviendas según su material constructivo

Fuente: INEI- Encuesta Nacional de Hogares 
b. Materiales usados para las paredes de las viviendas en Lima Metropolitana

En Lima metropolitana, existen más de 1 millón 800 mil viviendas independientes, más de dos millones de viviendas tienen como material predominante en sus paredes, el ladrillo o bloque de cemento.

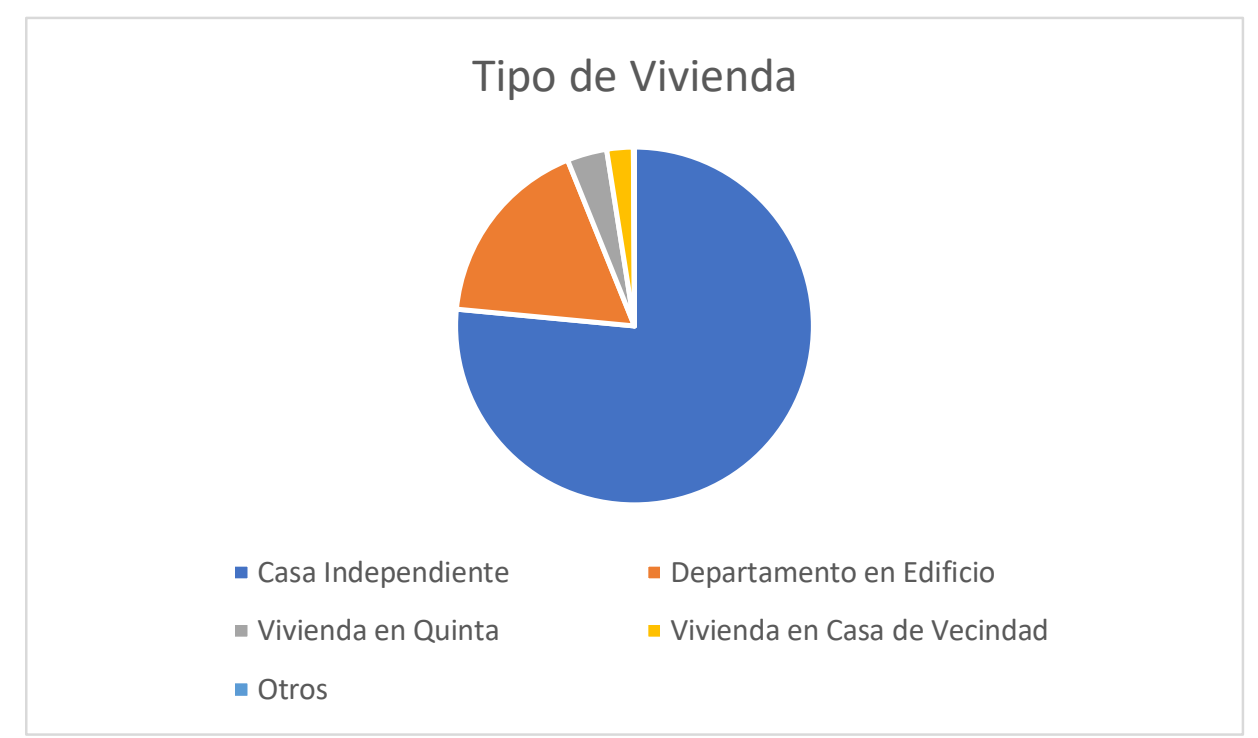

Figura 12. Tipos de Vivienda

Fuente: INEI - Encuesta Nacional de Hogares 2013

Existen cerda de dos millones y medio de viviendas. De cada 100 viviendas particulares, 76 son independientes. 


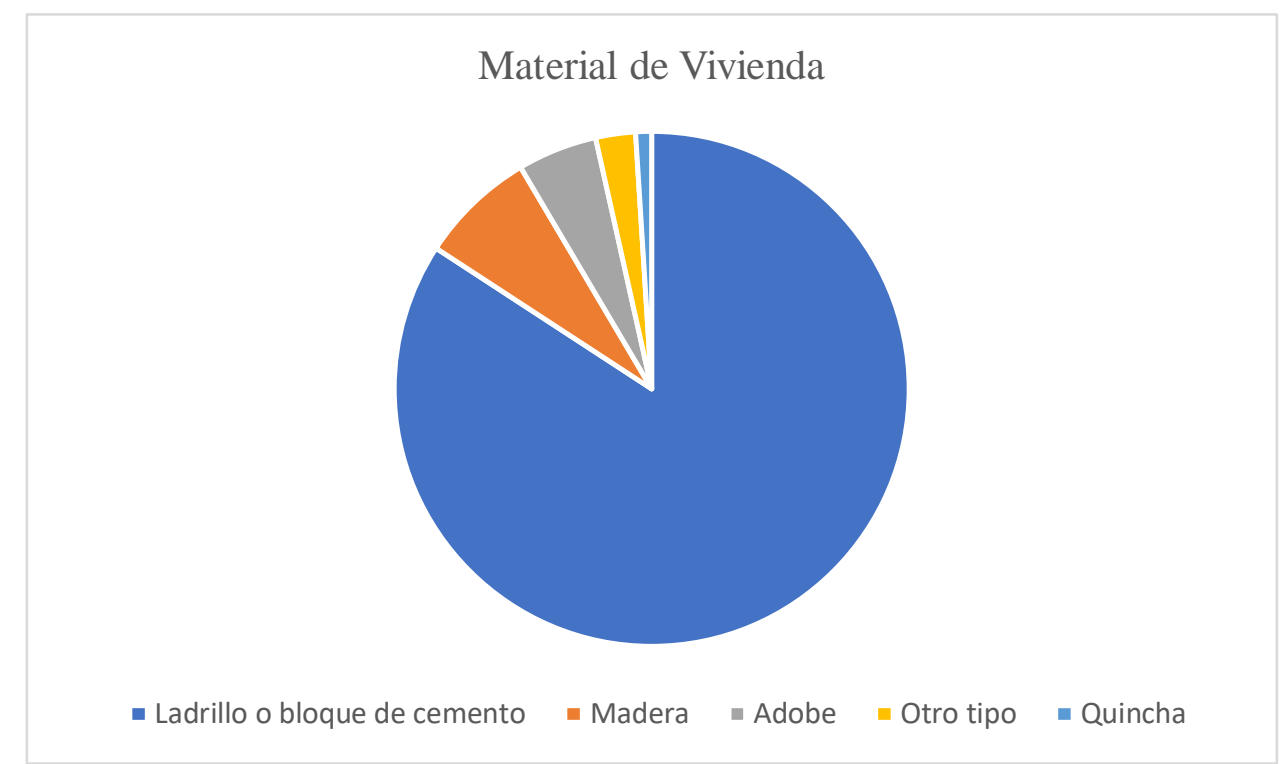

Figura 13. Tipo de Material de la Vivienda

Fuente: INEI - Encuesta Nacional de Hogares 2013

El 84\% de las viviendas tienen el ladrillo o cemento como material predominante en sus paredes exteriores.

c. Sindicatos y delincuencia en el sector construcción

En Lima, existen alrededor de 129 mafias que cobran cupos en las obras de construcción, las cuales se hacen llamar sindicatos, y desgraciadamente son reconocidos por el Ministerio de Trabajo, quienes no hacen mayor revisión de antecedentes penales, los cuales hacen un festín cobrando a cambio de seguridad, contratando hasta sicarios para atacar a quien no cumpla o hasta a la misma competencia.

Actualmente la ley no obliga a estos seudo sindicatos a afiliarse a la CGTP ni a la CTP, simplemente les basta acreditar a más de 25 miembros para obtener el reconocimiento.

Cuando se inicia una obra estos individuos se encargan de ubicar a los encargados, llámense los ingenieros responsables y comienzan con su tarea de extorsión, buscando amenazarlos hasta con sus propias familias. Estos sindicatos terminan pidiendo cupos que van desde los 20 mil soles hasta el $2 \%$ del valor de la obra. 
Todo esto afecta la decisión de un inversionista de iniciar una obra de construcción civil, limitando el crecimiento y potencial del sector, perjudicando enormemente a la empresa. (http://larepublica.pe/13-01-2014/solo-en-lima-metropolitana-129-mafias-cobran-cupos-porobras-de-construccion-civil)

\subsubsection{Análisis Tecnológico}

Los investigadores en todo el mundo están trabajando en nuevos materiales, sistemas de construcción y sistemas de fachadas innovadores, que afectaran sin duda la construcción a largo plazo; ya que el sector de la construcción ha experimentado un gran cambio. Junto a la creciente digitalización de los procesos de trabajo, las tendencias sociales como la vida sostenible y saludable se consolidarán en los próximos años.

a. Sostenibilidad y Vida Saludable

La construcción para un entorno de vida saludable está estrechamente relacionada con la sostenibilidad. Con los distintos planes de protección del clima del 2050, los distintos gobiernos se esfuerzan por reducir las emisiones de $\mathrm{CO}$ 2. Esto significa específicamente una reducción de los gases de efecto invernadero del 80 al 95 por ciento en comparación con los niveles de 1990. Este enfoque holístico incluye el uso de materiales de construcción y aislamiento respetuosos con el medio ambiente. El cáñamo, el lino, la celulosa y las algas marinas se están estableciendo como nuevos materiales en el mercado. El enfoque aquí es sobre las materias primas renovables que pueden ser recicladas o eliminadas sin dañar el medio ambiente. Algunos de los materiales de aislamiento respetuosos con el medio ambiente incluso tienen mejores resultados que los materiales convencionales en términos de sus propiedades químicas y físicas. La celulosa, por ejemplo, tiene unos costes de producción increíblemente bajos y una baja inflamabilidad. La tendencia en los materiales adhesivos y de sellado es similar en la reducción de las emisiones 
nocivas tanto como sea posible, mediante el uso de materiales innovadores y respetuosos del medio ambiente.

b. Sistemas modulares de construcción: flexibles y rápidos

La tendencia puede llevarnos a un nuevo tipo de construcción, las casas modulares. En el contexto de los retos demográficos a los que nos enfrentamos hoy en día (personas solteras, frecuentes desplazamientos, falta de alojamiento en los centros urbanos, etc.), estos sistemas de construcción ya preparados ofrecen una gran flexibilidad. Pueden configurarse de cualquier forma que usted desee y trasladarse cuando usted se mueve. Este nuevo enfoque de la construcción reduce los tiempos de construcción, lo que significa que grandes complejos de edificios se pueden erigir en pocos días. Los módulos son más pequeños que un kit convencional, simplificando el transporte y al mismo tiempo abriendo opciones para la libertad creativa.

c. Fachadas del futuro

Las fachadas del futuro no sólo nos protegerán del mal tiempo, sino que también colaborarán la producción de energía mediante la tecnología solar incorporada. Varias instituciones de investigación en todo el mundo están buscando formas de diseñar elementos fotovoltaicos para que absorban la energía solar y dejen pasar la luz del día. Esto incluye métodos innovadores para una producción más rápida de módulos basados en obleas, concentradores solares y madera transparente. El objetivo de los nuevos sistemas automatizados de sombreado y ventilación es optimizar aún más el intercambio de calor entre el aire interior y exterior. 


\section{d. Nuevos Materiales de Construcción}

También se utilizan materiales de construcción inteligentes en las fachadas. En lugar de ser estáticos, estos materiales son dinámicos, lo que significa que responden a los cambios en el medio ambiente. En una fachada bioreactiva en Hamburgo, por ejemplo, las microalgas han estado creciendo en módulos especiales de vidrio desde 2013. Esto convierte la energía solar en energía térmica y produce biomasa al mismo tiempo que también se utiliza para generar biogás.

Uno de los materiales clásicos de la construcción, la madera, está experimentando actualmente un nuevo renacimiento. Debido a que la madera almacena dióxido de carbono en sus fibras, un edificio hecho de este material, intrínsecamente simple, puede reducir la emisión de gases de efecto invernadero. Los nuevos materiales de construcción inteligentes, así como los que ya están probados, cambiarán el sector de la construcción a largo plazo.

\section{- Madera Translucida}

Un grupo de investigadores del KTH Royal Institute of Technology de Estocolmo, ha desarrollado recientemente Optically Transparent Wood (TW), un nuevo material que podría impactar enormemente en la manera en que desarrollamos nuestros proyectos de arquitectura. Publicado en la revista de la American Chemical Society -Biomacromolecules-, se trata de un proceso que elimina químicamente la Lignina de la madera, haciendo que se vuelva muy blanca. El sustrato poroso resultante es impregnado con un polímero transparente, igualando las propiedades ópticas de ambos.

\section{- Cemento con capacidad para generar luz}

Como una respuesta a los nuevos modelos de construcción, el Dr. En Ciencias José Carlos

Rubio Ávalos de la UMSNH de Morelia, ha desarrollado un cemento con la capacidad de 
absorber e irradiar energía lumínica, con el fin de brindar una mayor funcionalidad y versatilidad al concreto desde el punto de vista de eficiencia energética.

e. Domótica: La red digital de edificios

Una de las tendencias que configuran el sector de la construcción es el concepto de casas inteligentes (la red digital de servicios de construcción, electrodomésticos y electrónica de entretenimiento). Este enfoque técnico persigue tres objetivos:

- Uso eficiente de la energía.

- Mayor seguridad.

- Mayor confort.

Ya hay un gran número de proveedores en el mercado, ofreciendo varias soluciones inalámbricas. La tendencia actual es aumentar la cooperación entre los diferentes fabricantes. Por lo tanto, están creando sistemas que son universalmente compatibles, ofreciendo más flexibilidad para la conexión del dispositivo.

\subsubsection{Análisis Ecológico.}

a. Cuidado del medio ambiente

Eternit es una empresa que usa dentro de su fabricación productos químicos, alineada al cuidado del medio ambiente tiene desarrollado su plan de impacto ambiental además que todos sus productos y procesos están alineados con la ley general del Ambiente, Ley № 28611, de 2005.

b. Sustentabilidad

Las planchas de fibrocemento aportan a la sustentabilidad del planeta, debido a los bajos espesores de los productos, el impacto en la huella de carbono generado por la utilización de cemento en su fabricación es mucho menor que en otras soluciones tradicionales con base a 
concreto. El fibrocemento aporta a la mayor durabilidad y menor mantención requerida en edificaciones.

c. Riesgo cancerígeno

Actualmente el fibrocemento no trae ningún problema de asbestosis. Entre los años 1900 hasta 1990 para la fabricación del fibrocemento se usaba el amianto (asbesto) cuyo uso fue prohibido por el riesgo cancerígeno que presentaba, desde entonces el fibrocemento ha variado su composición y reemplazado el asbesto por materiales como la Celulosa o Fibra natural y la fibra sintética.

\subsection{Impacto en clientes / proveedores de cada una de las variables del entorno.}

Se detallarán las variables del entorno que consideramos generan impacto en clientes y proveedores de Eternit para la unidad de negocio de fibrocemento:

\subsubsection{Análisis Político Gubernamental}

Los casos de corrupción y las dudas respecto de los proyectos en marcha hacen que en el sector público "nadie quiera firmar nada", por temor a ser investigado luego. Entonces, la inversión pública simplemente no se mueve. Esto afecta de manera Negativa a los Clientes, sobre todo al mismo estado que ha retraído el gasto público, por las diversas barreras burocráticas.

Asimismo, los proveedores se ven afectados por la reducción de la demanda, incrementando costos por capacidad ociosa o exceso de Stocks, sobre todo los proveedores nacionales.

\subsubsection{Análisis Económico}

Las proyecciones de crecimiento global favorecen al Perú económicamente, por lo que esta situación es positiva para Clientes y Proveedores que ven al país económicamente con diversas 
oportunidades, y puedan comercializar sus productos o adquirir productos del país. El crecimiento de las exportaciones depende del crecimiento económico Mundial.

Los nuevos Planes de Inversión Pública y Privada, favorecen positivamente tanto a Clientes y proveedores quienes ven una oportunidad y una reactivación de la economía. Lo que podemos observar, es que muchos empresarios, en especial pequeños y medianos, tienen expectativas negativas respecto del futuro. No ven claro el panorama. Entonces la respuesta natural es postergar las decisiones que, de otro modo, hubieran tomado. Y esto basado en indecisiones, contradicciones, idas y venidas, falta de unidad, entre otras del gobierno y entonces aparecen las dudas.

\subsubsection{Análisis Legal}

Decreto Legislativo $\mathrm{N}^{\circ} 1269$ - Nuevo régimen tributario del impuesto a la renta para MYPE, genera un impacto IDÓNEO a los clientes y proveedores (MYPE), puesto que permite tener un capital adicional para invertir.

Ley N 30425 - Retiro del 95.5\% del fondo AFP y la Ley N 30478 - Disposición del 25\% AFP, genera un impacto IDÓNEO a los clientes y proveedores, puesto que esta ley permitirá incrementar el consumo privado y se desarrollen proyectos de construcción.

Ley N 30556 - Reconstrucción con cambios genera un impacto IDÓNEO a los clientes y proveedores, puesto que la ley permite que el estado destine un alto fondo para los proyectos de reconstrucción de viviendas, hospitales, colegias y demás infraestructura que consuman productos de fibrocemento. 


\subsubsection{Análisis Cultural}

Los materiales usados para las paredes de las viviendas a nivel nacional, genera un impacto IDÓNEO a los clientes, ya que según la estadística a nivel nacional existe un alto porcentaje de casas con paredes de adobe que podrían ser remplazadas por fibrocemento. Esta situación afecta de manera POSITIVA a los proveedores, ya que al concretarse el cambio de paredes de adobe se necesitará materia prima para la fabricación de fibrocemento.

\subsubsection{Análisis Tecnológico}

Este nuevo sentido de sostenibilidad y vida saludable de la industria en general impacta en los retos y la capacidad de adaptación que los proveedores puedan tener para pasar de los materiales convencionales a materiales que cumplan con las exigencias que hoy empiezan no solo a ser un deseo del futuro, sino que empiezan a volverse en reglamentaciones, normas técnicas, y exigencias legales.

Los compradores deberán adaptarse a las nuevas exigencias de sustentabilidad y formara parte de sus propias exigencias y de sus propios clientes. Por lo tanto, proveedores como compradores deberán desarrollar equipos de investigación y desarrollo que permitan adecuar las nuevas tecnologías de los materiales a sus productos que puedan ofrecer al mercado, desde materias primas, o productos terminados.

Decir que es positivo o negativo dependerá de la capacidad de adaptación al cambio de cada integrante de esta industria. La economía y los mercados globales evolucionan de manera vertiginosa y los países que no estén preparados e innoven sus procesos y gestión, se rezagarán cada vez más frente a los países más desarrollados. 


\subsubsection{Análisis Ecológico}

El cuidado del medio ambiente y la sustentabilidad, genera un impacto IDÓNEO a los clientes y proveedores, puesto que la unidad de negocio de fibrocemento de ETERNIT está alineada a los cuidados ambientales y diferenciarse positivamente por el menor impacto en la huella de carbono.

Con respecto al riesgo cancerígeno, esto no genera un impacto IDÓNEO a los clientes y proveedores, puesto que los usuarios finales por mala información siguen considerando al fibrocemento como producto peligroso.

\subsection{Efecto en la empresa de cada una de las variables del entorno.}

Para determinar el impacto en la unidad de negocio de fibrocemento se detallarán las siguientes variables:

\subsubsection{Análisis Político Gubernamental}

Los casos de corrupción afectan a Eternit (unidad de negocio de fibrocemento) siendo una Empresa dentro de la Industria de la Construcción. Un caso reciente son los cuestionamientos a los módulos de Vivienda adquiridos por el Estado, de los cuales Eternit vendió los primeros 2500 módulos. Estos fueron observados por algunas deficiencias en la instalación, y cuestionados por supuestos altos costos. Estas críticas tuvieron una intención Política más que de calidad del Producto, ya que se abalaba de Productos Chilenos, cuando estos habían sido fabricados en una Alianza entre Eternit y Andina Home, ambas empresas reconocidas.

\subsubsection{Análisis Económico}

El crecimiento Mundial favorecerá las exportaciones y la economía peruana será afectada positivamente, incrementando el consumo interno y las inversiones, esto favorecerá las ventas de fibrocemento. Asimismo, esto motivara las inversiones del Grupo en el País y Latinoamérica. 
Los planes de Reconstrucción proyectados a 3 años, la infraestructura para los Juego Olímpicos, son favorable para la unidad de negocio de fibrocemento, esta etapa demandara una serie de productos de la construcción entre ellos los comercializados por Eternit. Asimismo, los nuevos benéficos de techo propio abrirán el mercado de la construcción de viviendas.

Los Planes de Inversión Pública y la proyección de la inversión privada por los diversos proyectos, favorecerán positivamente a la unidad de fibrocemento, donde pueden realizarse alianzas para desarrollar proyectos para el estado.

\subsubsection{Análisis Legal}

Decreto Legislativo $\mathrm{N}^{\circ} 1269$ - Nuevo régimen tributario del impuesto a la renta para MYPE, se considera una OPORTUNIDAD a largo plazo, porque muchos de nuestros clientes podrán regularizar y eliminar sus deudas tributarias, fortaleciendo a las MYPES para el incremento del consumo de fibrocemento.

Ley $\mathrm{N}^{\circ} 30425$ - Retiro del 95.5\% del fondo AFP y Ley N³0478 - Disposición del 25\% AFP para compra de un primer inmueble, se consideran una OPORTUNIDAD debido a que esta ley permitirá incrementar el consumo privado y se desarrollen proyectos de construcción.

Ley $\mathrm{N}^{\circ} 30556$ - Reconstrucción con cambios, se considera una OPORTUNIDAD debido a que la ley permite que el estado destine un alto fondo para los proyectos de reconstrucción de viviendas, hospitales, colegias y demás infraestructura que consuman productos de fibrocemento.

\subsubsection{Análisis Cultural}

A nivel nacional existe un alto porcentaje de casas con paredes de adobe que podrían ser remplazadas por fibrocemento, esta situación se considera una OPORTUNIDAD. 
Los materiales usados para las paredes de las viviendas en Lima Metropolitana, se considera una AMENAZA, ya que la cultura de Lima Metropolitana se inclina por las paredes de ladrillo o bloque de cemento.

Los sindicatos y delincuencia en el sector construcción, se considera una AMENAZA debido a que se genera un obstáculo para el desarrollo de la industria de la construcción.

\subsubsection{Análisis Ecológico}

El cuidado del medio ambiente y la sustentabilidad, se consideran una OPORTUNIDAD, debido a que la unidad de fibrocemento de ETERNIT está alineada a los cuidados ambientales y el menor impacto en la huella de carbono, el cual es un factor diferenciador que podemos usar como argumento de venta.

El riesgo cancerígeno, se considera una AMENAZA, debido a que los usuarios finales por mala información siguen considerando al fibrocemento como producto peligroso. Disminuyendo el consumo de fibrocemento en sus proyectos de construcción.

\subsection{Oportunidades y Amenazas}

Con la información detallada anteriormente sobre el entorno, se analizarán las siguientes oportunidades para la unidad de negocio de fibrocemento de Eternit.

\subsubsection{Oportunidades y Amenazas de la unidad de negocio de fibrocemento de Eternit.}

La tabla 5, nos detalla las oportunidades de la unidad de negocio y su impacto. 
Tabla 5. Oportunidades Eternit (Unidad de negocio de fibrocemento)

\begin{tabular}{|c|c|c|c|}
\hline ITEM & ANALISIS & DETALLE & IMPACTO \\
\hline \multirow[t]{2}{*}{1} & \multirow[t]{2}{*}{$\begin{array}{c}\text { Político } \\
\text { Gubernamental }\end{array}$} & $\begin{array}{l}\text { Nuevo Gabinete } \\
\text { Ministerial }\end{array}$ & $\begin{array}{l}\text { Se considera una oportunidad } \\
\text { a corto Plazo por que evitara las } \\
\text { barreras políticas para la } \\
\text { inversión Pública y generada } \\
\text { confianza en la Inversión Privada }\end{array}$ \\
\hline & & $\begin{array}{l}\text { Casos de corrupcion } \\
\text { y censura de ministros }\end{array}$ & $\begin{array}{l}\text { Se considera una amenaza por } \\
\text { que genera una inestabilidad que } \\
\text { afectará negativamente a toda la } \\
\text { economía. }\end{array}$ \\
\hline \multirow[t]{4}{*}{2} & \multirow[t]{4}{*}{ Económico } & $\begin{array}{l}\text { Proyección de } \\
\text { Crecimiento de la } \\
\text { Economía Global }\end{array}$ & $\begin{array}{l}\text { El crecimiento Mundial } \\
\text { favorecerá las exportaciones y la } \\
\text { Economía peruana será afectada } \\
\text { positivamente incrementando el } \\
\text { consumo interno y las } \\
\text { inversiones, favoreciendo las } \\
\text { ventas de fibrocemento. } \\
\text { Asimismo, esto motivara las } \\
\text { inversiones del Grupo en el País y } \\
\text { Latinoamérica. }\end{array}$ \\
\hline & & \begin{tabular}{l}
\multicolumn{1}{c}{ Plan integral de } \\
Reconstrucción y \\
Juegos Panamericanos
\end{tabular} & $\begin{array}{l}\text { Se considera una oportunidad } \\
\text { dado que la inversión pública } \\
\text { generara un crecimiento en el } \\
\text { sector de construcción, siendo } \\
\text { favorable para la unidad de } \\
\text { negocio de fibrocemento de } \\
\text { Eternit }\end{array}$ \\
\hline & & Fondo Mi Vivienda & $\begin{array}{l}\text { El nuevo sistema Mi vivienda } \\
\text { y sus beneficios incrementara la } \\
\text { construcción de Vivienda, } \\
\text { generando una oportunidad para } \\
\text { la unidad de fibrocemento de } \\
\text { Eternit }\end{array}$ \\
\hline & & $\begin{array}{l}\text { Déficit de Vivienda } \\
\text { en el País }\end{array}$ & $\begin{array}{l}\text { Se considera una oportunidad } \\
\text { dado que Eternit puede apostar } \\
\text { por introducir en el Mercado los } \\
\text { Sistemas de Viviendas Modulares } \\
\text { como alternativa a Viviendas de } \\
\text { Carácter Social, o Viviendas } \\
\text { Modulares para sectores } \\
\text { económicos altos }\end{array}$ \\
\hline
\end{tabular}




\begin{tabular}{|c|c|c|c|}
\hline ITEM & ANALISIS & DETALLE & IMPACTO \\
\hline \multirow[t]{3}{*}{3} & \multirow[t]{3}{*}{ Legal } & $\begin{array}{l}\quad \text { Decreto Legislativo } \\
\mathrm{N}^{\circ} 1269 \text { - Nuevo } \\
\text { régimen tributario del } \\
\text { impuesto a la renta para } \\
\text { MYPE }\end{array}$ & $\begin{array}{l}\text { Se considera una oportunidad a } \\
\text { largo plazo, porque muchos de } \\
\text { nuestros clientes podrán } \\
\text { regularizar y eliminar sus deudas } \\
\text { tributarias, fortaleciendo a las } \\
\text { MYPES para el incremento del } \\
\text { consumo de fibrocemento }\end{array}$ \\
\hline & & $\begin{array}{l}\text { Ley } \mathrm{N}^{\circ} 30425 \text { - Retiro } \\
\text { del } 95.5 \% \text { del fondo AFP } \\
\text { y Ley } \mathrm{N}^{\circ} 30478- \\
\text { Disposición del } 25 \% \text { AFP } \\
\text { para compra de un primer } \\
\text { inmueble }\end{array}$ & $\begin{array}{l}\text { Se considera una oportunidad } \\
\text { debido a que esta ley permitirá } \\
\text { incrementar el consumo privado y } \\
\text { se desarrollen proyectos de } \\
\text { construcción. }\end{array}$ \\
\hline & & $\begin{array}{l}\text { Ley } \mathrm{N}^{\circ} 30556- \\
\text { Reconstrucción con } \\
\text { cambios }\end{array}$ & $\begin{array}{l}\text { Se considera una oportunidad } \\
\text { debido a que la ley permite que el } \\
\text { estado destine un alto fondo para } \\
\text { los proyectos de reconstrucción de } \\
\text { viviendas, hospitales, colegias y } \\
\text { demás infraestructura que } \\
\text { consuman fibrocemento }\end{array}$ \\
\hline \multirow[t]{2}{*}{4} & \multirow[t]{2}{*}{ Cultural } & \multirow{2}{*}{$\begin{array}{l}\text { Materiales usados para } \\
\text { las paredes de las } \\
\text { viviendas a nivel nacional }\end{array}$} & $\begin{array}{l}\text { A nivel nacional existe un alto } \\
\text { porcentaje de casas con paredes de } \\
\text { adobe que podrían ser } \\
\text { remplazadas por fibrocemento, } \\
\text { esta situación se considera una } \\
\text { oportunidad }\end{array}$ \\
\hline & & & $\begin{array}{l}\text { Por otro lado también puede ser } \\
\text { considerada una ámenaza, ya que } \\
\text { estos materiales convencionales } \\
\text { están arraigados en la cultura } \\
\text { nacional. }\end{array}$ \\
\hline \multirow[t]{2}{*}{5} & \multirow[t]{2}{*}{ Tecnológico } & $\begin{array}{l}\text { Nueva tendencia de } \\
\text { Sistemas Flexibles y } \\
\text { Modulares }\end{array}$ & $\begin{array}{l}\text { Se considera una oportunidad } \\
\text { porque el fibrocemento encaja en } \\
\text { este tipo de Sistemas, livianos } \\
\text { flexibles y de gran resistencia }\end{array}$ \\
\hline & & $\begin{array}{l}\text { Nuevas tecnologías en } \\
\text { la construccion }\end{array}$ & $\begin{array}{l}\text { Se puede considerar una } \\
\text { ámenaza al no tener la certeza de } \\
\text { que tan rápido se puede ajustar la } \\
\text { economía a estas nuevas } \\
\text { tecnologías. }\end{array}$ \\
\hline
\end{tabular}




\begin{tabular}{|c|c|c|c|}
\hline & & $\begin{array}{l}\text { Programas Nacionales } \\
\text { de Construcción } \\
\text { Sostenible }\end{array}$ & $\begin{array}{l}\text { Se considera una oportunidad } \\
\text { dado que el fibrocemento es } \\
\text { reciclable, tanto para producir el } \\
\text { mismo producto como para su uso } \\
\text { en construcción, y sería un valor } \\
\text { agregado comercialmente }\end{array}$ \\
\hline \multirow[t]{3}{*}{6} & \multirow[t]{3}{*}{ Ecológico } & $\begin{array}{l}\text { Cuidado del medio } \\
\text { ambiente }\end{array}$ & $\begin{array}{l}\text { La unidad de negocio de } \\
\text { fibrocemento de Eternit está } \\
\text { alineada a los cuidados } \\
\text { ambientales, el cual es un factor } \\
\text { diferenciador que podemos usar } \\
\text { como argumento de venta. }\end{array}$ \\
\hline & & $\begin{array}{l}\text { Paradigma de riesgo } \\
\text { cancerigeno }\end{array}$ & $\begin{array}{l}\text { Se considera una amenaza ya } \\
\text { que afecta directamente a la } \\
\text { demanda de fibrocemento. }\end{array}$ \\
\hline & & Sustentabilidad & $\begin{array}{l}\text { Este factor nos permite } \\
\text { diferenciarnos positivamente por } \\
\text { el menor impacto en la huella de } \\
\text { carbono, el cual es un factor } \\
\text { diferenciador que podemos usar } \\
\text { como argumento de venta. }\end{array}$ \\
\hline
\end{tabular}

\subsection{Matriz de evaluación de los factores externos EFE}

La matriz de evaluación de los factores externos (EFE) permite resumir y evaluar las principales oportunidades y amenazas de la unidad de negocio de fibrocemento de Eternit. Para elaborar la matriz, primero se deben listar los factores determinantes; luego, se asigna un peso relativo a cada factor, el cual indica el nivel de importancia del factor para alcanzar el éxito y la suma de los pesos deben dar 1.0. Posteriormente, se asigna un valor entre 1 y 4 a cada factor de calificación:

$1=$ Pobre respuesta estratégica de la empresa.

$2=$ Regular respuesta estratégica de la empresa.

3 = Buena respuesta estratégica de la empresa.

4 = Muy buena respuesta estratégica de la empresa. 
Por último, se multiplican ambos factores y se suman los pesos ponderados de todos los factores, obteniendo el peso ponderado total de las oportunidades y amenazas de la empresa.

Mayor a 2.5 = Estrategias están respondiendo

Menor a $2.5=$ Estrategias no son efectivas

Tabla 6. Matriz EFE

\begin{tabular}{|c|c|c|c|}
\hline FACTORES EXTERNOS CLAVE & VALOR & $\begin{array}{l}\text { CALIFIC } \\
\text { ACION }\end{array}$ & $\begin{array}{c}\text { VALOR } \\
\text { PONDERADO } \\
\end{array}$ \\
\hline \multicolumn{4}{|l|}{ Oportunidades } \\
\hline $\begin{array}{l}\text { Plan integral de Reconstrucción y } \\
\text { Juegos Panamericanos Ley } \mathrm{N}^{\circ} 30556 \text { - } \\
\text { Reconstrucción con cambios }\end{array}$ & 0.1 & 3 & 0.3 \\
\hline $\begin{array}{l}\text { Nueva tendencia de Sistemas Flexibles } \\
\text { y Modulares sostenibles }\end{array}$ & 0.1 & 2 & 0.2 \\
\hline Déficit de Vivienda en el País & 0.1 & 2 & 0.2 \\
\hline Fondo Mi Vivienda & 0.08 & 2 & 0.16 \\
\hline $\begin{array}{l}\text { Proyección de Crecimiento de la } \\
\text { Economía Global }\end{array}$ & 0.08 & 2 & 0.16 \\
\hline $\begin{array}{l}\text { Ley N } \mathrm{N}^{\circ} 30478 \text { - Disposición del 25\% } \\
\text { AFP para compra de un primer inmueble }\end{array}$ & 0.05 & 1 & 0.05 \\
\hline $\begin{array}{l}\text { Decreto Legislativo } \mathrm{N}^{\circ} 1269 \text { - Nuevo } \\
\text { régimen tributario del impuesto a la renta } \\
\text { para MYPE }\end{array}$ & 0.05 & 1 & 0.05 \\
\hline $\begin{array}{l}\text { Ley } \mathrm{N}^{\circ} 30425 \text { - Retiro del } 95.5 \% \text { del } \\
\text { fondo AFP }\end{array}$ & 0.05 & 1 & 0.05 \\
\hline \multicolumn{4}{|l|}{ Amenazas } \\
\hline $\begin{array}{l}\text { Casos de Corrupción y Censura de } \\
\text { Ministros }\end{array}$ & 0.1 & 3 & 0.3 \\
\hline $\begin{array}{l}\text { Materiales usados para las paredes de } \\
\text { las viviendas en Lima Metropolitana }\end{array}$ & 0.1 & 3 & 0.3 \\
\hline $\begin{array}{l}\text { Nuevas tecnologías en Materiales de } \\
\text { Construcción }\end{array}$ & 0.08 & 2 & 0.16 \\
\hline Paradigma de riesgo cancerígeno & 0.05 & 1 & 0.05 \\
\hline \multirow[t]{2}{*}{$\begin{array}{l}\text { Amenaza de Políticas proteccionistas } \\
\text { de USA }\end{array}$} & 0.06 & 1 & 0.06 \\
\hline & 1 & & 2.04 \\
\hline
\end{tabular}


El resultado de la Matriz EFE 2.04 indica que la unidad de negocio de fibrocemento de Eternit está por debajo del promedio (2.5) en utilizar asertivamente las estrategias de la empresa y que las acciones que están realizando para combatir las amenazas del entorno no son suficientes.

Con respecto al área de oportunidades se tiene rangos predominantes de 1 y 0.8 , los cuales corresponden a factores que generan un alto impacto sobre la unidad de negocio de fibrocemento de Eternit. Por ejemplo, el Plan Integral de Reconstrucción con Cambios tiene una inversión de S/ 23 millones aproximadamente, de los cuales, el 75\% del presupuesto son una oportunidad porque están destinados a las obras de construcción, de ese presupuesto se proyecta reconstruir 45,613 viviendas. Asimismo, con respecto a los Juegos Panamericanos, Lima ha sido escogida como sede de los eventos más importantes para febrero 2019, proyectándose a construir 8,500 departamentos para que habiten los más de 9000 atletas. A continuación, se detallan las sedes por

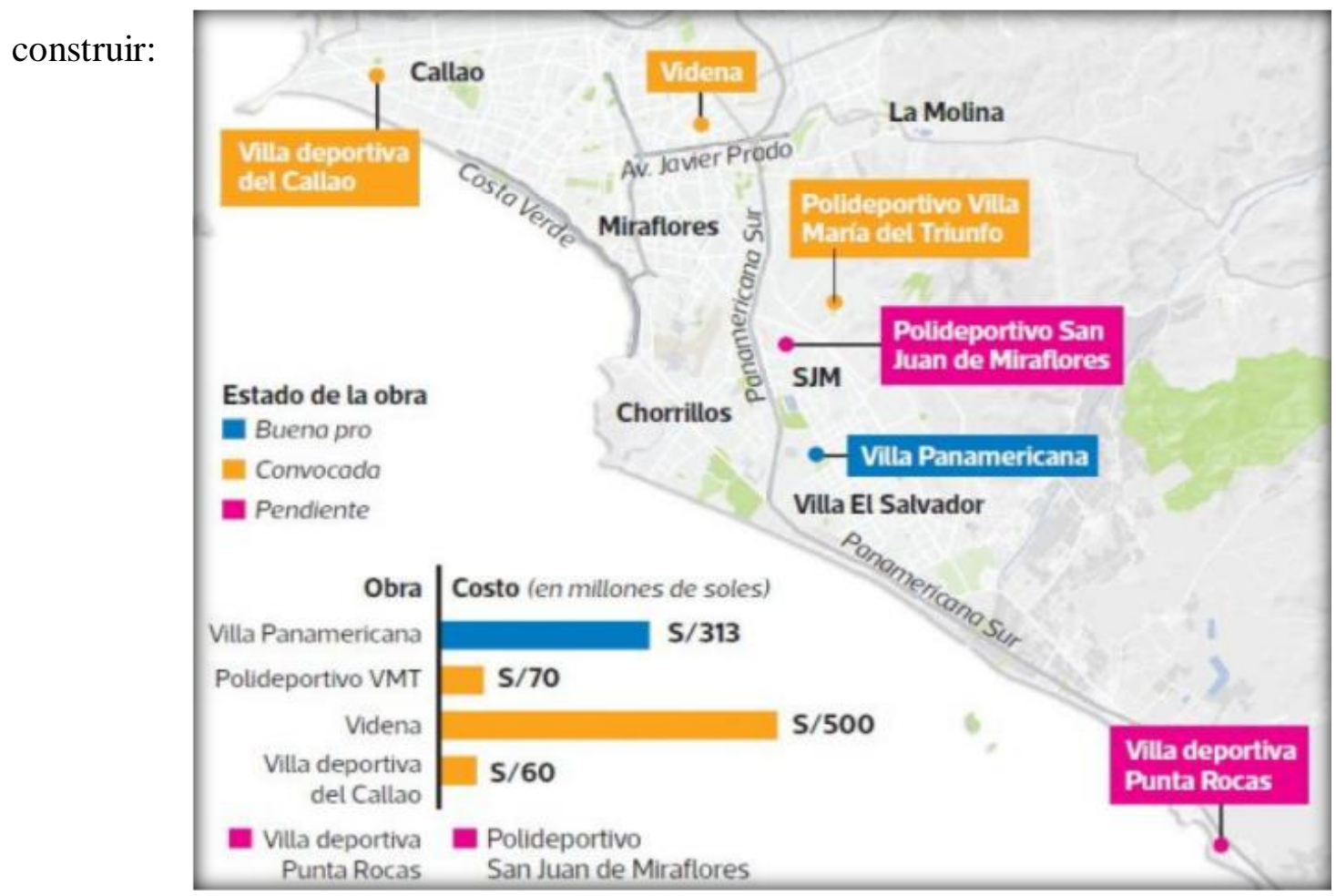

Figura 14. Sedes por construir Panamericanos

Fuente: Copal 
Teniendo en cuenta que han pasado más de 4 años de haber sido nominados como sede de los Juegos, y que solo se ha avanzado el 10\%, el fibrocemento es una opción idónea porque permiten realizar construcciones más rápidas por la facilidad de instalación del producto. Para este evento se tienen presupuestados S/ 2,306 millones, lo cual permite que haya un crecimiento del 8,8\% en el rubro de construcción para el 2018.

El déficit habitacional en Lima Metropolitana tiene un valor alto también por la cantidad de unidades habitaciones que representa: 612,464 (Andina, 2016), los cuales corresponden el 59\% a viviendas con deficiencias en calidad. El distrito que lidera con el 15.6\% es SJL (HGP Group, 2016). Asimismo, la opción de Fondo Mi Vivienda permite que la población adquiera un crédito para adquirir una vivienda en donde financian hasta el 90\% siempre y cuando el costo sea desde $\mathrm{S} / 56,700$ hasta $\mathrm{S} / 300,000$. Esto facilita la adquisición de hogares por lo que la demanda aumenta de las construcciones.

Finalmente, todo es posible gracias al crecimiento económico que hay en el país, ya que a pesar del FEN costero y la paralización de obras, Perú ha liderado el crecimiento económico en América Latina con un crecimiento del 2,3\% por encima de los países que lo integran, ubicándolo en el país con mejor proyección en inversiones de construcción.

Con respecto a las amenazas, se identifica como mayor amenaza los casos de corrupción y censura de ministros en el país, ya que ponen al país en un esquema inestable por lo que genera incertidumbre en inversionistas extranjeros deteniéndolos en una decisión de inversión. Casos como los de Odebrecht han frenado de forma directa la economía y lo que aún no se esclarece con respecto al Gasoducto Sur Peruano podría mantener esta desaceleración afectando los proyectos de Inversión Pública. Por otro lado, la tendencia en cuanto a los materiales de construcción que usa la población peruana también tiene un alto valor, ya que el 66\% de la 
población urbana tiende a construir sus viviendas con ladrillo y bloques de cemento como primera opción, adobe un 21\%, madera un $7.5 \%$, entre otros. Solo un $2.5 \%$ se animan a construir con otros materiales en donde se incluiría el fibrocemento, sin embargo, tengamos en cuenta que la propuesta es para divisiones de paredes y no para estructura de construcción.

Finalmente, se considera como otras de las amenazas principales las nuevas tecnologías, ya que el producto es atractivo por la rapidez y facilidad de instalación, entre otras propiedades; lo cual hoy en día con la tecnología avanzada otros productos podrían sustituirlo con materiales de construcción inteligentes, lo cual se afianza fácilmente con la tendencia a lo ambientalista inclusive, ya que puede dar soluciones térmicas a través de la energía solar, o al mismo cemento darle la capacidad de generar luz, entre otras innovaciones que buscan el uso eficiente de la energía, dar mayor seguridad y confort. 


\section{Capítulo V. Análisis Interno}

\subsection{Descripción de la Cadena de Valor}

El análisis interno se enfocará en encontrar las competencias diferenciadoras de la unidad de negocio de fibrocementos que nos permita generar las estrategias financieras y comerciales para potenciar estas fortalezas y mitigar las debilidades. Las fortalezas de la unidad de negocio más relevantes serán aquellas que no pueden ser igualadas o imitadas fácilmente por la competencia.

\subsubsection{Actividades Primarias}

\section{a. Supply Chain}

La cadena de abastecimiento de la empresa está encargada de la adquisición, recepción y almacenamiento de las materias primas, compras y adquisiciones, almacenamiento y despachos de productos terminados.

Esta actividad es liderada por el Gerente de Supply Chain de la compañía.

\section{- Materias Primas:}

La adquisición de las materias primas tiene dos procesos diferencias, la adquisición Local y la adquisición corporativa a través de la dirección de Supply Chain Management Latam. Las materias primas que se negocian a través del grupo son la Celulosa y las Fibras sintéticas. Los productos que son adquiridos localmente son el cemento y la sílice y el caolín. Estos productos para poder ser usados en nuestro proceso sean locales o importados, deben seguir un proceso de validación a través de del centro de innovación y tecnología del grupo ubicado en Bélgica, quienes definen si estas materias primas de proveedores específicos cumplen con los estándares definidos para nuestros productos.

Estos productos por sus características e importancia son almacenados en las instalaciones de la compañía, bajo techo, y no requieren de ningún área con ambiente acondicionada. 
La gestión de materias primas se describe a continuación

Control de inventarios: Se revisan los stocks y consumos proyectados de materias primas, a través de inventarios semanales coordinados con el área de producción, se emite un reporte de balance de materias primas e inventario actualizado.

Solicitud de Materias Primas: La entrada para la solicitud es el reporte de inventario, a través de una reunión de coordinación entre producción y supply chain se determina la cantidad de materia prima a solicitar, tanto nacional como importada, y queda registrada en acta de reunión. Supply chain emite las solicitudes a través del sistema para las importaciones (a través del grupo Etex), y vía e mail para proveedores locales.

Recepción de materias primas: El área de importaciones genera un plan de entregas de importados, con esta información se programa los transportes y la recepción. La materia prima local es gestionada por el área de compras locales y se hacen solicitudes de acuerdo con el nivel de stock y consumos semanales. La unidad de transporte ingresa a la planta de acuerdo con el plan de entregas locales e importadas, son pesados a la entrada y salida a través de la balanza de la compañía, y se comprueban las toneladas ingresadas. Los pesos son validados con lo indicado en las guías de remisión y se emite el reporte de ingreso de materia prima.

Control de calidad de las materias primas: Las materias primas ingresadas, siguen una evaluación física de control de calidad, donde se evalúan propiedades como humedad, granulometría, densidad, aspecto visual, los cuales siguen parámetros establecidos por el grupo y de acuerdo con el centro de innovación y tecnología.

Despacho de Materias primas: Los movimientos de materias primas son controlados a través de vales de entrega física, el área de producción realiza un pesado interno y estos son registrados en el módulo SAP., estos controles son las entradas para los inventarios semanales. 


\section{- Productos terminados:}

Los productos terminados son recibidos por el almacén de PT. Los productos de fibrocemento ondulados por su proceso de producción deben ser almacenados por un periodo de tiempo no mayor a 28 días, ni menor a 20 días, debido que requieren culminar su proceso químico de reacción al ambiente para completar sus características de calidad y resistencia, posterior a ello pueden ser liberados para la venta y despacho. En el caso de los productos planos no requiere este tiempo y pueden ser liberados inmediatamente después de ser producidos y recibidos por los almacenes.

La gestión de productos terminados se describe a continuación

Recepción de productos terminados: De acuerdo con el programa de producción se programa los recursos para la recepción de los productos terminados, teniendo en cuenta que los equipos de transporte como montacargas, codificadores para el proceso de embalaje son tercerizados. Los productos son entregados en la siguiente presentación: productos ondulados de fibrocemento, en paquetes de 150 unidades en parihuelas código nacional y productos planos de fibrocemento, en paquetes de 200 unidades en parihuelas de código nacional.

Ambas presentaciones deben encontrarse debidamente embaladas con zunchos de sujeción y esquineros de cartón para evitar daños por golpes.

Los productos recibidos, son contabilizados físicamente por el responsable del almacén de productos terminados a través del documento cierre técnico diario el cual muestra las cantidades producidas a entregas, el cual después de ser validado por el APT y el encargado de entregas de producción, son ingresados al sistema, donde pasan a un almacén virtual de control de calidad. Este documento es posteriormente visado por Jefe de producción y el Jefe de almacenes.

El producto es retirado de las áreas productivas hacia las áreas de almacenamiento 
Control de inventarios: El control de inventarios de productos terminados se realiza semanalmente. Se realiza con personal del APT y personal de planificación y control de la producción. Se emite el reporte de inventario físico. Se realiza el contraste del producto físico con respecto a los stocks registrados en el sistema, si existieran diferencias se hacen un reconteo y evaluación, se corrige cualquier diferencia en el sistema en caso exista algún error. Si el error no puede ser subsanado, se emite un reporte a Gerencia General y a contabilidad para las acciones a tomar y ajustes necesarios. Los cierres de inventario se realizan a fin de mes a través del sistema y se generan los reportes traducidos en dinero, de los despachos, inventarios, ventas.

Control de calidad de productos terminados: Los productos terminados al ser recibidos por el APT son ingresados al sistema en condición de calidad, lo cual significa que son lotes de productos que están en proceso de evaluación de sus propiedades de acuerdo con lo establecido de los parámetros de control de productos terminados. Para los productos planos la evaluación de calidad tiene una duración de 1 día, después del cual son liberados o rechazados, se registra en el sistema y pasan a libre disponibilidad de venta, o a cuarentena para reevaluación o proceso de disposición final. Para los productos ondulados, el proceso dura 28 días, debido a que el producto requiere este tiempo para culminar su reacción química y lograr obtener sus propiedades de calidad esperadas. Pasado este tiempo sigue el mismo proceso de los productos planos. Las propiedades que se evalúan son: Resistencia a la Rotura (N/M), humedad, densidad, características dimensionales, apariencia física.

Despacho de productos terminados: El responsable de planificación de despachos del área de gestión de servicios emite el plan de despachos semanal.

Para el despacho local se recibe la hoja de transporte donde se especifica los datos del vehículo, el código de cliente y despacho, así como la asignación de turno de despacho, según la 
hora de emisión de la hoja de transporte. El vehículo es conducido al patio de despacho y es pesado en vacío, se genera la carga de los productos de acuerdo con el código de cliente y despacho. El vehículo pasa el control de vigilancia, en el cual se hace el conteo y verificación de la carga. Se emite la guía de remisión de acuerdo con la hoja de transporte. Se emite una constancia de despacho en tres copias vigilancia, transportista y APT, que garantiza que la carga es la establecida en la hoja de transporte y guía de remisión. Se ingresa al sistema el detalle de los productos despachados.

\section{b. Producción}

La producción de los productos de fibrocemento se fabrica en una planta industrial ubicada en Lima. La gestión de este proceso y las áreas relacionadas a este, se encuentran a cargo del Gerente de Producción. El proceso se inicia con la programación establecida por el área de planificación de la demanda. Este plan se alimenta de la proyección de ventas elaborada por el área comercial.

La producción consta de los procesos de preparación y mezclado de las materias primas de acuerdo con las proporciones establecidas por la formulación que tiene cada producto, posteriormente esta mezcla de productos concentrado es conducido a un proceso denominado Hatsheck, en el cual se genera la formación de una pasta producto de la mezcla, esta pasta continua hacia un proceso de moldeado y posterior curado (sea ondulado o plano). El curado se realiza a temperaturas superiores a $60^{\circ}$ y depende del tipo de producto. Finalmente, el producto es embalado y entregado al almacén de productos terminados.

El proceso de producción se explica a continuación:

- Programación de la producción: El programa de producción se elabora mensualmente para los productos de fibrocemento, y se realiza a través del informe planificación de la 
demanda, donde se especifica el volumen de producción por producto requerido para el mes en curso. Con esta información se elabora un programa diario de producción, que incluye cambios de producto, mantenimientos programados, programación de personal, y él \% de utilización de la línea. Este documento representa la formalidad para la ejecución de la producción.

- Proceso de producción: El proceso de producción se detalla a continuación:

- Preparación de materias primas: El proceso de producción del fibrocemento inicia su proceso con la preparación de las materias primas:

- Fibras: Las fibras (celulosa) pasan por un proceso de pulpeado, que consiste en diluir el material seco en un tanque con agua y agitación, logrando un producto concentrado. Posteriormente pasa por un proceso de refinado, que consiste en separar las fibras y lograr un efecto de abertura de fibras, sin disminuir la longitud de las mismas, esto permite un mejor filtrado de los finos durante el proceso de formación.

○ Ligantes: El cemento y la sílice son las materias primas que generan dentro del proceso químico la adhesión de todas ellas. El cemento es vertido en polvo y no requiere un proceso de pre-concentración. En el caso de la Sílice, este producto pasa por un proceso de molienda para lograr una granulometría más fina en favor de las reacciones químicas para la adhesión de los productos durante el proceso de curado a alta temperatura.

○ Materiales Auxiliares: Los materiales auxiliares son preparados en una concentración de agua para facilitar su transporte a la siguiente etapa de mezclado de materias primas.

En el siguiente cuadro se detalla la función específica de cada materia prima para el proceso y el producto

Tabla 7. Materias primas para la fabricación de fibrocemento 


\begin{tabular}{|c|c|c|c|c|c|}
\hline \multirow{2}{*}{$\begin{array}{l}\text { ITE } \\
\text { M }\end{array}$} & \multirow{2}{*}{$\begin{array}{l}\text { MATERIAS } \\
\text { PRIMAS }\end{array}$} & \multirow{2}{*}{ TIPO } & \multicolumn{2}{|c|}{$\begin{array}{r}\text { FUNCION } \\
\text { ESPECIFICA }\end{array}$} & \multirow{2}{*}{$\begin{array}{l}\text { CALIDAD } \\
\text { PRUEBAS } \\
\end{array}$} \\
\hline & & & PROCESO & PRODUCTO & \\
\hline \multicolumn{6}{|c|}{ Fibras } \\
\hline \multirow[t]{3}{*}{1} & \multirow{3}{*}{$\begin{array}{l}\text { Fibra } \\
\text { vegetal } \\
\text { celulosa }\end{array}$} & \multirow[t]{3}{*}{$\begin{array}{l}\text { Celulos } \\
\text { a Virgen }\end{array}$} & \multirow{3}{*}{\begin{tabular}{l}
\multicolumn{1}{c}{ Formar } \\
una capa que \\
actúa como \\
un filtro \\
sobre el \\
tamiz y \\
mejorar la \\
retención de \\
particulares
\end{tabular}} & \multirow{3}{*}{$\begin{array}{l}\quad \text { Para } \\
\text { reforzar el } \\
\text { producto y } \\
\text { mejorar la } \\
\text { matriz en } \\
\text { flexibilidad y } \\
\text { resistencia al } \\
\text { esfuerzo. }\end{array}$} & Humedad \\
\hline & & & & & Longitud de fibra \\
\hline & & & & & Contenido de lignina \\
\hline \multicolumn{6}{|c|}{ Ligantes-Aglutinantes (BINDER) } \\
\hline \multirow[b]{4}{*}{2} & \multirow[b]{4}{*}{ Cemento } & \multirow[b]{4}{*}{$\begin{array}{l}\text { Portlan } \\
\text { d } 1\end{array}$} & \multirow{4}{*}{\begin{tabular}{|l|}
\multicolumn{1}{c|}{$\mathrm{Su}$} \\
función es \\
construir una \\
matriz \\
compacta y \\
resistente \\
involucrando \\
a todos los \\
materiales \\
\end{tabular}} & \multirow[b]{4}{*}{-} & Granulometría \\
\hline & & & & & Superficie Específica \\
\hline & & & & & Tiempo de fragua inicial \\
\hline & & & & & Tiempo de fragua final \\
\hline \multirow[t]{2}{*}{3} & \multirow[t]{2}{*}{ Sílice } & \multirow[t]{2}{*}{-} & \multirow{2}{*}{\begin{tabular}{l}
\multicolumn{1}{c}{ La sílice } \\
es un \\
aglutinante \\
que \\
reacciona \\
con el \\
cemento \\
durante la \\
operación de \\
autoclave. \\
Uso para \\
placas \\
planas.
\end{tabular}} & \multirow[t]{2}{*}{-} & Humedad \\
\hline & & & & & Granulometría \\
\hline \multicolumn{6}{|c|}{ Materiales Auxiliares } \\
\hline \multirow[b]{2}{*}{4} & \multirow[b]{2}{*}{ Caolín } & \multirow[b]{2}{*}{-} & \multirow{2}{*}{$\begin{array}{l}\text { Plasticida } \\
\text { d y adhesión } \\
\text { de capas }\end{array}$} & \multirow{2}{*}{ Impermeabl } & Humedad \\
\hline & & & & & $\begin{array}{l}\text { Velocidad de } \\
\text { Decantación }\end{array}$ \\
\hline 5 & $\begin{array}{l}\text { Carbonat } \\
\text { o de Calcio }\end{array}$ & - & - & $\begin{array}{l}\text { Estabilidad } \\
\text { a la Matriz }\end{array}$ & Humedad \\
\hline
\end{tabular}

Fuente: Elaboración propia 
Mezcla de materias primas: Después de la preparación de las materias primas, estas son juntadas en un recipiente de 1.2 toneladas de capacidad, que contiene un sistema de mezclado helicoidal, de tal manera de homogenizar la mezcla. El proceso de mezclado se realiza con la siguiente proporción de materias primas:

Cemento entre 30 a $40 \%$

Celulosa entre 3 a $8 \%$

Caolín entre 5 a $8 \%$

Sílice; hasta de $60 \%$

Formación de la película o pasta para moldear: La tecnología utilizada para esta etapa es el proceso Hatschek, el grafico nos muestra cómo funciona este proceso y líneas abajo se describe las etapas.

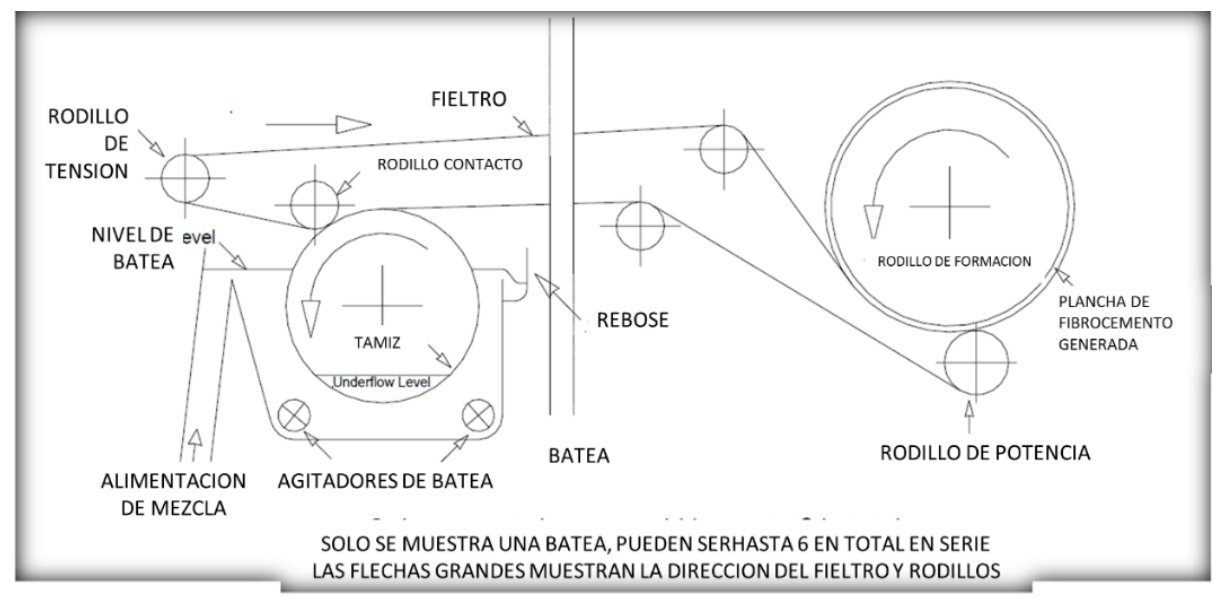

Figura 15. Proceso Hatschek

Fuente: Cook, Tony (1998). Formation of Films on Hatschek Machines. Building Materials and Technology.

Recuperado de:

http://www.fibrecementconsulting.com/publications/011011.hatschekfilmsummary.pdf 
La máquina hatschek fue patentado por Ludwick Hatschek en la década de 1890, y se diseñó para la fabricación de planchas de cemento con amianto (Asbesto). Sin embargo, la maquina fue evolucionando con nuevas tecnologías y en la actualidad está diseñada para la producción de fibrocemento, y se ha eliminado el asbesto en el proceso.

El proceso Hatschek consiste principalmente de una batea en la que una malla de tamiz envuelta en una estructura cilíndrica gira dentro de la batea que contiene la mezcla de fibras, cemento y materiales auxiliares a base de agua, los cuales se encuentran como partículas en suspensión. El tamiz cilíndrico este ensamblado en un eje con la batea, y gira impulsado por el fieltro, (como una faja transportadora), cuyo contacto entre si se genera a través del rodillo de contacto. El fieltro a su vez es impulsado por el rodillo de potencia cuyo giro es generado por un sistema motor- reductor. Este mismo rodillo de potencia genera la transferencia de la pasta generada a través de presión entre el fieltro y el rodillo formador de la película o pasta.

La película se forma de la siguiente manera:

La batea es alimentada de la mezcla, cuando el tamiz gira en contacto con la mezcla genera que los sólidos en suspensión se aglomeren en la superficie, el agua es filtrada a través de los orificios del tamiz,

Esta película formada en el tamiz es trasferida por presión de contacto entre el fieltro y el tamiz, la película se transfiere al fieltro, y continúa su recorrido a través de este.

La película formada (normalmente de entre $1 \mathrm{a} 1.5 \mathrm{~mm}$ ) es transportada en la dirección del fieltro y es transferida hacia el formador de pasta por presión de contacto entre el rodillo de potencia y rodillo formador. 
Este proceso continuo y se generan tantas capas en el rodillo formador como espesor se requiera en la pasta, a través de un control de espesores, pasta es cortada y retirada de manera automática del formador, para que el proceso continúe y se forme una nueva pasta.

Moldeado de la pasta: Luego de formada la pasta, es transportada de manera automática por un conjunto de fajas hacia el proceso de moldeado. Para el caso de Planchas onduladas se cuenta con moldes metálicos con la forma ondulada. La pasta es colocada en el molde y por gravedad y acción de vacío, toma la forma del molde. Estas pastas son acumuladas, pasta molde en un apilamiento de 100 a 150. Para el caso de planchas planas el molde es plano y sigue el proceso similar al ondulado, el apilamiento es de 200 pastas.

Curado: Después de ser apiladas las pastas, son ingresadas a una cabina de curado, donde se ingresa vapor a $80^{\circ} \mathrm{Cpor}$ un tiempo de 8 horas. Esto permite generar las reacciones químicas de los componentes para lograr las propiedades del producto.

Autoclaveado: El proceso de autoclaveado es un proceso de curado inmediato, sin embargo, por su composición o formulación solo puede ser aplicado a las planchas planas. Este proceso se realiza a una presión de entre 7 - 10 bar y temperaturas de entre 150 y $180{ }^{\circ} \mathrm{C}$.

Desmoldado: Después del proceso de curado el producto es separado de sus moldes, para ser embalados y entregados al almacén de productos terminados.

Entrega de Productos terminados: Después de producido el producto pasa por un proceso de embalado, y es entregado al almacén de productos terminados, a través del cierre técnico de producción, donde se especifica las cantidades producida. este documento se valida físicamente y es visado por las jefaturas de las áreas, posteriormente el producto se ingresa al sistema y pasa a estado de calidad. 
Control de Calidad de Productos Terminados: Los productos terminados al ser recepcionados por el APT son ingresados al sistema en condición de calidad, lo cual significa que son lotes de productos que están en proceso de evaluación de sus propiedades de acuerdo con lo establecido de los parámetros de control de productos terminados. Para los productos planos la evaluación de calidad tiene una duración de 1 día, después del cual son liberados o rechazados, se registra en el sistema y pasan a libre disponibilidad de venta, o a cuarentena para reevaluación o proceso de disposición final. Para los productos ondulados, el proceso dura 28 días, debido a que el producto requiere este tiempo para culminar su reacción química y lograr obtener sus propiedades de calidad esperadas. Pasado este tiempo sigue el mismo proceso de los productos planos. Las propiedades que se evalúan son: resistencia a la rotura (N/M), humedad, densidad, características dimensionales, apariencia física.

\section{c. Marketing y Ventas}

El proceso de ventas se encuentra a cargo del Gerente Comercial quien también está a cargo del área de Marketing y Gestión de Servicio.

El cliente solicita su pedido a través de la web de la compañía, el sistema envía un correo electrónico al gestor de servicio, quien procesa el pedido y evalúa en el sistema y con cada área correspondiente, stocks, descuentos, línea de crédito. Posteriormente se envía una respuesta formal al cliente, de los tiempos de entrega y formas de pago. El pedido continúa su proceso y se planifica y gestiona el despacho del producto.

Las ventas se dividen 4 procesos:

- Venta distribuidores tradicionales: Eternit cuenta con más de 300 distribuidores tradicionales. 
- Venta distribuidores especializados: Eternit cuenta con 50 distribuidores especializados, el proceso de venta está enfocado en brindar asesorías y capacitaciones a los proyectos de estos distribuidores que brindan soluciones de construcción flexibles.

- Ventas Home Center: Las ventas en home center son a través de sistema que se encuentra enlazado con la cadena, los inventarios son compartidos y la disponibilidad de productos. Los pedidos son directamente al sistema.

- Ventas cliente directo: Los clientes de venta directa son personas naturales o jurídicas, sus pedidos son igualmente evaluados por área de finanzas, y usualmente el pago es contra entrega.

Existe una fuerza de ventas organizados por regiones en todo el país, la cual se detalla en la figura organigrama fuerza de ventas:

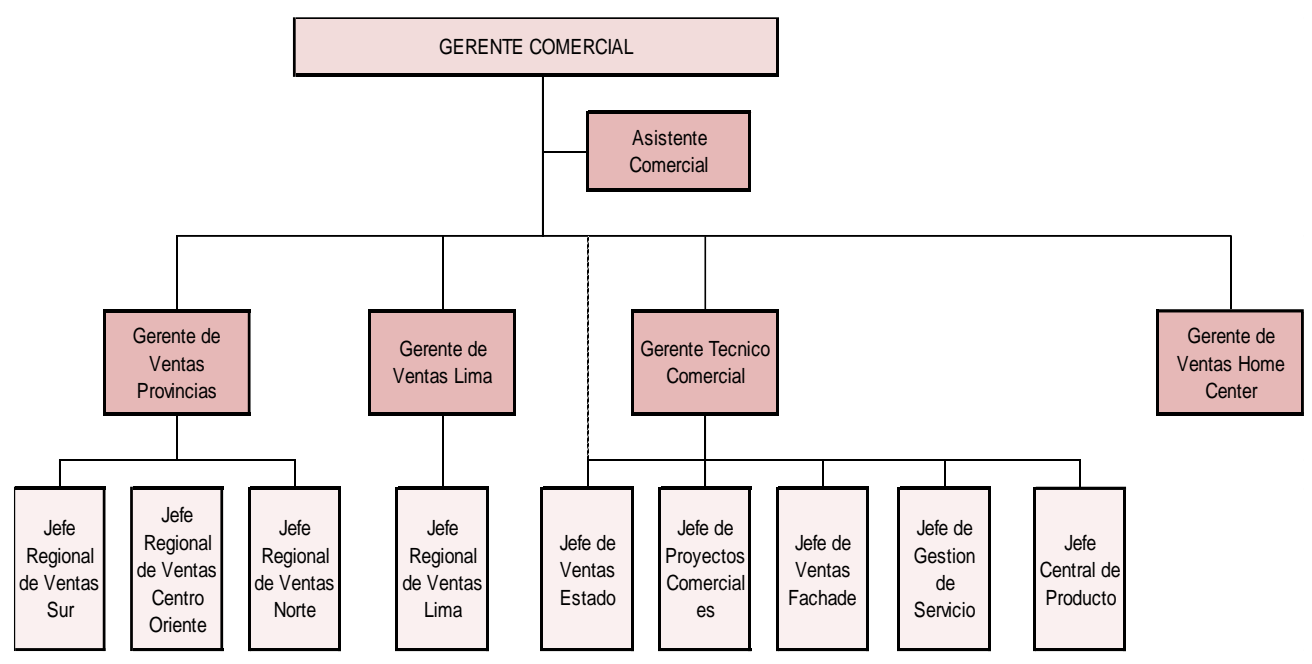

Figura 16. Organigrama Gerencia Comercial

Fuente: Elaboración propia 
- Gerente de Ventas:

- Es el responsable del cumplimiento de los objetivos de ventas en todas las Regiones del

País

- Asimismo, se encarga de la línea equitone, línea de productos de fibrocemento especializado para obras de fachadas

- Se encarga del área de Gestión de Servicios, y es responsable del servicio post venta, asesoría técnica, plan de despachos, atención de reclamos.

- Evaluar con la Gerencia de Administración y Finanzas los créditos para los clientes.

- Evaluación del desempeño de la fuerza de ventas.

- Definición de las estrategias y planes de acción para el cumplimiento de Objetivos

- Gerente Técnico Comercial:

- Es el responsable de los proyectos comerciales especializados de la compañía, dirigidos al estado o empresas privadas. Cumplimiento de los objetivos de Ventas en todas las regiones del país

- Evaluación de requerimientos de capacitación de la fuerza de ventas

- Establecer la demanda proyectada mensual por regiones

- Evaluar con la Gerencia de Administración y Finanzas los créditos para los clientes.

- Evaluación del desempeño de la fuerza de ventas.

- Definición de las estrategias y planes de acción para el cumplimiento de Objetivos

- Gerencia de Marketing:

- El área de Marketing se encarga de diseñar las estrategias de comunicación de la marca y productos Eternit. Así como la investigación de mercados potenciales y tendencias de mercado. 
- Asimismo, se encarga del diseño de contenido de las campañas de comunicación, digital e impreso.

- Establece las capacitaciones, cursos, talleres para los clientes de Eternit. Se encarga de planificarlas y ejecutarlas. El enfoque del área está orientado al sistema drywall.

- Se encarga de los proyectos digitales y publicaciones a través de las redes sociales

(Facebook, twitter, Pinterest)

- Además, es responsable del mantenimiento de la infraestructura del canal y la implementación de nuevos puntos de venta. Propone y ejecuta las promociones de los productos.

La compañía ha implementado y mantiene su campaña de comunicación:

- Marca Eternit: Buses, paneles publicitarios

- Difusión del Producto: Campaña rompiendo mitos

- Comunicación en redes sociales: actualmente se ha llegado a los 250,000 seguidores en

Facebook.

La estructura del Área Comercial se define a continuación.

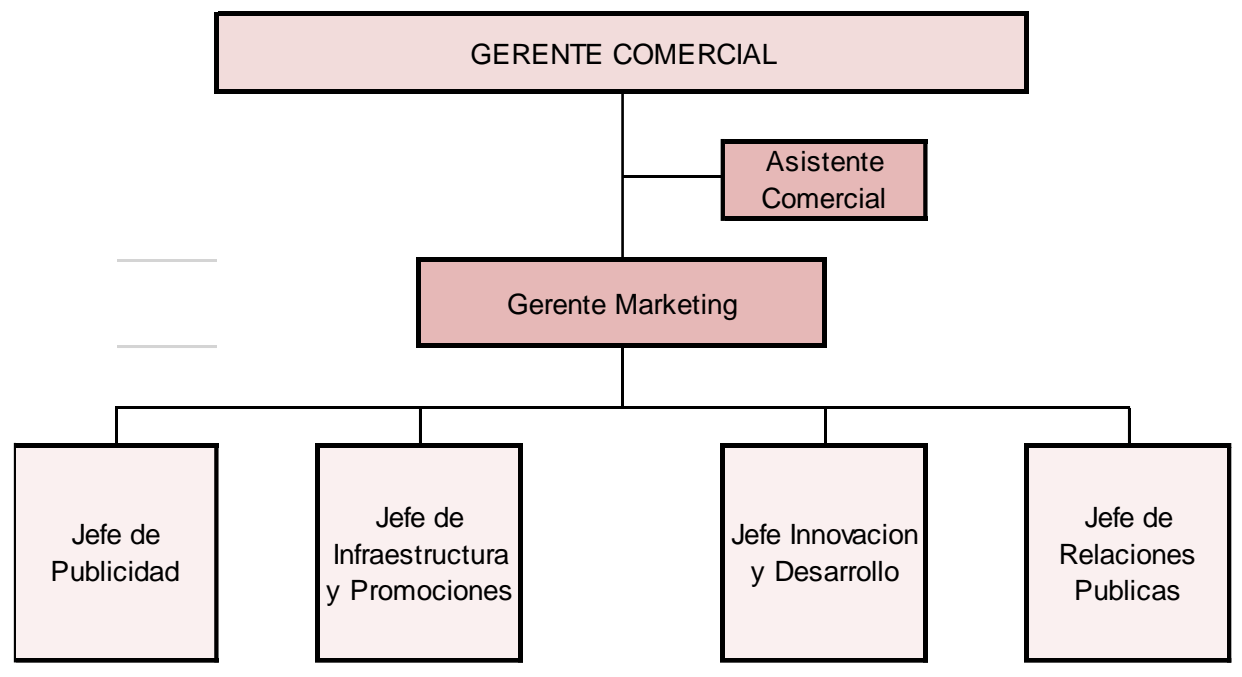

Figura 17. Organigrama Gerencia de Marketing Fuente: Elaboración propia 


\section{- Gestión de Servicios:}

El área de gestión de servicios está a cargo de la Gerencia Comercial de la compañía. Esta área se encarga de:

- Gestión de pedidos: El cliente o distribuidor debe ingresar su pedido web. Se generará un código del sistema que el cliente enviará al gestor de servicio, vía email. Posteriormente esta información se envía al área de créditos y cobranzas donde se verifica razón social, descuentos, forma de pago, promociones, precios, de tal manera que se libere el pedido. Posteriormente a la liberación el área de programación de distribución y transporte generara la orden de despacho.

Este proceso lo podemos apreciar en el anexo 1: Proceso de atención y gestión de pedidos y despachos.

- Gestión de reclamos: Se registra el reclamo en el software de servicio post venta. vía email se informa el detalle del reclamo a la Gerencia General, Gerencia Comercial, Gerencia de Producción y Gerencia de Supply Chain. La jefatura de calidad evalúa el reclamo, de ser necesario in situ, y emite un reporte donde se concluye la naturaleza del reclamo: Defecto de producción, defecto de almacenamiento, defecto de despacho y/o transporte, defecto no aplicable a la organización (mala instalación, inadecuado almacenamiento del distribuidor, u otros). La Gerencia Comercial puede decidir si el reclamo es aplicable, independientemente de la conclusión del reporte de calidad, para lo cual se considera un reclamo con aceptación comercial. El anexo 2: Formato de Reclamo, nos muestra cómo se registra en nuestro sistema de gestión.

- Soporte Técnico: La compañía brinda capacitaciones a los clientes directos (distribuidores, y retáils), respecto a nuestros productos. 
Asimismo, brinda información a través del departamento técnico de proyectos comerciales, donde se derivan las consultas y se facilita información al cliente.

El área de soporte técnico realiza un programan anual de capacitación y visitas guiadas a la planta de producción. Lo que se busca es que el personal promotor, vendedor de nuestros distribuidores o home centers conozcan las características, usos, procesos de producción, calidad, y procedimientos de instalación, con el objetivo que puedan difundirlo a los clientes directos y brindar ellos mismos asesorías.

Las capacitaciones son quincenales, y se hace a los principales distribuidores y promotores de home center.

\section{d. Administración y Finanzas:}

El área de Administración y Finanzas está estructurada de la siguiente manera:

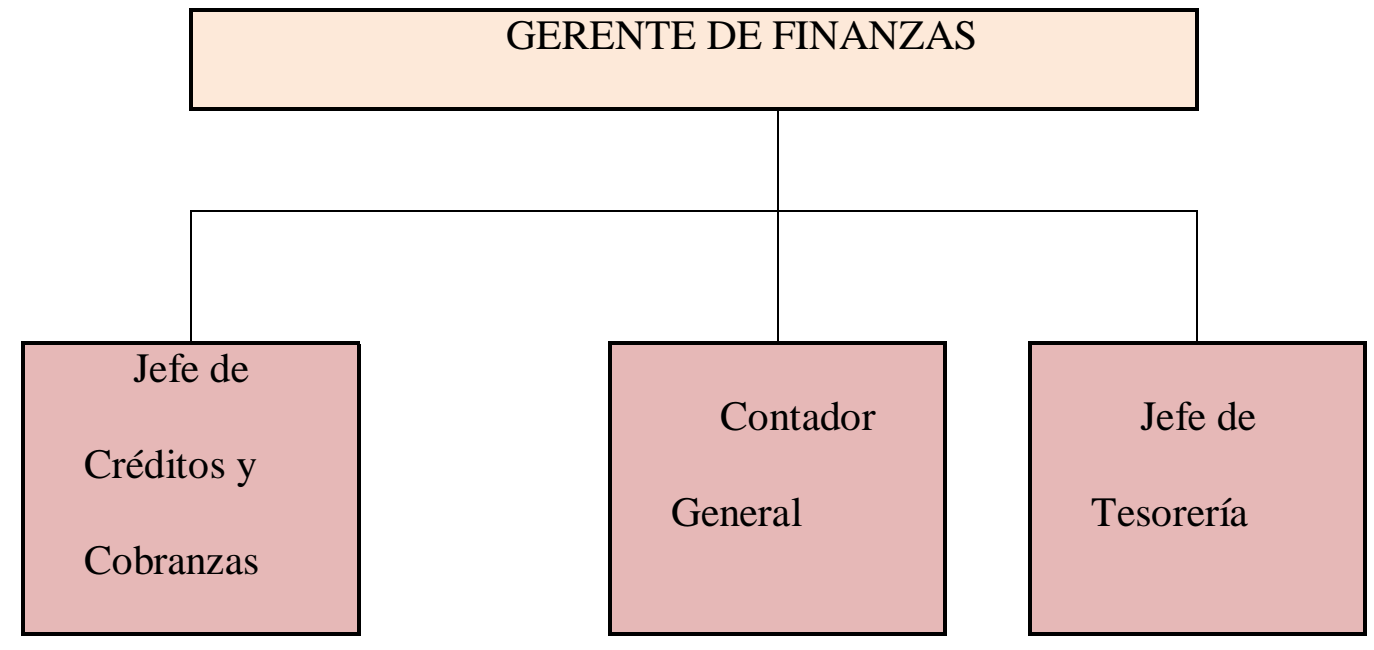

Figura 18. Organigrama Gerencia de Finanzas

Fuente: Elaboración propia

- La Jefatura de crédito y cobranzas es la encargada de liberar las órdenes de pedido de los clientes y evaluar los créditos a los clientes o distribuidores de la empresa. El área realiza una avaluación de la empresa a través de una serie de requisitos económicos y financieros, los cuales se solicitan al cliente o distribuidor. Asimismo, emite una evaluación del récord de cumplimiento 
de pagos, para emitir las promociones, descuentos y demás para cada cliente. Asimismo, se encarga de facturar de acuerdo con lo establecido en el contrato y / u orden de pedido. Es el área de emitir los indicadores financieros.

- El Contador general procesa toda la información de ingresos y egresos (facturación, planillas, etc.) y se encarga que los cálculos se encuentren correctamente realizados y que los documentos cumplan con las disposiciones legales. Es el responsable de emitir los indicadores financieros, así como el balance general y el estado de resultados de la compañía.

- El Gerente de Finanzas es el representante legal de la empresa. Es quien determina las directivas para el código de ética de la compañía, así como las políticas financieras, supervisa y valida los presupuestos de cada área de la compañía y establece los planes estratégicos para el cumplimiento de los indicadores financieros. Responsable de la evaluación financiera de los proyectos de inversión de la compañía y la viabilidad de estos.

\subsubsection{Actividades de apoyo}

\section{a. Recursos Humanos}

La gestión de los Recursos Humanos de la compañía está a cargo de la Gerencia de Recursos Humanos, quienes determinan y proveen los recursos necesarios para el desarrollo de las operaciones.

El área de RRHH está organizada de la siguiente manera: 


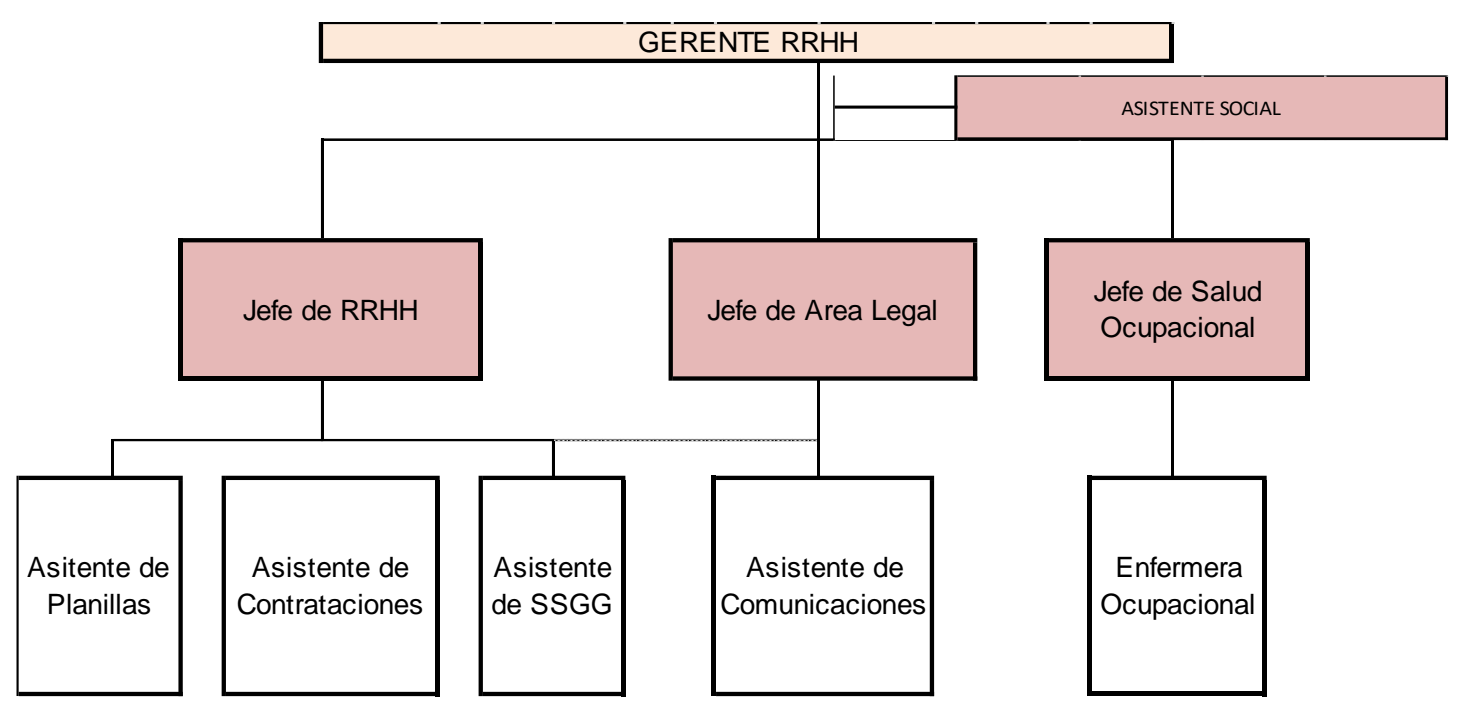

Figura 19. Organigrama Recursos Humanos

Fuente: Elaboración propia

La Jefatura de recursos humanos se encarga del pago de planillas de los trabajadores el cual se realiza semanalmente para el personal obrero y de manera quincenal al personal empleado. Para lo cual se realiza la compilación del personal de las horas trabajadas, y horas extras, así como los beneficios, esta información es enviada al área contable para que genere los depósitos en las entidades financieras correspondientes. Los pagos son a través de transferencias financieras y a cuentas sueldo. No existen pagos en efectivo.

\section{- $\quad$ Reclutamiento y Selección}

Las contrataciones de personal ya sea por reemplazos, creación de nuevos cargos o promociones se realiza a través de una solicitud formal del área usuaria.

\section{- $\quad$ Selección del Personal}

- El Jefe de recursos humanos, recibe el formato de requerimiento de personal, debidamente llenado y firmado por el jefe inmediato, Gerencia de Área, Gerencia de RRHH y Gerencia General. 
○ El Área de reclutamiento y selección, inicia la convocatoria de acuerdo con el perfil del puesto requerido (Ver anexo 3: ejemplo de perfil de puesto y funciones). De ser un puesto nuevo, se realizará el levantamiento del perfil de puesto en coordinación con el área solicitante, dicha información será consignada en el formato perfil de puesto. De requerirse los servicios de un tercero que se encargue de la selección de personal, el área de RRHH designará la empresa a realizar dicho proceso.

○ Área de reclutamiento y selección, realiza la publicación de la vacante en los diversos medios, evalúa y realiza un pre selección de los currículos de acuerdo con el perfil de puesto. El área solicitante realizará un segundo filtro curricular tomando en cuenta aspectos técnicos del puesto, con la finalidad de efectivizar el proceso de selección. Esta evaluación curricular puede proceder de fuentes internas y/o externas, las cuales se detallan a continuación:

Fuentes internas: A todos los empleados de la empresa que cuenten con las competencias cognitivas, personales y técnicas necesarias para cubrir el puesto vacante. $\mathrm{Al}$ asumir un nuevo cargo, el trabajador deberá ser capacitado en las competencias necesarias para que cumpla con el perfil, en caso de los practicantes, pasarán a la planilla de empleados, siendo capacitados según el perfil del puesto a cubrir.

Fuentes externas: Se consideran las siguientes: base de datos, medios escritos, web, bolsas de trabajo de instituciones académicas, agencias de empleo, internet, redes sociales, entre otros.

○ Después de la pre selección de candidatos, se procederá con el proceso de evaluaciones psico laborales y entrevistas correspondientes. En base a la información obtenida se procederá con la elaboración de los informes psicológicos respectivos, así como de la realización de las verificaciones laborales según sea el caso (ficha de referencias laborales), culminado el proceso 
de evaluación se entrega al solicitante lo siguiente: RRHH-F-008 evaluación psicológica personal empleado, evaluación psicológica personal operario, ficha de referencias laborales.

- Se presentará una terna finalista de candidatos al área solicitante, quienes entrevistarán y evaluarán a dichos candidatos con la finalidad de determinar su idoneidad.

- El área solicitante deberá comunicar con inmediatez los resultados de su elección a través del envió de un email al área de reclutamiento y selección, jefatura de recursos humanos o gerencia de RRHH. Solo en caso de personal operario los resultados deberán enviarse en físico (currículum) con el $\mathrm{V}^{\circ} \mathrm{B}^{\circ}$ de la Jefatura y/o Superintendencia de producción, siendo éste el sustento para su contratación.

\section{- Protocolo de Incorporación:}

- El personal seleccionado deberá pasar el protocolo de incorporación (exámenes médicos pre-ocupacionales, verificaciones laborales e inducción), asimismo se le solicitará los requisitos determinados en el formato check list personal ingresante, el cual será parte del file del personal y entregado al área de administración de personal. El personal que este apto en todos los procesos, pasará a ser contratado.

\section{- Contratación de Personal:}

- El área de administración de personal elabora el contrato de trabajo según el requerimiento de personal y gestiona la firma del mismo.

- Se considera como requisitos mínimos para su elaboración.

$\checkmark$ El cargo que debe ocupar el personal seleccionado.

$\checkmark$ El tipo de contrato.

$\checkmark$ La remuneración (básico).

$\checkmark$ Tiempo de contratación. 
○ Todo contrato del personal tiene un periodo de vigencia mínimo de 03 meses, en caso de personal de confianza este se extiende a 6 meses y de 12 meses para el personal de dirección de acuerdo con ley.

○ Una vez firmado el contrato de trabajo entre el trabajador y el empleador, se entregarán: "Reglamento Interno de Trabajo", "Reglamento de Seguridad y Salud en el Trabajo", "Directiva sobre prevención del consumo y abuso de alcohol y otras drogas" y copia de "contrato de trabajo de acuerdo con ley".

○ El área de administración de personal se encargará de presentar el contrato de trabajo ante el MTPE.

o Programa y paga a la entidad autorizada la tasa correspondiente para el registro de contrato.

- Registra el contrato ante el MTPE, para esto, utiliza la modalidad de registro de contrato vigente.

- El MTPE otorga un plazo de 15 días para el registro del contrato de trabajo. Vencido este plazo podrá registrarlo de modo extemporáneo, para cuyo efecto deberá pagar una tasa adicional.

\section{- Renovación de contrato de trabajo}

○ El área de administración de personal informará a las gerencias sobre los contratos próximos a vencer, para que autoricen su renovación y plazo estimado.

- De no proceder la renovación, deberán precisar los motivos que justifican su resolución.

Las promociones de personal se hacen a través del documento de desempeño y resultados de evaluación $360^{\circ}$, donde se especifica las razones de la promoción. Este documento es aprobado por la gerencia de área, y gerencia de RRHH.

\section{- Programas de RRHH}


El área de RRHH cuenta con programas internos dentro de los cuales los más relevantes son evaluación del clima laboral de la empresa, donde se identifican oportunidades de mejora y se generan los planes de acción para cada área, programa de incentivos basado en los resultados de seguridad y salud del personal. Evaluación $360^{\circ}$ del desempeño del personal, donde se identifican las oportunidades en las competencias de cada perfil de puesto, lo cual permite elaborar el plan de capacitación.

El área es responsable de la generación, difusión y actualización del reglamento interno de trabajo (RIT) y reglamento interno de seguridad y salud en el trabajo (RISST), en las cuales se establecen las políticas de asistencia, ausentismo, y puntualidad, al igual que la Política de Seguridad.

\section{- Salud Ocupacional}

La compañía cuenta con un tópico con funcionamiento las 24 horas durante todos los días de labores, donde se atiende al personal respecto a problemas de salud, y se evalúa si requiere atención especializada en otros establecimientos. Todo el personal de planta pasa por una evaluación médica ocupacional una vez al año, la cual es coordinado por el jefe de salud, con instituciones privadas.

\section{b. Tecnología de Información y Comunicaciones (IT)}

El área de Información y Comunicaciones es la encargada de implementar, mantener los sistemas informáticos, redes, hardware, software, ERP, de la compañía.

El área de IT Administra y mantiene:

- Sistema Web de la compañía, en la que se reciben los pedidos de los clientes y distribuidores, así como la página web propia 
- Correo electrónico, actualmente la compañía cuenta con el Outlook empresas incluyendo Skype Bussiness.

- Telefonía móvil y fija

- Sistema de red interna

- Usuarios de los sistemas.

Asimismo, capacita al personal en el uso de los sistemas de información de acuerdo con su campo de responsabilidad y funciones.

Los principales Sistemas se detallan a continuación

- SAP

El SAP es la herramienta utilizada para la gestión de la información de las áreas de la compañía. Los módulos utilizados en la compañía son:

- Módulos SD (Sales and distribución) dentro de los cuales se usa el Módulo de Facturación y el módulo de Gestión de Ventas.

- Modulo PP Productión Planning dentro del cual se utiliza plan de capacidades, plan de materiales, ordenes de fabricación, coste de producto, configuración de producto.

- Modulo PM (Plant Maintainance) dentro del cual se utiliza el módulo de mantenimiento preventivo y ordenes de mantenimiento.

- Modulo AM (Asset Management) usando el módulo compras.

- Intranet:

La intranet es usada para compartir información entre compañías del grupo y donde se generan comunidades para realizar Benchmarking. 
Asimismo, es una ventana para compartir noticias del grupo respecto a decisiones globales, cambios organizacionales, etc.

\section{- Outlook}

El Outlook es la herramienta de correo implementada en la compañía, que incluye el Skype Business para teleconferencias, chat y video llamadas.

\section{- Bex Analizer}

Aplicación que permite extraer los datos del SAP y ordenarlos en tablas dinámicas en excel. Esta aplicación es interactiva y pueden generarse informes de acuerdo con cada necesidad.

\section{- Power BI}

Herramienta que permite extraer de una base de datos generada desde SAP para generar los indicadores de las principales áreas de la compañía.

\subsection{Indicadores de cada una de las actividades de la cadena de valor}

La compañía tiene implementado una serie de indicadores que permiten realizar seguimiento a las operaciones y generar los planes de acción para mantenerlos o mejorarlos. El cuadro siguiente muestra los indicadores principales y su significado para la toma de decisiones. 
Tabla 8. Indicadores Principales de Gestión

\begin{tabular}{|c|c|c|c|c|c|}
\hline INDICADOR & AREA & OBJETIVO & U.M & FORMULA & META \\
\hline EBITDA & $\begin{array}{l}\text { Admin. \& } \\
\text { Fin. }\end{array}$ & $\begin{array}{l}\text { Medir la } \\
\text { explotación } \\
\text { bruta de la } \\
\text { operación }\end{array}$ & $\%$ & $\begin{array}{l}\text { EBITDA / } \\
\text { Ventas }\end{array}$ & $\geq 19.4 \%$ \\
\hline $\begin{array}{l}\text { Cumplimiento } \\
\text { del } \\
\text { Presupuesto }\end{array}$ & $\begin{array}{l}\text { Admin. \& } \\
\text { Fin. }\end{array}$ & $\begin{array}{l}\text { Controlar } \\
\text { los gastos de } \\
\text { la empresa }\end{array}$ & $\%$ & $\begin{array}{l}\text { Total de } \\
\text { Gastos / } \\
\text { Presupuesto de } \\
\text { Gasto }\end{array}$ & $95 \%$ \\
\hline $\begin{array}{l}\text { Margen de } \\
\text { Contribución }\end{array}$ & Comercial & $\begin{array}{l}\text { Medir la } \\
\text { contribución } \\
\text { marginal de } \\
\text { la empresa }\end{array}$ & $\%$ & $\begin{array}{l}\quad \mathrm{CM}= \\
\text { (Precio de } \\
\text { Venta - Costo) } \\
\text { / Precio de } \\
\text { Venta }\end{array}$ & $\geq 36 \%$ \\
\hline Ventas & Comercial & $\begin{array}{l}\text { Medir la } \\
\text { evolución de } \\
\text { las ventas }\end{array}$ & $\%$ & $\begin{array}{c}\text { MM de } \\
\text { Venta Anual }\end{array}$ & $\begin{array}{l}\geq 242 \\
\mathrm{MM}\end{array}$ \\
\hline $\begin{array}{l}\text { Efectividad de } \\
\text { Licitaciones } \\
\text { con el Estado }\end{array}$ & Comercial & $\begin{array}{l}\text { Medir la } \\
\text { efectividad } \\
\text { del cierre de } \\
\text { ventas en }\end{array}$ & $\%$ & $\begin{array}{l}\text { Licitaciones } \\
\text { Ganadas / } \\
\text { Total de } \\
\text { Licitaciones }\end{array}$ & $\geq 75 \%$ \\
\hline
\end{tabular}




\begin{tabular}{|c|c|c|c|c|c|}
\hline & & $\begin{array}{l}\text { licitaciones } \\
\text { estatales }\end{array}$ & & & \\
\hline Market Share & Comercial & $\begin{array}{l}\text { Medir la } \\
\text { participación } \\
\text { en el } \\
\text { mercado }\end{array}$ & $\%$ & - & $90 \%$ \\
\hline $\begin{array}{l}\text { Gasto de Flete } \\
\text { Bruto }\end{array}$ & Logística & $\begin{array}{l}\text { Controlar } \\
\text { el Gasto de } \\
\text { Transporte }\end{array}$ & $\%$ & $\begin{array}{c}\text { Gasto de } \\
\text { Flete / Ventas }\end{array}$ & $\leq 6 \%$ \\
\hline $\begin{array}{l}\text { Cobertura de } \\
\text { Stock de } \\
\text { Materia Prima }\end{array}$ & Logística & $\begin{array}{l}\text { Controlar } \\
\text { el nivel de } \\
\text { stock de } \\
\text { Materia } \\
\text { Prima }\end{array}$ & 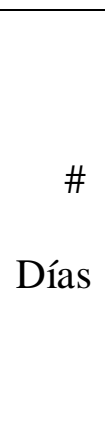 & $\begin{array}{l}\text { Stock de } \\
\text { MP/ Consumo } \\
\text { Promedio de } \\
\text { MP }\end{array}$ & 35 días \\
\hline
\end{tabular}

\begin{tabular}{|c|c|c|c|c|c|}
\hline INDICADOR & AREA & OBJETIVO & U.M & FORMULA & META \\
\hline $\begin{array}{l}\text { Cobertura } \\
\text { de Stock de } \\
\text { Producto } \\
\text { Terminado }\end{array}$ & Logística & $\begin{array}{l}\text { Controlar el } \\
\text { nivel de stock } \\
\text { de Productos } \\
\text { Terminados }\end{array}$ & \# Días & $\begin{array}{l}\text { Stock de PT / } \\
\text { Venta Promedio } \\
\text { de PT }\end{array}$ & 35 días \\
\hline $\begin{array}{l}\text { Exactitud de } \\
\text { la Demanda }\end{array}$ & Planificación & $\begin{array}{l}\text { Medir la } \\
\text { asertividad de la }\end{array}$ & $\%$ & $\begin{array}{l}1 \text { - [Abs } \\
\text { (Volumen } \\
\text { Vendido }^{1-}\end{array}$ & $\begin{array}{l}\geq 92 \\
\%\end{array}$ \\
\hline
\end{tabular}




\begin{tabular}{|c|c|c|c|c|c|}
\hline & & $\begin{array}{l}\text { planificación de } \\
\text { la demanda }\end{array}$ & & $\begin{array}{l}\text { Volumen } \\
\text { Planificado }^{2} \text { )/ } \\
\text { Volumen } \\
\text { Planificado }^{2} \text { ] }\end{array}$ & \\
\hline $\begin{array}{l}\text { Exactitud de } \\
\text { la } \\
\text { Planificación }\end{array}$ & Planificación & $\begin{array}{l}\text { Medir la } \\
\text { asertividad del } \\
\text { plan de } \\
\text { producción }\end{array}$ & $\%$ & $\begin{array}{l}\quad 1 \text { - [(Volumen } \\
\text { Producido - } \\
\text { Volumen } \\
\text { Planificado) / } \\
\text { Volumen } \\
\text { Planificado] }\end{array}$ & $\begin{array}{l}\geq 90 \\
\%\end{array}$ \\
\hline $\begin{array}{l}\text { OEE - Planta } \\
\text { Lima }\end{array}$ & Producción & $\begin{array}{l}\text { Medir la } \\
\text { Eficiencia } \\
\text { Global de los } \\
\text { Equipos en } \\
\text { las Líneas de } \\
\text { Fibrocemento } \\
\text { (P2/P5/P6) }\end{array}$ & $\%$ & $\begin{array}{l}\text { Disponibilidad } \\
\text { * Rendimiento* } \\
\text { Calidad }\end{array}$ & $\begin{array}{l}\geq 70 \\
\%\end{array}$ \\
\hline $\begin{array}{l}\text { Accidentes } \\
\text { con tiempo } \\
\text { perdido }\end{array}$ & Producción & $\begin{array}{l}\text { Medir la } \\
\text { cantidad de } \\
\text { accidentes } \\
\text { industriales } \\
\text { con pérdida }\end{array}$ & $\begin{array}{l} \\
\# \\
\text { Incidentes }\end{array}$ & - & $\begin{array}{l}0 \\
\text { incidentes }\end{array}$ \\
\hline
\end{tabular}




\begin{tabular}{|c|c|c|c|c|c|}
\hline & & $\begin{array}{l}\text { de tiempo } \\
\text { operativo }\end{array}$ & & & \\
\hline $\begin{array}{l}\text { Nivel de } \\
\text { Rotación }\end{array}$ & $\begin{array}{l}\text { Recursos } \\
\text { Humanos }\end{array}$ & $\begin{array}{l}\text { Controlar } \\
\text { la rotación de } \\
\text { personal }\end{array}$ & $\%$ & $\begin{array}{l}\text { (Altas - Bajas) } \\
\text { / Headcount } \\
\text { Actual }\end{array}$ & $100 \%$ \\
\hline $\begin{array}{l}\text { Personal } \\
\text { Presupuestado } \\
\text { (S/.) }\end{array}$ & $\begin{array}{l}\text { Recursos } \\
\text { Humanos }\end{array}$ & $\begin{array}{l}\text { Medir el } \\
\text { cumplimiento } \\
\text { del presupuesto } \\
\text { de personal }\end{array}$ & $\%$ & $\begin{array}{l}\text { Gasto de } \\
\text { Persona/ } \\
\text { Presupuesto de } \\
\text { Personal }\end{array}$ & $100 \%$ \\
\hline
\end{tabular}

Fuente: Elaboración propia 


\subsection{Benchmarking y Comparación con los líderes de la Industria}

Tabla 7. Benchmarking Principales competidores

\begin{tabular}{|c|c|c|c|}
\hline $\begin{array}{l}\text { ACTIVIDADES DE LA CADENA DE } \\
\text { VALOR }\end{array}$ & ETERNIT & PLYCEM & VOLCAN \\
\hline \multicolumn{4}{|l|}{ Supply Chain } \\
\hline Planta de Almacenamiento en Lima & $\mathrm{Si}$ & No & No \\
\hline Logística Interna Propia & $\mathrm{Si}$ & $\mathrm{Si}$ & $\mathrm{Si}$ \\
\hline \multicolumn{4}{|l|}{ Producción } \\
\hline Planta de Producción en Lima & $\mathrm{Si}$ & No & No \\
\hline Know how Proceso Fibrocemento & $\mathrm{Si}$ & $\mathrm{Si}$ & $\mathrm{Si}$ \\
\hline \multicolumn{4}{|l|}{ Ventas } \\
\hline Market Share & $93 \%$ & $1 \%$ & $5 \%$ \\
\hline Reconocimiento Nacional de Marca & $\mathrm{Si}$ & No & No \\
\hline Años en el Mercado Nacional & 75 & 5 & 15 \\
\hline $\begin{array}{l}\text { Empresa dentro de los } 3 \text { líderes del } \\
\text { Mundo }\end{array}$ & $\mathrm{Si}$ & No & No \\
\hline \multicolumn{4}{|l|}{ Recursos Humanos } \\
\hline Reconocimiento como GPTW & No & No & No \\
\hline Equipos especializados en FC & $\mathrm{Si}$ & $\mathrm{Si}$ & $\mathrm{Si}$ \\
\hline \multicolumn{4}{|l|}{ Servicio Post Venta } \\
\hline Soporte Técnico Local especializado & $\mathrm{Si}$ & No & No \\
\hline
\end{tabular}

Fuente: Elaboración propia 


\subsection{Competencias de la Empresa}

\subsubsection{Líder Mundial en Tecnología del Fibrocemento:}

Eternit pertenece al Grupo Etex, quienes en conjunto con la Empresa James Hardie, lideran la industria de fibrocemento en el mundo. El fibrocemento es una tecnología no muy difundida ni conocida, es por esa razón que el grupo tiene implementado dos centros tecnológicos, uno es el ITC (Innovation and Technology Center) cuya función es desarrollar investigaciones científicas para el desarrollo de nuevas formulaciones, tecnologías y procesos, para la industria del fibrocemento. CCFC (Competence Center for Fiber Cement) cuya función principal es desarrollar proyectos de mejora e ingeniería, para todas las plantas del mundo, cuenta con ingenieros especializados en los diferentes procesos de la tecnología del fibrocemento, y brindan soporte y asesoría.

\subsubsection{Respaldo Financiero}

El grupo Etex determina y soporta las inversiones requeridas en el país, de acuerdo con los planes estratégico-globales y regionales. El anexo 4: Proyectos e Inversiones, muestra que para el año 2018 el grupo hará una inversión de 1.5 millones de euros, y la planta debe generar un ahorro de 0.9 millones de euros. Esto se realiza a través de un análisis de proyectos viables de mejoramiento y ahorros.

\subsubsection{Marca Reconocida}

Eternit tiene 77 años en el mercado nacional y es una marca reconocida por sus productos Techos Eternit. Asimismo, de acuerdo con lo indicado por su actual Gerente General al diario Gestión:" La empresa está próxima a renovar su imagen, sin perder la tradición de una marca reconocida y buscando mostrar la amplitud de su portafolio, que va más allá de los tanques de 
agua y los techos ondulados. El objetivo del relanzamiento es aprovechar las oportunidades del sector construcción y mejorar la calidad de vida de las personas. Mediante la construcción en seco se puede revertir esto de forma eficiente" (Diario Gestión, 28.09.2016).

\subsubsection{Dominio del mercado}

Eternit es líder nacional del mercado de fibrocemento, el market share en fibrocemento es del 95\%. El cuadro muestra la evolución a través de los años de su dominio de mercado

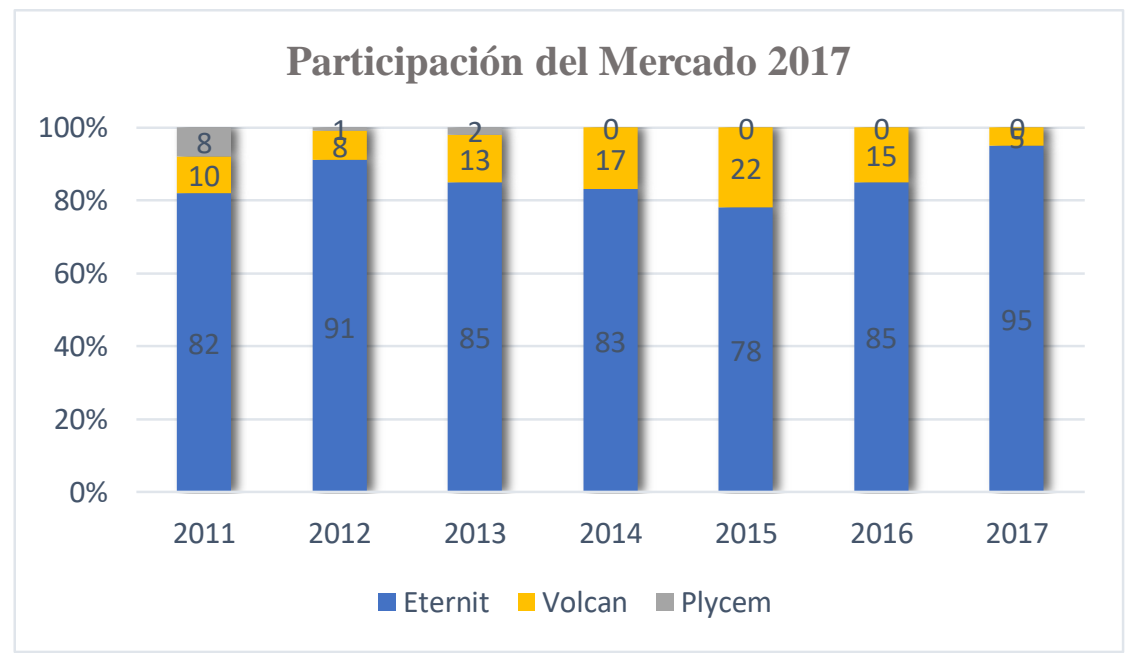

Fuente: Elaboración propia

Figura 20. Participación de Mercado y Comparación con competencia directa

\subsubsection{Variedad de productos y flexibilidad en productos y proyectos:}

Eternit cuenta con tres líneas de fibrocemento, especializadas en planchas onduladas y planchas planas, con una capacidad anual de 12 MM de metros cuadrados de producción, en el país no existe empresas con esta tecnología. Asimismo, Eternit tiene convenios con otras empresas como Andina Home, con quienes elabora proyectos integrales como las casas temporales Moduplack para el gobierno (fenómeno del niño costero 2017). Además, cuenta con 
un departamento técnico de asesoría y diseño de proyectos, con profesionales en arquitectura e ingeniería civil.

El sistema de construcción en seco-drywall, donde los productos Eternit brindan esta flexibilidad, es un sistema constructivo en seco, basado en una estructura de acero galvanizado o madera, revestido con placas de fibrocemento superboard en exterior, zonas húmedas y de impacto unidos por fijaciones y con elementos de acabado final. Tiene 20 años en el en el Perú, pero más de 100 años de uso en el mundo.

\subsection{Identificación de la ventaja competitiva de la empresa}

Para identificar la ventaja competitiva de la Empresa, evaluaremos las competencias de la Empresa a través de cuatro condiciones:

a. Valor: ¿Podemos explotar una oportunidad o neutralizar una amenaza externa con este recurso?

b. Raro: ¿Está este recurso sólo en manos de unos pocos? ¿O por el contrario está al alcance de todos?

c. Inimitable: ¿Recurso Difícil de imitar? A un competidor que lo quisiera ¿le sería costoso obtenerlo o desarrollarlo?

d. Organización: ¿Está la compañía organizada para explotar este recurso al 100\% y a un costo adecuado? 


\begin{tabular}{|c|c|c|c|c|c|}
\hline $\begin{array}{l}\text { RECURSO / } \\
\text { CAPACIDAD }\end{array}$ & VALOR & RARO & INIMITABLE & ORGANIZACIÓN & COMPETENCIA \\
\hline $\begin{array}{c}\text { Marca } \\
\text { Reconocida }\end{array}$ & $\mathrm{Si}$ & $\mathrm{Si}$ & $\mathrm{Si}$ & $\mathrm{Si}$ & $\begin{array}{l}\text { Ventaja } \\
\text { Competitiva } \\
\text { Sostenida }\end{array}$ \\
\hline $\begin{array}{r}\text { Dominio } \\
\text { del Mercado }\end{array}$ & $\mathrm{Si}$ & $\mathrm{Si}$ & No & & $\begin{array}{l}\text { Ventaja } \\
\text { Competitiva } \\
\text { Temporalment } \\
\text { e }\end{array}$ \\
\hline $\begin{array}{l}\text { Tecnologí } \\
\text { a del } \\
\text { Fibrocement } \\
\text { o }\end{array}$ & $\mathrm{Si}$ & No & & & $\begin{array}{l}\text { Paridad } \\
\text { competitiva. } \\
\text { Ni suma ni } \\
\text { resta. }\end{array}$ \\
\hline $\begin{array}{l}\text { Respaldo } \\
\text { Financiero }\end{array}$ & $\mathrm{Si}$ & No & & & $\begin{array}{l}\text { Paridad } \\
\text { competitiva. } \\
\text { Ni suma ni } \\
\text { resta. }\end{array}$ \\
\hline
\end{tabular}

Tabla 8. Ventaja Competitiva

Fuente: Elaboración propia 
La ventaja competitiva identificada para Eternit es la marca reconocida en nuestro país por los 77 años de existencia. Esto ha sido gracias a la calidad de sus productos y a la confianza que sus productos han generado a lo largo del tiempo.

El uso de fibrocemento en el país es la mitad de lo que consume Colombia y diez veces menor que Chile, por lo tanto, existe una gran oportunidad en el mercado nacional para incrementar el consumo, y siendo líderes del mercado, es una gran oportunidad para incrementar la rentabilidad de la compañía.

\subsection{Matriz de evaluación de los factores internos:}

La elaboración de la matriz EFI nos ha llevado a definir dentro de las fortalezas y debilidades:

a. Fortaleza importante: Dentro de este grupo hemos considerado la marca Eternit en el mercado nacional, El know-how del proceso dado que no es un proceso difundido a nivel mundial, y los estudios y bibliografía son de propiedad del grupo. El dominio del mercado, dado que el Perú es un país con una oportunidad de crecimiento en el uso del fibrocemento. Las fortalezas importantes estarán en un rango de [0.08 a 0.1] como valor dentro de la matriz EFI.

b. Fortaleza menor: Hemos considerado en este grupo las demás fortalezas identificadas, dado que solo dependen de la infraestructura o recursos que pueda obtener o no una compañía, por tanto, puede ser alcanzables en corto plazo por la competencia. La fortaleza menor las mantendremos en un rango de 0.02 a 0.04 dentro de la matriz EFI.

c. Debilidad importante: Dentro de este grupo hemos considerado aquellas que impactan directamente al costo del producto, como un nivel alto de stock debido a una inadecuada planificación de la demanda. Esto sumado a una innovación de los productos o de los usos que podrían tener, hoy mantenemos nuestra línea de productos y servicios, sin cambios considerables 
a los de hace más de 10 años. Las debilidades importantes las hemos colocado dentro de un rango de valor de 0.06 a 0.08 dentro de la matriz EFI.

d. Debilidad menor: Dentro de este grupo hemos considerado lo relacionado a la poca gestión en el desarrollo del personal que tiene la compañía, desde la poca polivalencia hasta una reglamentación no acorde a la necesidad del negocio, lo cual afecta directamente al costo del producto. Asimismo, las inherentes dificultades de almacenamiento y manipulación del producto, las cuales deben ser resueltas con tecnología creada por la misma compañía, dado que no existe un estándar para nuestros productos, en temas de almacenamiento y carga. Las debilidades menores las hemos colocado dentro de un rango de valor de 0.02 a 0.04 dentro de la matriz EFI.

Tabla 9. Matriz EFI

\begin{tabular}{|c|r|c|c|}
\hline FACTORES EXTERNOS CLAVE & VALOR & CALIFICACION & PONDERADO \\
\hline Fortalezas & 0.08 & 4 & 0.32 \\
\hline Marca Eternit (77 años) & 0.08 & 4 & 0.32 \\
\hline Know - How de la Empresa & 0.08 & 4 & 0.32 \\
\hline Líder del Mercado 90\% Market & & & 0.16 \\
\hline Share & 0.04 & 4 & 0.08 \\
\hline $\begin{array}{c}\text { Soporte Técnico Regional y del } \\
\text { Infraestructura acorde a la }\end{array}$ & 0.02 & 4 & 0.12 \\
\hline necesidad & & & \\
\hline Capacidad de Producción & 0.04 & 3 & \\
\hline
\end{tabular}




\begin{tabular}{|c|c|c|c|}
\hline Flexibilidad de la Operación & 0.04 & 3 & 0.12 \\
\hline $\begin{array}{l}\text { Sistema Integrado de Gestión } \\
\text { (Calidad, Seguridad, Medio } \\
\text { Ambiente) }\end{array}$ & 0.04 & 3 & 0.12 \\
\hline $\begin{array}{l}\text { Programa anual de Mejoramiento } \\
\text { continuo y ahorros }\end{array}$ & 0.04 & 3 & 0.12 \\
\hline $\begin{array}{l}\text { Materias primas de primera } \\
\text { Calidad y validadas por el } \\
\text { Departamento de Investigación del } \\
\text { Grupo }\end{array}$ & 0.02 & 3 & 0.06 \\
\hline $\begin{array}{c}\text { Respaldo Financiero } \\
\text { Internacional del Grupo Etex }\end{array}$ & 0.02 & 3 & 0.06 \\
\hline Plan de Capacitación Establecido & 0.02 & 3 & 0.06 \\
\hline Evaluación anual $360^{\circ}$ & 0.02 & 3 & 0.06 \\
\hline Plan de Clima Anual & 0.02 & 3 & 0.06 \\
\hline \multicolumn{4}{|l|}{ Debilidades } \\
\hline $\begin{array}{l}\text { Poca Polivalencia de } \\
\text { Trabajadores }\end{array}$ & 0.02 & 2 & 0.04 \\
\hline $\begin{array}{l}\text { Alta necesidad de Mano de Obra } \\
\text { (rotación) }\end{array}$ & 0.02 & 2 & 0.04 \\
\hline $\begin{array}{l}\text { Normas y Reglamentos de trabajo } \\
\text { muy generales }\end{array}$ & 0.02 & 2 & 0.04 \\
\hline
\end{tabular}




\begin{tabular}{|c|c|c|c|}
\hline $\begin{array}{l}\text { Plan de Línea de Carrera interna } \\
\text { no establecida }\end{array}$ & 0.02 & 2 & 0.04 \\
\hline $\begin{array}{l}\text { No existe diferenciación a nivel } \\
\text { operativo (Bandas salariales) }\end{array}$ & 0.03 & 2 & 0.06 \\
\hline Manipulación y transporte difícil & 0.02 & 2 & 0.04 \\
\hline Dificultad de almacenamiento & 0.01 & 2 & 0.02 \\
\hline $\begin{array}{l}\text { No se han innovado o } \\
\text { desarrollado productos }\end{array}$ & 0.08 & 1 & 0.08 \\
\hline $\begin{array}{l}\text { Bajo \% de utilización de Equipos } \\
\text { genera incremento de costos }\end{array}$ & 0.07 & 1 & 0.07 \\
\hline Sistema de información deficiente & 0.07 & 1 & 0.07 \\
\hline $\begin{array}{l}\text { Planificación de la Producción no } \\
\text { alineada a la demanda }\end{array}$ & 0.08 & 1 & 0.08 \\
\hline & 1 & & 2.56 \\
\hline
\end{tabular}

De acuerdo con la evaluación de la matriz EFI el resultado obtenido de 2.56, muestra que la empresa se encuentra en el promedio del resultado, por lo que tiene grandes oportunidades para mitigar las debilidades, y aprovechar las fortalezas. Por tanto, un planeamiento estratégico enfocado en mejorar este resultado es necesario para la compañía.

Siendo Eternit una empresa reconocida y con muchos años en el Perú, sus fortalezas importantes son aquellas adquiridas en este tiempo, algo que no puede ser imitado por algún competidor nuevo o ya posicionado, por esa razón las colocamos en un rango diferenciado de sus 
fortalezas menores, las cuales no dependen en gran medida de su experiencia y reconocimiento como empresa.

Eternit es una empresa con buen posicionamiento en la Industria tanto comercial como financieramente, de acuerdo a lo indicado por su Gerente de Finanzas Sr. Aldo Orihuela "Para el presente año se realizaran inversiones del orden de 4,4 millones de US\$ y hay inversiones proyectadas de 8,7 mill US\$ para los próximos 2 años, ambas destinadas a mejorar los estándares de seguridad y productividad de nuestras plantas, esperando duplicar las ventas de las líneas de placas planas de Fibro cemento hacia el 2022"( BVL, 2017), por tanto las debilidades referidas a gestión logística o recursos humanos que afecten sus costos, pueden ser resueltas de manera integral, es así que el rango del valor considerado en la matriz son menores a las consideradas en las fortalezas.

Asimismo, detallaremos como las más relevantes fortalezas y debilidades están siendo o no aprovechadas y mitigadas respectivamente:

\section{a. Fortalezas}

- Marca Eternit: La marca Eternit tiene más de 77 años en el país, mantenerla y reforzarla es muy importante para la compañía en su camino de crecimiento en los próximos años. Esto lo demuestra su Gerente General Sr. Manzur Fegale quien refiere: “La empresa está próxima a renovar su imagen, sin perder la tradición de una marca reconocida" (Diario Gestión, 28.09.2016). Por tanto, consideramos que su marca es de suma importancia para su éxito actual y las metas de los próximos años, esto se refleja en la matriz EFI, con un valor de 0.08 y un puntaje de 4 dada las acciones de marketing como la publicidad "Rompiendo Mitos".

- El know how de la empresa es una fortaleza de gran impacto para el éxito de Eternit, dado que es la fortaleza que le permitirá su camino en la innovación alineado a su valor pioneros 
en liderar. Esto lo demuestra los planes para el 2020 que refiere su Gerente General Manzur Fegale en entrevista con el diario el Comercio: "Prueba de ello es que este 2017, la compañía alista cinco productos nuevos, no solo por el lado del drywall sino también en tanques y techos" (Diario El comercio, Mayo 2017). De esta manera esta fortaleza es considerada dentro de la matriz EFI con un valor de 0.08 y un ponderado de 4 dado el know how lo aprovecha para la generación de nuevos productos y su dominio del Mercado.

- Dominio del Mercado: Eternit domina el mercado de fibrocemento, la Figura 6: “Participación de Mercado 2011 al 2017”, nos muestra esta fortaleza de la compañía. Su market share nos permite considerar dentro de la matriz EFI un valor de 0.08 y un ponderado de 4 .

\section{b. Debilidades}

- Falta de innovación de productos: El Gerente General Manzur Fegale considera dentro de sus planes hacia el 2020, la introducción de nuevos productos en el mercado, de acuerdo con la entrevista con el diario el Comercio en mayo de este año. Lo cual demuestra que la Empresa está tomando acción sobre esto, y la ponderación en la Matriz EFI es de 0.08.

- Planificación de la producción no alineada a la demanda: Los niveles de stock de la empresa se han venido manteniendo en 2 a tres meses de inventario, lo cual se muestra en su Índice de Rotación de Inventario. Demostrando que las proyecciones de Venta, no se están cumpliendo, y los requerimientos de Producción no se alinean a la demanda, generando sobre stocks. Esto Genera reducidos espacios de almacenamiento, paradas de líneas por excesos de inventario.

- Bajo porcentaje de utilización de la línea de fibrocemento: La figura 1 muestra que la línea de fibrocemento tiene un porcentaje de utilización en promedio de $60 \%$. Este es el fondo del problema evaluado y por lo tanto consideramos un valor de 0.07 en la matriz EFI. 


\section{Capítulo VI. Análisis de la Industria}

\subsection{Descripción del Mercado (demanda) e Industria (oferta)}

El consumo per cápita de fibrocemento en Perú es de $0.3 \mathrm{~m} 2$ por habitante (10 millones de m2 de consumo al año), en Chile el consumo per cápita es de $3 \mathrm{~m} 2$ por habitante y en las naciones de Europa el consumo per cápita supera los $5 \mathrm{~m} 2$ por habitante, según información de Eternit. Esto demuestra que el país tiene un gran potencial si se logra incrementar el consumo per cápita.

La figura 34 muestra el crecimiento del consumo de fibrocemento desde el 2011, durante los primeros años se tuvo un crecimiento del $15 \%$ aproximadamente y luego el crecimiento ha sido lento, en el 2016 se dio un decrecimiento del $1 \%$.

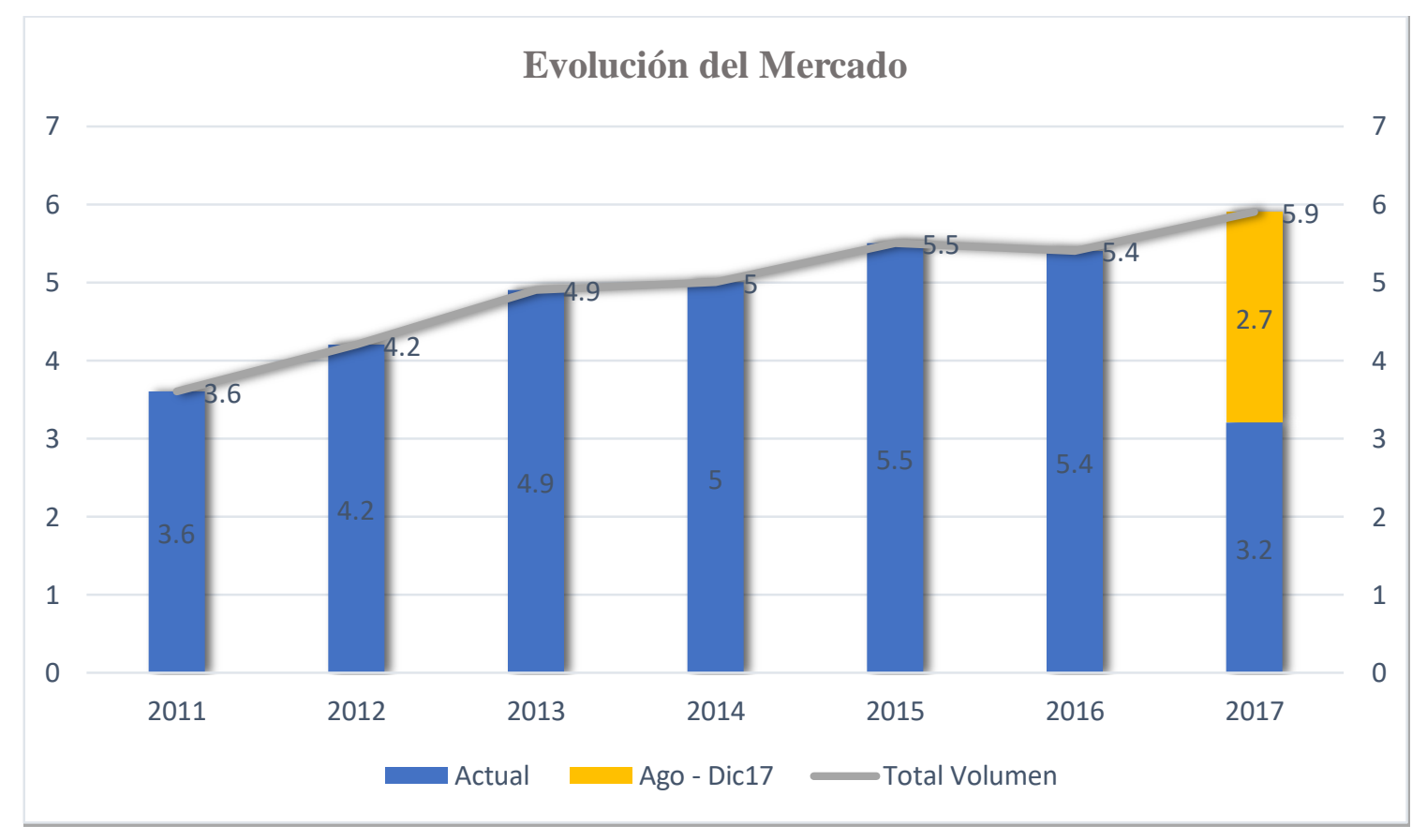

Figura 21. Evolución en el mercado en los periodos 2011 al 2017

Fuente: Elaboración propia

Según la información de Eternit, el 95\% de la comercialización de planchas de fibrocemento lo tiene Eternit y el 5\% restante está comercializado por Volcán. La figura 35 muestra el 
porcentaje de cuota del fibrocemento desde el 2011, durante los años 2011 y 2013 se tuvo presencia de Plycem.

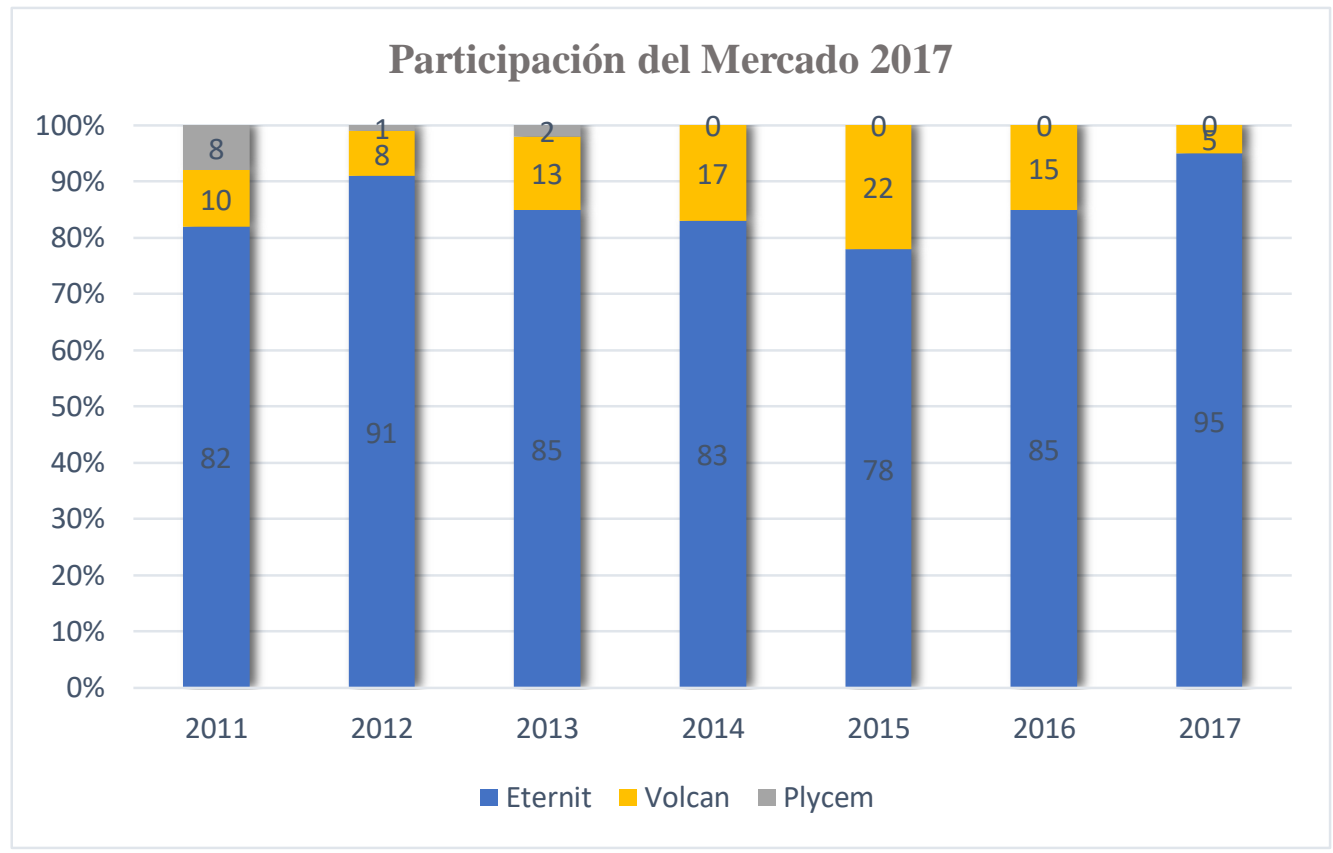

Figura 22. Participación de Mercado 2011 al 2017

Fuente: Elaboración propia

De los tres principales comercializadores de planchas de fibrocemento, solo Eternit tiene fabricación local, mientras Volcán y Plycem importan sus productos.

\subsection{Descripción las cinco fuerzas competitivas de la industria}

En este capítulo se analizarán las 5 fuerzas competitivas de la industria en el cual se desenvuelve la unidad de negocio de fibrocemento de Eternit.

\subsubsection{Sustitutos}

Para el análisis de los productos sustitutos se considera que las planchas de fibrocemento tienen propiedades como: resistencia, incombustible, impermeable, de fácil adaptación y manipulación e inmune a plagas y hongos. En tal sentido, se considera como sustitutos al 
Triplay, al yeso y las placas metálicas con propiedades similares que permitirían al cliente considerarlas en su construcción.

\section{a. Nivel percibido de diferenciación del producto:}

Según el INEI, alrededor de un millón de familias viven en hogares con paredes de adobe, lo cual podrían ser reemplazadas por paredes de planchas de fibrocemento; sin embargo, la percepción por la población nacional aún no identifica las bondades del producto.

La percepción de diferenciación del producto debería ser reconocida por las propiedades de ser un excelente aislante térmico y acústico; como también incombustible.

En tal sentido, las planchas de fibrocemento deben ser difundido considerando sus excelentes propiedades, la población debería reconocerlo rápidamente como la opción idónea.

\begin{tabular}{|c|c|c|c|c|}
\hline PROPIEDAD & FIBROCEMENTO & YESO & TRIPLAY & $\begin{array}{l}\text { PLACAS } \\
\text { METALICAS }\end{array}$ \\
\hline Incombustible & 3 & 2 & 1 & 1 \\
\hline Resistente & 2 & 1 & 1 & 3 \\
\hline Fácil de trabajar & 2 & 2 & 3 & 1 \\
\hline Versátil & 3 & 1 & 3 & 3 \\
\hline Duradero & 3 & 2 & 1 & 3 \\
\hline Reutilizable & 3 & 2 & 3 & 3 \\
\hline Aislante Térmico & 3 & 2 & 2 & 1 \\
\hline Aislante Acústico & 3 & 2 & 2 & 1 \\
\hline Puntaje & $\mathbf{2 2}$ & $\mathbf{1 4}$ & $\mathbf{1 6}$ & $\mathbf{1 6}$ \\
\hline
\end{tabular}

\begin{tabular}{|l|l|l|l|} 
Leyenda & Malo=1 & Regular=2 & Bueno=3 \\
\hline
\end{tabular}


Tabla 10. Comparativo características de planchas de Fibrocemento vs Sustitutos.

Fuente: Elaboración propia.

De la tabla 14 se observa que las planchas de fibrocemento tienen mejores propiedades que sus sustitutos, como aislamiento térmico, aislamiento acústico e incombustible. Igualado en versatilidad y duración con las placas metálicas, reutilización con las placas metálicas y triplay.

Solamente es superado en resistencia por las placas metálicas y en facilidad de trabajar por el triplay. En conclusión, las combinaciones de estas propiedades a favor de las planchas de fibrocemento permiten tener una ventaja.

\section{b. Precio relativo de los productos sustitutos:}

Los precios de los productos sustitutos son bien cercanos, el siguiente cuadro muestra que el precio de las placas metálicas es más alto y el precio del fibrocemento y yeso son de menor costo.

\begin{tabular}{|c|c|c|c|c|}
\hline PROPIEDAD & FIBROCEMENTO & YESO & TRIPLAY & PCAS \\
\hline Bajo costo & 2 & & & METALICAS \\
\hline
\end{tabular}

\begin{tabular}{|l|l|l|c|}
\hline Leyenda & Malo=1 & Regular $=2$ & Bueno=3 \\
\hline
\end{tabular}

Tabla 11. Comparativo Precios Fibrocemento vs Sustitutos

Fuente: Elaboración propia

De la tabla 15 se observa que a pesar de todas las propiedades a favor de las planchas de fibrocemento presenta un costo atractivo, solo el triplay presente menor precio, pero no iguala las propiedades de la plancha plana de fibrocemento. 


\subsubsection{Potenciales}

\section{a. Economía de Escala:}

Eternit cuenta con tres plantas de fabricación de fibrocemento, con el objetivo de incrementar su fabricación con procesos más eficientes, de igual forma las dos empresas que comparten el mercado de fibrocemento tienen planta de fabricación en su país de origen.

Las inversiones previas que han realizado estas empresas limitan el ingreso de nuevos competidores, de querer ingresar deberán construir sus plantas con procesos industrializados.

\section{b. Conocimiento especializado y tecnología:}

En el Perú el mercado de las empresas de fibrocemento está marcado por la experiencia, Plycem empresa con 51 años de experiencia, Volcán empresa con más de 80 años de experiencia y Eternit con más de 70 años de experiencia (respaldada por ETEX con más 100 años de experiencia). Esta experiencia permite crear una barrera de entrada a las nuevas empresas ya que deben considerar la curva de aprendizaje en sus procesos.

La tecnología es una variable importante la cual es considerada por los fabricantes de fibrocemento, que construyen plantas de fabricación modernas e innovadoras. En el Perú ETERNIT, solo este año, destinarán US\$4,4 millones en sus plantas productivas, según indica el gerente general de la firma (entrevista en el comercio Manzur Fegale)

\section{c. Preferencia de la marca:}

En el mercado de fibrocemento la marca no está claramente definida, cada fabricante tiene su propio nombre comercial, la cual no es recordada por el usuario final, las preferencias van por la empresa, que da el soporte y tiene presencia en el mercado. Eternit es una de las empresas más reconocidas del mercado. 
Pero son los clientes intermedios (arquitectos, contratista, maestro de obra, e instaladores) quien da las alternativas al usuario final para el uso de fibrocemento.

\section{d. Canales de distribución adecuados:}

Eternit comercializa las planchas de fibrocemento por distribuidores, los cuales cuentan con flota de transporte que recogen los productos en la fábrica, son los distribuidores que comercializan los productos al usuario final.

\subsubsection{Clientes}

La cartera de clientes de fibrocemento de Eternit está distribuida: en grandes distribuidores donde tres clientes representan el 35\%, medianos distribuidores que representan el 38\%, pequeños distribuidores y ferreterías que representan el $23 \%$ y el estado representa un $4 \%$.

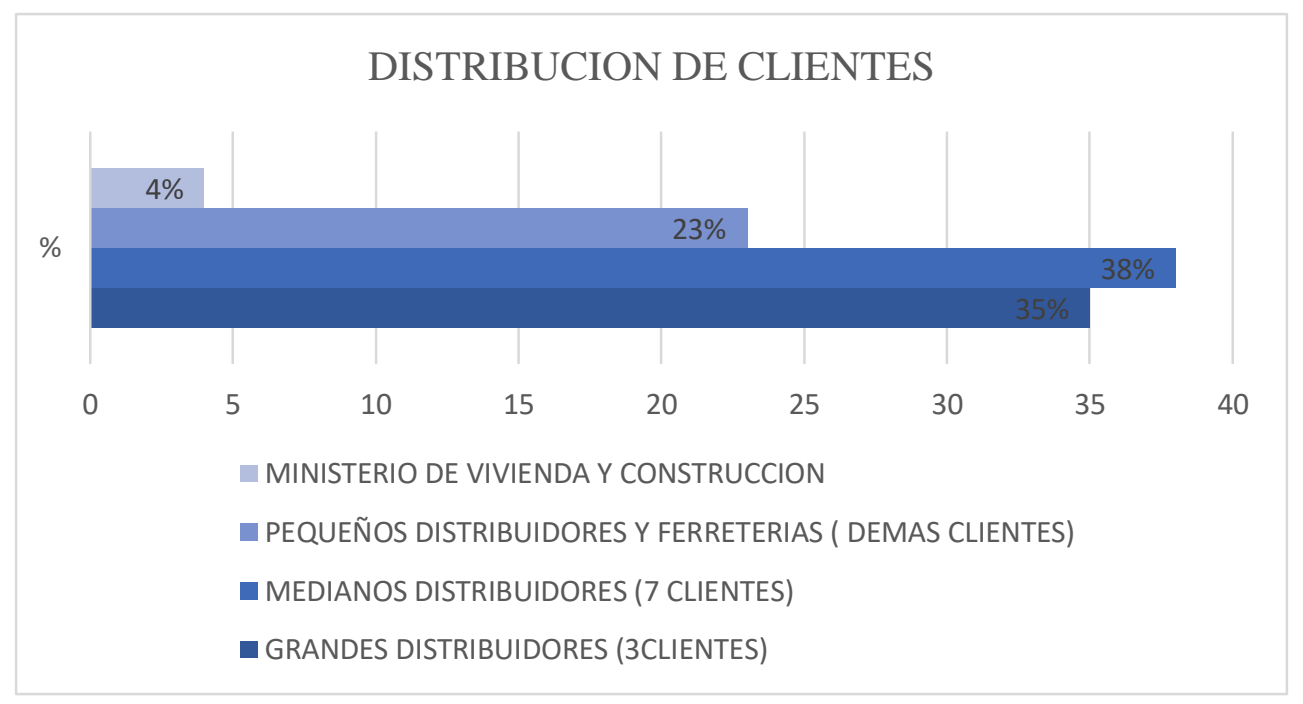

Figura 23. Distribución de clientes

Fuente: Elaboración propia

Dentro de los grandes distribuidores se encuentran Sodimac, Maestro y Homes Centers como Promart. 


\section{a. Sodimac}

Proviene de Chile desde 1952. Tiene más de 100 tiendas que se encuentran distribuidas en Perú, Colombia, Uruguay y Argentina; y próximamente en México. Inició como cooperativa abastecedora de empresas constructoras, pero hoy en día es una cadena que brinda productos de construcción, mejoramiento del hogar y ferreterías.

Actualmente ha alcanzado el liderazgo entre las tiendas que se enfocan en mejorar el hogar. A nivel nacional como indica el gráfico cuenta con 28 tiendas, 14 ubicadas entre Lima y el Callao y 14 en diferentes provincias, todas cuentan con una propuesta innovadora que satisface las necesidades del consumidor final; a través de brindar soluciones a proyectos de construcción, enfocados en decorar y mejorar hogares con un servicio de atención especializado que asesora y acompaña al comprador durante su búsqueda por productos de bajo costo y alta calidad.

\section{b. Maestro}

Precursora en el Perú en dar un concepto especializado en el mejoramiento del hogar y construcción. Cuenta con más de 20 años en el mercado, teniendo como objetivo generar una experiencia de compra en el sector de la construcción amigable brindando personal especializado, en una tienda donde puedan encontrar todo en un solo lugar. A nivel nacional tiene 30 tiendas entre Lima y Provincia, con proyección de seguir expandiéndose. Maestro no solo da productos de calidad, sino que cuenta con personal capacitado para dar el asesoramiento idóneo. 


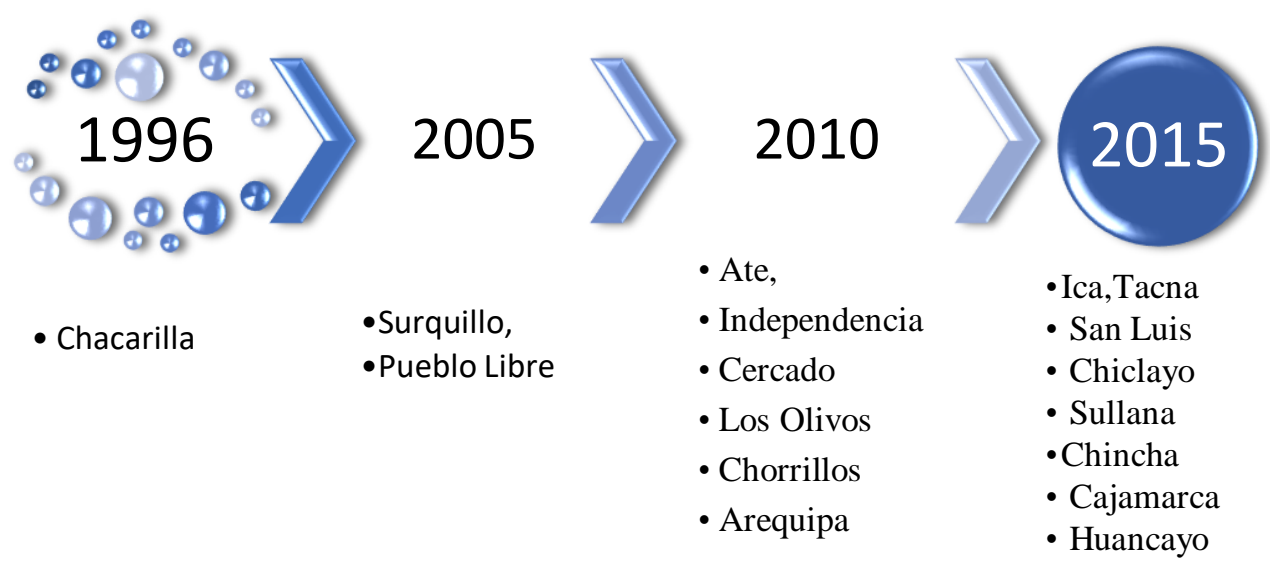

Figura 24. Tiendas Maestro en Perú en Línea de Tiempo.

Fuente: Elaboración propia

Dentro de los servicios que ofrece es el matizado de pintura, servicio de corte y dimensionado, instalaciones y despacho a domicilio.

Para poder realizar el análisis sobre el poder de negociación se toma en cuenta las consecuencias de cambiarse a otro proveedor, las diferencias entre los productos y si hay una amenaza de integración con el cliente.

\section{a. Diferenciación de los productos:}

No hay variedad en las opciones de productos de fibrocemento que se tienen disponibles, generalmente las características de los productos son similares y la decisión de compra de los grandes distribuidores está enfocada en el precio del producto; el usuario final ve influenciada su compra por la facilidad que ofrece el distribuidor. No existe diferenciación por marca, el usuario final le resulta indistinto comprar una u otra marca. 


\section{b. Costo de cambio a otro proveedor:}

Para el cliente (distribuidor) resulta un gran problema el cambio de proveedor, ya que, por lo general, se necesita contar con un stock para abastecer sus tiendas, pero podrían cambiar de proveedor siempre y cuando el nuevo proveedor asegure los tiempos de stock luego de la importación.

\section{c. El cliente no plantea una amenaza de integración hacia atrás:}

No existe una amenaza de integración vertical hacia atrás ya que abrir operaciones para fabricar fibrocemento demanda mayor inversión. No se considera una amenaza.

\subsubsection{Proveedores}

Para la fabricación de las planchas de fibrocemento, Eternit tienen proveedores nacionales y extranjeros, de los cinco principales proveedores para la fabricación se tiene

\begin{tabular}{|c|c|c|}
\hline MATERIA PRIMA & PROVEEDOR & ORIGEN \\
\hline Cemento Portland 1 & Unacem & Nacional \\
\hline Celulosa & Arauco & Extranjero \\
\hline Sílice & Etrachul & Nacional \\
\hline Hidróxido de & ETI & Extranjero \\
Aluminio & & \\
\hline Caolín & Insumex & Nacional \\
\hline
\end{tabular}

Tabla 12. Proveedores de las principales materias primas Fuente: Elaboración propia

Para el análisis del poder de negociación de los proveedores se considera la variedad de proveedores y si el proveedor representa una amenaza de integración hacia adelante. 


\section{a. Variedad de proveedores:}

Las materias primas que abastecen los proveedores son esenciales para la calidad del producto, son pocos los proveedores que cumplen con los estándares que se necesita, se tienen proveedores nacionales y también se importa algunas materias primas con los que se tienen contratos con precios establecidos.

En ese sentido, los proveedores son esenciales para la fabricación de los productos, tiene que pasar por exhaustivo proceso de homologación donde se considera varias pruebas y luego de estar homologados se puede hacer el cambio.

\section{b. Amenaza de integración hacia delante:}

Los proveedores no tienen capacidad de fabricar productos de fibrocemento, debido a que están especializados en la materia que ofrecen y abrir operaciones demandaría una mayor inversión

A continuación, una breve descripción de los proveedores de las materias primas más relevantes:

\section{- UNACEM}

Fundada un 6 de julio de 1916, a través de Compañía Peruana de Cemento Pórtland S.A. predecesora de Cementos Lima S.A, importando Producto. En 1924 implementa su primera planta de producción Maravillas iniciando la producción Local y dejando la Importación. Unacem se dedica a la Fabricación y Comercialización de cemento en sus diferentes tipos (Portland, Andino). Tiene actualmente 3 unidades de negocio adicionales en el País:

- PROGRESOL Comercializa sus cementos a través de la Red de Ferretería Progresol y distribuidores en provincias. 
- HATUNSOL A través de Hatunsol brinda Préstamo en materiales de construcción y mano de obra.

Asimismo, la figura 38 y 39 nos muestra los resultados Financieros e inversiones de UNACEM lo cual nos muestra una solidez financiera de esta compañía, lo cual nos da la confianza que unas de nuestras principales materias primas podrán ser abastecidas. Asimismo, demuestra a su vez un gran poder de negociación de esta Empresa.

UNACEM tiene subsidiarias y otros negocios, como UNICON S.A. alineados al rubro de concreto premezclado. Sus negocios están relacionados al rubro de la construcción, sin embargo, no compiten con nuestra compañía, y su Know How está alineado específicamente al cemento y concreto premezclado.

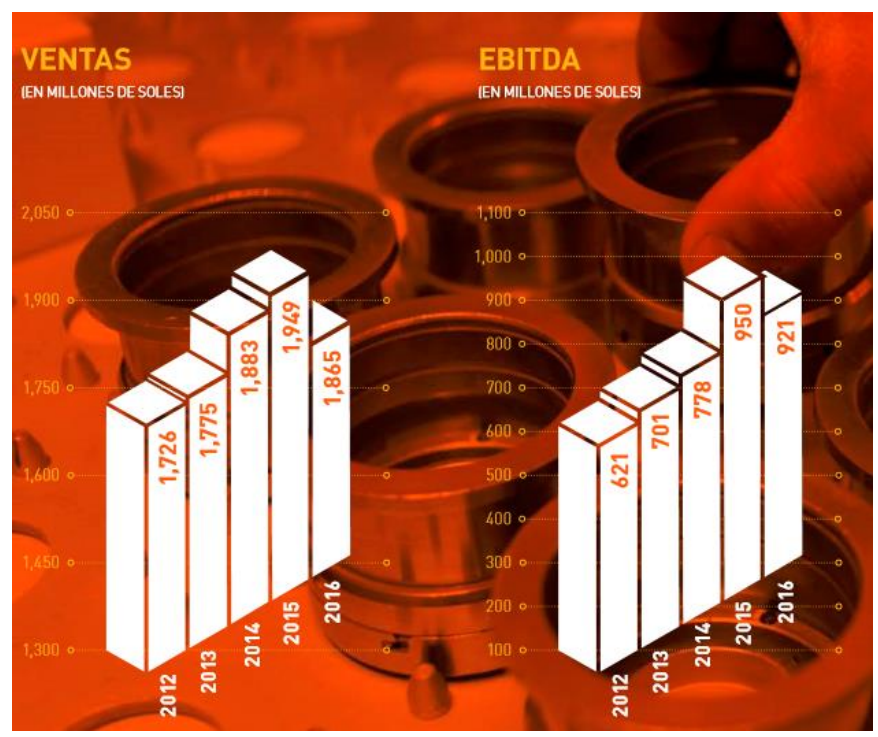

Figura 25. Ventas y EBITDA UNACEM

Fuente: UNACEM, (2017). Memoria Anual. Recuperado de:

http://www.unacem.com.pe/mayrs/ma2016/assets/pdf/UNACEM-MEMORIA-2016.pdf 


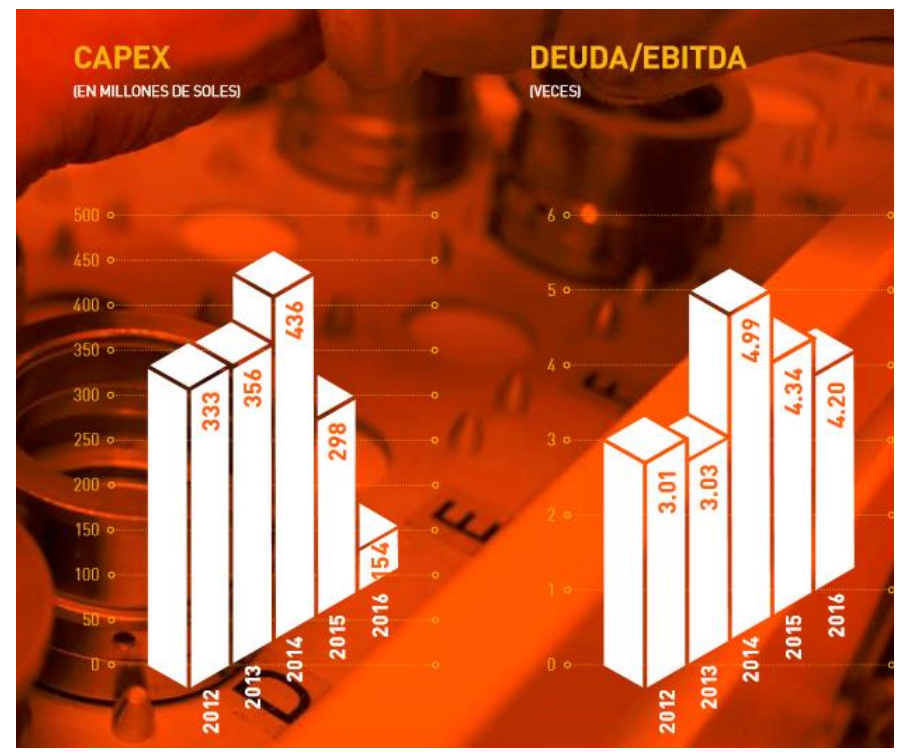

Figura 26. Capex UNACEM

Fuente: UNACEM, (2017). Memoria anual. Recuperado de: http://www.unacem.com.pe/mayrs/ma2016/assets/pdf/UNACEM-MEMORIA-2016.pdf

- ARAUCO:

ARAUCO es uno de los principales productores de celulosa en el mundo. La Celulosa producida utiliza madera proveniente de plantaciones de pino y eucalipto. Entre los tipos de Celulosa tenemos: celulosa blanqueada, para la fabricación de diversos tipos de papel; celulosa sin blanquear, utilizada para la producción de material para embalaje, productos de fibrocemento, papeles dieléctricos, entre otros; celulosa fluff, para producción de pañales y toallas higiénicas.

La figura 40 nos muestra los resultados de ARAUCO al 2009, lo cual muestra una empresa Solida. Eternit actualmente se encuentra evaluando otras alternativas de las diferentes que existen en el Mercado, en busca de mejores precios, por tanto, el poder de Negociación de Arauco no es significativo. 


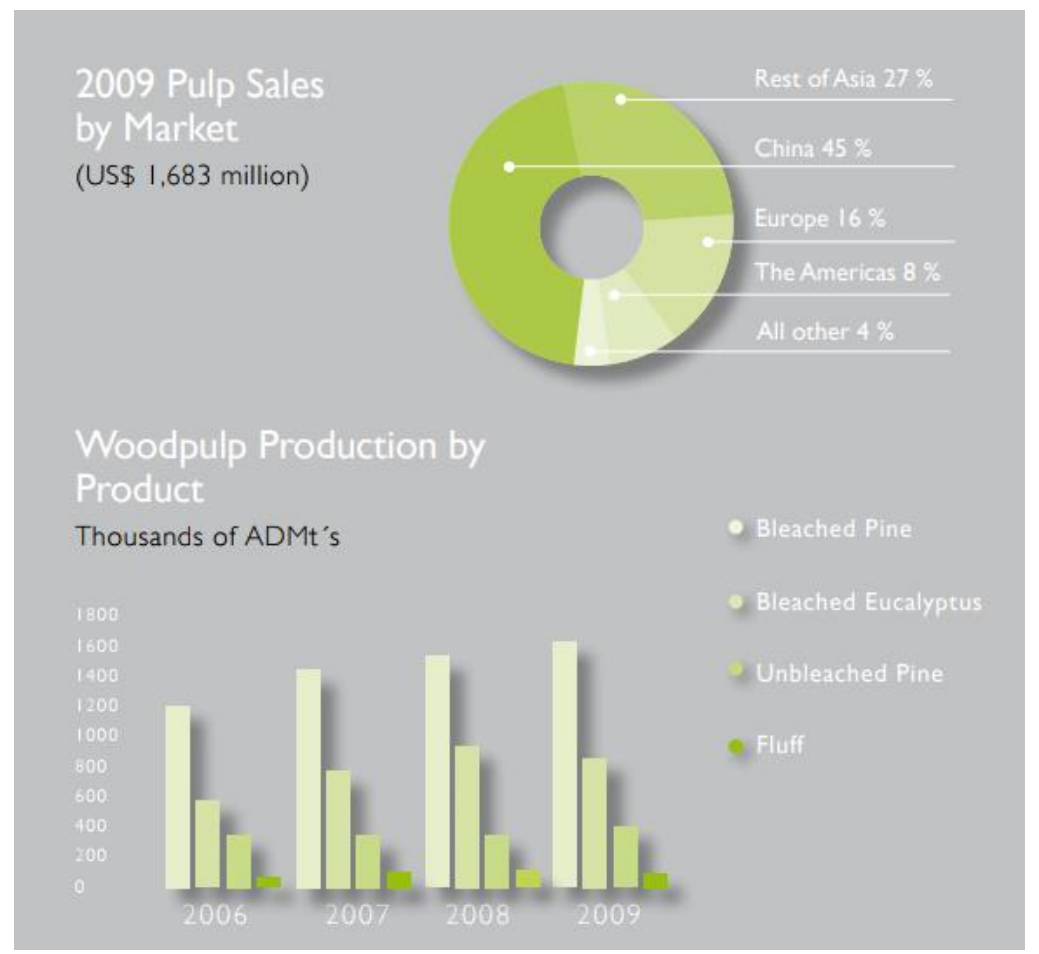

Figura 27. Resultados Arauco

Fuente: Arauco, 2010. Arauco around the world. Recuperado de: http://web.arauco.cl/_file/file_3143_pulp\%20catalog.pdf

\subsubsection{Competencia en el mismo sector}

Para poder identificar si hay enfrentamiento entre los competidores existentes debemos considerar cuántos hay en la industria, cómo crece el mercado y las barreras más relevantes de salida.

\section{a. Crecimiento del mercado:}

El mercado atraviesa un crecimiento menor en estos últimos años pasos de un $2 \%$ en el 2014, $10 \%$ en el 2015 y bajar en -1\% en el 2016, en comparación a los altos crecimientos observados en los años 2011 y 2012 donde se obtuvo crecimientos del 16 y $15 \%$ respectivamente. El consumo de fibrocemento que se espera en el 2017 es de un $8 \%$ mayor al del 2016, tomando como referencia las ventas de Eternit que tiene el 95\% del mercado. 


\section{b. Cantidad de competidores:}

El mercado de fibrocemento en el Perú está divido en tres principales empresas: Eternit, Volcán, Plycem.

En el 2011, Eternit representaba el 82\%, Volcán el 10\% y Plycem el 8\%. El 2013, Eternit representaba el $82 \%$, Volcán el 10\% crecimiento del mercado ha sido bajo en estos últimos pasos de un $2 \%$ en el $2014,10 \%$ en el 2015 y bajar en - $1 \%$ en el 2016, en comparación a los altos crecimientos observados en los años 2011 y 2012 donde se obtuvo crecimientos del 16 y $15 \%$ respectivamente. El 2017 se proyecta cerrar con un crecimiento del 8\% del mercado fibrocemento, tomando como referencia las ventas de Eternit que tiene el 95\% del mercado.

\subsection{Matriz de atractividad de cada una de las cinco fuerzas}

En base al análisis realizado para cada una de las cinco fuerzas de Porter, presentamos la matriz de atractividad de las cinco fuerzas, por cada uno de los criterios analizados.

Tabla 13. Matriz de atractividad de las Cinco Fuerzas Competitivas

\begin{tabular}{|c|c|c|c|}
\hline FUERZAS COMPETITIVAS & ALTA & BAJA & GLOBAL \\
\hline \multicolumn{4}{|c|}{ Amenaza de Productos Sustitutos } \\
\hline $\begin{array}{l}\text { Nivel percibido de } \\
\text { diferenciación del producto }\end{array}$ & & $\mathrm{X}$ & \multirow{2}{*}{ Baja } \\
\hline $\begin{array}{l}\text { Precio relativo de los } \\
\text { productos sustitutos }\end{array}$ & & $\mathrm{X}$ & \\
\hline \multicolumn{4}{|c|}{ Amenaza de Entrada de Nuevos Competidores Potenciales } \\
\hline Economía de Escala & & $\mathrm{X}$ & Bajo \\
\hline
\end{tabular}




\begin{tabular}{|c|c|c|c|}
\hline $\begin{array}{l}\text { Conocimiento especializado } \\
\text { y tecnología }\end{array}$ & & $\mathrm{X}$ & \\
\hline Preferencia de la marca & $\mathrm{X}$ & & \\
\hline $\begin{array}{l}\text { Canales de distribución } \\
\text { adecuados }\end{array}$ & & $\mathrm{X}$ & \\
\hline \multicolumn{4}{|c|}{ Poder de Negociación de los Clientes } \\
\hline $\begin{array}{l}\text { Diferenciación de los } \\
\text { productos }\end{array}$ & $\mathrm{X}$ & & \multirow{3}{*}{ Bajo } \\
\hline $\begin{array}{l}\text { Costo de cambio a otro } \\
\text { proveedor }\end{array}$ & & $\mathrm{X}$ & \\
\hline $\begin{array}{l}\text { El cliente no plantea una amenaza } \\
\text { de integración hacia atrás }\end{array}$ & & $\mathrm{X}$ & \\
\hline \multicolumn{4}{|c|}{ Poder de Negociación de Proveedores } \\
\hline Variedad de proveedores & $\mathrm{X}$ & & \multirow[b]{2}{*}{ Alto } \\
\hline $\begin{array}{l}\text { Amenaza de integración } \\
\text { hacia delante }\end{array}$ & & $\mathrm{X}$ & \\
\hline \multicolumn{4}{|c|}{ Rivalidad entre Competidores de la Industria } \\
\hline Crecimiento del mercado & & $\mathrm{X}$ & \multirow{2}{*}{ Bajo } \\
\hline Cantidad de competidores & & $\mathrm{X}$ & \\
\hline
\end{tabular}

\subsection{Análisis del Grado de atractividad de la industria}

Las cinco fuerzas competitivas de Portet, permite realizar un completo análisis de la empresa por medio de un estudio de la industria en ese momento, con el fin de saber dónde está colocada 
una empresa con base en otra en ese momento. Nos hablan de cómo usar la estrategia competitiva y además determinan la rentabilidad que se pueden tener en el mercado a largo plazo.

\subsubsection{Amenaza de Productos Sustitutos}

En base al análisis realizado en cuanto a la amenaza de productos sustitutos, a continuación, identificaremos la actividad que cada uno de los ítems analizados representa para la industria.

\section{a. Nivel percibido de diferenciación del producto:}

Esto constituye una ATRACTIVIDAD BAJA para ETERNIT porque los productos de fibrocemento no están correctamente difundidos y el usuario final no cuenta con la información correcta de las bondades del producto.

\section{b. Precio relativo de los productos sustitutos:}

Esta situación constituye una BAJA ATRACTIVIDAD debido a que los precios de los productos sustitutos son mayores que el precio de la plancha plana de fibrocemento

\subsubsection{Amenaza de Entrada de Nuevos Competidores Potenciales}

En base al análisis realizado en cuanto a la amenaza de entrada de nuevos competidores, a continuación, identificaremos la atractividad que cada uno de los ítems analizados representa para la industria.

\section{a. Economía de Escala:}

Se considera una ATRACTIVIDAD BAJA ya que si nuevos competidores deciden ingresar al mercado deberán tener una gran inversión para lograr una economía a escala con la que ya cuenta Eternit (unidad de negocio de fibrocemento)

\section{b. Conocimiento especializado y tecnología:}


La experiencia, el conocimiento de los procesos y la alta tecnología convierten en una ACTRACTIVIDAD BAJA, considerando que todo este know how es producto de la actividad que ha tenido Eternit durante varias décadas atrás, no hay manera que una empresa pueda lograrlo de la noche a la mañana.

\section{c. Preferencia de la marca:}

La preferencia de la marca se considera una ATRACTIVIDAD ALTA, ya que Eternit es una empresa reconocida, pero la marca de la plancha plana de fibrocemento no es conocida, el posicionamiento que tiene en el mercado es bajo, como se ha visto en capítulos anteriores, la gente no conoce al producto y por ende no lo compra.

\section{d. Canales de distribución adecuados:}

Podemos considerar como BAJA ATRACTIVIDAD, ya que Eternit (unidad de negocio de fibrocemento) no cuenta con servicio de distribución, utiliza los distribuidores existentes en el mercado; pero, aun así, siendo el primero en cuota de mercado con 95\%, es imposible que los distribuidores puedan ir a la competencia para abastecer sus requerimientos.

\subsubsection{Poder de Negociación de los Clientes}

En base al análisis realizado al poder de negociación de los clientes, a continuación, identificaremos la atractividad que cada uno de los ítems analizados representa para la industria.

\section{a. Diferenciación de los productos:}

No existe diferenciación por marca, por lo que para el cliente le resulta indistinto comprar en una u otra empresa, se concluye que existe una ATRACTIVIDAD ALTA. Siendo un producto tan estándar como lo son los productos de fibrocemento, realmente no hay punto de diferenciación en lo que se refiere específicamente al producto de estudio.

\section{b. Costo de cambio a otro proveedor:}


Se considera una ATRACTIVIDAD BAJA ya que el cliente puede tener problemas de desabastecimiento de cambiar por otra empresa del sector. Considerando, de nuevo, que Eternit maneja el $95 \%$ del mercado, el cliente no tiene incentivos para cambiar de proveedor.

\section{c. El cliente no plantea una amenaza de integración hacia atrás:}

No existe una amenaza de integración vertical hacia atrás ya que abrir operaciones para fabricar productos de fibrocemento demanda una mayor inversión, por lo que es una BAJA ATRACTIVIDAD, habiendo visto esto en los puntos anteriores, la inversión inicial que correspondería hacer, así como el conocimiento que se requiere para montar una operación eficiente hacen virtualmente imposible replicar el funcionamiento de una planta de de fibrocemento en un corto plazo.

\subsubsection{Poder de Negociación de Proveedores}

En base al análisis al poder de negociación de los proveedores, a continuación, identificaremos la atractividad que cada uno de los ítems analizados representa para industria.

\section{a. Variedad de proveedores:}

El poder negociación de los proveedores homologados es alta debido a la poca alternativa que se tiene, generando al sector una ATRACTIVIDAD ALTA

En ese sentido, los proveedores son esenciales para la fabricación de los productos, tiene que pasar por exhaustivo proceso de homologación donde se considera varias pruebas y luego de estar homologados se puede hacer el cambio.

\section{b. Amenaza de integración hacia delante:}

Los proveedores no cuentan con la tecnología e inversión para abrir operaciones. Se considera una BAJA ATRACTIVIDAD. 


\subsubsection{Rivalidad entre Competidores de la Industria}

En base al análisis realizado a la rivalidad entre los competidores existentes, a continuación, identificaremos la atractividad que cada uno de los ítems analizados representa para la industria.

\section{a. Crecimiento del mercado:}

Se considera una ATRACTIVIDAD BAJA, debido a que el mercado de fibrocemento tiene un alto potencial de crecimiento, a pesar de que en estos últimos años el crecimiento ha sido lento.

\section{b. Cantidad de competidores:}

El mercado de fibrocemento tiene pocos competidores, se considera ATRACTIVIDAD BAJA, en gran medida por que el ingreso al mercado es bastante difícil y sobre todo considerando la cuota de mercado que maneja la empresa.

\subsection{Matriz de Perfil Competitivo MPC}

Los factores críticos del éxito analizados se desprenden del análisis de las fuerzas competitivas de Porter

$$
\begin{aligned}
& \text { Puntaje: } \\
& 1 \text { = Debilidad principal } \\
& 2=\text { Debilidad menor } \\
& 3=\text { Fortaleza menor } \\
& 4=\text { Fortaleza principal } \\
& \text { Peso total ponderado: } \\
& \text { Mayor a } 2.5=\text { Fortaleza } \\
& \text { Menor a } 2.5 \text { = Debilidad }
\end{aligned}
$$


Los factores críticos del éxito analizados se desprenden del análisis de las fuerzas competitivas de Porter y sus ponderaciones y calificaciones son resultados de entrevista sostenida al Gerente de Operaciones de ETERNIT con más de 5 años de experiencia en la Empresa. Asimismo, se revisó las páginas web y fuentes de información de los principales competidores, considerando que el perfil competitivo de la unidad de negocio de fibrocemento es el mismo de la empresa Eternit y su competencia.

Definiciones de los Factores críticos de Éxito, todos enfocados a la unidad de fibrocemento.

a. Fabricación local: La empresa, cuenta con infraestructura local en el país para la manufactura, almacenamiento y distribución de sus productos.

b. Marca reconocida: La marca de estos productos es reconocida en el país y a nivel mundial

c. Know How de la empresa: La empresa tiene la tecnología y equipos de investigación para el desarrollo de sus productos o la mejora de estos, tanto local como externamente.

d. Precio: Los precios están dentro del mercado y son competitivos

e. Participación de mercado: El porcentaje de participación que tiene cada compañía en el Mercado local

f. Costos de producción: El nivel de infraestructura que tiene la empresa para reducir sus costos.

g. Calidad del producto: Referido a la garantía del producto y sistemas de gestión implementados en la empresa.

h. Personal capacitado: Años de experiencia del Personal y de la compañía en el negocio, así como los sistemas de gestión implementados en la Empresa 
i. Distribución a nivel nacional: Distribuidores asociados a la empresa a nivel nacional y presencia en los diferentes departamentos y/o regiones

j. Desarrollo de nuevos productos: La empresa con Centros de Innovación y ha introducido nuevos productos al mercado.

Cabe resaltar que la ponderación otorgada a cada factor crítico ha sido previamente validad con profesionales del sector.

Tabla 14. Matriz del Perfil Competitivo de la unidad de fibrocemento de Eternit

\begin{tabular}{|c|c|c|c|c|c|c|c|}
\hline \multirow{3}{*}{$\begin{array}{l}\text { FACTORES } \\
\text { CRITICOS DE } \\
\text { ÉXITO }\end{array}$} & \multirow{3}{*}{ POND. } & \multicolumn{6}{|c|}{ EMPRESA } \\
\hline & & \multicolumn{2}{|c|}{ Eternit } & \multicolumn{2}{|c|}{ Volcán } & \multicolumn{2}{|c|}{ Plycem } \\
\hline & & Calif. & Punt. & Calif. & Punt. & Calif. & Punt. \\
\hline Fabricación Local & 0.1 & 4 & 0.4 & 1 & 0.1 & 1 & 0.1 \\
\hline Marca reconocida & 0.1 & 4 & 0.4 & 3 & 0.3 & 3 & 0.3 \\
\hline $\begin{array}{l}\text { Know How de la } \\
\text { Empresa }\end{array}$ & 0.1 & 4 & 0.4 & 3 & 0.3 & 3 & 0.3 \\
\hline Precio & 0.1 & 3 & 0.3 & 3 & 0.3 & 3 & 0.3 \\
\hline $\begin{array}{l}\text { Participación de } \\
\text { mercado }\end{array}$ & 0.09 & 3 & 0.27 & 2 & 0.18 & 1 & 0.09 \\
\hline $\begin{array}{l}\text { Costos de } \\
\text { producción }\end{array}$ & 0.08 & 2 & 0.16 & 2 & 0.16 & 2 & 0.16 \\
\hline $\begin{array}{l}\text { Calidad del } \\
\text { producto }\end{array}$ & 0.08 & 3 & 0.24 & 3 & 0.24 & 3 & 0.24 \\
\hline
\end{tabular}




\begin{tabular}{|l|r|r|r|r|r|r|r|} 
Personal capacitado & 0.08 & 4 & 0.32 & 3 & 0.24 & 3 & 0.24 \\
\hline Posicionamiento & 0.08 & 4 & 0.32 & 2 & 0.16 & 2 & 0.16 \\
\hline $\begin{array}{l}\text { Capacidad de } \\
\text { abastecimiento }\end{array}$ & 0.07 & 4 & 0.28 & 2 & 0.14 & 2 & 0.14 \\
\hline Distribución a nivel & 0.07 & 2 & 0.14 & 2 & 0.14 & 2 & 0.14 \\
nacional & & & & & & & \\
\hline Desarrollo de nuevos & 0.05 & 2 & 0.1 & 3 & 0.15 & 4 & 0.2 \\
productos & & & & & & & \\
\hline \multicolumn{1}{|c|}{ Total } & $\mathbf{1}$ & - & $\mathbf{3 . 3 3}$ & - & $\mathbf{2 . 1 1}$ & - & $\mathbf{2 . 0 7}$ \\
\hline
\end{tabular}

El resultado de la Matriz del Perfil Competitivo da una puntuación de 3.33 para la unidad de fibrocemento de ETERNIT, 2.11 para Volcan y 2.07 para Plycem.

$\mathrm{Al}$ respecto, se evidencia que, ETERNIT (unidad de negocio de fibrocemento) cuenta con fortalezas bien desarrolladas como fabricación local, marca reconocida, know how, personal capacitado, posicionamiento y capacidad de abastecimiento. Esto permite a ETERNIT ser líder en el mercado de fibrocemento y crear una unidad de negocio con los requerimientos estratégicos a desarrollar. 


\section{Capítulo VII: Formulación de los objetivos y diseño de las estrategias.}

Los objetivos estratégicos son las estrategias planteadas por una empresa para lograr sus metas a largo plazo, realizando acciones que los lleven a cumplir dichos objetivos.

En principio se establecerán los objetivos estratégicos de la empresa, para luego, a través de herramientas como la matriz FODA, PEYEA y la Matriz Ampliada, identificar las posibles estrategias que permitirán cumplir con estos objetivos.

\subsection{Objetivos Estratégicos}

Los objetivos estratégicos de la empresa están alineados con los pilares de rentabilidad, eficiencia operativa y crecimiento en un marco de 5 años, los cuales son:

a. Mantener el Market Share de la compañía en $95 \%$

b. Incrementar el ROE de $5 \%$ a $13 \%$

\subsection{Diseño y formulación de estrategias}

El diseño y la formulación de estrategias se realizarán en función a las matrices FODA, PEYEA y la Matriz Ampliada de plan negocio, las cuales brindarán un sustento teórico al análisis presentado.

\subsection{Matriz FODA}

La herramienta de la matriz FODA, la cual obtiene su nombre por las siglas en ingles SWOT, consiste en "realizar una evaluación de los factores fuertes y débiles que en su conjunto diagnostican la situación interna de la organización, así como su evaluación externa; es decir, las oportunidades y amenazas. También es una herramienta que puede considerarse sencilla y permite obtener una perspectiva general de la situación estratégica de una organización determinada (Talancón, 2006).” 
Dentro del proceso del plan de negocio, la matriz FODA se encuentra situada dentro de la Etapa de Ajuste, la cual se "centra en la creación de alternativas de estrategias posibles por medio del ajuste de los factores externos e internos clave (David. F. R., 2003).”

A continuación, se listarán todas las fortalezas, debilidades, oportunidades y amenazas relevantes al estudio y recopiladas en las diversas matrices de insumos que se señalaron en los capítulos anteriores:

\section{a. Fortalezas de la unidad de negocio de fibrocemento.}

1. Marca Eternit (77 años)

2. Know How (Saber cómo hacer) de la empresa

3. Líder en el mercado, $90 \%$ de participación

4. Soporte técnico regional y de grupo

5. Infraestructura responde a necesidad

6. Capacidad de Producción

7. Flexibilidad de la Operación

8. Sistema integrado de gestión (calidad, seguridad y medio ambiente)

9. Programa anual de mejoramiento continuo y ahorros

10. Departamento de investigación valida la materia prima.

11. Respaldo financiero internacional del grupo Etex

12. Plan de capacitación establecido

13. Evaluación anual $360^{\circ}$

14. Plan de mejora del clima organizacional anual

\section{b. Debilidades de la unidad de negocio de fibrocemento.}

1. Poca polivalencia de trabajadores 
2. Sistema de información deficiente

3. Planificación de la producción no alineada a la demanda

4. Sobre stocks

5. Requerimiento de mano de obra por trabajos de manuales

6. porcentaje de utilización de equipos al 50\%, mano de obra ociosa

7. Normas y reglamentos de trabajo muy generales

8. Plan de crecimiento no establecido

9. No existe diferenciación a nivel operativo (bandas salariales)

10. Características del producto no permiten un fácil transporte y manipulación.

11. Dificultad de almacenamiento del producto

12. No existe innovación o desarrollo de nuevos productos asociados.

\section{c. Oportunidades de la unidad de negocio de fibrocemento.}

1. Plan integral de Reconstrucción.

2. Juegos Panamericanos Ley $N^{\circ} 30556$ - Reconstrucción con cambios

3. Nueva tendencia de Sistemas Flexibles y Modulares

4. Fondo Mi Vivienda

5. Insuficiente número de Vivienda en el País

6. Ley $\mathrm{N}^{\circ} 30425$ - Retiro del $95.5 \%$ del fondo AFP

7. Ley $\mathrm{N}^{\circ} 30478$ - Disposición del 25\% AFP para compra de un primer inmueble

8. Proyección de Crecimiento de la Economía Global

9. Decreto Legislativo $\mathrm{N}^{\circ} 1243$ - Muerte civil a funcionarios del estado por corrupción

10. Nuevas tecnologías en Materiales de Construcción 
11. Decreto Legislativo $\mathrm{N}^{\circ} 1269$ - Nuevo régimen tributario del impuesto a la renta para MYPE

\section{d. Amenazas de la unidad de negocio de fibrocemento.}

1. Casos de Corrupción y Censura de Ministros - Corrupción generalizada

2. Materiales usados para las paredes de las viviendas en Lima Metropolitana

3. Infiltración de senderistas en organización sindicales de construcción civil

4. Amenaza de Políticas proteccionistas de USA

5. Creencias y/o ideas irracionales acerca del riesgo cancerígeno del producto.

\section{Tipificación de estrategias:}

El análisis que proporciona la herramienta de la matriz FODA da como resultado cuatro tipos de estrategias:

- Estrategias FO: entendida como la aplicación de las fuerzas internas de la empresa para aprovechar las oportunidades externas.

- Estrategias DO: las oportunidades externas permiten superar las debilidades internas

- Estrategias FA: las fuerzas de la empresa son aprovechadas para evitar o disminuir las repercusiones de las amenazas externas.

- Estrategia DA: Son tácticas defensivas que pretenden disminuir las debilidades internas y evitar las amenazas del entorno, llámese, fusión, disminución, declarar la quiebra u optar por la liquidación (Talancón, 2006).

A continuación, se presenta la matriz FODA: 
Tabla 15. Matriz FODA

\begin{tabular}{|c|c|c|c|}
\hline & \multirow[b]{2}{*}{$\mathrm{F} 1$} & \multirow[b]{2}{*}{ Marca Eternit (77 años) } & \multirow[b]{2}{*}{ Poca polivalencia de trabajadores } \\
\hline & & & \\
\hline & $\mathrm{F} 2$ & Know How de la empresa & Sistema de información deficiente \\
\hline & F3 & Líder en el mercado & Alto nivel de stocks \\
\hline & F4 & Soporte técnico regional y del grupo & $\begin{array}{l}\text { Planificación de la producción no } \\
\text { alineada a la demanda }\end{array}$ \\
\hline & F5 & Infraestructura acorde a la necesidad & Alta necesidad de mano de obra \\
\hline & F6 & Capacidad de Producción & $\begin{array}{l}\text { Bajo porcentaje de utilización } \\
\text { capacidad }\end{array}$ \\
\hline & F7 & Flexibilidad de la Operación & $\begin{array}{c}\text { Normas y reglamentos muy } \\
\text { generales }\end{array}$ \\
\hline & F8 & Sistema integrado de gestión & Plan de crecimiento no establecido \\
\hline & F9 & $\begin{array}{c}\text { Programa anual de mejoramiento continuo y } \\
\text { ahorros }\end{array}$ & $\begin{array}{l}\text { No existe diferenciación de } \\
\text { personal }\end{array}$ \\
\hline & F10 & Materias primas de primera calidad & Producto de dificil Manipulación \\
\hline & F11 & Respaldo financiero del grupo Etex & Producto dificil de almacenar \\
\hline & F12 & Plan de capacitación establecido & Poca innovación nuevos productos \\
\hline & OPORTUNIDADES & ESTRATEGIA FO & ESTRATEGIA DO \\
\hline $\mathrm{O} 1$ & $\begin{array}{l}\quad \text { Plan integral de } \\
\text { Reconstrucción y Juegos } \\
\text { Panamericanos } \\
\end{array}$ & $\begin{array}{l}\text { F3,F5, F6, F7, F11, O1, O2,O3,O4,O5 Crear } \\
\text { la unidad de Negocio de Planchas planas de }\end{array}$ & D3, D6, D11, O1, O4, O5 \\
\hline $\mathrm{O} 2$ & $\begin{array}{l}\text { Nueva tendencia de Sistemas } \\
\text { Flexibles y Modulares }\end{array}$ & $\begin{array}{l}\text { fibrocemento que permita introducir el producto } \\
\text { con mayor participacion en el mercado. }\end{array}$ & $\begin{array}{l}\text { Enfocarse en el segmento del Plan de } \\
\text { Reconstrucción (Incrementó de } \\
\text { Participación de mercado) }\end{array}$ \\
\hline $\mathrm{O} 3$ & Fondo Mi Vivienda & F5, F6, O1, O3, O4 Fortalecer al equipo & \\
\hline $\mathrm{O} 4$ & Déficit de Vivienda & $\begin{array}{l}\text { comercial para enfocarse en el nuevo mercado } \\
\text { potencial surgido de la reconstrucción nacional y } \\
\text { los juegos panamericanos (Viviendas temporales, }\end{array}$ & $\begin{array}{l}\text { D1, D5, O2 Fortalecer al equipo } \\
\text { operativo Establecer un plan de carrera } \\
\text { para los operarios }\end{array}$ \\
\hline O5 & $\begin{array}{l}\text { Proyección de Crecimiento } \\
\text { de la Economía Global }\end{array}$ & zonas del interior del pais y otros) & $\begin{array}{l}\text { D2, D4, D12,O5 Incrementar la } \\
\text { coordinación e interacción entre areas. }\end{array}$ \\
\hline O6 & $\begin{array}{l}\text { DL1243-Muerte civil a } \\
\text { funcionarios corruptos }\end{array}$ & $\begin{array}{l}\text { F3, F7, F11, O7 Desarrollar una política } \\
\text { financiera que busque la reducción de gastos } \\
\text { administrativos (Liderazgo en costos) }\end{array}$ & \\
\hline O7 & $\begin{array}{l}\text { DL } 1269 \text { - Nuevo régimen } \\
\text { tributario del impuesto a la renta } \\
\text { para MYPE }\end{array}$ & $\begin{array}{l}\text { F3, F8, F9,O5 Reducción de los tiempos de } \\
\text { pago de clientes, del capital de trabajo y mejora el } \\
\text { ciclo de conversión del efectivo. (Incrementó de la } \\
\text { liquidez) }\end{array}$ & \\
\hline $\mathrm{O} 8$ & $\begin{array}{l}\text { Ley } \mathrm{N}^{\circ} 30425 \text { - Retiro del } \\
95.5 \% \text { del fondo AFP }\end{array}$ & & \\
\hline O9 & $\begin{array}{l}\text { Ley } \mathrm{N}^{\circ} 30478 \text { - Disposición } \\
\text { del } 25 \% \text { AFP para compra de un } \\
\text { primer inmueble }\end{array}$ & & \\
\hline & AMENAZAS & ESTRATEGIA FA & $\begin{array}{c}\text { ESTRATEGIA DA } \\
\end{array}$ \\
\hline A1 & $\begin{array}{l}\text { Casos de Corrupción y } \\
\text { Censura de Ministros }\end{array}$ & F11, F3, F7, A3 Establecer los proyectos de & $\begin{array}{l}\text { D10,D11,D12, A2, A3 Reforzar la } \\
\text { relacion y desarrollar un plan de } \\
\text { fidelización a los distribuidores }\end{array}$ \\
\hline A2 & $\begin{array}{l}\text { Materiales usados para las } \\
\text { paredes de las viviendas en Lima } \\
\text { Metropolitana }\end{array}$ & $\begin{array}{l}\text { inversion para la Unidad de negocio, que nos } \\
\text { permita innovar y mejorar nuestros productos. }\end{array}$ & $\begin{array}{l}\text { D1, D5, A6 Fidelizar a los } \\
\text { colaboradores a través de planes de } \\
\text { capacitación }\end{array}$ \\
\hline A3 & $\begin{array}{l}\text { Nuevas tecnologías en } \\
\text { Materiales de Construcción }\end{array}$ & $\begin{array}{l}\text { F11, F10, F5, F6, A6 Generar un plan de } \\
\text { difusión de las ventajas del fibrocemento. }\end{array}$ & $\begin{array}{r}\text { D5, D8, D9, A3 Implementar un } \\
\text { sistema de reconocimientos y bandas }\end{array}$ \\
\hline
\end{tabular}




\begin{tabular}{|c|c|c|}
\hline A4 & $\begin{array}{l}\text { Infiltraciones senderistas, } \\
\text { sindicatos y delincuencia en el } \\
\text { sector construcción }\end{array}$ & $\begin{array}{l}\text { salariales para los colaboradores de la } \\
\text { unidad de negocio. }\end{array}$ \\
\hline A5 & $\begin{array}{l}\text { Amenaza de Políticas } \\
\text { proteccionistas de USA }\end{array}$ & \multirow{2}{*}{$\begin{array}{l}\mathrm{D} 4, \mathrm{D} 5, \mathrm{D} 6, \mathrm{~A} 3 \text { Automatizar el } \\
\text { proceso de producción actual y } \\
\text { rediseñar la línea de producción para la } \\
\text { reduccion de costos. }\end{array}$} \\
\hline A6 & $\begin{array}{l}\text { Paradigma de riesgo } \\
\text { cancerígeno }\end{array}$ & \\
\hline
\end{tabular}

\subsection{Matriz PEYEA}

Creada en 1982 por Rowe, Manson y Dickel, tiene como objetivo determinar cuáles son las estrategias más adecuadas para una organización una vez definidas sus posiciones estratégicas interna y externa (Rincón F. A, 2012, p.103-120).

Los ejes de la matriz corresponden a dos dimensiones internas, fortaleza financiera y ventaja competitiva, y dos dimensiones externas, estabilidad ambiental y fortaleza industrial.

A continuación, se listarán las diversas variables que integraran cada una de las dimensiones, a las cuales se les otorgará el puntaje de acuerdo a la metodología propia de la matriz.

Tabla 16. Matriz PEYEA

\section{Estabilidad Ambiental}

\begin{tabular}{|c|c|c|c|c|c|c|c|c|c|c|}
\hline$N$ & Factores & \multicolumn{8}{|c|}{ Calificación } & Tot \\
\hline 1 & $\begin{array}{c}\text { Cambios } \\
\text { tecnológicos }\end{array}$ & Pocos & 1 & 2 & 3 & 4 & 5 & 6 & Muchos & -5 \\
\hline 2 & $\begin{array}{l}\text { Tasa de } \\
\text { inflación }\end{array}$ & Baja & 1 & 2 & 3 & 4 & 5 & 6 & Alta & -2 \\
\hline 3 & $\begin{array}{l}\text { Variabilida } \\
\text { d de la } \\
\text { demanda }\end{array}$ & Pequeña & 1 & 2 & 3 & 4 & 5 & 6 & Grande & -2 \\
\hline 4 & \begin{tabular}{l}
\multicolumn{1}{c}{ Rango de } \\
precios de \\
productos \\
competitivos
\end{tabular} & Estrecho & 1 & 2 & 3 & 4 & 5 & 6 & Amplio & -4 \\
\hline 5 & $\begin{array}{l}\quad \text { Barreras de } \\
\text { entrada al } \\
\text { mercado }\end{array}$ & Muchas & 1 & 2 & 3 & 4 & 5 & 6 & Pocas & -1 \\
\hline 6 & $\begin{array}{l}\text { Rivalidad / } \\
\text { Presión } \\
\text { competitiva }\end{array}$ & Baja & 1 & 2 & 3 & 4 & 5 & 6 & Alta & -1 \\
\hline
\end{tabular}




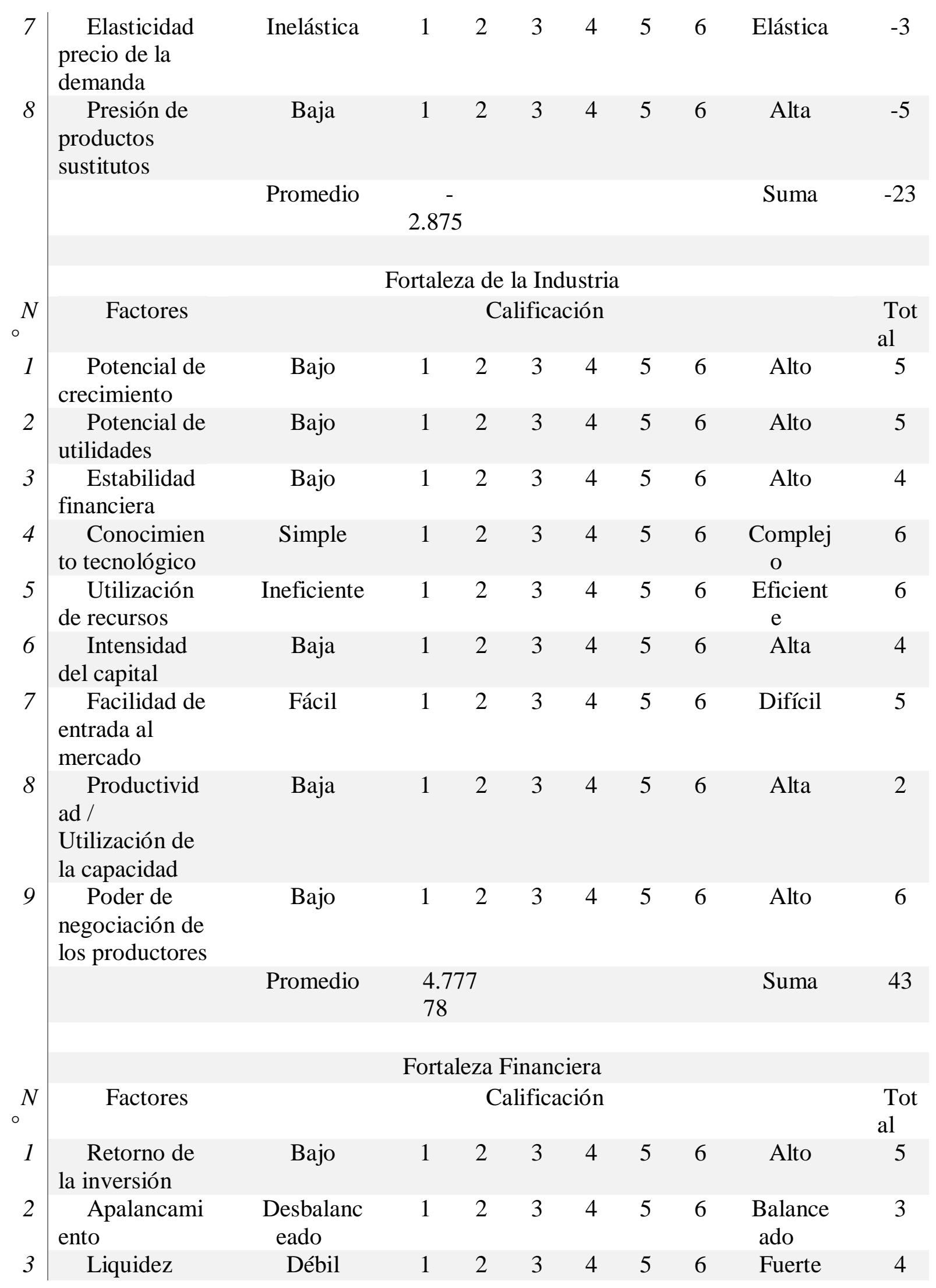




\begin{tabular}{|c|c|c|c|c|c|c|c|c|c|c|}
\hline 4 & $\begin{array}{l}\quad \text { Capital } \\
\text { requerido vs } \\
\text { Capital } \\
\text { disponible }\end{array}$ & Alto & 1 & 2 & 3 & 4 & 5 & 6 & Bajo & 4 \\
\hline 5 & $\begin{array}{l}\text { Flujo de } \\
\text { caja }\end{array}$ & Bajo & 1 & 2 & 3 & 4 & 5 & 6 & Alto & 5 \\
\hline 5 & $\begin{array}{l}\quad \text { Facilidad de } \\
\text { salida del } \\
\text { mercado }\end{array}$ & Difícil & 1 & 2 & 3 & 4 & 5 & 6 & Fácil & 1 \\
\hline 7 & $\begin{array}{l}\text { Riesgo } \\
\text { involucrado en } \\
\text { el negocio }\end{array}$ & Alto & 1 & 2 & 3 & 4 & 5 & 6 & Bajo & 3 \\
\hline 3 & $\begin{array}{l}\text { Rotación de } \\
\text { inventarios }\end{array}$ & Lento & 1 & 2 & 3 & 4 & 5 & 6 & Rápido & 1 \\
\hline 9 & Economías & Bajas & 1 & 2 & 3 & 4 & 5 & 6 & Altas & 5 \\
\hline & & Promedio & $\begin{array}{l}3 . \\
4\end{array}$ & & & & & & Suma & 31 \\
\hline & \multicolumn{10}{|c|}{ Ventaja Competitiva } \\
\hline & Factores & \multicolumn{8}{|c|}{ Calificación } & $\begin{array}{l}\text { Tot } \\
\text { al }\end{array}$ \\
\hline & $\begin{array}{l}\quad \text { Participació } \\
\text { n en el } \\
\text { mercado }\end{array}$ & Grande & 1 & 2 & 3 & 4 & 5 & 6 & Pequeña & -1 \\
\hline ? & $\begin{array}{l}\text { Calidad del } \\
\text { producto }\end{array}$ & Superior & 1 & 2 & 3 & 4 & 5 & 6 & Inferior & -1 \\
\hline 3 & $\begin{array}{l}\text { Ciclo de } \\
\text { vida del } \\
\text { producto }\end{array}$ & Temprano & 1 & 2 & 3 & 4 & 5 & 6 & $\begin{array}{l}\text { Avanza } \\
\text { do }\end{array}$ & -2 \\
\hline 4 & $\begin{array}{l}\text { Lealtad del } \\
\text { consumidor }\end{array}$ & Alta & 1 & 2 & 3 & 4 & 5 & 6 & Baja & -2 \\
\hline 5 & $\begin{array}{l}\text { Conocimien } \\
\text { to tecnológico }\end{array}$ & Alto & 1 & 2 & 3 & 4 & 5 & 6 & Bajo & -1 \\
\hline 5 & $\begin{array}{l}\text { Integración } \\
\text { vertical }\end{array}$ & Alta & 1 & 2 & 3 & 4 & 5 & 6 & Baja & -5 \\
\hline 7 & Velocidad & Rápida & 1 & 2 & 3 & 4 & 5 & 6 & Lenta & -6 \\
\hline & & Promedio & 2.5 & & & & & & Suma & -18 \\
\hline
\end{tabular}




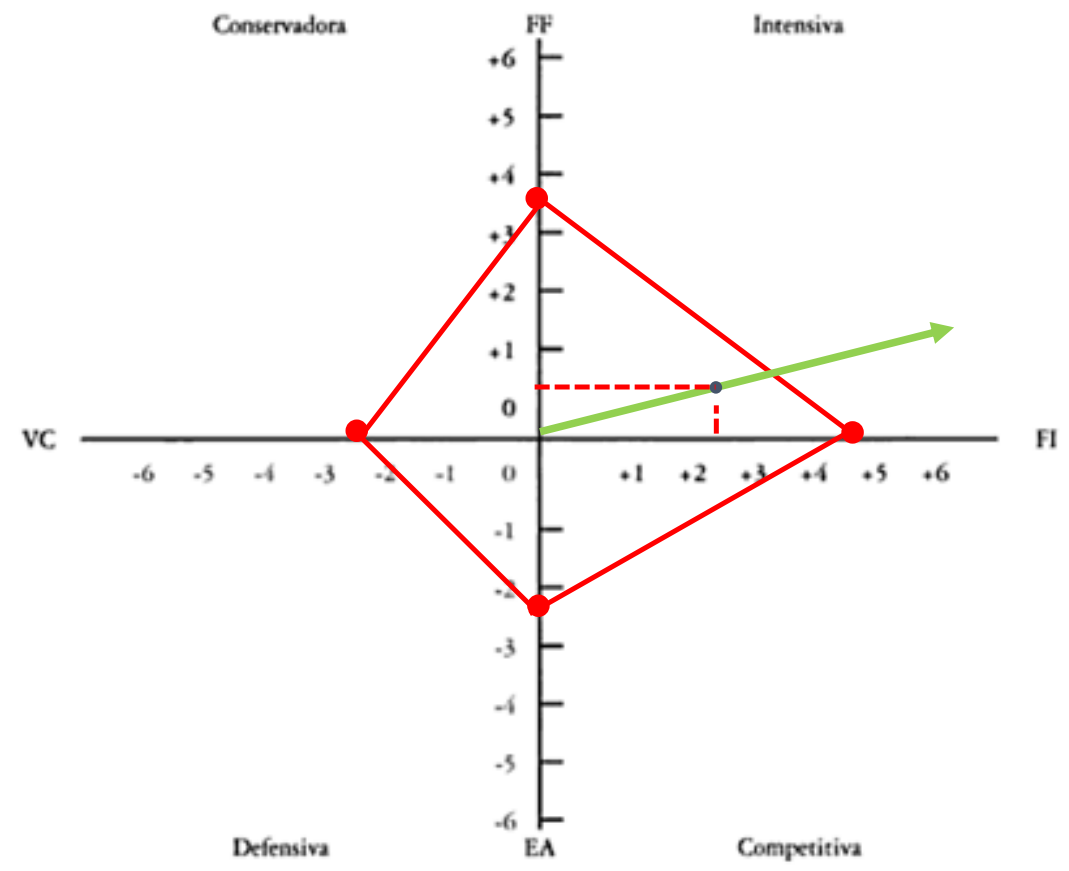

Figura 28. Resultado de la matriz PEYEA

\begin{tabular}{|c|c|c|c|}
\hline \multirow{2}{*}{ Eje } & FI & 4.78 & \multirow{2}{*}{2.21} \\
\cline { 2 - 3 } $\mathrm{X}$ & $\mathrm{VC}$ & - & \\
\hline \multirow{2}{*}{ Eje } & FF & 3.44 & \\
\cline { 2 - 3 } $\mathrm{Y}$ & EA & - & \multirow{2}{*}{0.57} \\
\cline { 2 - 4 } & & 2.88 & \\
\hline
\end{tabular}

Figura28. Coordenada de la matriz PEYEA. 
En base al polígono conformado por los puntajes obtenidos para cada factor, se puede concluir:

- Muy buena fuerza de la industria

- Muy buena ventaja competitiva

- Muy buena estabilidad del entorno

- Moderada fuerza financiera

De esta manera, de acuerdo con la propuesta teórica, a la empresa Eternit le correspondería utilizar una estrategia intensiva, entre las cuales pueden estar las de penetración de mercado, el desarrollo de mercado, desarrollo de productos y la integración horizontal, para adelante o para atrás, etc. (David F. R, 2003).

Según D’alezzio Ipinza, esta postura es típica de un mercado estable de lento crecimiento, una organización que debe buscar alcanzar una estabilidad financiera y que encuentra el factor crítico en la competitividad de su producto (Fernando d’Alessio, 2008).

\subsection{Matriz Interna - Externa}

La matriz IE, es conocida como una matriz de cartera. De acuerdo a Fred David, se basa en dos dimensiones claves: los puntajes de valor totales de la matriz EFI sobre el eje x y los puntajes de valor totales de la matriz EFE en el eje y.

El puntaje total ponderado de la matriz EFI se coloca sobre el eje de las " $\mathrm{x}$ " y refleja la posición interna de la empresa:

- $\quad$ Un puntaje de 1.0 a 1.99 se considera débil

- $\quad$ Un puntaje de 2.0 a 2.99 se considera promedio

- $\quad$ Un puntaje de 3.0 a 4.0 se considera fuerte 
Por otro lado, el puntaje obtenido de la matriz EFE se colocará sobre el eje "y”, reflejando la capacidad de la división para capitalizar oportunidades y evitar amenazas:

- Un puntaje de 1.0 a 1.99 se considera bajo

- Un puntaje de 2.0 a 2.99 se considera medio

- Un puntaje de 3.0 a 4.0 se considera alto (David F. R, 2003)

La matriz IE cuenta con tres grandes grupos, con implicaciones estratégicas bastante marcadas, como son:

- Crecer y construir: celdas I, II o IV Crecer y construir

- Retener y mantener: celdas III, V o VII

- Cosechar o desinvertir: celdas VI, VIII y IX

A continuación, se muestra la matriz IE para la empresa Eternit SA, considerando los siguientes resultados presentados en las matrices EFE y EFI 
Tabla 17. Matriz IE

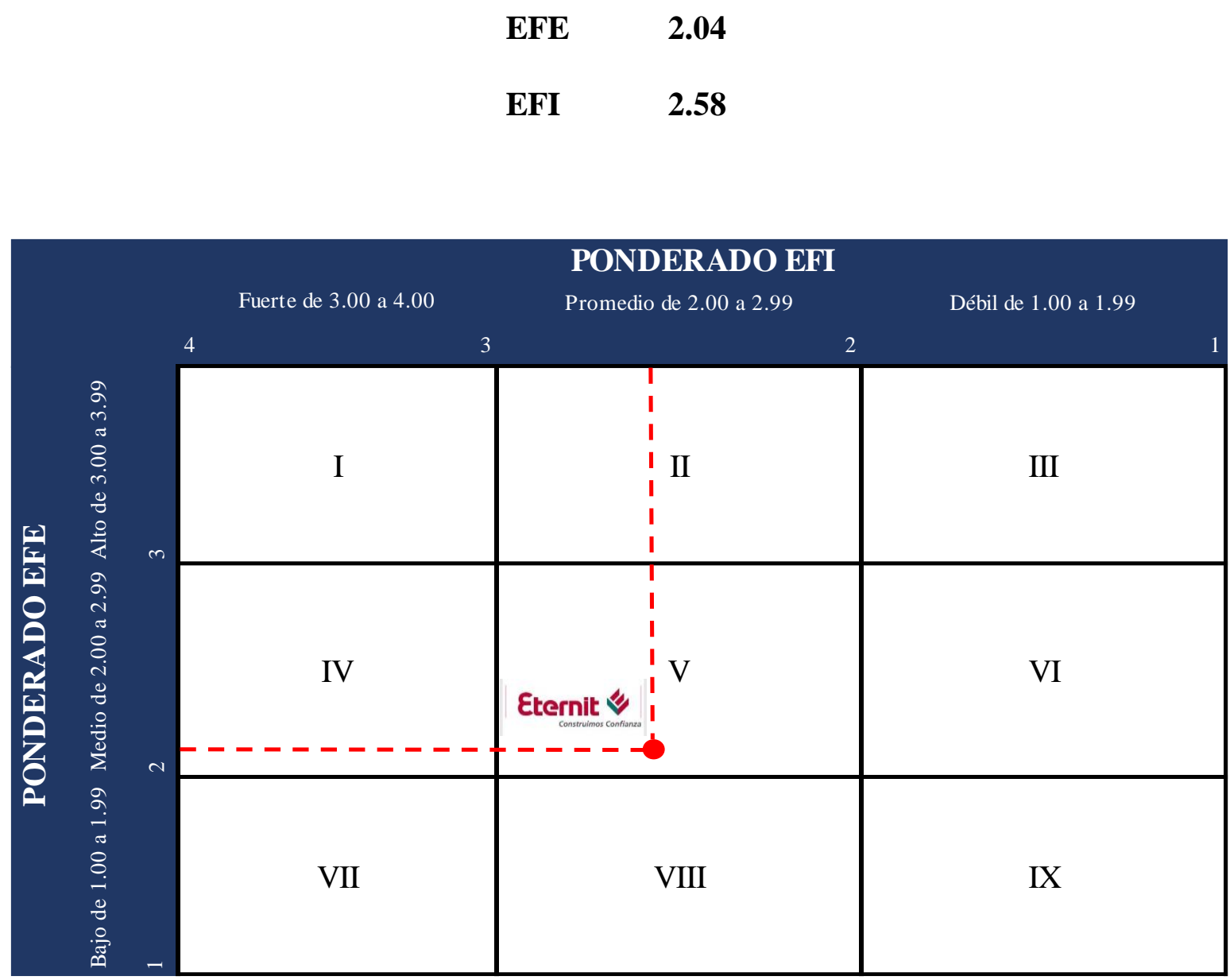

Como se puede observar en el grafico XX, la matriz IE da como resultado que la posición de Eternit se encuentra en el cuadrante V, conservar y mantener, donde las estrategias sugeridas son la penetración de mercado y/o desarrollo de producto (David. F. R, 2003).

\subsection{La matriz de la gran estrategia}

También llamada matriz de la estrategia principal, se basa en el análisis de dos dimensiones: la posición competitiva y el crecimiento del mercado. A continuación, se lista las diversas estrategias de acuerdo a la posición en el cuadrante al que pertenecen:

Cuadrante I 
1. Desarrollo de mercados

2. Penetración en el mercado

3. Desarrollo de productos

4. Integración hacia delante

5. Integración hacia atrás

6. Integración horizontal

7. Diversificación concéntrica

Cuadrante II

1. Desarrollo de mercados

2. Penetración en el mercado

3. Desarrollo de productos

4. Integración horizontal

5. Enajenación

6. Liquidación

Cuadrante III

1. Recorte de gastos

2. Diversificación concéntrica

3. Diversificación horizontal

4. Diversificación de conglomerados

5. Enajenación

6. Liquidación

Cuadrante IV

1. Diversificación concéntrica 


\section{Diversificación horizontal}

3. Diversificación de conglomerados

4. Alianzas estratégicas

De acuerdo a lo descrito líneas arriba, la empresa Eternit se encuentra dentro del cuadrante 1, considerando que la empresa es líder en el mercado, con una participación del 95\%; pero un crecimiento medio alto, tal como se ha podido advertir en los capítulos anteriores.

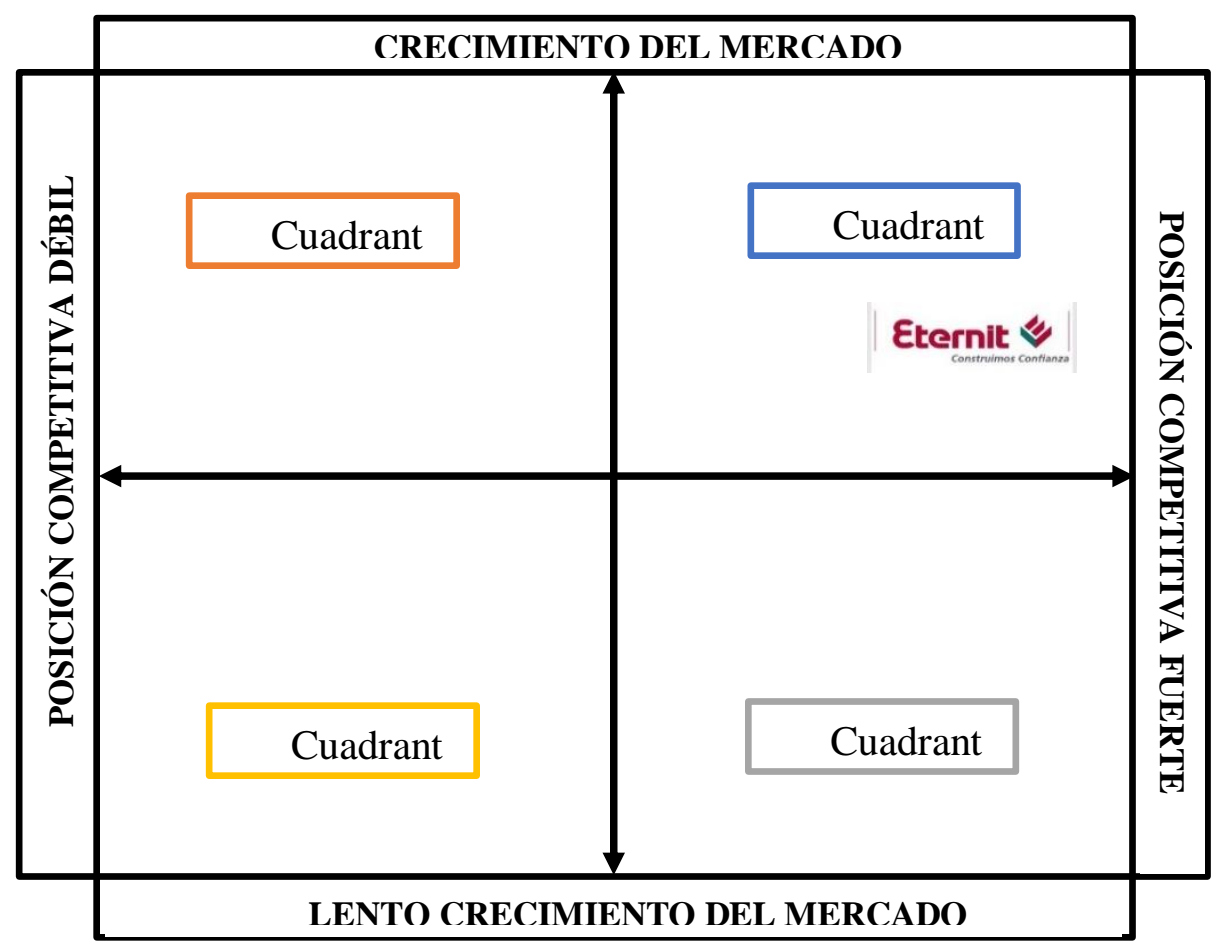

Figura 29. Resultado de la matriz Estratégica.

Ubicándose en el cuadrante 1, la empresa debería optar por una de estas cuatro estrategias: desarrollo de mercados, penetración en el mercado, desarrollo de productos, integración hacia delante, integración hacia atrás, integración horizontal, diversificación concéntrica, considerando que se tiene posición sólida en el mercado (David F. R, 2003). 


\subsection{Resumen de las Estrategias Formuladas}

En conclusión y de acuerdo con el análisis realizado a las matrices FODA, PEYEA, Matriz de la gran estrategia, Matriz Interna-Externa, se puede observar que las principales estrategias a tomar en cuenta son el desarrollo de mercado y la penetración de mercado, las cuales nos llevaran al cumplimiento de los objetivos estratégicos dentro del marco de la Visión y Misión de la compañía.

En base a esta información, las estrategias han sido convenientemente alineadas y se ha visto necesario complementarlas con un conjunto de estrategias enfocadas desde la perspectiva financiera, de clientes, de los procesos internos y de aprendizaje y crecimiento que nos permita entre otras cosas, buscar la eficiencia en el uso de recursos y la reducción de costos, que puedan soportar los flujos de inversión y efectivo que van a ser necesario para la creación y el fortalecimiento de la unidad de negocio de fibrocemento. 


\section{Capítulo VIII. Selección de la Estrategia}

El siguiente capítulo buscará seleccionar la mejor estrategia aplicando el método de factores estratégicos claves y la matriz de planeación estratégica cuantitativa.

\subsection{Método factores estratégicos claves}

El método de factores estratégicos claves consiste en seleccionar una estrategia acorde con factores que nos permitan tener una ventaja competitiva en el mercado. Los criterios por manejar pueden ser cuantitativos como capacidad de abastecimiento, participación del mercado. También puede ser cualitativos como marca reconocida y experiencia.

\subsubsection{Criterios de selección}

Para seleccionar la mejor estrategia, se ha considerado los siguientes criterios de decisión basado en los factores críticos de la unidad de fibrocemento de éxito de la empresa, analizada en capítulos anteriores.

Tabla 18. Criterios de selección

\begin{tabular}{|l|c|}
\hline CRITERIOS DE DECISION & PESO \\
\hline Fabricación Local & $17 \%$ \\
\hline Capacidad de abastecimiento & $17 \%$ \\
\hline Participación de mercado & $17 \%$ \\
\hline Posicionamiento & $17 \%$ \\
\hline Marca reconocida & $16 \%$ \\
\hline Know How de la Empresa & $16 \%$ \\
\hline Total & $\mathbf{1 0 0 \%}$ \\
\hline
\end{tabular}




\subsubsection{Matriz de selección}

La elección de la mejor estrategia involucra el análisis de la alternativa más beneficioso para la empresa según fortalezas y oportunidades que se han examinado en capítulos anteriores.

Para la elaboración de la matriz de selección de la estrategia por el método de factores estratégicos claves, se coloca horizontalmente en la matriz los factores críticos de éxito para la empresa descrita en el punto 8.1.1.

En la parte vertical de la matriz se coloca las tres estrategias seleccionadas en el capítulo anterior: penetración de mercado, desarrollo de producto y desarrollo de mercado.

Luego se califica cada estrategia en función a los factores estratégicos claves, que nos permitirá al final obtener una puntuación que permite corroborar cuál de las estrategias opcionales es mejor. La valoración para la calificación considera una escala del 1 al 5; en donde 1 es muy débil y 5 representa muy fuerte.

Tabla 19. Matriz de selección.

\begin{tabular}{|l|c|c|c|c|c|}
\hline \multirow{2}{*}{$\begin{array}{l}\text { CRITERIOS DE } \\
\text { DECISIÓN }\end{array}$} & \multirow{2}{*}{ PESO } & \multicolumn{2}{|c|}{ ESTRATEGIA 1 } & \multicolumn{2}{c|}{ ESTRATEGIA 2 } \\
\cline { 3 - 6 } & & Penetración Mercado & \multicolumn{2}{c|}{ Desarrollo Mercado } \\
\cline { 3 - 6 } & $17 \%$ & 5 & 0.85 & 3 & 0.51 \\
\hline Fabricación Local & $17 \%$ & 5 & 0.85 & 5 & 0.85 \\
\hline $\begin{array}{l}\text { Capacidad de } \\
\text { abastecimiento }\end{array}$ & & & & & 0.34 \\
\hline Participación de & $17 \%$ & 4 & 0.68 & 2 & \\
\hline mercado & & & & & Punt. \\
\hline
\end{tabular}




\begin{tabular}{|l|c|c|c|c|c|} 
Posicionamiento & $17 \%$ & 4 & 0.68 & 2 & 0.34 \\
\hline Marca reconocida & $16 \%$ & 5 & 0.8 & 2 & 0.32 \\
\hline Know How de la & $16 \%$ & 4 & 0.64 & 5 & 0.8 \\
Empresa & & & & & $\mathbf{3 . 1 6}$ \\
\hline \multicolumn{1}{|c|}{ Total } & $\mathbf{1 0 0 \%}$ & - & $\mathbf{4 . 5}$ & - & \\
\hline
\end{tabular}

La estrategia más atractiva es la que tiene mejor calificación: PENETRACIÓN DE

\section{MERCADO, con un puntaje ponderado de 4.5.}

\subsection{Matriz de planeación estratégica cuantitativa (MPEC) del plan de negocios}

"La matriz de planeación estratégica cuantitativa del plan de negocios es una herramienta que permite a los estrategas evaluar alternativas de estrategias con objetividad, con base en los factores de éxito crítico, tanto externos como internos, identificados con anterioridad". (Fred R. David, 2003, p. 216)

La columna izquierda de la matriz se constituye por los factores claves internos y externos, la siguiente columna considera el puntaje obtenido en la matriz EFE y EFI. La fila superior muestra las alternativas de estrategias derivadas del Capítulo VII.

Puntaje del grado de atracción (PA)

$1=\sin$ atractivo

$2=$ Algo atractivo

3 = más o menos atractivo

$4=$ muy atractivo. 
Tabla 20. Matriz MPEC.

\begin{tabular}{|c|c|c|c|c|c|}
\hline \multirow{3}{*}{ FACTORES } & \multirow{3}{*}{ VALOR } & \multicolumn{2}{|c|}{$\begin{array}{l}\text { E1: PENETRACIÓN } \\
\text { DE MERCADO }\end{array}$} & \multicolumn{2}{|c|}{$\begin{array}{l}\text { E2: DESARROLLO } \\
\text { DE MERCADO }\end{array}$} \\
\hline & & \multicolumn{2}{|c|}{$\begin{array}{l}\text { Crear de la unidad de } \\
\text { negocio de planchas planas de } \\
\text { fibrocemento }\end{array}$} & \multicolumn{2}{|c|}{$\begin{array}{l}\text { Fortalecer al equipo } \\
\text { comercial para enfocarse en el } \\
\text { nuevo mercado de la } \\
\text { reconstrucción nacional y los } \\
\text { juegos. }\end{array}$} \\
\hline & & $\mathbf{P A}$ & PTA & PA & PTA \\
\hline \multicolumn{6}{|l|}{ Oportunidades } \\
\hline $\begin{array}{c}\text { Plan integral de } \\
\text { Reconstrucción y Juegos. }\end{array}$ & 0.09 & 4 & 0.36 & 0 & 0 \\
\hline $\begin{array}{l}\quad \text { Nueva tendencia de } \\
\text { Sistemas Flexibles y } \\
\text { Modulares }\end{array}$ & 0.09 & 1 & 0.09 & 2 & 0.18 \\
\hline Fondo Mi Vivienda & 0.07 & 4 & 0.28 & 0 & 0 \\
\hline $\begin{array}{l}\text { Déficit de Vivienda en el } \\
\text { País }\end{array}$ & 0.07 & 4 & 0.28 & 0 & 0 \\
\hline $\begin{array}{c}\text { Programas Nacionales } \\
\text { de Construcción Sostenible }\end{array}$ & 0.07 & 4 & 0.28 & 0 & 0 \\
\hline $\begin{array}{c}\text { Cuidado del medio } \\
\text { ambiente y Sustentabilidad }\end{array}$ & 0.07 & 3 & 0.21 & 0 & 0 \\
\hline $\begin{array}{c}\text { Proyección de } \\
\text { Crecimiento de la } \\
\text { Economía Global }\end{array}$ & 0.05 & 1 & 0.05 & 3 & 0.15 \\
\hline $\begin{array}{l}\text { Nuevo Gabinete } \\
\text { Ministerial }\end{array}$ & 0.03 & 2 & 0.06 & 1 & 0.03 \\
\hline $\begin{array}{l}\text { Muerte civil a } \\
\text { funcionarios por corrupción }\end{array}$ & 0.03 & 2 & 0.06 & - & - \\
\hline $\begin{array}{l}\text { Fraccionamiento } \\
\text { especial de deudas } \\
\text { tributarias. }\end{array}$ & 0.03 & - & - & - & - \\
\hline $\begin{array}{l}\text { Nuevo régimen } \\
\text { tributario del IR para } \\
\text { MYPE }\end{array}$ & 0.03 & - & - & - & - \\
\hline $\begin{array}{l}\text { Retiro del 95.5\% del } \\
\text { fondo AFP }\end{array}$ & 0.03 & 4 & 0.12 & - & - \\
\hline $\begin{array}{l}\text { Disposición del 25\% } \\
\text { AFP }\end{array}$ & 0.03 & 4 & 0.12 & - & - \\
\hline \multicolumn{6}{|l|}{ Amenazas } \\
\hline $\begin{array}{l}\text { Casos de Corrupción y } \\
\text { Censura de Ministros }\end{array}$ & 0.09 & - & - & - & - \\
\hline
\end{tabular}




\begin{tabular}{|c|c|c|c|c|c|}
$\begin{array}{c}\text { Materiales usados para } \\
\text { las paredes de las viviendas } \\
\text { en Lima Metropolitana }\end{array}$ & 0.09 & 3 & 0.27 & - & - \\
\hline $\begin{array}{c}\text { Nuevas tecnologías en } \\
\text { Materiales de Construcción }\end{array}$ & 0.09 & 2 & 0.18 & 3 & 0.27 \\
\hline $\begin{array}{c}\text { Amenaza de Conflictos } \\
\text { Bélicos }\end{array}$ & 0.01 & - & - & 2 & 0.02 \\
\hline $\begin{array}{c}\text { Infiltraciones } \\
\text { senderistas, sindicatos y } \\
\text { delincuencia en el sector } \\
\text { construcción }\end{array}$ & 0.01 & - & - & - & - \\
\hline $\begin{array}{c}\text { Amenaza de Políticas } \\
\text { proteccionistas de USA }\end{array}$ & 0.01 & - & - & 2 & 0.02 \\
\hline Riesgo cancerígeno & 0.01 & 3 & 0.03 & 3 & 0.03 \\
\hline
\end{tabular}


Tabla 21. Matriz MPEC. (Continuación)

\begin{tabular}{|c|c|c|c|c|c|}
\hline \multirow{3}{*}{ FACTORES } & \multirow{3}{*}{ VALOR } & \multicolumn{2}{|c|}{$\begin{array}{c}\text { E1: PENETRACIÓN } \\
\text { DE MERCADO }\end{array}$} & \multirow{2}{*}{\multicolumn{2}{|c|}{\begin{tabular}{l}
\multicolumn{1}{|c|}{ E2: DESARROLLO } \\
\multicolumn{1}{|c|}{ DE MERCADO } \\
\multicolumn{1}{|c}{ Fortalecer al equipo } \\
comercial para enfocarse en \\
el nuevo mercado de la \\
reconstrucción nacional y los \\
juegos.
\end{tabular}}} \\
\hline & & \multicolumn{2}{|c|}{$\begin{array}{l}\text { Crear de la unidad de } \\
\text { negocio de planchas planas } \\
\text { de fibrocemento }\end{array}$} & & \\
\hline & & PA & PTA & $\mathbf{P A}$ & PTA \\
\hline \multicolumn{6}{|l|}{ Fortalezas } \\
\hline $\begin{array}{l}\text { Marca Eternit (77 } \\
\text { años) }\end{array}$ & 0.08 & 3 & 0.24 & 3 & 0.24 \\
\hline $\begin{array}{l}\text { Know - How de la } \\
\text { Empresa }\end{array}$ & 0.08 & 3 & 0.24 & 3 & 0.24 \\
\hline $\begin{array}{l}\text { Lider del Mercado } \\
90 \% \text { de participación }\end{array}$ & 0.08 & 3 & 0.24 & 3 & 0.24 \\
\hline $\begin{array}{c}\text { Soporte Técnico } \\
\text { Regional y del Grupo }\end{array}$ & 0.04 & 3 & 0.24 & 3 & 0.12 \\
\hline $\begin{array}{c}\text { Infraestructura } \\
\text { acorde a la necesidad }\end{array}$ & 0.02 & 4 & 0.32 & 3 & 0.06 \\
\hline $\begin{array}{l}\text { Capacidad de } \\
\text { Producción }\end{array}$ & 0.04 & 4 & 0.32 & 3 & 0.12 \\
\hline $\begin{array}{l}\text { Flexibilidad de la } \\
\text { Operación }\end{array}$ & 0.04 & 2 & 0.16 & 3 & 0.12 \\
\hline $\begin{array}{l}\text { Sistema Integrado de } \\
\text { Gestión }\end{array}$ & 0.04 & 2 & 0.16 & 3 & 0.12 \\
\hline $\begin{array}{l}\text { Programa anual de } \\
\text { Mejoramiento continuo } \\
\text { y ahorros }\end{array}$ & 0.04 & 1 & 0.08 & - & - \\
\hline \begin{tabular}{l}
\multicolumn{1}{c}{ Materias primas de } \\
primera Calidad y \\
validadas por el \\
Departamento de \\
Investigación del Grupo
\end{tabular} & 0.02 & 3 & 0.24 & 3 & 0.06 \\
\hline $\begin{array}{l}\text { Respaldo Financiero } \\
\text { Internacional del Grupo } \\
\text { Etex }\end{array}$ & 0.02 & 3 & 0.24 & 3 & 0.06 \\
\hline $\begin{array}{l}\text { Plan de Capacitación } \\
\text { Establecido }\end{array}$ & 0.02 & 2 & 0.16 & 2 & 0.04 \\
\hline $\begin{array}{l}\text { Evaluación anual } \\
360^{\circ}\end{array}$ & 0.02 & 2 & 0.16 & 2 & 0.04 \\
\hline Plan de Clima Anual & 0.02 & 2 & 0.16 & 2 & 0.04 \\
\hline
\end{tabular}


Tabla 22. Matriz MPEC. (Fin)

\begin{tabular}{|c|c|c|c|c|c|}
\hline \multirow{3}{*}{ FACTORES } & \multirow{3}{*}{ VALOR } & \multicolumn{2}{|c|}{$\begin{array}{l}\text { E1: PENETRACIÓN DE } \\
\text { MERCADO }\end{array}$} & \multicolumn{2}{|c|}{$\begin{array}{l}\text { E2: DESARROLLO DE } \\
\text { MERCADO }\end{array}$} \\
\hline & & \multicolumn{2}{|c|}{$\begin{array}{l}\text { Crear de la unidad de negocio de } \\
\text { planchas planas de fibrocemento }\end{array}$} & \multicolumn{2}{|c|}{$\begin{array}{l}\text { Fortalecer al equipo comercial } \\
\text { para enfocarse en el nuevo mercado } \\
\text { de la reconstrucción nacional y los } \\
\text { juegos. }\end{array}$} \\
\hline & & PA & PTA & PA & PTA \\
\hline \multicolumn{6}{|l|}{ Debilidades } \\
\hline $\begin{array}{l}\text { Poca } \\
\text { Polivalencia de } \\
\text { Trabajadores }\end{array}$ & 0.02 & 1 & 0.08 & - & - \\
\hline $\begin{array}{r}\text { Alta necesidad } \\
\text { de Mano de Obra } \\
\end{array}$ & 0.02 & - & - & 2 & 0.04 \\
\hline \begin{tabular}{l}
\multicolumn{1}{c}{ Normas y } \\
Reglamentos de \\
trabajo muy \\
generales
\end{tabular} & 0.01 & 1 & 0.08 & 1 & 0.01 \\
\hline $\begin{array}{l}\text { Plan de } \\
\text { crecimiento no } \\
\text { establecido }\end{array}$ & 0.02 & 0 & 0 & 1 & 0.02 \\
\hline $\begin{array}{l}\text { No existe } \\
\text { diferenciación a } \\
\text { nivel operativo }\end{array}$ & 0.02 & 0 & 0 & 1 & 0.02 \\
\hline $\begin{array}{l}\text { Manipulación } \\
\text { y transporte } \\
\text { difícil }\end{array}$ & 0.03 & 0 & 0 & 2 & 0.06 \\
\hline $\begin{array}{r}\text { Dificultad de } \\
\text { almacenamiento }\end{array}$ & 0.04 & 0 & 0 & 2 & 0.08 \\
\hline $\begin{array}{l}\quad \text { No se han } \\
\text { innovado o } \\
\text { desarrollado } \\
\text { productos }\end{array}$ & 0.07 & 1 & 0.08 & 2 & 0.14 \\
\hline \begin{tabular}{l}
\multicolumn{1}{c}{ Bajo \% de } \\
utilización de \\
Equipos genera \\
incremento de \\
costos por \\
depreciación y \\
MO ociosa.
\end{tabular} & 0.06 & - & - & - & - \\
\hline \begin{tabular}{l}
\multicolumn{1}{c}{ Sistema de } \\
información \\
deficiente
\end{tabular} & 0.04 & 2 & 0.16 & 2 & 0.08 \\
\hline
\end{tabular}




\begin{tabular}{|l|c|c|c|c|c|}
\begin{tabular}{|l|l|l|l|} 
Alto nivel de \\
Stocks
\end{tabular} & 0.08 & - & - & 2 & 0.16 \\
\hline $\begin{array}{l}\text { Planificación } \\
\text { de la Producción } \\
\text { no alineada a la } \\
\text { demanda }\end{array}$ & 0.03 & 3 & 0.24 & - & - \\
\hline $\begin{array}{l}\text { Suma del } \\
\text { puntaje total del } \\
\text { grado de } \\
\text { atracción }\end{array}$ & - & - & 5.99 & - & 2.81 \\
\hline
\end{tabular}

LEYENDA: PA = puntaje del grado de atracción, $\mathrm{PTA}=$ puntaje total del grado de atracción 


\subsection{Descripción de estrategia seleccionada}

De acuerdo con la matriz de selección de factores estratégicos claves y la matriz MPEC aplicados a ETERNIT existe relación en que la mejor estrategia a tomar es penetración de mercado, la cual es acorde con los objetivos estratégicos.

Las estrategias específicas de penetración de mercado que se aplicará a la unidad de negocio de fibrocemento de ETERNIT serán:

- Creación de la unidad de negocio de planchas planas de fibrocemento.

Esta estrategia permitirá:

- Fortalecer la gestión comercial de la nueva unidad de negocio planchas planas de fibrocemento.

- Generar un plan de difusión de las ventajas del fibrocemento, externa como internamente.

- Introducir el producto en los mercados mostrándose como una alternativa para la construcción tradicional

\subsection{Descripción de estrategia contingente}

Las estrategias contingentes que se ha tomado en consideración para el plan serán:

- Fortalecer al equipo comercial para enfocarse en el nuevo mercado de la reconstrucción nacional, los juegos panamericanos y el déficit de vivienda.

Esto quiere decir aprovechar el proceso de reconstrucción nacional, toda la inversión que está haciendo el estado en la infraestructura para los juegos panamericanos, así como el déficit de vivienda que generará mayores edificaciones para introducir el producto directamente a estos nuevos mercados. 


\section{Capítulo IX. Implementación de la Estrategia}

En este capítulo se describe la estrategia seleccionada que involucra principalmente a las áreas de recursos humanos, comercial y financiera. En recursos humanos se busca el crecimiento de la empresa a través del crecimiento y formación del personal, en el área comercial uno de los objetivos es dar a conocer los beneficios que se obtienen cuando el usuario final toma la decisión de comprar fibrocemento teniendo claro la perspectiva de clientes y los procesos internos; y en el área financiera se va a ver reflejado el impacto de las estrategias a desarrollar analizando los indicadores financieros.

Para monitorear la implementación de la estrategia se usará el Cuadro de Mando Integral, Según Kaplan \& Norton (2014) el Cuadro de Mando Integral es una herramienta que permite seguir el progreso de la organización de forma estratégica, bajo cuatro perspectivas: la financiera, la de clientes, la de procesos internos y la de formación y aprendizaje.

Tomando en cuenta el marco teórico propuesto y considerando que como resultado de la evaluación de matrices del capítulo anterior se seleccionó la estrategia de penetración de Mercado, se elaboró el cuadro de mando integral teniendo en cuenta que el objetivo estratégico principal de la empresa ETERNIT es incrementar el ROE de 5\% a 13\% en cinco años. 


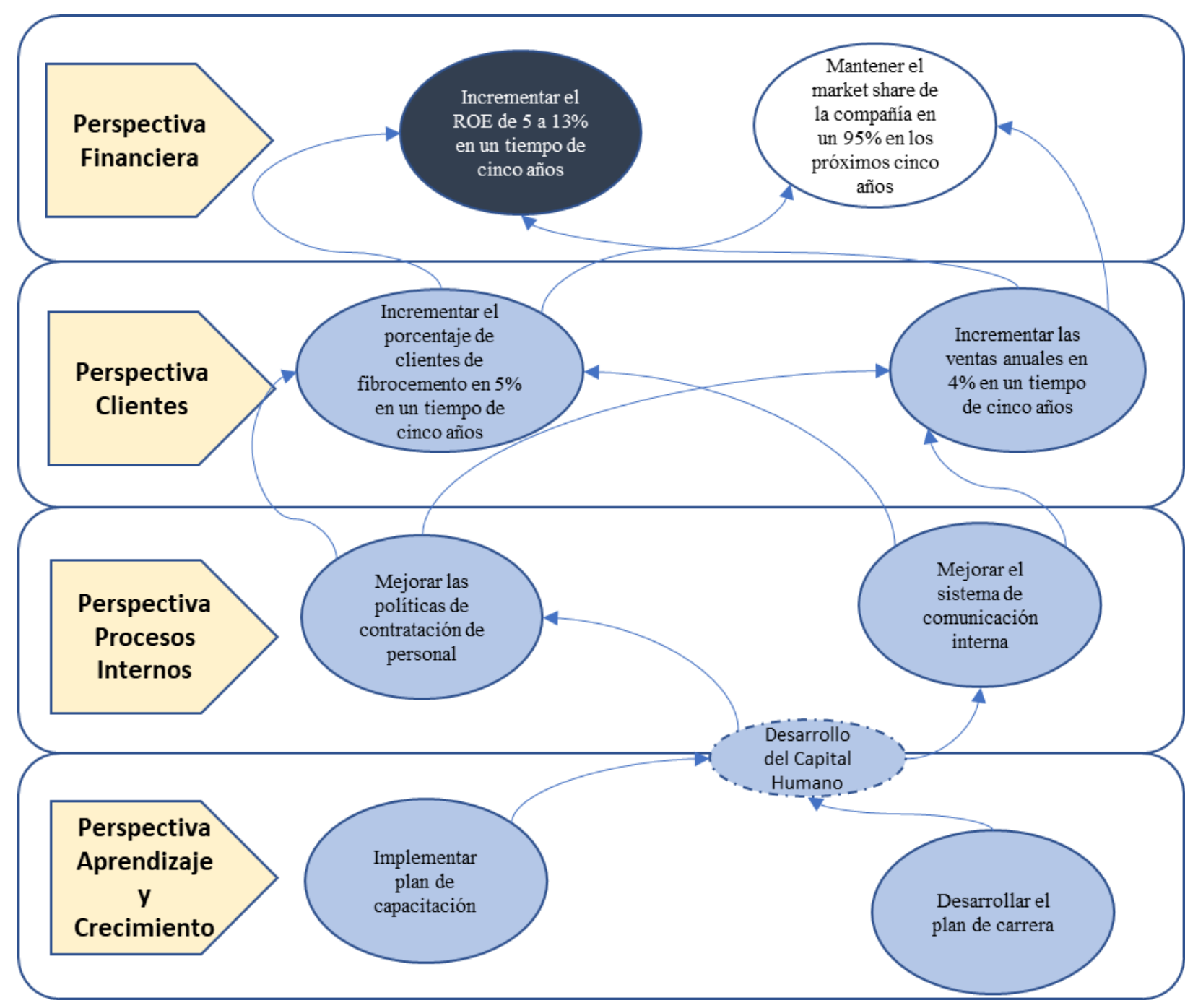

Figura 30. Mapa de estrategia ETERNIT. Adaptado de "El cuadro de mando integral" por Kaplan y Norton 2014, Ediciones Gestión 2000. Copyright 2014

Los objetivos específicos elegidos están descritos en los círculos celestes, debido a que responden a las necesidades predominantes identificadas en las matrices EFI, EFE y MPC; como también, están alineados a la estrategia seleccionada que es la penetración del mercado. Todo ello permite desarrollar el objetivo estratégico que tiene como foco principal incrementar el ROE de 5 a $13 \%$ en cinco años el cual está descrito en el círculo azul. 


\subsection{Objetivos específicos según el Mapa de Estrategia}

Según el cuadro de cuadro de mando integral se han definido los siguientes objetivos específicos por perspectiva:

Perspectiva Financiera

- Incrementar el ROE de 5\% a 13\% en un tiempo de cinco años.

- Mantener el market share de la compañía en 95\% en los próximos cinco años.

Perspectiva de Clientes

- Incrementar el porcentaje de clientes de fibrocemento en 5\% en un tiempo de cinco años.

- Incrementar las ventas anuales en $4 \%$ en un tiempo de cinco años.

Perspectiva de Procesos Internos

- Mejorar las políticas de contratación de personal.

- Mejorar el sistema de comunicación interna.

Perspectiva de Aprendizaje y crecimiento

- Implementar plan de capacitación.

- Desarrollar el plan de carrera.

\subsection{Indicadores para cada uno de los Objetivos Específicos}

En la tabla 24 se puede visualizar los indicadores de medición para cada uno de los objetivos específicos planteados. 
Tabla 23. Indicadores de medición para cada objetivo específico

Perspectiva Financiera

Objetivo Indicador

Incrementar el ROE de $5 \%$ a $13 \%$ en un tiempo de $\quad$ ROE (\%)

cinco años.

Mantener el market share de la compañía en 95\% \% market share

en los próximos cinco años

\begin{tabular}{lc}
\hline Perspectiva de Clientes & Indicador \\
\hline Objetivo & $\%$ de crecimiento \\
\hline Incrementar el porcentaje de clientes de & de clientes \\
fibrocemento en 5\% en un tiempo de cinco años & fibrocemento \\
Incrementar las ventas anuales en 4\% en un tiempo & Ventas anuales ( en \\
& \\
\hline Perspectiva de Procesos Internos & Indicador soles) \\
\hline Objetivo & Política \\
\hline Mejorar las políticas de contratación de personal. & \\
\hline
\end{tabular}


Mejorar el sistema de comunicación interna

Sistema

Implementado

\begin{tabular}{lc}
\hline Perspectiva de Aprendizaje y Crecimiento & \\
\hline Objetivo & Indicador \\
\hline Implementar plan de capacitación. & Plan de \\
& capacitación \\
Desarrollar el plan de carrera. & implementado de carrera \\
& implementado
\end{tabular}

\subsection{Metas para cada uno de los Objetivos Específicos}

De la misma forma se han definido las metas para los indicadores anteriormente descritos, las cuales se detallan en la tabla 25.

Tabla 24.

Metas para cada objetivo específico

Perspectiva financiera

\begin{tabular}{lcc}
\hline Objetivo & Indicador & Meta \\
\hline Incrementar el ROE de 5\% a 13\% en un tiempo & ROE (\%) & $13 \%$ \\
de cinco años. & & \\
Mantener el market share de la compañía en 95\% & market & $95 \%$ \\
en los próximos cinco años & share
\end{tabular}


Perspectiva de clientes

\begin{tabular}{ccc}
\hline Objetivo & Indicador & Meta \\
\hline Incrementar el porcentaje de clientes de & $\%$ de & $5 \%$ \\
fibrocemento en 5\% en un tiempo de cinco años & crecimiento & $4 \%$ \\
Incrementar las ventas anuales en 4\% en un & fibrocemento & Ventas \\
tiempo de cinco años & anuales ( en \\
& miles de \\
& soles $)$
\end{tabular}

Perspectiva de procesos internos

\begin{tabular}{lcc}
\hline Objetivo & Indicador & Meta \\
\hline Mejorar las políticas de contratación de personal. & Política & 1 \\
Mejorar el sistema de comunicación interna & Implementada & 1 \\
& Implementado & \\
\hline Perspectiva de formación y crecimiento & & \\
\hline Objetivo & Meta & \\
\hline Implementar plan de capacitación & Indicador \\
\hline
\end{tabular}


Desarrollar el plan de carrera.

Plan de

carrera

implementado

9.8 Iniciativas (acciones a llevar a cabo para cado uno de los objetivos específicos), Estrategias, Programas, Políticas, Reglas, Procedimiento

Las iniciativas para cada uno de los objetivos específicos se detallan en la tabla 26.

Tabla 25.

Iniciativa para cada objetivo específico

\begin{tabular}{ll}
\hline Perspectiva Financiera & \\
\hline Objetivos específicos & Iniciativa \\
\hline Incrementar el ROE de 5\% a 13\% & Crear una unidad de negocios de \\
en un tiempo de cinco años. & planchas planas de fibrocemento \\
Mantener el market share de la & Reforzar las relaciones comerciales con \\
compañía en 95\% en los próximos & nuestros distribuidores \\
cinco años & \\
\hline Perspectiva de clientes & Iniciativa \\
\hline Objetivos específicos & Generar un plan de difusión.
\end{tabular}

Generar un plan de difusión. 
Incrementar el porcentaje de

clientes de fibrocemento en $5 \%$ en un

tiempo de cinco años

Incrementar las ventas anuales en

Participar en proyectos de reconstrucción

$4 \%$ en un tiempo de cinco años

nacional

Perspectiva de procesos internos

\begin{tabular}{cl}
\hline Objetivos específicos & Iniciativa \\
\hline Mejorar las políticas de & Revisar los beneficios laborales. \\
contratación de personal. & Actualizar los perfiles. \\
Mejorar el sistema de & Realizar reuniones bimestrales entre \\
comunicación interna & áreas estratégicas.
\end{tabular}

Perspectiva de formación y crecimiento

Objetivos específicos Iniciativa

Implementar plan de capacitación Capacitaciones soft / hard skills

Establecer políticas sobre la línea de

Desarrollar el plan de carrera.

carrera de operarios.

\section{Iniciativas de perspectiva financiera}

Crear una unidad de negocio de planchas planas de fibrocemento

¿Qué es lo que se busca? 
- Fortalecer la gestiones operativas, comerciales y marketing de las planchas planas de fibrocemento donde tenemos un 59\% de utilización de planta

¿Cómo hacerlo?

- Contratando nuevo personal: un jefe, quien liderará a nueva unidad y se enfocará en su desarrollo; 2 staff, encargados en las ventas de los clientes pequeños como ferreterías.

Reforzar las relaciones comerciales con nuestros distribuidores.

¿Qué es lo que se busca?

- Asegurar que nuestros principales distribuidores estén alineados al plan estratégico a implantar

¿Cómo hacerlo?

- Brindando capacitación, actividades de confraternización y acompañamiento en las ventas a principales distribuidores.

\section{Iniciativas de perspectiva de clientes}

Generar un plan de difusión.

¿Qué es lo que se busca?

- Difundir los beneficios del fibrocemento por diferentes medios de comunicación, abarcando la mayor cantidad de público objetivo.

¿Cómo hacerlo?

- Publicando la página de Facebook de Eternit (ya se tiene) una publicación detallando las ventajas y bondades de las planchas planas de fibrocemento

- Realizando comerciales televisivos, 3 anuncios todos los domingos en canales de mayor sintonía

- Publicando anuncios por prensa escrita, en suplementos del Trome 
Participar en proyectos de reconstrucción nacional

¿Qué es lo que se busca?

- Asegurar la participación en la mayor cantidad de proyectos en el estado, enfocando en el trabajo de especificaciones

¿Cómo hacerlo?

- Contratando a un asesor comercial dedicado $100 \%$ a los proyectos del estado.

Iniciativas de procesos internos

Revisar los beneficios laborales.

¿Qué es lo que se busca?

- Retener a los colaboradores, por lo que se debe saber qué beneficios laborales brinda nuestros principales competidores.

¿Cómo hacerlo?

- Realizando un benchmarking.

Actualizar los perfiles.

¿Qué es lo que se busca?

- Mejorar los perfiles de contratación.

¿Cómo hacerlo?

- Contratando un consultor externo para diferenciar 3 perfiles operativos.

Realizar reuniones bimestrales entre áreas estratégicas.

¿Qué es lo que se busca?

- Asegurar el proceso de comunicación

¿Cómo hacerlo? 
- Conversando con los líderes de cada área para garantizar la asistencia y realizando cronograma de reuniones.

\section{Iniciativas de aprendizaje y crecimiento}

Generar un plan de difusión.

Realizar capacitaciones soft / hard skills

¿Qué es lo que se busca?

- Brindar capacitación acorde con la necesidades de nuestros colaboradores y tengamos un impacto positivo.

¿Cómo hacerlo?

- Levantando información con los líderes de cada área, sobre los temas requeridos como los horarios estratégicos a ser desarrollados.

Establecer políticas sobre la línea de carrera de operarios.

¿Qué es lo que se busca?

- Asegurar que nuestros colaboradores estén motivados

¿Cómo hacerlo?

- Revisando los ranks actuales y ajustarlo a los nuevos perfiles establecidos.

\subsection{Responsable de cada una de las iniciativas}

Los responsables de cada iniciativa indicada se detallan en la tabla 27.

Tabla 26.

Responsable para cada iniciativa formulada

Perspectiva financiera

Objetivo

Iniciativa

Responsables 


\begin{tabular}{lcc}
\hline Incrementar el ROE de 5\% & Crear una unidad de & Gerente \\
a 13\% en un tiempo de cinco & negocios de planchas & Comercial / \\
años. & planas de fibrocemento & Finanzas \\
Mantener el market share & Reforzar las relaciones & Gerente \\
de la compañía en 95\% en los & comerciales con nuestros & Comercial \\
próximos cinco años & distribuidores &
\end{tabular}

Perspectiva de clientes

\begin{tabular}{ccc}
\hline Objetivo & Iniciativa & Responsables \\
\hline Incrementar el porcentaje & & Gerente \\
de clientes de fibrocemento en & Generar un plan de & Comercial \\
$5 \%$ en un tiempo de cinco & difusión. & \\
años & & Gerente \\
Incrementar las ventas & Participar en proyectos & Comercial \\
anuales en $4 \%$ en un tiempo de & de reconstrucción & \\
cinco años & nacional &
\end{tabular}

Perspectiva de procesos internos

Objetivo

Iniciativa

Responsables

Mejorar las políticas de

Revisar los beneficios

Gerente de

contratación de personal.

laborales.

Compensaciones

Actualizar los perfiles.

Gerente de

RRHH 
Mejorar el sistema de

comunicación interna
Realizar reuniones

bimestrales entre áreas

estratégicas.
Gerente de

RRHH

Perspectiva de formación y crecimiento

\begin{tabular}{ccc}
\hline Objetivo & Iniciativa & Responsables \\
\hline Implementar plan de & Capacitaciones soft / & Gerente de \\
capacitación & hard skills & RRHH \\
Desarrollar el plan de & Establecer políticas & Gerente de \\
carrera. & sobre la línea de carrera & RRHH \\
& de operarios. &
\end{tabular}

\subsection{Presupuesto de cada una de las iniciativas}

Las iniciativas planteadas revisadas en las tablas anteriores deben tener un presupuesto para ser implementadas. La tabla 28 detalla el presupuesto definido para cada iniciativa 
Tabla 27. Presupuesto por cada una de las iniciativas

Iniciativa

Crear una unidad de negocio de planchas planas de

fibrocemento.

Reforzar las relaciones comerciales con nuestros

distribuidores

Generar un plan de difusión.

Participar en proyectos de reconstruccion nacional

Revisar los beneficioes laborales.

Actualizar los perfiles.

Realizar reuniones bimestrales entre áreas estratégicas.

Capacitaciones soft / hard skills

Establecer políticas sobre la línea de carrera de operarios.
Presupuesto

S/422,933.78

S/110,280.00

S/153,123.73

S/112,146.67

$\mathrm{S} / 0.00$

S/900.00

$\mathrm{S} / 0.00$

$\mathrm{S} / 11,000.00$

$\mathrm{S} / 0.00$

S/810,384.18 


\section{Capítulo X: Evaluación financiera de la empresa}

\subsection{Proyección de estados financieros (situación actual y situación con la nueva} estrategia)

Para efectos de análisis se considera los estados financieros de los años 2014 y 2015, para luego realizar la proyección para los siguientes cinco años $(2018$ - 2023).

Los estados financieros están publicados en la Superintendencia de Mercado de Valores.

\subsection{Estado de resultados - situación actual}

Como es posible observar la empresa ha pasado de un EBITDA del $9 \%$ a uno del $12 \%$ con respecto a las ventas del 2015 al 2016, lo que deja observar la mejora en la situación económica de la empresa. Esto significó un crecimiento de casi $20 \%$.

Así también el margen directo de la empresa se encuentra en 32\% al cierre del 2016, lo que refuerza la idea anterior sobre la buena situación de la empresa.

Otro punto importante para resaltar son sus ratios de rotación de cuentas por pagar y rotación de cuentas por cobrar, 160 días y 109 días respectivamente.

Además, se puede observar que, aun así, existe una caída de las ventas del 2015 al 2016, la empresa pudo contrarrestarlo con una producción más eficiente que se tradujo en un mejor margen directo y por lo tanto una mayor utilidad al final del periodo. 
Tablan 28. Estado de Ganancia y Pérdidas

Estado de ganancias y pérdidas (en miles de nuevos soles)

\begin{tabular}{|c|c|c|c|}
\hline \multirow[b]{2}{*}{ Ingresos de Actividades Ordinarias } & 2,015 & \multicolumn{2}{|l|}{2,016} \\
\hline & 259,485 & \multicolumn{2}{|l|}{236,929} \\
\hline \multirow{2}{*}{$\begin{array}{r}\text { Costo de Ventas } \\
\text { Ganancia (Pérdida) Bruta }\end{array}$} & $185,627^{-}$ & $\begin{array}{r}- \\
159,339\end{array}$ & \\
\hline & $\mathbf{7 3 , 8 5 8}$ & 77,590 & \\
\hline Gastos de Ventas y Distribución & 20,323 & 22,046 & - \\
\hline Gastos de Administración & 25,979 & 24,256 & - \\
\hline Otros Ingresos Operativos & 534 & - & \\
\hline \multirow{2}{*}{ Ganancia (Pérdida) Operativa } & 2,790 & 837 & - \\
\hline & 25,300 & 30,451 & \\
\hline \multirow{3}{*}{$\begin{array}{r}\text { Ganancia (Pérdida) por Deterioro de Valor (Pérdidas Crediticias } \\
\text { Esperadas o Reversiones) } \\
\text { Ganancia (Pérdida) antes de Impuestos }\end{array}$} & 6,141 & 6,720 & - \\
\hline & 2,665 & 1,734 & - \\
\hline & 21,824 & 21,997 & \\
\hline \multirow[t]{2}{*}{ Ingreso (Gasto) por Impuesto } & 11,029 & 12,172 & - \\
\hline & 10,795 & $\mathbf{9 , 8 2 5}$ & \\
\hline
\end{tabular}


Tabla 30. Estado de Ganancias y Pérdidas - Análisis Vertical

Estado de ganancias y pérdidas - Análisis Vertical (en miles de nuevos soles)

\begin{tabular}{|c|c|c|c|c|}
\hline CUENTA & 2,015 & Var. \% & 2,016 & Var. \% \\
\hline Ingresos de Actividades Ordinarias & 259,485 & $100.00 \%$ & 236,929 & $100.00 \%$ \\
\hline Costo de Ventas & $-185,627$ & $-71.54 \%$ & $-159,339$ & $-67.25 \%$ \\
\hline Ganancia (Pérdida) Bruta & 73,858 & $28.46 \%$ & $\mathbf{7 7 , 5 9 0}$ & $32.75 \%$ \\
\hline Gastos de Ventas y Distribución & $-20,323$ & $-7.83 \%$ & $-22,046$ & $-9.30 \%$ \\
\hline Gastos de Administración & $-25,979$ & $-10.01 \%$ & $-24,256$ & $-10.24 \%$ \\
\hline Otros Ingresos Operativos & 534 & $0.21 \%$ & - & $0.00 \%$ \\
\hline Otras Ganancias (Pérdidas) & $-2,790$ & $-1.08 \%$ & -837 & $-0.35 \%$ \\
\hline Ganancia (Pérdida) Operativa & 25,300 & $9.75 \%$ & 30,451 & $12.85 \%$ \\
\hline Gastos Financieros & $-6,141$ & $-2.37 \%$ & $-6,720$ & $-2.84 \%$ \\
\hline $\begin{array}{r}\text { Ganancia (Pérdida) por Deterioro de Valor (Pérdidas Crediticias } \\
\text { Esperadas o Reversiones) }\end{array}$ & 2,665 & $1.03 \%$ & $-1,734$ & $-0.73 \%$ \\
\hline Ganancia (Pérdida) antes de Impuestos & 21,824 & $8.41 \%$ & 21,997 & $9.28 \%$ \\
\hline Ingreso (Gasto) por Impuesto & $-11,029$ & $-4.25 \%$ & $-12,172$ & $-5.14 \%$ \\
\hline Ganancia (Pérdida) Neta de Operaciones Continuadas & 10,795 & $4.16 \%$ & 9,825 & $4.15 \%$ \\
\hline
\end{tabular}


Tabla 29. Estado de Ganancias y Pérdidas - Análisis Horizontal

Estado de ganancias y pérdidas - Análisis horizontal

\begin{tabular}{|c|c|c|c|c|}
\hline CUENTA & 2,015 & 2,016 & Var. & $\%$ \\
\hline Ingresos de Actividades Ordinarias & 259,485 & 236,929 & $-22,556$ & $-8.69 \%$ \\
\hline Costo de Ventas & $-185,627$ & $-159,339$ & 26,288 & $-14.16 \%$ \\
\hline Ganancia (Pérdida) Bruta & $\mathbf{7 3 , 8 5 8}$ & $\mathbf{7 7 , 5 9 0}$ & 3,732 & $5.05 \%$ \\
\hline Gastos de Ventas y Distribución & $-20,323$ & $-22,046$ & $-1,723$ & $8.48 \%$ \\
\hline Gastos de Administración & $-25,979$ & $-24,256$ & 1,723 & $-6.63 \%$ \\
\hline Otros Ingresos Operativos & 534 & - & -534 & $100.00 \%$ \\
\hline Otras Ganancias (Pérdidas) & $-2,790$ & -837 & 1,953 & $-70.00 \%$ \\
\hline Ganancia (Pérdida) Operativa & 25,300 & 30,451 & 5,151 & $20.36 \%$ \\
\hline Gastos Financieros & $-6,141$ & $-6,720$ & -579 & $9.43 \%$ \\
\hline $\begin{array}{r}\text { Ganancia (Pérdida) por Deterioro de Valor (Pérdidas Crediticias } \\
\text { Esperadas o Reversiones) }\end{array}$ & 2,665 & $-1,734$ & $-4,399$ & $165.07 \%$ \\
\hline Ganancia (Pérdida) antes de Impuestos & 21,824 & 21,997 & 173 & $0.79 \%$ \\
\hline Ingreso (Gasto) por Impuesto & $-11,029$ & $-12,172$ & $-1,143$ & $10.36 \%$ \\
\hline Ganancia (Pérdida) Neta de Operaciones Continuadas & 10,795 & $\mathbf{9 , 8 2 5}$ & -970 & $-8.99 \%$ \\
\hline
\end{tabular}




\subsection{Balance General - situación actual}

De esta información podemos observar que la razón corriente se ha reducido del 2015 al 2016 , al igual que la prueba acida, lo que muestra que la empresa ha reducido su liquidez en el último año, producto de una reducción de su cuenta de efectivo principalmente por una reducción de las ventas.

Por otro lado, vemos que el índice de rotación de las cuentas por cobrar es menor al de cuentas por pagar, lo cual es lo normal. La empresa recibe los pagos al día 109 debiendo de pagar 50 días después.

La ratio de endeudamiento muestra que la empresa ha elevado su nivel de endeudamiento a corto plazo y reducido su deuda a largo plazo, lo cual aunado a su reducción de del índice de liquidez se podría convertir en un problema en el futuro. 
Tabla 30. Balance General

Balance General (en miles de nuevos soles)

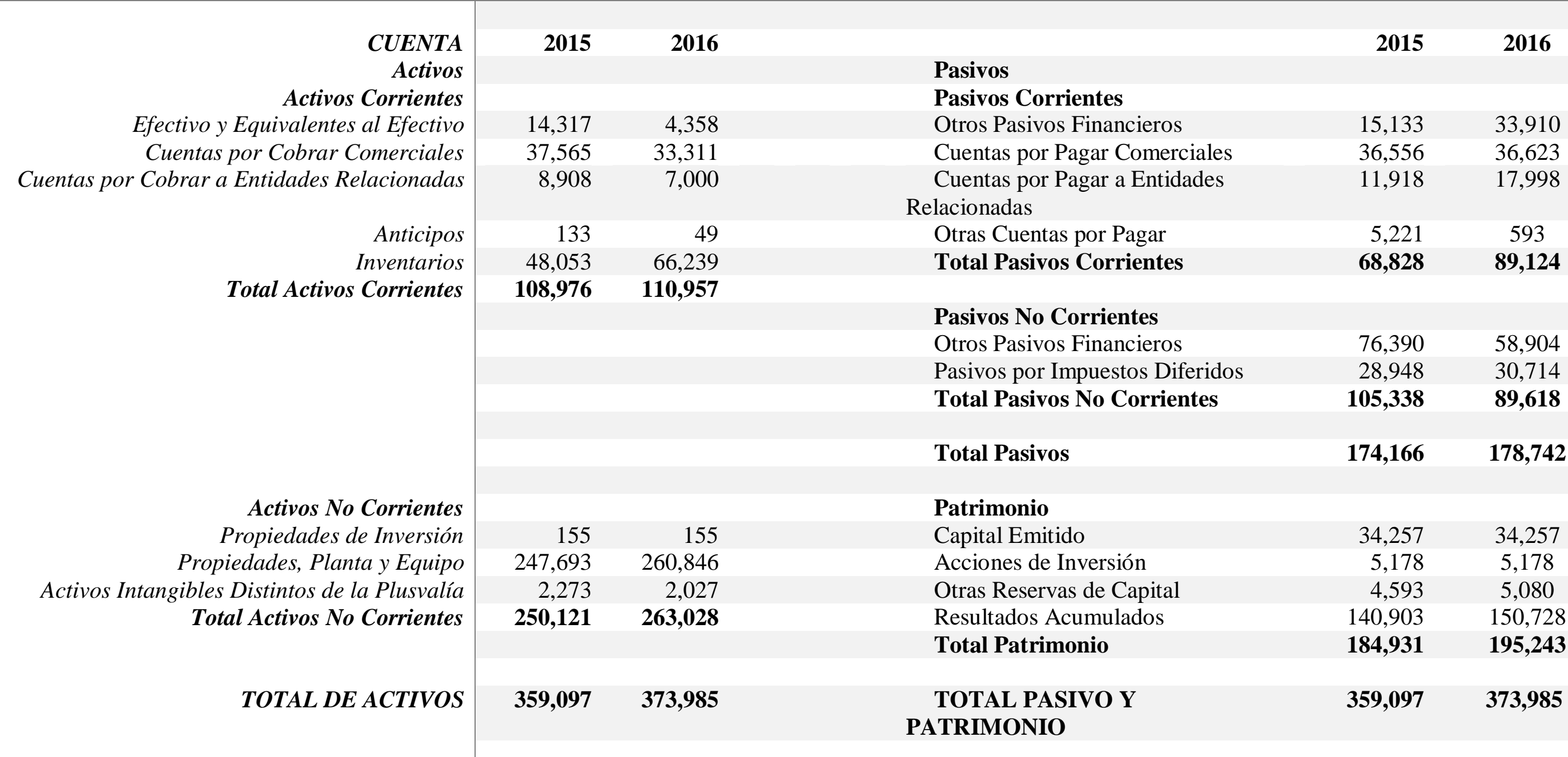


Tabla 31. Balance General - Análisis Vertical

\section{BALANCE GENERAL - ANALISIS VERTICAL ( en miles de nuevos soles)}

$\begin{array}{lrrrr}\text { CUENTA } & \mathbf{2 0 1 5} \% & \mathbf{2 0 1 6} \% \\ \text { Activos } & & & & \\ \text { Activos Corrientes } & & & & \\ \text { Efectivo y Equivalentes al Efectivo } & 14,317 & 3.99 \% & 4,358 & 1.17 \% \\ \text { Cuentas por Cobrar Comerciales } & 37,565 & 10.46 \% & 33,311 & 8.91 \% \\ \text { Cuentas por Cobrar a Entidades } & 8,908 & 2.48 \% & 7,000 & 1.87 \% \\ \text { Anticipos } & 133 & 0.04 \% & 49 & 0.01 \% \\ \text { Inventarios } & 48,053 & 13.38 \% & 66,239 & 17.71 \% \\ \text { Total Activos Corrientes } & \mathbf{1 0 8 , 9 7 6} & 30.35 \% & \mathbf{1 1 0 , 9 5 7} & 29.67 \%\end{array}$

Activos No Corrientes

Propiedades de Inversión

Propiedades, Planta y Equipo

Activos Intangibles Distintos de la

$\begin{array}{rrrr}155 & 0.04 \% & 155 & 0.04 \% \\ 247,693 & 68.98 \% & 260,846 & 69.75 \% \\ 2,273 & 0.63 \% & 2,027 & 0.54 \% \\ \mathbf{2 5 0 , 1 2 1} & 69.65 \% & \mathbf{2 6 3 , 0 2 8} & 70.33 \%\end{array}$

\section{Pasivos}

$2015 \%$

$2016 \%$

Total Activos No Corrientes

\section{Pasivos Corrientes}

$\begin{array}{lllll}\text { Otros Pasivos Financieros } & 15,133 & 4.21 \% & 33,910 & 9.07 \%\end{array}$

Cuentas por Pagar a

Otras Cuentas por Pagar

36,556

$10.18 \%$

36,623

17,998

Total Pasivos

5,221

$3.32 \%$

593

68,828

$19.17 \%$

89,124

$0.16 \%$

Pasivos No Corrientes

Otros Pasivos Financieros

Pasivos por Impuestos

Total Pasivos No

$\begin{array}{rrrr}76,390 & 21.27 \% & 58,904 & 15.75 \% \\ 28,948 & 8.06 \% & 30,714 & 8.21 \% \\ \mathbf{1 0 5 , 3 3 8} & 29.33 \% & \mathbf{8 9 , 6 1 8} & 23.96 \% \\ & & & \\ \mathbf{1 7 4 , 1 6 6} & 48.50 \% & \mathbf{1 7 8 , 7 4 2} & 47.79 \%\end{array}$

\section{Total Pasivos}

174,166

$48.50 \%$

$4.79 \%$

\section{Patrimonio}

Capital Emitido

$$
\begin{array}{llll}
34,257 & 9.54 \% & 34,257 & 9.16 \%
\end{array}
$$

$\begin{array}{lllll}\text { Acciones de Inversión } & 5,178 & 1.44 \% & 5,178 & 1.38 \%\end{array}$

$\begin{array}{llll}\text { Otras Reservas de Capital } \quad 4,593 \quad 1.28 \% & 5,080 \quad 1.36 \%\end{array}$

Resultados Acumulados $\quad 140,903 \quad 39.24 \% \quad 150,728 \quad 40.30 \%$

$\begin{array}{lllll}\text { Total Patrimonio } & \mathbf{1 8 4 , 9 3 1} & 51.50 \% & \mathbf{1 9 5 , 2 4 3} & 52.21 \%\end{array}$

TOTAL PASIVO Y

$\mathbf{3 5 9 , 0 9 7} 100.00 \%$

373,985 
Tabla 32. Balance General - Análisis Horizonta

\section{BALANCE GENERAL ( en miles de nuevos soles)}

\section{CUENTA}

Activos

\section{Activos Corrientes}

Efectivo y Equivalentes al Efectivo

Cuentas por Cobrar Comerciales

Cuentas por Cobrar a Entidades Relacionadas

Anticipos

Inventarios

Total Activos Corrientes

Activos No Corrientes

Propiedades de Inversión

Propiedades, Planta y Equipo

Activos Intangibles Distintos de la Plusvalía

Total Activos No Corrientes

\begin{tabular}{rrrr}
155 & 155 & 0 & $0.00 \%$ \\
247,693 & 260,846 & 13,153 & $5.30 \%$ \\
2,273 & 2,027 & -246 & $-10.80 \%$ \\
\cline { 1 - 2 } $\mathbf{2 5 0 , 1 2 1}$ & $\mathbf{2 6 3 , 0 2 8}$ & 12,907 & $5.20 \%$
\end{tabular}

$\begin{array}{llll}14,317 & 4,358 & -9,959 & -69.60 \%\end{array}$

$37,565 \quad 33,311-4,254-11.30 \%$

$\begin{array}{lllll}8,908 & 7,000 & -1,908 & -21.40 \%\end{array}$

$133 \quad 49 \quad-84 \quad-63.20 \%$

$\begin{array}{llll}48,053 & 66,239 & 18,186 \quad 37.80 \%\end{array}$

$\begin{array}{llll}\mathbf{1 0 8 , 9 7 6} & \mathbf{1 1 0}, 957 & 1,981 & 1.80 \%\end{array}$

\begin{abstract}
20152016 Var. \%
\end{abstract}
Pasivos

Pasivos Corrientes

Otros Pasivos Financieros

Cuentas por Pagar Comerciales

Cuentas por Pagar a Entidades Relacionadas

Otras Cuentas por Pagar

Total Pasivos Corrientes

\section{Pasivos No Corrientes}

Otros Pasivos Financieros

Pasivos por Impuestos Diferidos

Total Pasivos No Corrientes

\section{Total Pasivos}

\section{Patrim onio}

Capital Emitido

Acciones de Inversión

Otras Reservas de Capital

Resultados Acumulados

Total Patrimonio
20152016 Var. \%

\begin{tabular}{rrrr}
15,133 & 33,910 & 18,777 & $124.10 \%$ \\
36,556 & 36,623 & 67 & $0.20 \%$ \\
11,918 & 17,998 & 6,080 & $51.00 \%$ \\
5,221 & 593 & $-4,628$ & $-88.60 \%$ \\
\cline { 1 - 2 } $\mathbf{6 8 , 8 2 8}$ & $\mathbf{8 9 , 1 2 4}$ & 20,296 & $29.50 \%$
\end{tabular}

$\begin{array}{llll}76,390 & 58,904 & -17,486 & -22.90 \%\end{array}$

$\begin{array}{llll}28,948 & 30,714 & 1,766 & 6.10 \%\end{array}$

$\begin{array}{llll}\mathbf{1 0 5 , 3 3 8} & \mathbf{8 9 , 6 1 8} & -15,720 & -14.90 \%\end{array}$

$\begin{array}{llll}\mathbf{1 7 4}, 166 & \mathbf{1 7 8}, \mathbf{7 4 2} \quad 4,576 \quad 2.60 \%\end{array}$

\begin{tabular}{rrrr}
34,257 & 34,257 & 0 & $0.00 \%$ \\
5,178 & 5,178 & 0 & $0.00 \%$ \\
4,593 & 5,080 & 487 & $10.60 \%$ \\
140,903 & 150,728 & 9,825 & $7.00 \%$ \\
\cline { 1 - 2 } $\mathbf{1 8 4 , 9 3 1}$ & $\mathbf{1 9 5 , 2 4 3}$ & 10,312 & $5.60 \%$
\end{tabular}

$359,097 \quad 373,985 \quad 14,888 \quad 4.10 \%$ 


\subsection{Flujo de efectivo - situación actual}

Se puede notar que en el 2015 hubo un déficit de efectivo, el cual se tuvo que contrarrestar con un préstamo en el periodo por 75 millones, lo que significó una inyección de efectivo para la empresa bastante sustancial para la empresa, colocándola en una buena posición para los próximos años.

Además, se puede notar que la empresa tiene una constante compra de plantas y/o equipos, ya que considera un egreso regular del 22.5 millones de soles anuales. 
Tabla 33 Flujo de efectivo

FLUJO DE EIFECTIVO (en miles de nuevos soles)

\section{CUENTA}

Venta de Bienes y Prestación de Servicios

Otros Cobros de Efectivo Relativos a las Actividades de Operación

Proveedores de Bienes y Servicios

Pagos a y por Cuenta de los Empleados

Otros Pagos de Efectivo Relativos a las Actividades de Operación

Flujos de Efectivo y Equivalente al Efectivo procedente de (utilizados en) Operaciones

250,083

125
218,237

$-33,457$

$-3,916$

243,165

Intereses Pagados (no incluidos en la Actividad de Financiación)

Impuestos a las Ganancias (Pagados) Reembolsados

$-5,402$

$-175,929$

$-38,989$

$-1,513$

$-6,141$

26,734

$-8,306$

$-6,531$

Flujos de Efectivo y Equivalente al Efectivo procedente de (utilizados en) Actividades de Operación

$-19,849$

Venta de Propiedades, Planta y Equipo

Compra de Propiedades, Planta y Equipo

Compra de Activos Intangibles

$-92$

Flujos de Efectivo y Equivalente al Efectivo procedente de (utilizados en) Actividades de Inversión

$-22,861$

Obtención de Préstamos

Amortización o Pago de Préstamos

Dividendos Pagados

75,000

$-19,807$

Flujos de Efectivo y Equivalente al Efectivo procedente de (utilizados en) Actividades de Financiación

55,184

$-7,403$

Aumento (Disminución) Neto de Efectivo y Equivalente al Efectivo, antes de las Variaciones en las Tasas de Cambio

12,474

12,474

Aumento (Disminución) Neto de Efectivo y Equivalente al Efectivo

$\mathbf{1 , 8 4 3}$

Efectivo y Equivalente al Efectivo al Inicio del Ejercicio

14,317 
Tabla 34. Flujo de efectivo - Análisis Horizontal

FLUJO DE EFECTIVO - ANÁLISIS HORIZONTAL (en miles de nuevos soles)

\section{CUENTA}

Venta de Bienes y Prestación de Servicios

Otros Cobros de Efectivo Relativos a las Actividades de Operación

Proveedores de Bienes y Servicios

Pagos a y por Cuenta de los Empleados

Otros Pagos de Efectivo Relativos a las Actividades de Operación

Flujos de Efectivo y Equivalente al Efectivo procedente de (utilizados en) Operaciones

Intereses Pagados (no incluidos en la Actividad de Financiación)

Impuestos a las Ganancias (Pagados) Reembolsados

Flujos de Efectivo y Equivalente al Efectivo procedente de (utilizados en) Actividades de Operación

Venta de Propiedades, Planta y Equipo

Compra de Propiedades, Planta y Equipo

Compra de Activos Intangibles

\section{Flujos de Efectivo y Equivalente al Efectivo procedente de (utilizados en) Actividades de Inversión}

Obtención de Préstamos

Amortización o Pago de Préstamos

Dividendos Pagados

\section{Flujos de Efectivo y Equivalente al Efectivo procedente de (utilizados en) Actividades de Financiación}

Aumento (Disminución) Neto de Efectivo y Equivalente al Efectivo, antes de las Variaciones en las Tasas de Cambio

Aumento (Disminución) Neto de Efectivo y Equivalente al Efectivo

\begin{tabular}{|c|c|c|c|}
\hline 2015 & 2016 & Var. & $\%$ \\
\hline 250,083 & 243,165 & $-6,918$ & $-2.77 \%$ \\
\hline 125 & 0 & -125 & $-100.00 \%$ \\
\hline$-218,237$ & $-175,929$ & 42,308 & $-19.39 \%$ \\
\hline$-33,457$ & $-38,989$ & $-5,532$ & $16.53 \%$ \\
\hline$-3,916$ & $-1,513$ & 2,403 & $-61.36 \%$ \\
\hline$-5,402$ & 26,734 & 32,136 & $-594.89 \%$ \\
\hline$-6,141$ & $-6,531$ & -390 & $6.35 \%$ \\
\hline$-8,306$ & $-7,403$ & 903 & $-10.87 \%$ \\
\hline$-19,849$ & 12,800 & 32,649 & $-164.49 \%$ \\
\hline o & 48 & 48 & \\
\hline$-22,769$ & $-23,568$ & -799 & $3.51 \%$ \\
\hline-92 & o & 92 & $-100.00 \%$ \\
\hline$-22,861$ & $-23,520$ & -659 & $2.88 \%$ \\
\hline 75,000 & 16,000 & $-59,000$ & $-78.67 \%$ \\
\hline$-19,807$ & $-15,234$ & 4,573 & $-23.09 \%$ \\
\hline-9 & -5 & 4 & $-44.44 \%$ \\
\hline 55,184 & 761 & $-54,423$ & $-98.62 \%$ \\
\hline 12,474 & $-9,959$ & $-22,433$ & $-179.84 \%$ \\
\hline 12,474 & $-9,959$ & $-22,433$ & $-179.84 \%$ \\
\hline 1,843 & 14,317 & 12,474 & $676.83 \%$ \\
\hline 14,317 & 4,358 & $-9,959$ & $-69.56 \%$ \\
\hline
\end{tabular}

Efectivo y Equivalente al Efectivo al Finalizar el Ejercicio

14,317

$-69.56 \%$ 


\subsection{Proyección de Flujos - sin estrategia}

Para la proyección de flujos sin estrategia se han considerado las siguientes condiciones:

1. Para la proyección de las ventas, se toma la ratio de cuentas por cobrar de 109 días, dispuesto por la empresa. Además, la empresa establece un crecimiento anual de las ventas del $2.5 \%$.

2. Se asume que la empresa mantiene la proporción promedio de los costos de ventas a lo largo de los 5 años, considerando una mejora en la eficiencia del uso de los recursos del $2.5 \%$ anual, dato que está establecido como objetivo institucional en la empresa.

3. El margen bruto de utilidad crece a una tasa de $3.5 \%$

4. Para proyectar el pago de proveedores se utilizará la ratio de 160 días para la rotación de cuentas por pagar.

5. Los rubros de pagos a empleados, obtención de préstamos y amortización de préstamos se proyectarán con un crecimiento en función a la inflación $(2.6 \%)$

6. Se puede observar que los intereses pagados crecen un $6 \%$ en función al año anterior, por lo que se mantendrá esa tasa para la proyección.

7. Los rubros de los impuestos a las ganancias (3\%) y Compra de propiedades (10\%) representan un porcentaje estable de las ventas en años anteriores por lo que se utilizará el promedio de estos.

8. Para los dividendos pagados se utilizará el monto promedio de los años anteriores. 
Tabla 35. Proyección de flujo de caja proyectado sin estrategia

\begin{tabular}{|c|c|c|c|c|c|c|}
\hline \multicolumn{7}{|l|}{ FABRICA PERUANA ETERNIT S.A. } \\
\hline \multicolumn{7}{|c|}{ ESTADOS FINANCIEROS |Individual | Anual al 31 de Diciembre del 2016 (en miles de NUEVOS SOLES) } \\
\hline CUENTA & 2018 & 2019 & 2020 & 2021 & 2022 & 2023 \\
\hline Flujo de Efectivo de Actividades de Operación & 254,994 & 261,369 & 267,903 & 274,601 & 281,466 & 288,503 \\
\hline Venta de Bienes y Prestación de Servicios & 253,137 & 259,466 & 265,952 & 272,601 & 279,416 & 286,401 \\
\hline Proveedores de Bienes y Servicios & $-172,145$ & $-173,005$ & $-173,076$ & $-173,096$ & $-173,547$ & $-174,804$ \\
\hline Pagos a y por Cuenta de los Empleados & $-41,043$ & $-42,110$ & $-43,205$ & $-44,328$ & $-45,481$ & $-46,663$ \\
\hline Otros Pagos de Efectivo Relativos a las Actividades de Operación & $-2,769$ & $-2,839$ & $-2,910$ & $-2,982$ & $-3,057$ & $-3,133$ \\
\hline Flujos de Efectivo y Equivalente al Efectivo procedente de (utilizads & 37,180 & 41,512 & 46,762 & 52,194 & 57,332 & 61,801 \\
\hline Intereses Pagados (no incluidos en la Actividad de Financiación) & $-7,338$ & $-7,779$ & $-8,245$ & $-8,740$ & $-9,264$ & $-9,820$ \\
\hline Impuestos a las Ganancias (Pagados) Reembolsados & $-8,057$ & $-8,258$ & $-8,465$ & $-8,677$ & $-8,893$ & $-9,116$ \\
\hline Flujos de Efectivo y Equivalente al Efectivo procedente de (utilizade & 21,785 & 25,475 & 30,052 & 34,778 & 39,174 & 42,865 \\
\hline Compra de Propiedades, Planta y Equipo & $-23,791$ & $-24,386$ & $-24,995$ & $-25,620$ & $-26,261$ & $-26,917$ \\
\hline Flujos de Efectivo y Equivalente al Efectivo procedente de (utilizade & $-23,791$ & $-24,386$ & $-24,995$ & $-25,620$ & $-26,261$ & $-26,917$ \\
\hline Obtención de Préstamos & 16,843 & 17,281 & 17,730 & 18,191 & 18,664 & 19,149 \\
\hline Amortización o Pago de Préstamos & $-16,036$ & $-16,453$ & $-16,881$ & $-17,320$ & $-17,770$ & $-18,232$ \\
\hline Dividendos Pagados & -7 & -7 & -7 & -7 & -7 & -7 \\
\hline Flujos de Efectivo y Equivalente al Efectivo procedente de (utilizade & 799 & 820 & 842 & 864 & 887 & 910 \\
\hline Aumento (Disminución) Neto de Efectivo y Equivalente al Efectivo, antes de & $-1,207$ & 1,910 & 5,899 & 10,022 & 13,800 & 16,857 \\
\hline Aumento (Disminución) Neto de Efectivo y Equivalente al Efectivo & $-1,207$ & 1,910 & 5,899 & 10,022 & 13,800 & 16,857 \\
\hline Efectivo y Equivalente al Efectivo al Inicio del Ejercicio & 3,960 & 2,754 & 4,663 & 10,562 & 20,583 & 34,383 \\
\hline Efectivo y Equivalente al Efectivo al Finalizar el Ejercicio & 2,754 & 4,663 & 10,562 & 20,583 & 34,383 & 51,240 \\
\hline
\end{tabular}




\subsection{Proyección de Flujos y Estado de Ganancias y Pérdidas - con estrategia}

Para la proyección de flujo con estrategia se ha considerado los siguientes supuestos:

1. De acuerdo con el objetivo planteado por la estrategia objetiva, las ventas de la línea de planchas planas crecerán en un 40\%, por lo que su crecimiento anual se distribuye equitativamente.

2. Las ventas del resto de líneas de la empresa mantienen un crecimiento del $2.5 \%$ anual.

3. La línea de planchas planas representa un $13 \%$ del total de las ventas.

4. Se asume que la creación de la nueva unidad de línea incrementará la eficiencia de la empresa a $4 \%$, lo que significará que a medida que pasa el tiempo el margen bruto de utilidad crecerá en $4 \%$

5. Para la proyección de las ventas, se toma el ratio de cuentas por cobrar de 109 días, dispuesto por la empresa. Además, la empresa establece un crecimiento anual de las ventas del $2.5 \%$.

6. Se asume que la empresa mantiene la proporción promedio de los costos de ventas a lo largo de los 5 años, considerando una mejora en la eficiencia del uso de los recursos del 2.5\% anual, dato que está establecido como objetivo institucional en la empresa.

7. Para proyectar el pago de proveedores se utilizará el ratio de 160 días para la rotación de cuentas por pagar.

8. Los rubros de pagos a empleados, obtención de préstamos y amortización de préstamos se proyectarán con un crecimiento en función a la inflación (2.6\%)

9. Se puede observar que los intereses pagados crecen un $6 \%$ en función al año anterior, por lo que se mantendrá esa tasa para la proyección. 
10. Los rubros de los impuestos a las ganancias (3\%) y Compra de propiedades (10\%) representan un porcentaje estable de las ventas en años anteriores por lo que se utilizará el promedio de estos.

11. Para los dividendos pagados se utilizará el monto promedio de los años anteriores.

12. La inversión necesaria para la ejecución de la estrategia será considerada en el año 0 (2017) y dentro del rubro Otros Pagos de Efectivo Relativos a las Actividades de Operación y el monto considerado es el de 371 mil soles, detallado en el capítulo anterior. Así mismo, se asume que este monto será reinvertido anualmente durante todo el periodo de estudio e irá aumentando de acuerdo con la inflación. 
Tabla 36. Proyección de flujo de caja proyectado con estrategia

\begin{tabular}{|c|c|c|c|c|c|c|}
\hline \multicolumn{7}{|l|}{ FABRICA PERUANA ETERNIT S.A. } \\
\hline \multicolumn{7}{|c|}{ ESTADOS FINANCIEROS |Individual | Anual al 31 de Diciem bre del 2016 ( en miles de NUEVOS SOLES ) } \\
\hline CUENTA & 2018 & 2019 & 2020 & 2021 & 2022 & 2023 \\
\hline Ingresos de Actividades Ordinarias & 256,438 & 264,392 & 272,653 & 281,235 & 290,155 & 299,430 \\
\hline Planchas Planas & 34,592 & 37,001 & 39,577 & 42,332 & 45,280 & 48,432 \\
\hline Otros & 221,845 & 227,391 & 233,076 & 238,903 & 244,875 & 250,997 \\
\hline Costo de Ventas & $171,956.64$ & $173,806.58$ & $175,500.50$ & $177,016.34$ & $178,329.75$ & $179,413.80$ \\
\hline Ganancia (Pérdida) Bruta & 84,481 & 90,585 & 97,152 & 104,219 & 111,825 & 120,016 \\
\hline Gastos de Ventas y Distribución & $-23,953$ & $-25,321$ & $-26,725$ & $-28,166$ & $-29,644$ & $-31,160$ \\
\hline Gastos de Administración & $-25,534$ & $-26,198$ & $-26,879$ & $-27,578$ & $-28,295$ & $-29,030$ \\
\hline \multicolumn{7}{|l|}{ Otros Ingresos Operativos } \\
\hline Otras Ganancias (Pérdidas) & $-1,585$ & $-1,624$ & $-1,665$ & $-1,706$ & $-1,749$ & $-1,793$ \\
\hline \multirow[t]{2}{*}{ Ganancia (Pérdida) Operativa } & 33,410 & 37,442 & 41,884 & 46,769 & 52,138 & 58,033 \\
\hline & - & - & - & - & - & - \\
\hline Gastos Financieros & $-5,771$ & $-5,915$ & $-6,063$ & $-6,215$ & $-6,370$ & $-6,530$ \\
\hline Ganancia (Pérdida) por Deterioro de Valor & 327 & 336 & 344 & 353 & 361 & 370 \\
\hline \multirow[t]{2}{*}{ Ganancia (Pérdida) antes de Impuestos } & 27,966 & 31,863 & 36,164 & 40,907 & 46,129 & 51,874 \\
\hline & - & - & - & - & - & - \\
\hline Ingreso (Gasto) por Impuesto & $-10,413$ & $-10,673$ & $-10,940$ & $-11,214$ & $-11,494$ & $-11,781$ \\
\hline Ganancia (Pérdida) Neta de Operaciones & 17,553 & 21,189 & 25,224 & 29,693 & 34,635 & 40,092 \\
\hline
\end{tabular}


Tabla 37. Proyección de flujo de caja proyectado con estrategia

\begin{tabular}{|c|c|c|c|c|c|c|}
\hline FABRICA PERUANA ETERNIT S.A. & & & & & & \\
\hline ESTADOS FINANCIEROS |Individual | Anual al 31 de Diciem bre del 201 & miles de & NUEVOS SOLES & & & & \\
\hline CUENTA & 2018 & 2019 & 2020 & 2021 & 2022 & 2023 \\
\hline Flujo de Efectivo de Actividades de Operación & 256,438 & 264,392 & 272,653 & 281,235 & 290,155 & 299,430 \\
\hline Venta de Bienes y Prestación de Servicios & 254,149 & 262,017 & 270,186 & 278,672 & 287,491 & 296,660 \\
\hline Proveedores de Bienes y Servicios & $-171,378$ & $-173,288$ & $-175,050$ & $-176,644$ & $-178,046$ & $-179,230$ \\
\hline Pagos a y por Cuenta de los Empleados & $-41,478$ & $-42,991$ & $-44,543$ & $-46,136$ & $-47,771$ & $-49,448$ \\
\hline Otros Pagos de Efectivo Relativos a las Actividades de Operación & $-3,162$ & $-3,248$ & $-3,337$ & $-3,430$ & $-3,526$ & $-3,627$ \\
\hline Flujos de Efectivo y Equivalente al Efectivo procedente de (utilizads & 38,132 & 42,491 & 47,256 & 52,462 & 58,148 & 64,355 \\
\hline Intereses Pagados (no incluidos en la Actividad de Financiación) & $-7,338$ & $-7,779$ & $-8,245$ & $-8,740$ & $-9,264$ & $-9,820$ \\
\hline Impuestos a las Ganancias (Pagados) Reembolsados & $-8,089$ & $-8,340$ & $-8,600$ & $-8,870$ & $-9,150$ & $-9,442$ \\
\hline Flujos de Efectivo y Equivalente al Efectivo procedente de (utilizadc & 22,705 & 26,372 & 30,411 & 34,853 & 39,734 & 45,093 \\
\hline Compra de Propiedades, Planta y Equipo & $-23,886$ & $-24,625$ & $-25,393$ & $-26,191$ & $-27,020$ & $-27,881$ \\
\hline Flujos de Efectivo y Equivalente al Efectivo procedente de (utilizadc & $-23,886$ & $-24,625$ & $-25,393$ & $-26,191$ & $-27,020$ & $-27,881$ \\
\hline Obtención de Préstamos & 16,843 & 17,281 & 17,730 & 18,191 & 18,664 & 19,149 \\
\hline Amortización o Pago de Préstamos & $-16,036$ & $-16,453$ & $-16,881$ & $-17,320$ & $-17,770$ & $-18,232$ \\
\hline Dividendos Pagados & -7 & -7 & -7 & -7 & -7 & -7 \\
\hline Flujos de Efectivo y Equivalente al Efectivo procedente de (utilizadc & 799 & 820 & 842 & 864 & 887 & 910 \\
\hline Aumento (Disminución) Neto de Efectivo y Equivalente al Efectivo, antes de & -382 & 2,567 & 5,859 & 9,526 & 13,601 & 18,121 \\
\hline Aumento (Disminución) Neto de Efectivo y Equivalente al Efectivo & -382 & 2,567 & 5,859 & 9,526 & 13,601 & 18,121 \\
\hline Efectivo y Equivalente al Efectivo al Inicio del Ejercicio & 4,221 & 3,839 & 6,406 & 12,265 & 21,791 & 35,392 \\
\hline Efectivo y Equivalente al Efectivo al Finalizar el Elercicio & 3,839 & 6,406 & 12,265 & 21,791 & 35,392 & 53,513 \\
\hline
\end{tabular}


Tabla 38. Flujo de caja diferencial

\section{FABRICA PERUANA ETERNIT S.A.}

ESTADOS FINANCIEROS |Individual | Anual al 31 de Diciem bre del 2016 ( en miles de NUEVOS SOLES )

\begin{tabular}{|c|c|c|c|c|c|c|c|}
\hline CUENTA & 2017 & 2018 & 2019 & 2020 & 2021 & 2022 & 2023 \\
\hline Flujo de Efectivo de Actividades de Operación & & 1,443 & 3,023 & 4,749 & 6,634 & 8,689 & 10,927 \\
\hline Venta de Bienes y Prestación de Servicios & & 1,012 & 2,551 & 4,234 & 6,071 & 8,075 & 10,259 \\
\hline Proveedores de Bienes y Servicios & & 767 & -282 & $-1,974$ & $-3,547$ & $-4,499$ & $-4,426$ \\
\hline Pagos a y por Cuenta de los Empleados & & -435 & -881 & $-1,339$ & $-1,808$ & $-2,290$ & $-2,785$ \\
\hline Otros Pagos de Efectivo Relativos a las Actividades de Operación & $-4,648$ & & & & & & \\
\hline Flujos de Efectivo y Equivalente al Efectivo procedente de (utilizadc & $-4,648$ & 952 & 979 & 494 & 268 & 817 & 2,554 \\
\hline Impuestos a las Ganancias (Pagados) Reembolsados & & -32 & -81 & -135 & -193 & -257 & -327 \\
\hline Flujos de Efectivo y Equivalente al Efectivo procedente de (utilizad & $-4,648$ & 920 & 898 & 359 & 75 & 560 & 2,228 \\
\hline Compra de Propiedades, Planta y Equipo & & -95 & -240 & -398 & -571 & -759 & -964 \\
\hline Flujos de Efectivo y Equivalente al Efectivo procedente de (utilizadc & 0 & -95 & -240 & -398 & -571 & -759 & -964 \\
\hline Aumento (Disminución) Neto de Efectivo y Equivalente al Efectivo, antes de & $-4,648$ & 825 & 658 & -39 & -496 & -199 & 1,264 \\
\hline Aumento (Disminución) Neto de Efectivo y Equivalente al Efectivo & $-4,648$ & 825 & 658 & -39 & -496 & -199 & 1,264 \\
\hline Efectivo y Equivalente al Efectivo al Inicio del Ejercicio & & 260 & 1,085 & 1,743 & 1,704 & 1,208 & 1,009 \\
\hline Efectivo y Equivalente al Efectivo al Finalizar el Ejercicio & $-4,648$ & 1,085 & 1,743 & 1,704 & 1,208 & 1,009 & 2,272 \\
\hline
\end{tabular}




\subsection{Evaluación financiera}

En el punto anterior se ha definido la proyección de flujos de caja sin estrategia y con estrategia hasta el año 2023.

Para proceder con el calcula del valor actual neto (VAN) se necesitará de:

\subsubsection{Rendimiento Libre de riesgo}

Sera el rendimiento de los Bonos de EEUU a 5 años, tomado de la página web

\section{BLOOMBERG}

\section{Treasury Yields}

\begin{tabular}{|c|c|c|c|c|c|c|}
\hline NAME & COUPON & PRICE & YIELD & $1 \mathrm{MONTH}$ & 1 YEAR & TIME (EST) \\
\hline $\begin{array}{l}\text { GB3:GOV } \\
\text { 3 Month }\end{array}$ & 0.00 & 1.24 & $1.26 \%$ & +10 & +80 & $12 / 1 / 2017$ \\
\hline $\begin{array}{l}\text { GB6:GOV } \\
6 \text { Month }\end{array}$ & 0.00 & 1.41 & $1.44 \%$ & +15 & +83 & $12 / 1 / 2017$ \\
\hline $\begin{array}{l}\text { GB12:GOV } \\
12 \text { Month }\end{array}$ & 0.00 & 1.57 & $1.61 \%$ & +17 & +84 & $12 / 1 / 2017$ \\
\hline $\begin{array}{l}\text { GT2:GOV } \\
\mathbf{2} \text { Year }\end{array}$ & 1.75 & 99.96 & $1.77 \%$ & +16 & +68 & $12 / 1 / 2017$ \\
\hline $\begin{array}{l}\text { GT5:GOV } \\
\mathbf{5} \text { Year }\end{array}$ & 2.00 & 99.47 & $2.11 \%$ & +11 & +29 & $12 / 1 / 2017$ \\
\hline $\begin{array}{l}\text { GT10:GOV } \\
10 \text { Year }\end{array}$ & 2.25 & 99.02 & $2.36 \%$ & +2 & -2 & $12 / 1 / 2017$ \\
\hline $\begin{array}{l}\text { GT30:GOV } \\
\text { 30 Year }\end{array}$ & 2.75 & 99.77 & $2.76 \%$ & -6 & -30 & $12 / 1 / 2017$ \\
\hline
\end{tabular}

Tabla 39. Rendimiento Bonos EEUU

Fuente: https://www.bloomberg.com/markets/rates-bonds/government-bonds/us

Entonces el rendimiento libre de riesgo seria $2.11 \%$. Sin embargo, este rendimiento es una medición estadística, para mejorar análisis se utilizará los promedios geométricos históricos, conforme se describe en el siguiente punto. 


\subsubsection{Prima de Riesgo}

Considera la rentabilidad de mercado menos el activo libre de riesgo. En este caso, es la diferencia histórica de los rendimientos del mercado (S\&500) y de los Bonos a los 10 años, calculados por medio de promedios geométricos. Se considera los rendimientos históricos al 2016 de tal forma que el resultado brinda un mejor acercamiento al comportamiento del mercado en relación con los bonos de tesoro americano a largo plazo (10 años)

A continuación, la información histórica y los promedios geométricos tomados de DAMODARAN:

Tabla 40. Retornos anuales / rendimientos históricos:

\begin{tabular}{r|ccc}
\multicolumn{1}{c}{ Year } & S\&P 500 & 3-month & 10-year $\boldsymbol{T}$ \\
& & T.Bill & Bond \\
\hline 1928 & $43.81 \%$ & $3.08 \%$ & $0.84 \%$ \\
1938 & $29.28 \%$ & $0.08 \%$ & $4.21 \%$ \\
1958 & $5.70 \%$ & $1.02 \%$ & $1.95 \%$ \\
1968 & $43.72 \%$ & $1.78 \%$ & $-2.10 \%$ \\
2000 & $10.81 \%$ & $5.26 \%$ & $3.27 \%$ \\
2010 & $-9.03 \%$ & $5.76 \%$ & $16.66 \%$ \\
2011 & $14.82 \%$ & $0.13 \%$ & $8.46 \%$ \\
2012 & $2.10 \%$ & $0.03 \%$ & $16.04 \%$ \\
2013 & $15.89 \%$ & $0.05 \%$ & $2.97 \%$ \\
2014 & $32.15 \%$ & $0.07 \%$ & $-9.10 \%$ \\
2015 & $13.52 \%$ & $0.05 \%$ & $10.75 \%$ \\
2016 & $1.38 \%$ & $0.21 \%$ & $1.28 \%$ \\
& $11.74 \%$ & $0.51 \%$ & $0.69 \%$ \\
\hline
\end{tabular}




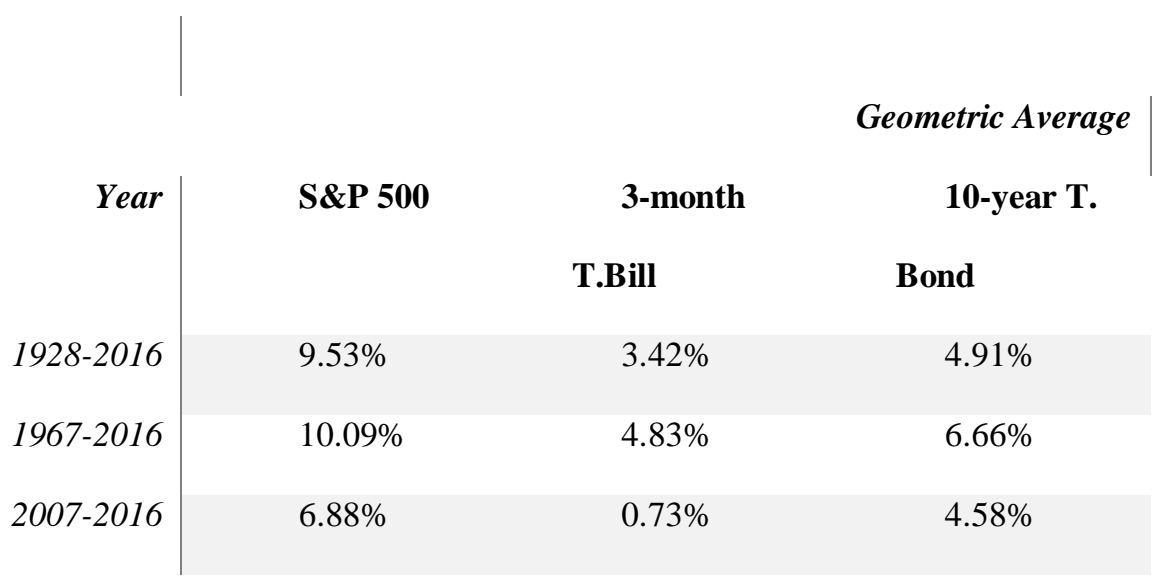

Fuente: http://pages.stern.nyu.edu/ adamodar/New_Home_Page/datafile/histretSP.html revisado el 25 de noviembre del 2017

Entonces la prima de riesgo será el resultado del rendimiento de mercado (9.53\%) menos la tasa libre de riesgo a largo plazo (4.91\%) dando como resultado: $4.62 \%$.

\subsubsection{Beta}

Especialista en finanzas han elaborado un listado de Betas por sector. DAMODARAN proporciona información a enero 2016 de los Betas por sector de las Empresas de EE.UU.

Tabla 41. Beta

\begin{tabular}{rrrrrrrrr} 
Industry & Num & & Bet & D/E & Tax & Unleve & Cash/Fi \\
Name & ber of & a & & Ratio & rate & red beta & rm value \\
& firms & & & & & & & \\
\hline Building & 41 & & 1.0 & 26.98 & 23.39 & 0.83 & $4.05 \%$ \\
Materials & & 1 & & $\%$ & $\%$ & &
\end{tabular}

Fuente: http://pages.stern.nyu.edu/ adamodar/New_Home_Page/datafile/Betas.html revisado el 25 de noviembre del 2017 
Hay que tener en cuenta que la beta proporcionado por DAMODARAN (1.01) tiene incluido un efecto deuda capital (D/E) pues en el sector la ratio en promedio es de $26.98 \%$ que se caracterizan por tener mayor proporción de capital que deuda.

\subsubsection{Ecuación del modelo CAPM}

A continuación, la ecuación por la cual se obtiene el valor de CAPM que se usara para la evaluación financiera:

$\mathrm{Ke}=\mathrm{Rf}+(\mathrm{Rmdo}-\mathrm{Rf}) \mathrm{B}$

Aplicando al caso en análisis, tenemos:

$\mathrm{Rf}=$ Tasa libre de riesgo $=4.91 \%$

$(\mathrm{Rmdo}-\mathrm{Rf})=$ Prima de riesgo $=7.42 \%$

$\mathrm{B}=$ beta del sector $=1.01$

Entonces $=4.91 \%+(7.42 \%) * 1.01$

$\mathrm{Ke}=12.40 \%$

El costo de capital hallado es un Ke corriente, es decir tiene inflación, para hallar el Ke real a precios constantes donde no se tenga la incidencia de la inflación, se requiere utilizar el método de DAMODARAN:

Ke corrEEUU $=$ Rf + $($ Rmdo - Rf $)$ B
Ke real EEUU $=((1+$ Ke corrEEUU $) /(1+$ inflación $))-1$
Ke real Peru $=$ Ke real EEUU + Riesgo pais

Para hallar el resultado, se requiere la inflación de EEUU y el riesgo país de Peru.

\subsubsection{Inflación de EEUU}

Se conoce como CPI (Consumer Price Index) y es publicado por la Bureau of Labor Statistics 
Tabla 42. CPI histórico

Table 24. Historical Consumer Price Index for All Urban Consumers (CPI-U): U. S. city average, all

items-Continued

(1982-84=100, unless otherwise noted)

\begin{tabular}{|c|c|c|c|c|c|}
\hline \multirow{2}{*}{ Year } & \multicolumn{2}{|c|}{$\begin{array}{l}\text { Semiannual } \\
\text { averages }\end{array}$} & \multirow{2}{*}{$\begin{array}{l}\text { Annual } \\
\text { avg. }\end{array}$} & \multicolumn{2}{|c|}{$\begin{array}{l}\text { Percent change } \\
\text { from previous }\end{array}$} \\
\hline & $\begin{array}{l}\text { 1st } \\
\text { half }\end{array}$ & $\begin{array}{l}\text { 2nd } \\
\text { half }\end{array}$ & & Dec. & $\begin{array}{l}\text { Annual } \\
\text { avg. }\end{array}$ \\
\hline 1913 & & - & 9.9 & & \\
\hline 1914 & & . & 10.0 & 1.0 & 1.0 \\
\hline 1915 & & - & 10.1 & 2.0 & 1.0 \\
\hline 1916 & & 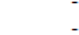 & 10.9 & 12.6 & 7.9 \\
\hline 1917 & & . & 12.8 & 18.1 & 17.4 \\
\hline 1918 & & . & 15.1 & 20.4 & 18.0 \\
\hline 1919 & & . & 17.3 & 14.5 & 14.6 \\
\hline 1920 & & - & 20.0 & 2.6 & 15.6 \\
\hline 1921 & & 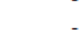 & 17.9 & -10.8 & -10.5 \\
\hline 1922 & & . & 16.8 & -2.3 & -6.1 \\
\hline 1923 & & . & 17.1 & 2.4 & 1.8 \\
\hline 1924 & & . & 17.1 & 0 & 0 \\
\hline
\end{tabular}

\begin{tabular}{l|l|l|l|r|r}
2000 & 170.8 & 173.6 & 172.2 & 3.4 & 3.4 \\
2001 & 176.6 & 177.5 & 177.1 & 1.6 & 2.8 \\
2002 & 178.9 & 180.9 & 179.9 & 2.4 & 1.6 \\
2003 & 183.3 & 184.6 & 184.0 & 1.9 & 2.3 \\
2004 & 187.6 & 190.2 & 188.9 & 3.3 & 2.7 \\
& & & & & \\
2005 & 193.2 & 197.4 & 195.3 & 3.4 & 3.4 \\
2006 & 200.6 & 202.6 & 201.6 & 2.5 & 3.2 \\
2007 & 205.709 & 208.976 & 207.342 & 4.1 & 2.8 \\
2008 & 214.429 & 216.177 & 215.303 & .1 & 3.8 \\
2009 & 213.139 & 215.935 & 214.537 & 2.7 & -.4 \\
& & & & & \\
2010 & 217.535 & 218.576 & 218.056 & 1.5 & 1.6 \\
2011 & 223.598 & 226.280 & 224.939 & 3.0 & 3.2 \\
2012 & 228.850 & 230.338 & 229.594 & 1.7 & 2.1 \\
2013 & 232.366 & 233.548 & 232.957 & 1.5 & 1.5 \\
2014 & 236.384 & 237.088 & 236.736 & .8 & 1.6 \\
& & & & & \\
2015 & 236.265 & 237.769 & 237.017 & .7 & .1 \\
2016 & 238.778 & 241.237 & 240.007 & 2.1 & 1.3 \\
2017 & 244.076 & & & - & - \\
\hline
\end{tabular}

- Data not available.

NOTE: Index applies to a month as a whole, not to any specific date.

Fuente: https://www.bls.gov/cpi/tables/detailed-reports/home.htm revisada el 25 de noviembre del 2017

Entonces la inflación correspondiente al año 2016 es $1.3 \%$ 
Reemplazando en la ecuación de DAMODARAN para hallar el costo del capital real de EEUU, tenemos:

Ke real EEUU $=((1+$ Ke corrEEUU $) /(1+$ inflación $))-1$

Ke real EEUU $=((1+12.40 \%) /(1+1.3 \%))-1$

Ke real EEUU $=10.96 \%$

\subsubsection{Riesgo País}

Corresponde a un listado elaborado por JP Morgan, EL EMBI + Peru se mide en función de la diferencia del rendimiento promedio de los títulos soberanos peruanos frente al rendimiento del bono del tesoro estadounidense.

Tabla 43. Riesgo País

PERU - Riesgo País (Embi+ elaborado por JP Morgan)

نंเтмо

114

ANTERIOR

111

VaRRACIÓN PORCENTULL

$\wedge 2,70 \%$

variaclón Puntos 3

MENSUAL ANUAL HISTÓRICO

Fuente: http://www.ambito.com/economia/mercados/riesgo-pais/info/?id=13 revisado el 25 de noviembre 2017

Entonces, el riesgo país es de 114 puntos, lo que indica que se adiciona al COK calculado el riesgo país de $1.14 \%$

Reemplazando en la ecuación de DAMODARAN para hallar el costo del capital real de Perú, tenemos

Ke real Peru $=$ Ke real EEUU + Riesgo país

Ke real Peru $=10.96 \%+1.14 \%$ 
Ke real Peru $=12.08 \%$

El COK a utilizar para el presente análisis de $12.08 \%$ la cual es una tasa real por lo tanto los precios a utilizar tendrán que ser a precios constantes sin incluir la incidencia de la inflación.

\subsubsection{Cálculo del WACC}

Para el cálculo del WACC se debe identificar la composición deuda / capital de Torres Unidas. La información disponible corresponde a los estados financieros de los años 2015 y 2016, por lo que se utilizara un promedio aritmético:

Tabla 44. Composición deuda - capital

\begin{tabular}{|c|c|c|c|c|c|}
\hline Detalle: & 2015 & 2016 & Promedio & $\%$ & \\
\hline $\begin{array}{l}\text { pasivo } \\
\text { total }\end{array}$ & 174,166 & 178,742 & 176,454 & $48 \%$ & D \\
\hline patrimonio & 184,931 & 195,243 & 190,087 & $52 \%$ & $\mathrm{E}$ \\
\hline Total & 359,097 & 373,985 & 366,541 & $100 \%$ & \\
\hline
\end{tabular}

Fuente: Elaboración propia

El WACC es el costo promedio ponderado de capital:

$$
\begin{aligned}
& \text { WACC }=\frac{E}{D+E}\left(r_{e}\right)+\frac{D}{D+E}\left(r_{d}\right)(1-t) \\
& E=\text { market value of equity } \\
& D=\text { market value of debt } \\
& r_{e}=\text { cost of equity } \\
& r_{d}=\text { cost of debt } \\
& \mathrm{t}=\text { corporate tax rate }
\end{aligned}
$$


En este caso:

$\mathrm{E}=52 \%$

$\mathrm{D}=48 \%$

$\mathrm{Re}=\mathrm{COK}=9.21 \%$

$\mathrm{Rd}=$ costo de la deuda $=14 \%$ (Tasa referencial usada por la compañía $)$

$\mathrm{t}=$ tasa de impuesto $=30 \%$

Se esta adicionando un $8 \%$ para el calculo del Wacc, considerando el riesgo inherente a una empresa/unidad de negocio nueva en economías emergentes según el Banco Mundial.

$\mathrm{WACC}=18.98 \%$

\subsubsection{Cálculo del VAN para cada flujo}

Tabla 45. Cálculo del VAN para cada flujo (en miles de nuevos soles)

\begin{tabular}{|c|c|c|c|c|c|c|c|}
\hline Año & 2,017 & 2,018 & 2,019 & 2,020 & 2,021 & 2,022 & 2,023 \\
\hline $\begin{array}{l}\text { Flujo sin } \\
\text { estrategia }\end{array}$ & & 2,754 & 4,663 & 10,562 & 20,583 & 34,383 & 51,240 \\
\hline VNA & $\mathrm{s} / \mathbf{5 4 , 6 2 5 . 6 6}$ & & & & & & \\
\hline $\begin{array}{l}\text { Flujo con } \\
\text { estrategia }\end{array}$ & & 3,839 & 6,406 & 12,265 & 21,791 & 35,392 & 53,513 \\
\hline VNA & S/59,606.92 & & & & & & \\
\hline $\begin{array}{r}\text { Flujo } \\
\text { diferencial }\end{array}$ & $-3,191$ & 1,085 & 1,743 & 1,704 & 1,208 & 1,009 & 2,272 \\
\hline VNA & $\mathrm{S} / \mathbf{1 , 5 0 4 . 3 4}$ & & & & & & \\
\hline TIR & $38 \%$ & & & & & & \\
\hline
\end{tabular}


Según los flujos de caja proyectados para ETERNIT, sin aplicar la estrategia y aplicando la estrategia, podemos concluir que la estrategia de penetración de mercado es la adecuada, ya que el VAN diferencial es de 1.5 millones de soles y la tasa interna de retorno es de $38 \%$. 


\section{CONCLUSIONES Y RECOMENDACIONES}

\section{Conclusiones:}

- El Plan estratégico es viable, ya que el VAN del flujo aplicando la estrategia es positivo obtenido es positivo y el TIR mayor que el Ke, por tanto y de acuerdo también a los flujos de caja proyectados para ETERNIT, sin aplicar la estrategia y aplicando la estrategia, podemos concluir que la estrategia de desarrollo de mercado es beneficio y debe ser implementada.

- La industria de la Construcción ira mejorando en la medida que la Situación Política del País se estabilice, y se inicie las Inversiones Públicas, mientras tanto es una gran oportunidad para las compañías de Construcción, como es el caso de Eternit de reinventarse e implementar estrategias que le permitan mantenerse en esta crisis actual y prepararse para el futuro.

- De acuerdo con las encuestas realizadas en este proyecto, se evidencia la preferencia de la población por el uso de material noble en sus construcciones y no confían en otras opciones por la poca difusión y conocimiento que se tiene de materiales alternativos, esta estrategia está pensada para Lima, sin embargo, la Empresa debe ampliar este proceso de difusión a niel nacional de tal manera que el mercado se expanda y se obtengan mayores alternativas de desarrollo de sus productos.

- La compañía debe establecer también una estrategia operativa que permita mantener o mejorar los costos de la operación de tal manera de ser competitivos en los mercados objetivos, y ser una alternativa optima frente a la competencia y los sustitutos. 


\section{Recomendaciones:}

- Implementar el Plan Estratégico elaborado para ETERNIT durante el periodo 2018 - 2022 en todo el Perú, realizando una revisión periódica que permita evaluar la evolución de la difusión de las planchas de fibrocemento y el fortalecimiento de las relaciones con los principales clientes de ETERNIT.

- En paralelo se debe empezar con las estrategias contingentes, implementando los perfiles laborales que permitan desarrollar un plan de carrera con una modificación salarial, obteniendo como resultado un área operativa motivada para alcanzar los objetivos con alta eficiencia.

- Evaluar la posibilidad de ingresar agresivamente a los mercados de la región, formando un equipo de ventas enfocados en dicho mercado, dado que el consumo por persona en los mercados de la región es mayor al Perú. Esto incrementara de una manera más rápida la utilización de la capacidad de la línea de fibrocemento. 


\section{Referencias}

Bolsa de Valores de Lima (BVL). (2017.) Hechos de Importancia. Recuperado de

http://www.bvl.com.pe/jsp/ShowDocument.jsp?_www_doc=/hhii/B30122/20170508160501/ AVISO32PERIODICO3208950532.PDF

Capdevilla, C. (12 de abril de 2004). Experto destaca la importancia de invertir en personal. Noticias Financieras. Recuperado de https://search.proquest.com/docview/466279878?accountid=43847.

Inga, C. (11 de mayo de 2017). Eternit estos son sus planes e inversiones hasta el $2020 . \quad$ El Comercio. Recuperado de https://elcomercio.pe/economia/dia-1/eternit-son-planes-einversiones-2020-419730

Gestión. (28 de septiembre de 2016). Eternit busca afianzar las líneas de fibrocemento y drywall. Recuperado de https://gestion.pe/economia/empresas/eternit-busca-afianzar-lineasfibrocemento-drywall-116340.

Waisbord, S. \& Amado, A. (2017). La comunicación pública: Mutaciones e interrogantes. Nueva Sociedad, (269), 96-109. 


\section{Anexos}

Anexo 1

Proceso de atención y Gestión de pedidos y despach

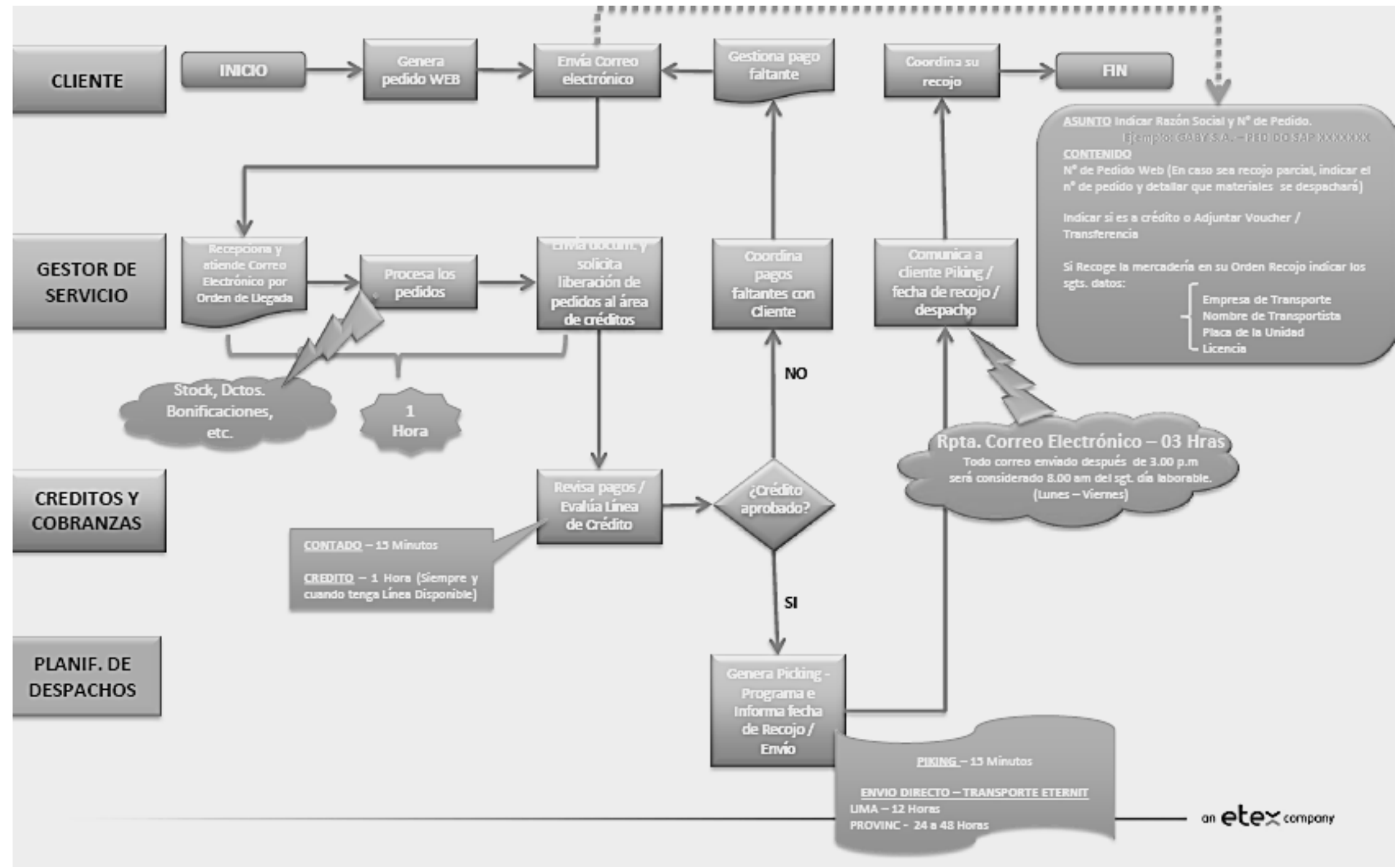


Anexo 2

\section{Formato de Reclamos}

\begin{tabular}{|c|c|c|}
\hline & \multirow[t]{2}{*}{ INFORME DE RECLAMOS DE PRODUCTOS } & No: \\
\hline & & Fecha: \\
\hline \multicolumn{3}{|l|}{ DATOS } \\
\hline \multirow{2}{*}{\multicolumn{3}{|c|}{$\begin{array}{l}\text { USUARIO FINAL: } \\
\text { DISTRIBUIDOR / HOME CENTER: } \ldots . . .\end{array}$}} \\
\hline & & \\
\hline \multicolumn{3}{|l|}{ DESCRIPCION : } \\
\hline \multicolumn{3}{|l|}{ PRODUCTO: } \\
\hline \multicolumn{2}{|l|}{ DEFECTO } & DEFECTOS POR \\
\hline \begin{tabular}{|l|} 
DESCRIPCIÓN \\
\end{tabular} & CANTIDAD (UNID.) & CANTIDAD (UNID.) \\
\hline BAJA RESISTENCIA & & \\
\hline \begin{tabular}{|l} 
CAMBIOS DIMENSIONALES \\
\end{tabular} & & \\
\hline \multicolumn{2}{|l|}{ CORTES DEFECTUOSOS(Rebarbas) } & \\
\hline \multicolumn{2}{|l|}{\begin{tabular}{|l|l|} 
ESPESOR & \\
\end{tabular}} & \\
\hline \multirow{2}{*}{\multicolumn{2}{|c|}{\begin{tabular}{|l|} 
FISURAS \\
FISURAS BORDE LONGITUDINAL \\
\end{tabular}}} & \\
\hline & & \\
\hline \multirow[t]{2}{*}{ TOTAL } & & \\
\hline & & \\
\hline
\end{tabular}

\begin{tabular}{|c|c|c|}
\hline \multicolumn{3}{|c|}{ TRAZABILIDA DE PRODUCTO } \\
\hline $\begin{array}{c}\text { FCCHADE } \\
\text { FABRICACION }\end{array}$ & TURNO & CANTIDAD \\
\hline & & \\
\hline & & \\
\hline & & \\
\hline & & \\
\hline & & \\
\hline & & \\
\hline & TOTAL & \\
\hline
\end{tabular}

OBSERVACIONES: 
Anexo 3

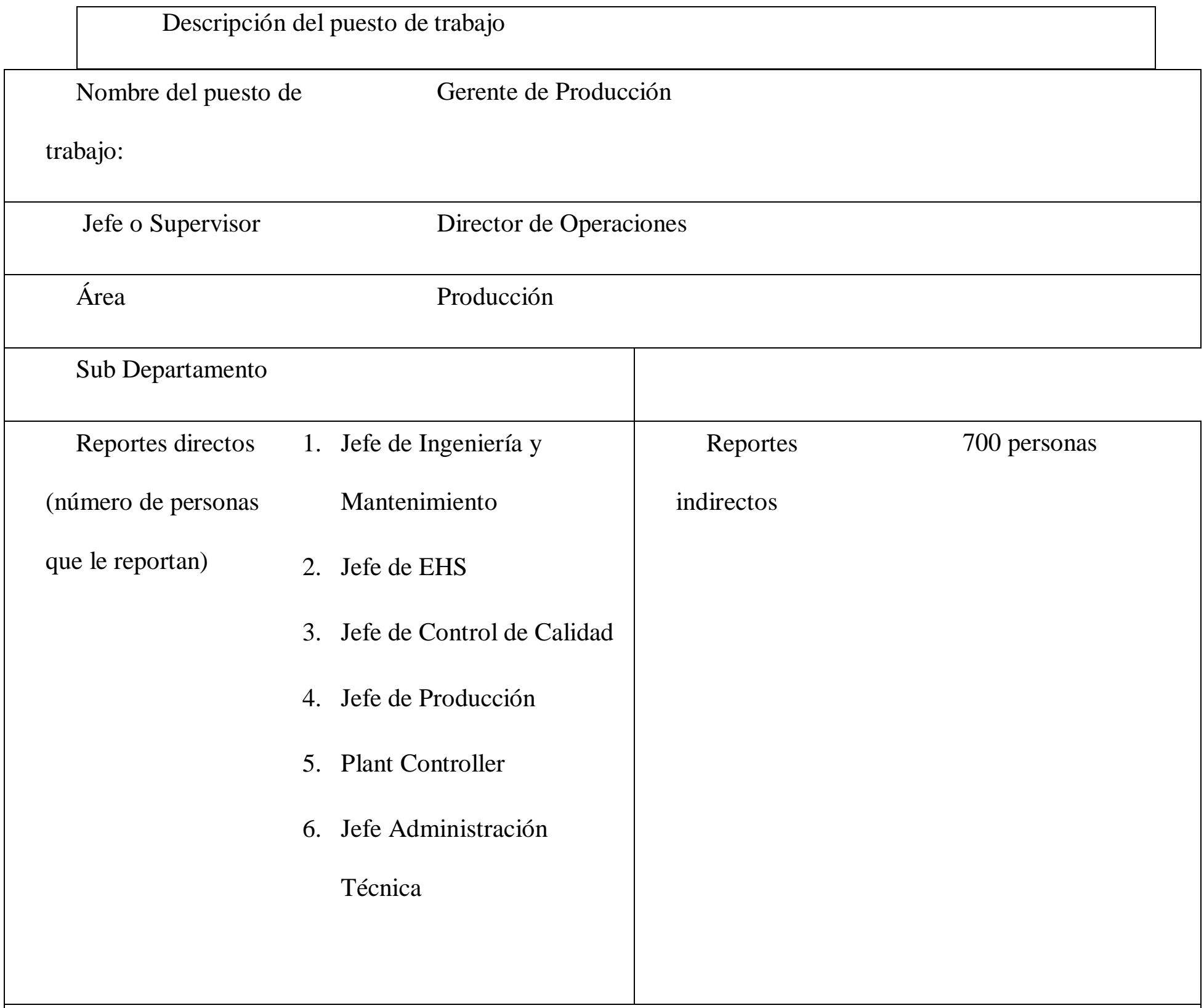

A. Por favor, indique cual es el objetivo principal de la funcion: escoja una de ellas. (Si no es posible, selecciones ambas alternativas).

$\square$ Se concentra en la destreza técnica y la contribucion individual.
XSe centra en la gestion. 


\begin{tabular}{|l|l|}
\hline (Contribucion individual - el puesto se centra en & (El puesto se centra en las personas, proyectos y la \\
mayor medida en la destreza técnica que en las & gestión de procesos). \\
personas, el proyecto o la gestion de procesos). & \\
\hline
\end{tabular}

\section{B. Misión:: Describa a continuación el proposito principal y la funcion de su puesto de trabajo. ¿Por qué}

este trabajo existe en la compañía.?

Por favor, formule su respuesta como se describe a continuación: que actividades $(\mathrm{a}, \mathrm{b}, \mathrm{c})$ necesitan ser

realizadas para obtener los resultados $(\mathrm{x}, \mathrm{y}, \mathrm{z})$

Mantener la visión, la misión y los valores a la vanguardia de la toma de decisiones y la acción.

Actividades que se necesitan ser realizadas:

- Cumplimiento de la Política EHS de la empresa.

Aplicación del Sistema Integrado de Gestión ( SIG ).

Responsabilidad en la fabricación de los productos teniendo en consideración: la seguridad de los trabajadores, la calidad de los productos, la optimización de los costos, la entrega a tiempo y la mejora continua.

- Cumplimiento de los procedimientos de fabricación de acuerdo a las Normas Técnicas.

- Cumplimiento del Presupuesto Técnico.

Entrenamiento y desarrollo del Recurso Humano.

Mantener y optimizar la confiabilidad y disponibilidad de las maquinarias de la fábrica al 100\%.

- Cumplimiento y optimización del plan de ahorros.

- Cumplimiento del CAPEX.

Resultados esperados: 
- Cero accidentes.

- No afectar al Medio Ambiente.

- No tener enfermedades ocupacionales.

Excelencia en el Servicio al Cliente.

- Fabricar productos que requiera el mercado con costos competitivos y de óptima calidad.

Desarrollo del personal (equipo de trabajo).

- Optimo clima laboral.

- Mejora Continua

- Innovación.

Ahorros que tengan impacto en el EBITDA.

Impacto de las inversiones (CAPEX) en la seguridad de los trabajadores y en el proceso productivo.

C. Roles claves y responsabilidades : Enumere de 5 a 7 roles claves y responsabilidades de su trabajo . Adicionalmente, por favor, indique el porcentaje de tiempo utilizado mensualmente para cada responsabilidad.

\begin{tabular}{|l|c|}
\hline Responsabilidades & $\%$ de tiempo \\
& utilizado \\
\hline Seguridad y Medio Ambiente & $20 \%$ \\
\hline Procesos de Producción & $10 \%$ \\
\hline Costos de fabricación & $25 \%$ \\
\hline
\end{tabular}




\begin{tabular}{|l|c|}
\hline Calidad de los productos & $10 \%$ \\
& $10 \%$ \\
\hline Desarrollo del Personal & $15 \%$ \\
\hline CAPEX & $10 \%$ \\
\hline Ahorros & $10 \%$ \\
\hline
\end{tabular}

D. Responsabilidad Financiera: es usted responsable de un presupuesto operacional. Si lo es, por favor proporcione un estimado de la cantidad. (SOLES)

7 millones euros +100 millones de soles

E. Por favor proporcione una lista de los factores más relevantes que determinen el éxito en su puesto de trabajo.

Pasión por la excelencia

Servicio al cliente de excelencia

Preocupación por las personas, su seguridad y el ambiente

Generación de soluciones innovadoras que creen valor 
F. Requisitos del Puesto de Trabajo y Aptitudes: Indique el nivel mínimo de educación y experiencia para este trabajo.

Educación

mínima:

Titulado en Ingeniería ( Industrial, Mecánica, Eléctrica, Electrónica Mecatrónica )

Experiencia

mínima:

10 años en puestos similares en industrias de proceso continuo.

Idiomas

requeridos:

Inglés nivel avanzado

Certificaciones

requeridas:

Maestría en Administración de Empresas.

G. Responsabilidades Adicionales requeridas para el desempeño de la función.

Por favor , tome en cuenta lo siguiente cuando complete el cuestionario:

- El cuestionario necesita ser completado tomando en cuenta los requisitos de trabajo y no habilidades

personales (ej. necesita negociar de manera frecuente con personas externas o es capaz de hacer su trabajo

basado en su experiencia previa?

- Al completar el cuestionario debe tomar en cuenta sus actividades diarias y excluir excepciones (ej. una única negociación con personas externas no significa que su función requiera que lo haga frecuentemente). 
Conocimiento Funcional:. Qué conocimientos técnicos necesita para desempeñar plenamente las responsabilidades en su posición?) El término instrucción se refiere a un tema específico.

Los siguientes enunciados le ayudarán a completar el cuestionario:

- Con el objetivo de ejercer su función, necesita la comprensión de conceptos y principios relacionados a su formación.

- Sin tomar en cuenta los conocimientos de su formación, necesitaría un básico o elevado entendimiento de otras formaciones.

- Manufactura Plantas Mineras o Productos Químicos

- SAP

- Lean Manufacturing

Liderazgo: La posición requiere de liderazgo y de guía a otros.

Los siguientes enunciados le ayudarán a complete el cuestionario:

¿Es responsable de liderar un equipo?

- Si lo está liderando, ¿son funciones de apoyo o de gestión?

- ¿Es responsable de la coordinación de actividades y también es responsable del desempeño de su equipo?

- ¿Está liderando un proyecto?

¿Brinda entrenamiento en el puesto de trabajo?

- ¿Es un entrenador/mentor? 
- Responsable del liderazgo del equipo de la División Producción.

- Es una función de gestión.

- Responsable de las coordinaciones y del desempeño del equipo.

- Lidero varios proyectos.

- Se brinda entrenamiento en el puesto de trabajo.

- Se realizan labores de: coaching, referente y tutor.

Resolución de Problemas: ¿Qué habilidades son necesarias para ejercer su función, cuál es la complejidad de las tareas a ejecutar y los problemas a ser resueltos?

Los siguientes enunciados lo ayudarán a completar el cuestionario:

¿Resolvería problemas basándose en su experiencia?

¿Existen procedimientos que deben ser seguidos al momento de ejercer su función?

¿Debe proveer soluciones basadas en el análisis de información? Si las hay, ¿qué fuentes de información utiliza?)

- Toma de decisiones: Obtener información, identificar y comprender situaciones claves y relevantes a fin de establecer metas a largo plazo, desarrollando alternativas basadas en suposiciones lógicas, hechos, recursos disponibles y en los valores del Grupo Etex. 
- Capacidad de reacción: Capacidad de hacer frente en forma positiva al encontrarse con adversidades significativas.

Naturaleza del Impacto: ¿cuál es la responsabilidad general de la posición y cómo impacta en la organización).

Los siguientes enunciados lo ayudarán a completar el cuestionario:

- ¿Es responsable de la calidad de las tareas que provee o también es determinada por las áreas que se le asignan?

¿Contribuye con las decisiones correspondientes a su gestión?

¿Contribuye con la definición de la estrategia con respecto a su propia gestión?

¿Es responsable de la determinación del presupuesto de su departamento /subdepartamento?

- Influencia en el margen de ganancia de la empresa

- Calidad

- Costos de los productos

- Tiempos de entrega

Conocimiento de Negocio: ¿qué conocimientos y destrezas acerca del negocio (excluyendo las destrezas técnicas) son requeridas?

Los siguientes enunciados le ayudarán a completar el cuestionario:

¿ ¿Debe contar con el conocimiento de las actividades de su equipo?

- ¿Debe contar con el conocimiento de las actividades de su equipo y equipos relacionados? 
- ¿Debe contar con el conocimiento de las actividades de un sub departamento o incluso de todo el

departamento)

¿.Debe tener algun conocimiento comercial?

- Conocimiento de fibrocemento.

- Conocimiento de rotomoldeo.

- Conocimientos de RRHH, Supply, Finanzas, EHS.

- Conocimiento de los procesos de Mejora Continua. / Lean Manufacturing

Área de Impacto: ¿cuál es el impacto que tiene este puesto en la organización, en un departamento o en un subdepartamento, etc?

Los siguientes enunciados lo ayudarán a completar el cuestionario:

- ¿Su función influye en su propio equipo o también en otros equipos?

- ¿Su posición tiene influencia en un departamento o subdepartamento (ej, ser un miembro del comité)?

- La función influye notablemente en el desempeño del equipo.

- La posición influye en otros departamentos (participación en el Comité de Gerencia).

Habilidades Interpersonales: ¿cuál es el nivel y tipo de habilidades personales?

Los siguientes enunciados lo ayudarán a completar el cuestionario:

¿Necesita intercambiar información regularmente? Por favor mencione los más importantes contactos lorganizaciones

- ¿Debe influenciar a otras personas? (ej. Colegas de formación diferente?)

- ¿Necesita negociar? Si es el caso, ¿solo de manera interna o también externa? 
Habilidades interpersonales:

- Comunicación: Transmitir de una manera clara la información e ideas a través de una variedad de medios al personal y/o al equipo de trabajo a fin de ayudar a entender y a cumplir las metas y objetivos.

- Ejecución y resultados: Alinear las personas, los procesos, los recursos, los sistemas y la comunicación para asegurar la implementación efectiva y la entrega de los resultados requeridos dentro de los plazos establecidos.

\section{Por acuerdo}

Titular de la Posición

Gerente 
Anexo 4

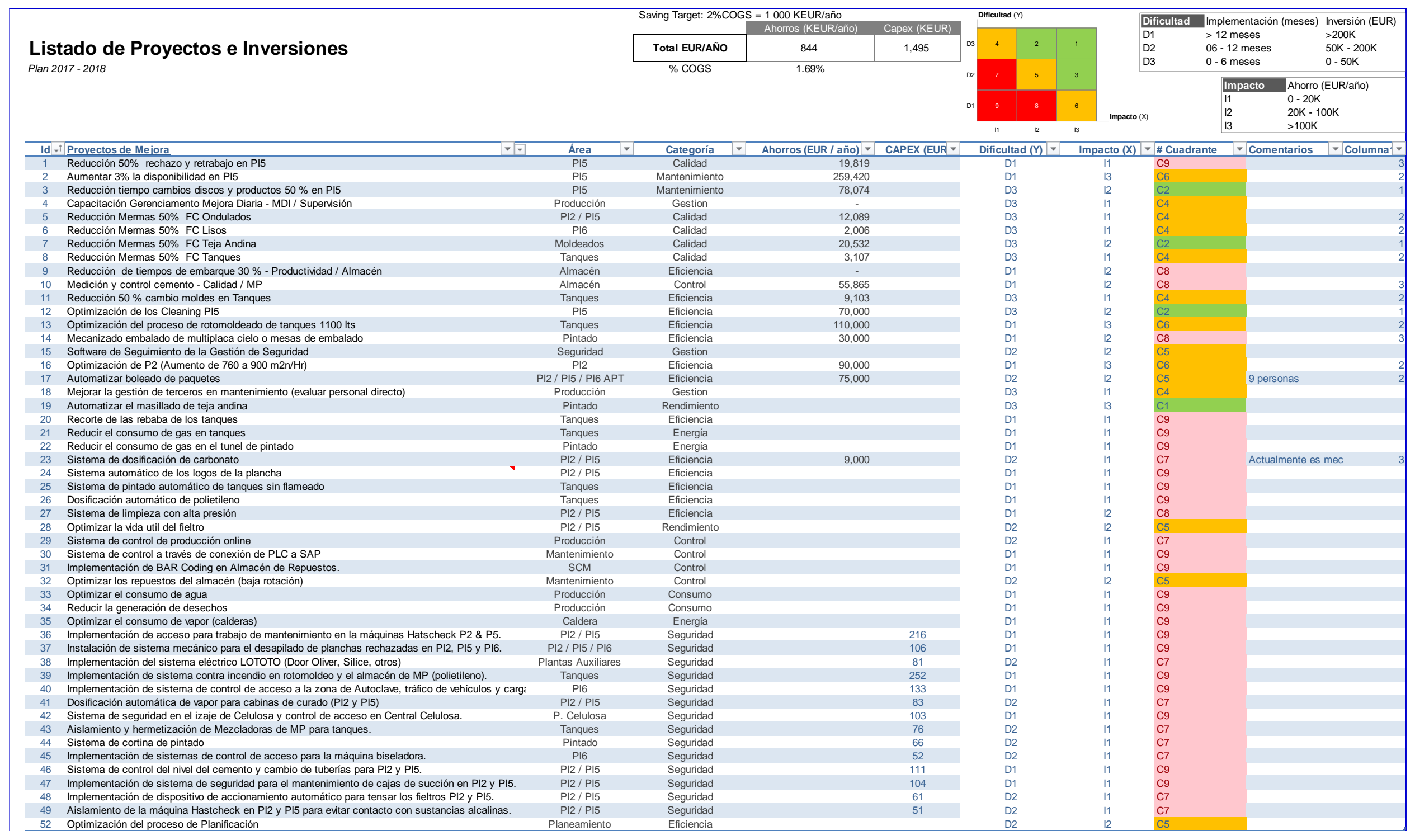


Anexo 5

ENCUESTA A CLIENTES

$\square$ Sexo: Masculino Femenino

$\square$ Edad: en años.

$\square$ Nivel de educación:
Primaria
Secundaria
Bachillerato

Universitario

- Ocupación:

Construcción

Salud

Educación

Ama de casa

1. ¿Usaría material de fibrocemento para construir su vivienda u oficina?
a) $\mathrm{Si}$
b) $\mathrm{No}$

2. ¿Sabía Ud. Que el fibrocemento constituye un sistema constructivo liviano?
a) $\mathrm{Si}$
b) $\mathrm{No}$

3. ¿Sabía Ud. que el fibrocemento constituye soluciones constructivas integrales de vivienda, colegios, oficinas, comercio, clínicas, fábricas y campamentos?
a) $\mathrm{Si}$
b) $\mathrm{No}$
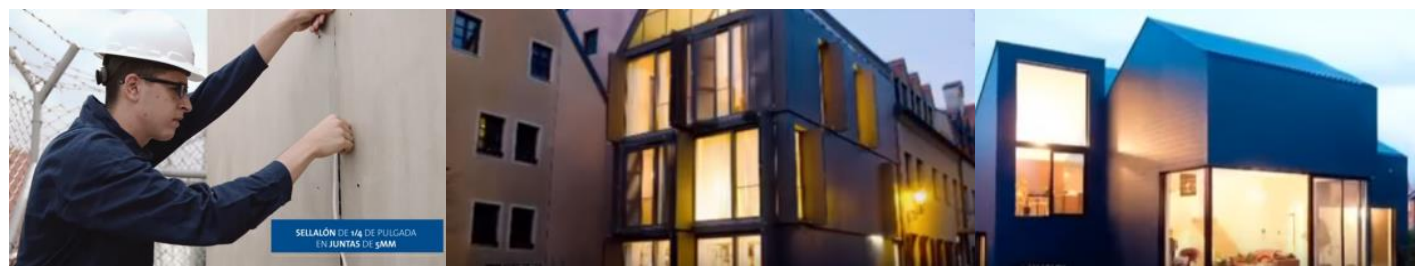
4. ¿Sabía Ud. que el fibrocemento es fácil de trabajar como la madera y durable como el cemento, apta para todo tipo de acabados?
a) $\mathrm{Si}$
b) No

5. ¿ Sabía Ud. que el fibrocemento son resistentes al fuego, no contribuyen a la propagación de llamas, ni a la emisión de humos?
a) $\mathrm{Si}$
b) No

6. ¿ Sabía Ud. que gracias al despiece en módulos de gran formato que ofrece el sistema de fibrocemento, se optimizan al máximo las cantidades de placas utilizadas, reduciendo los residuos resultantes?

7.
a) $\mathrm{Si}$
b) No

8. ¿ Sabía Ud. que por sus propiedades físicas, la transmisión de calor y del ruido a través del fibrocemento es menor que en otros productos.
a) $\mathrm{Si}$
b) No

9. ¿ Sabía Ud. que el fibrocemento es apto para recibir todo tipo de acabados?
a) $\mathrm{Si}$
b) No 
10. ¿Luego de revisar estos planos, considera que el Fibrocemento nos permite cambiar de uso del ambiente con facilidad?
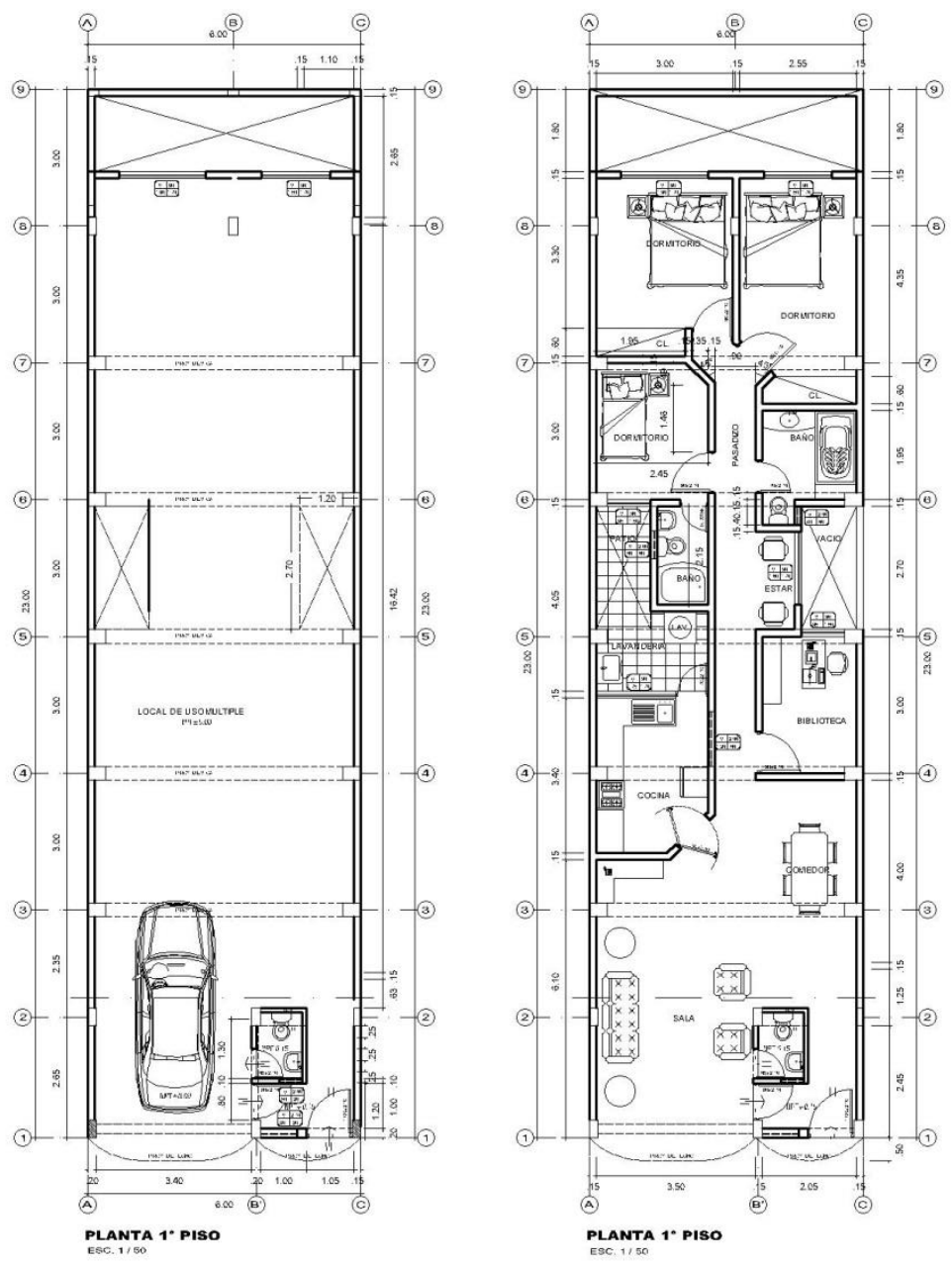
a) $\mathrm{Si}$
b) No

10 ¿Luego de conocer las características mencionadas, usaría fibrocemento en su futura vivienda, colegio, oficina, comercio, clínica, fábrica o campamento?
a) $\mathrm{Si}$
b) No 
Anexo 6

\section{ENCUESTA A NO CLIENTES}

$\square$ Sexo: Masculino Femenino

$\square$ Edad: en años.

$\square$ Nivel de educación:

Primaria__ Secundaria__ Bachillerato__

Universitario

1. Ocupación:

Construcción__ Salud__ Educación__ Ama de casa

El fibrocemento está fabricado con tecnología avanzada a base de cemento, sílice, fibras naturales y aditivos que mediante un proceso de auto clavado se someten a altas presiones y temperaturas para obtener un producto con un alto nivel de estabilidad dimensional. Está diseñado para soportar la humedad, gracias a sus características anti corrosivas. Además, es resistente a las termitas, lo que las convierte en la alternativa ideal para galpones, talleres o viviendas de campo. Es una buena opción para dividir ambientes con una instalación rápida y de bajo costo.

1. ¿Sabe usted de qué está compuesto el fibrocemento?
a) $\mathrm{Si}$
b) No

2. ¿Sabe qué utilidades tiene el fibrocemento? 

a) $\mathrm{Si}$
b) $\mathrm{No}$

3. ¿Sabía Ud. que el fibrocemento es material de construcción liviano?
a) $\mathrm{Si}$
b) $\mathrm{No}$

4. ¿Usaría fibrocemento para la construcción de su casa?
a) $\mathrm{Si}$
b) No

5. ¿Sabía Ud. el fibrocemento forma parte de soluciones de construcción fáciles para la de vivienda, colegios, oficinas, comercio, clínicas, fábricas y campamentos?
a) $\mathrm{Si}$
b) No

6. ¿Sabía Ud. que el fibrocemento es fácil de trabajar como la madera y durable como el cemento, apta para todo tipo de acabados?
a) $\mathrm{Si}$
b) No

7. ¿Sabía Ud. Que el fibrocemento es resistente al fuego, no contribuye a la propagación de llamas, ¿ni a la emisión de humos?
a) $\mathrm{Si}$
b) $\mathrm{No}$

8. ¿Sabía Ud. que por sus propiedades físicas, la transmisión de calor y del ruido a través del fibrocemento es menor que en otros productos?
a) $\mathrm{Si}$
b) No

9. ¿Sabía Ud. que el fibrocemento es apto para recibir todo tipo de acabados?
a) $\mathrm{Si}$
b) No

10. ¿Luego de conocer las características mencionadas, usaría fibrocemento para construir una futura vivienda?
a) $\mathrm{Si}$
b) $\mathrm{No}$ 
Anexo 7

ENTREVISTA

F1: Entrevistador

F2: Entrevistado

F1: Buenas tardes, gracias por recibirnos.

F2: hola, buenas tardes

(por temas de confidencialidad llamaremos Juan Pérez al entrevistado)

F1: la entrevista será breve, estamos realizando un Planeamiento Estratégico referente a las planchas planas de fibrocemento de su empresa, por lo que agradeceríamos nos responda algunas preguntas.

F2: perfecto, empecemos

F1: ¿Me podría comentar su cargo actual?

F2: Jefe de Operaciones de la Empresa.

F1: ¿Cuántos años lleva trabajando en la Empresa?

F2: Más de 5 años.

F1: ¿Cuántas personas están a su cargo?

F2: Son 420 Personas, de las cuales 400 Trabajan en la Planta de Lima, y 20 personas en la Planta de Chiclayo.

F1: ¿Considera que Eternit es una marca reconocida a nivel nacional?

F2: Por su puesto, Eternit tiene 77 años en el Mercado Peruano y es reconocida en la Industria de la Construcción. En el Mercado del Fibrocemento tenemos una Participación de Mercado del 95\% en el Perú.

F1: ¿A qué crees que se debe la preferencia del usuario? 
F2: Los productos de Fibrocemento requieren de un Proceso que no es muy conocido en el peru y en el mundo, por lo tanto, esa es una gran barrera de entrada, nuestros productos tienen una formulación y un proceso que ha sido desarrollado por el mismo Grupo a través de los años, y realizado por sus departamentos científicos en Europa. Este desarrollo continuo en la actualidad y es un proceso constante de mejora de nuestro Producto. Por lo tanto el Know- How de la compañía permite entregar productos de calidad y acordes a las necesidades del Mercado. Esta desarrollo no solo incluye la Calidad del Producto, sino el impacto social y ambiental, por ejemplo hace ya más de 15 años que Eternit no usa como Materia Prima el Asbesto, dado su efecto cancerígeno, asimismo hace más de 10 años se inició un proyecto Regional de reducción de desperdicios, y reutilización de los mismos, nuevamente bajo estudios realizados por los departamentos de Innovación y tecnologías del Grupo. Esto nos reducir el impacto de nuestros productos al ambiente. Asimismo, contamos con una planta de recuperación y tratamiento de Aguas

F1: ¿Cree usted que cuenta con el personal apropiado para ser una empresa competente?

F2: Para Eternit sus colaboradores son el recurso más importante, y esto está reflejado en uno de sus valores "Conexión y Cuidado" que significa crear y mantener relaciones duraderas con cada miembro y cuidarnos uno a otros, dentro de nuestras labores diarias y hasta en nuestra vida personal. Esto nos lleva a un desarrollo y mejora constante en Programas de Capacitación, evaluación de desempeño 360, Programas de Bienestar y Salud, de tal manera de mantener nuestro recurso, y el conocimiento que adquieren a lo largo del tiempo.

F1: ¿Considera que su personal se siente comprometido con la Empresa? 
F2: Hablar de personas es un poco complejo, y medir el compromiso de ellos también lo es, sin embargo, en Eternit tenemos una gran preocupación por ello, y es así que contamos con una encuesta anual de Clima Laboral, la cual incluye un Plan de acción Anual respecto a los resultados obtenidos. Como varias compañías tenemos mucho por trabajar en este sentido y el recurso humano va cambiando sus necesidades con el tiempo, nos toca ir mejorando nuestros propios reglamentos, y la diferenciación de competencias y funciones, que nos permite desarrollar bandas económicas que sirvan como base para un establecimiento de líneas de crecimiento, tanto a nivel operativo y mando medio. Eternit viene trabajando en estos temas a través del Área de RRHH.

\section{F1: ¿Emplea algún programa de innovación o mejora continua en su empresa?}

F2: La compañía anualmente elabora un Plan de Ahorros, el cual está basado en la identificación y evaluación de oportunidades en cada Área de la Compañía, esto representa el Objetivo anual el cual se alinea al cumplimiento de los KPI operativos. En temas de innovación, tenemos oportunidades de mejora, la compañía ha desarrollado productos como Viviendas Flexibles, pero más por solicitud de un cliente especifico como el estado, pero no por iniciativa propia, de esto ya la compañía ha tomado cartas en el asunto, y tenemos un área más fortalecida para el inicio de este cambio específicamente en Peru. Asimismo, hoy no contamos con un Sistema de Mejoramiento continuo Formal y establecido, para el 2018 es el reto, sobre todo orientado a los procesos productivos, y el Sistema de Información que manejamos, que son áreas que requieren cambios a corto y mediano plazo

\section{F1: ¿Cuáles considera son los mayores desafíos que afronta?}

F2: Uno de los grandes desafíos de la compañía es lograr una mayor difusión y conocimiento del Producto, tanto por los Satkeholders de la Industria, como de una 
persona común y corriente que desea realizar una ampliación en su hogar o tiene algún proyecto de construcción. Este mismo desafío nos lleva a otro igual de retador que es la reducción de nuestros costos, que permita tener productos asequibles para el mercado. Para ello tenemos los cimientos como son nuestra marca, conocimiento y experiencia y el soporte técnico y Financiero de nuestro grupo.

F1: Para finalizar, ¿Cómo visualiza su empresa en los próximos 2 años?

F2: Lo resumo en 2 cosas, siendo la mejor empresa para trabajar en el País, por ser la empresa más segura, confortable, y feliz. Y reconocida por su innovación en productos para la construcción. 


\section{Factores Internos Claves}

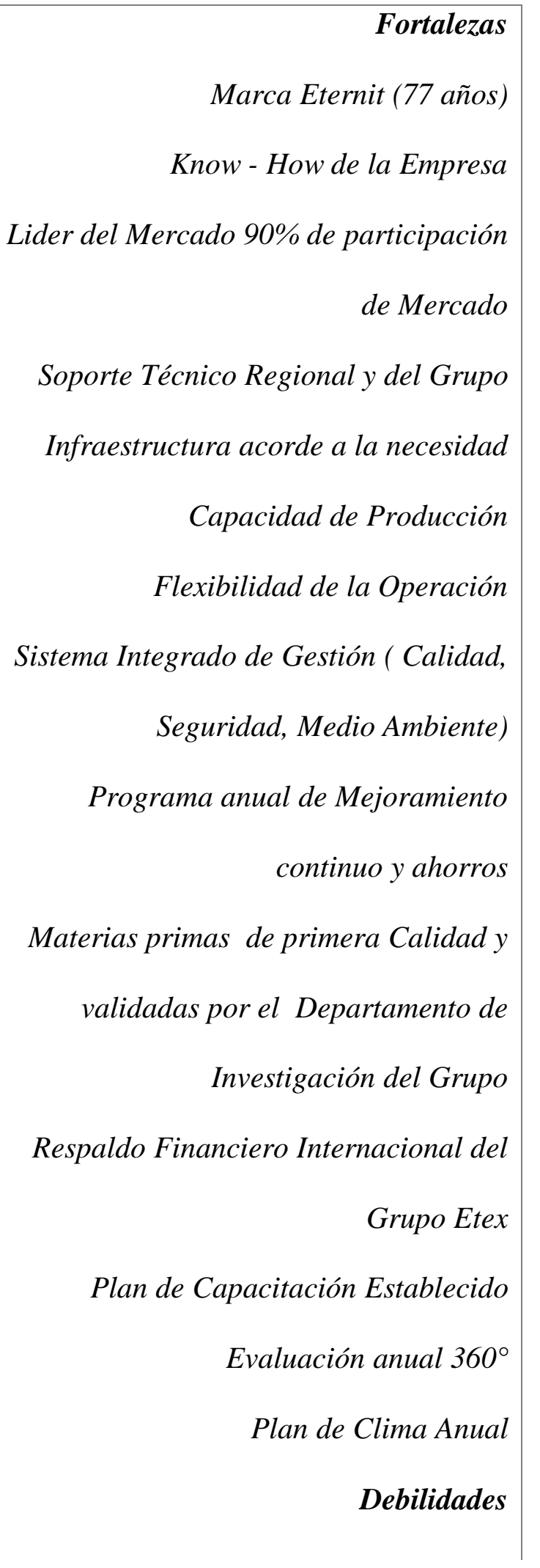




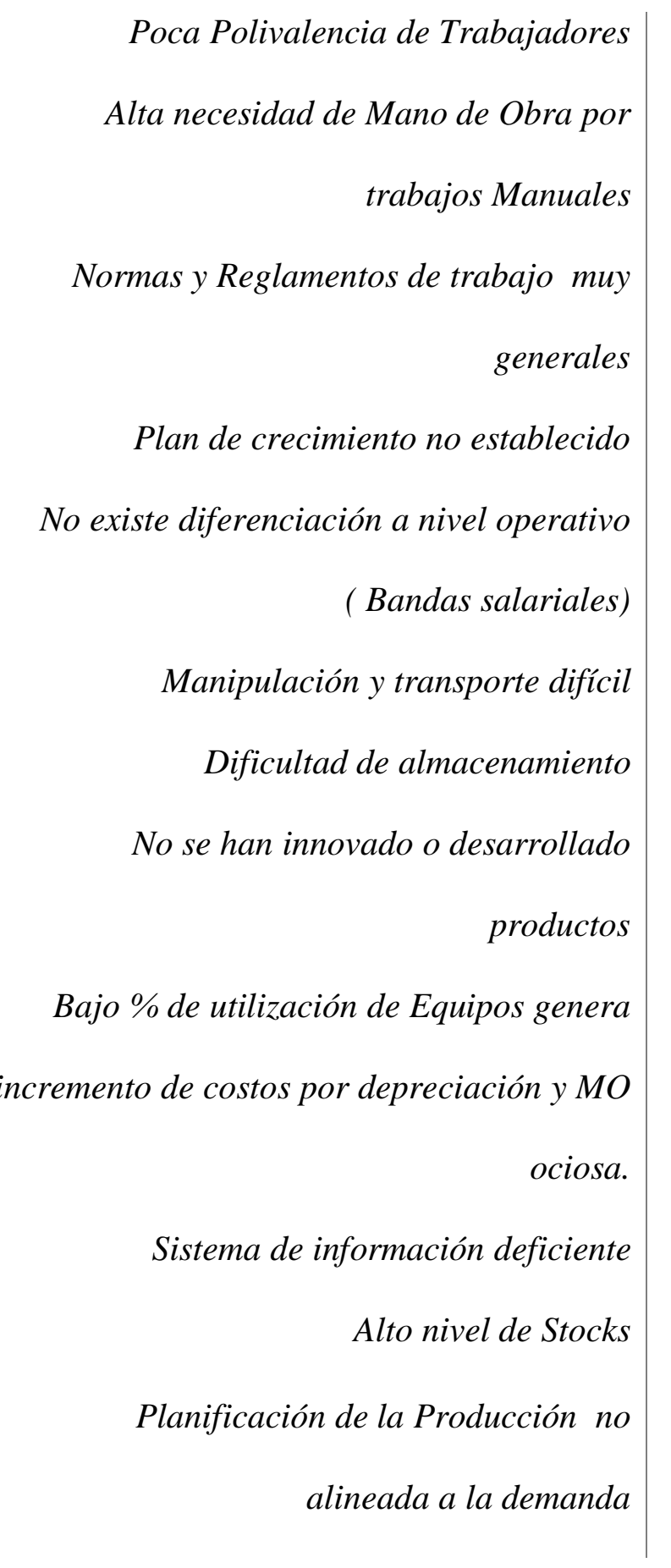


Entrevista a profundidad con especialista

\section{F1: Entrevistador}

F2: Entrevistado

\section{F1: ¿Cuál es su profesión?}

F2: Ingeniero Mecanico

F1: ¿A qué se dedica actualmente?

F2: Administrador de Contratos y docente

F1: Cuál es su opinión de la empresa eternit, específicamente de su línea de fibrocemento

F2 Empresa conocida en el mercado nacional

F1: ¿Conoce el soporte técnico que brinda la marca eternit?

F2: No

F1: ¿Cuál es su opinión acerca del fibrocemento como reemplazo de los materiales de construcción tradicionales?

F2: Interesante en el sector construccion

F1: ¿Cuales considera usted que son las principales debilidades del fibrocemento?

F2: No lo conozco a detalle

F1: De los siguientes factores críticos, ¿cómo calificaría usted su importancia? Considerar otorgarles un valor del 0 al 5, donde 0 significaría nada importantes y 5 , extremadamente importantes.

\begin{tabular}{|l|c|}
\hline FACTORES CRITICOS DE & \\
ÉXITO & PUNTAJE \\
\hline Fabricación Local & 3 \\
\hline Marca reconocida & 4 \\
\hline Know How de la Empresa & 4 \\
\hline Precio & 4 \\
\hline Participación de mercado & 4 \\
\hline Costos de producción & 4 \\
\hline Calidad del producto & 4 \\
\hline Personal capacitado & 3 \\
\hline Posicionamiento & 3 \\
\hline Capacidad de abastecimiento & 2 \\
\hline Distribución a nivel nacional & 2 \\
\hline Desarrollo de nuevos productos & 1 \\
\hline
\end{tabular}


F1: Según su opinión, cual seria la calificación que le daría a cada una de estas empresas en los siguientes factores de éxito, considerando la siguiente escala:

\section{1- Gran debilidad}

\section{2- Debilidad menor}

\section{3- Fuerza menor}

\section{4- Gran fortaleza.}

\begin{tabular}{|l|c|c|c|}
\hline \multirow{2}{*}{\begin{tabular}{|l|c|} 
FACTORES CRITICOS DE \\
ÉXITO
\end{tabular}} & \multicolumn{3}{|c|}{ EMPRESA } \\
\cline { 2 - 4 } & Eternit & Volcán & Plycem \\
\hline Fabricación Local & 4 & 1 & 1 \\
\hline Marca reconocida & 4 & 3 & 3 \\
\hline Know How de la Empresa & 4 & 2 & 4 \\
\hline Precio & 4 & 3 & 3 \\
\hline Participación de mercado & 3 & 3 & 2 \\
\hline Costos de producción & 2 & 1 & 2 \\
\hline Calidad del producto & 3 & 3 & 3 \\
\hline Personal capacitado & 3 & 3 & 3 \\
\hline Posicionamiento & 3 & 2 & 1 \\
\hline Capacidad de abastecimiento & 4 & 1 & 2 \\
\hline Distribución a nivel nacional & 2 & 3 & 2 \\
\hline Desarrollo de nuevos productos & 2 & 3 & 4 \\
\hline
\end{tabular}


Entrevista a profundidad con especialista

\section{F1: Entrevistador}

F2: Entrevistado

\section{F1: ¿Cuál es su profesión?}

F2: Ingeniero civil

F1: ¿A qué se dedica actualmente?

F2: Trabajo en obra

F1: Cuál es su opinión de la empresa eternit, específicamente de su línea de fibrocemento

F2 Es una buena opción para aligerar cargas

F1: ¿Conoce el soporte técnico que brinda la marca eternit?

F2: No

F1: ¿Cuál es su opinión acerca del fibrocemento como reemplazo de los materiales de construcción tradicionales?

F2: Es una buena opción

F1: ¿Cuales considera usted que son las principales debilidades del fibrocemento?

F2: Falta de conocimiento del constructor

F1: De los siguientes factores críticos, ¿cómo calificaría usted su importancia? Considerar otorgarles un valor del 0 al 5, donde 0 significaría nada importantes y 5 , extremadamente importantes.

\begin{tabular}{|l|c|}
\hline FACTORES CRITICOS DE & PUNTAJE \\
ÉXITO & 3 \\
\hline Fabricación Local & 4 \\
\hline Marca reconocida & 4 \\
\hline Know How de la Empresa & 4 \\
\hline Precio & 3 \\
\hline Participación de mercado & 3 \\
\hline Costos de producción & 3 \\
\hline Calidad del producto & 3 \\
\hline Personal capacitado & 3 \\
\hline Posicionamiento & 3 \\
\hline Capacidad de abastecimiento & 4 \\
\hline Distribución a nivel nacional & 3 \\
\hline Desarrollo de nuevos productos & \\
\hline
\end{tabular}


F1: Según su opinión, cual seria la calificación que le daría a cada una de estas empresas en los siguientes factores de éxito, considerando la siguiente escala:

\section{1- Gran debilidad}

\section{2- Debilidad menor}

\section{3- Fuerza menor}

\section{4- Gran fortaleza.}

\begin{tabular}{|l|c|c|c|}
\hline \multirow{2}{*}{\begin{tabular}{|l|c|} 
FACTORES CRITICOS DE \\
\cline { 2 - 4 }
\end{tabular}} & \multicolumn{4}{|c|}{ EMPITO } & Eternit & \multicolumn{1}{c|}{ Volcán } & Plycem \\
\cline { 2 - 4 } & Calif. & Calif. & Calif. \\
\hline Fabricación Local & 4 & 1 & 1 \\
\hline Marca reconocida & 4 & 3 & 2 \\
\hline Know How de la Empresa & 4 & 3 & 3 \\
\hline Precio & 4 & 3 & 3 \\
\hline Participación de mercado & 2 & 1 & 1 \\
\hline Costos de producción & 2 & 3 & 1 \\
\hline Calidad del producto & 4 & 3 & 3 \\
\hline Personal capacitado & 4 & 3 & 3 \\
\hline Posicionamiento & 4 & 1 & 2 \\
\hline Capacidad de abastecimiento & 4 & 3 & 2 \\
\hline Distribución a nivel nacional & 3 & 3 & 2 \\
\hline Desarrollo de nuevos productos & 3 & 2 & 4 \\
\hline
\end{tabular}


Entrevista a profundidad con especialista

\section{F1: Entrevistador}

F2: Entrevistado

\section{F1: ¿Cuál es su profesión?}

F2: Ingeniero civil

\section{F1: ¿A qué se dedica actualmente?}

F2: Ingeniero de producción en obras

F1: Cuál es su opinión de la empresa eternit, específicamente de su línea de fibrocemento

F2 He utilizado las planchas de fibrocemento de eternit para estructuras de drywall con adecuada resistencia climática y exteriores. El material es bueno; sin embargo, siempre existe un punto debil en las uniones de las planchas que deberán ser atendidos con bastante profesionalismo.

\section{F1: ¿Conoce el soporte técnico que brinda la marca eternit?}

F2: No

F1: ¿Cuál es su opinión acerca del fibrocemento como reemplazo de los materiales de construcción tradicionales?

F2: Actualmente el Perú tiene poca cultura en el uso del fibrocemento. Para esto hay que hacer que los arquitectos empiecen a promoverlos desde sus diseños.

\section{F1: ¿Cuales considera usted que son las principales debilidades del fibrocemento?}

F2: Las uniones de las planchas.

F1: De los siguientes factores críticos, ¿cómo calificaría usted su importancia? Considerar otorgarles un valor del 0 al 5, donde 0 significaría nada importantes y 5 , extremadamente importantes.

\begin{tabular}{|l|c|}
\hline FACTORES CRITICOS DE ÉXITO & PUNTAJE \\
\hline Fabricación Local & 4 \\
\hline Marca reconocida & 4 \\
\hline Know How de la Empresa & 3 \\
\hline Precio & 3 \\
\hline Participación de mercado & 3 \\
\hline Costos de producción & 4 \\
\hline Calidad del producto & 3 \\
\hline Personal capacitado & 3 \\
\hline Posicionamiento & 3 \\
\hline Capacidad de abastecimiento & 3 \\
\hline
\end{tabular}




\begin{tabular}{|l|c|} 
Distribución a nivel nacional & 4 \\
\hline Desarrollo de nuevos productos & 1 \\
\hline
\end{tabular}

F1: Según su opinión, cual seria la calificación que le daría a cada una de estas empresas en los siguientes factores de éxito, considerando la siguiente escala:

\section{1- Gran debilidad}

\section{2- Debilidad menor}

\section{3- Fuerza menor}

\section{4- Gran fortaleza.}

\begin{tabular}{|l|c|c|c|}
\hline \multirow{2}{*}{$\begin{array}{l}\text { FACTORES CRITICOS DE } \\
\text { ÉXITO }\end{array}$} & \multicolumn{3}{|c|}{ EMPRESA } \\
\cline { 2 - 4 } & Eternit & \multicolumn{1}{|c|}{ Volcán } & Plycem \\
\cline { 2 - 4 } Calif. & Calif. & Calif. \\
\hline Mabricación Local & 4 & 1 & 1 \\
\hline Know How de la Empresa & 4 & 3 & 4 \\
\hline Precio & 3 & 3 & 3 \\
\hline Participación de mercado & 2 & 2 & 3 \\
\hline Costos de producción & 2 & 3 & 2 \\
\hline Calidad del producto & 3 & 3 & 3 \\
\hline Personal capacitado & 4 & 2 & 3 \\
\hline Posicionamiento & 4 & 3 & 2 \\
\hline Capacidad de abastecimiento & 3 & 3 & 1 \\
\hline Distribución a nivel nacional & 2 & 2 & 1 \\
\hline Desarrollo de nuevos productos & 2 & 3 & 3 \\
\hline
\end{tabular}


Entrevista a profundidad con especialista

\section{F1: Entrevistador}

F2: Entrevistado

\section{F1: ¿Cuál es su profesión?}

F2: Ingeniero civil

F1: ¿A qué se dedica actualmente?

F2: Residente de obra y docente

F1: Cuál es su opinión de la empresa eternit, específicamente de su línea de fibrocemento

F2 Es un producto muy bueno para exteriores de rápido ejecución

F1: ¿Conoce el soporte técnico que brinda la marca eternit?

F2: No

F1: ¿Cuál es su opinión acerca del fibrocemento como reemplazo de los materiales de construcción tradicionales?

F2: Muy bueno resistente para intemperie y acorta el plazo de ejecución y su bajo costo.con el sistema tradicional

F1: ¿Cuales considera usted que son las principales debilidades del fibrocemento?

F2: Poca difusión.

F1: De los siguientes factores críticos, ¿cómo calificaría usted su importancia? Considerar otorgarles un valor del 0 al 5, donde 0 significaría nada importantes y 5 , extremadamente importantes.

\begin{tabular}{|l|c|}
\hline FACTORES CRITICOS DE & PUNTAJE \\
ÉXITO & 4 \\
\hline Fabricación Local & 4 \\
\hline Marca reconocida & 4 \\
\hline Know How de la Empresa & 4 \\
\hline Precio & 3 \\
\hline Participación de mercado & 3 \\
\hline Costos de producción & 4 \\
\hline Calidad del producto & 3 \\
\hline Personal capacitado & 4 \\
\hline Posicionamiento & 2 \\
\hline Capacidad de abastecimiento & 3 \\
\hline Distribución a nivel nacional & 2 \\
\hline Desarrollo de nuevos productos & \\
\hline
\end{tabular}


F1: Según su opinión, cual seria la calificación que le daría a cada una de estas empresas en los siguientes factores de éxito, considerando la siguiente escala:

\section{1- Gran debilidad}

2- Debilidad menor

3- Fuerza menor

4- Gran fortaleza.

\begin{tabular}{|l|c|c|c|}
\hline \multirow{2}{*}{\begin{tabular}{|l|c|} 
FACTORES CRITICOS DE \\
ÉXITO
\end{tabular}} & \multicolumn{3}{|c|}{ EMPRESA } \\
\cline { 2 - 4 } & Eternit & \multicolumn{1}{c|}{ Volcán } & Plycem \\
\hline Fabricación Local & 3 & 1 & 2 \\
\hline Marca reconocida & 4 & 2 & 4 \\
\hline Know How de la Empresa & 2 & 1 & 3 \\
\hline Precio & 3 & 3 & 2 \\
\hline Participación de mercado & 4 & 2 & 1 \\
\hline Costos de producción & 2 & 1 & 2 \\
\hline Calidad del producto & 3 & 2 & 3 \\
\hline Personal capacitado & 4 & 3 & 2 \\
\hline Posicionamiento & 4 & 1 & 1 \\
\hline Capacidad de abastecimiento & 3 & 1 & 2 \\
\hline Distribución a nivel nacional & 2 & 1 & 2 \\
\hline Desarrollo de nuevos productos & 1 & 2 & 3 \\
\hline
\end{tabular}


Entrevista a profundidad con especialista

\section{F1: Entrevistador}

F2: Entrevistado

\section{F1: ¿Cuál es su profesión?}

F2: Ingeniero civil

F1: ¿A qué se dedica actualmente?

F2: Docente tiempo completo

F1: Cuál es su opinión de la empresa eternit, específicamente de su línea de fibrocemento

F2 Buena opción y calidad de materiales

F1: ¿Conoce el soporte técnico que brinda la marca eternit?

F2: Sí

F1: ¿Cuál es su opinión acerca del fibrocemento como reemplazo de los materiales de construcción tradicionales?

F2: Una opción más eficiente y estética

F1: ¿Cuales considera usted que son las principales debilidades del fibrocemento?

F2: Su poco conocimiento en su uso como separadores de espacios

F1: De los siguientes factores críticos, ¿cómo calificaría usted su importancia?

Considerar otorgarles un valor del 0 al 5, donde 0 significaría nada importantes y 5 , extremadamente importantes.

\begin{tabular}{|l|c|}
\hline FACTORES CRITICOS DE & \\
ÉXITO & PUNTAJE \\
\hline Fabricación Local & 4 \\
\hline Marca reconocida & 3 \\
\hline Know How de la Empresa & 4 \\
\hline Precio & 4 \\
\hline Participación de mercado & 3 \\
\hline Costos de producción & 3 \\
\hline Calidad del producto & 3 \\
\hline Personal capacitado & 3 \\
\hline Posicionamiento & 3 \\
\hline Capacidad de abastecimiento & 3 \\
\hline Distribución a nivel nacional & 2 \\
\hline Desarrollo de nuevos productos & 2 \\
\hline
\end{tabular}


F1: Según su opinión, cual seria la calificación que le daría a cada una de estas empresas en los siguientes factores de éxito, considerando la siguiente escala:

\section{1- Gran debilidad}

\section{2- Debilidad menor}

\section{3- Fuerza menor}

\section{4- Gran fortaleza.}

\begin{tabular}{|c|c|c|c|}
\hline \multirow{3}{*}{$\begin{array}{l}\text { FACTORES CRITICOS DE } \\
\text { ÉXITO }\end{array}$} & \multicolumn{3}{|c|}{ EMPRESA } \\
\hline & Eternit & Volcán & Plycem \\
\hline & Calif. & Calif. & Calif. \\
\hline Fabricación Local & 4 & 2 & 2 \\
\hline Marca reconocida & 4 & 2 & 3 \\
\hline Know How de la Empresa & 4 & 2 & 3 \\
\hline Precio & 3 & 2 & 3 \\
\hline Participación de mercado & 3 & 2 & 1 \\
\hline Costos de producción & 3 & 3 & 1 \\
\hline Calidad del producto & 3 & 3 & 3 \\
\hline Personal capacitado & 3 & 3 & 3 \\
\hline Posicionamiento & 4 & 2 & 2 \\
\hline Capacidad de abastecimiento & 4 & 3 & 2 \\
\hline Distribución a nivel nacional & 1 & 3 & 3 \\
\hline Desarrollo de nuevos productos & 2 & 3 & 4 \\
\hline
\end{tabular}


Entrevista a profundidad con especialista

\section{F1: Entrevistador}

F2: Entrevistado

\section{F1: ¿Cuál es su profesión?}

F2: Ingeniero civil

F1: ¿A qué se dedica actualmente?

F2: Docente en el Instituto Capeco

F1: Cuál es su opinión de la empresa eternit, específicamente de su línea de fibrocemento

F2 Me parece una nueva manera de economizar y de disminuir peso a un edificio.

F1: ¿Conoce el soporte técnico que brinda la marca eternit?

F2: Sí

F1: ¿Cuál es su opinión acerca del fibrocemento como reemplazo de los materiales de construcción tradicionales?

F2: Me parece bien porque se tiene una mayor velocidad de ejecución de obra, con el consiguiente se puede lograr mayor beneficio financiero.

F1: ¿Cuales considera usted que son las principales debilidades del fibrocemento?

F2: Que son bastantes frágiles y quebradizas.

F1: De los siguientes factores críticos, ¿cómo calificaría usted su importancia? Considerar otorgarles un valor del 0 al 5, donde 0 significaría nada importantes y 5 , extremadamente importantes.

\begin{tabular}{|l|c|}
\hline FACTORES CRITICOS DE & PUNTAJE \\
\hline EXITO & 4 \\
\hline Fabricación Local & 4 \\
\hline Marca reconocida & 4 \\
\hline Know How de la Empresa & 4 \\
\hline Precio & 3 \\
\hline Participación de mercado & 4 \\
\hline Costos de producción & 3 \\
\hline Calidad del producto & 4 \\
\hline Personal capacitado & 3 \\
\hline Posicionamiento & 4 \\
\hline Capacidad de abastecimiento & 2 \\
\hline Distribución a nivel nacional & 2 \\
\hline Desarrollo de nuevos productos & \\
\hline
\end{tabular}


F1: Según su opinión, cual seria la calificación que le daría a cada una de estas empresas en los siguientes factores de éxito, considerando la siguiente escala:

\section{1- Gran debilidad}

\section{2- Debilidad menor}

\section{3- Fuerza menor}

\section{4- Gran fortaleza.}

\begin{tabular}{|c|c|c|c|}
\hline \multirow{3}{*}{$\begin{array}{l}\text { FACTORES CRITICOS DE } \\
\text { ÉXITO }\end{array}$} & \multicolumn{3}{|c|}{ EMPRESA } \\
\hline & Eternit & Volcán & Plycem \\
\hline & Calif. & Calif. & Calif. \\
\hline Fabricación Local & 4 & 2 & 2 \\
\hline Marca reconocida & 3 & 2 & 3 \\
\hline Know How de la Empresa & 3 & 3 & 3 \\
\hline Precio & 3 & 1 & 3 \\
\hline Participación de mercado & 3 & 2 & 1 \\
\hline Costos de producción & 2 & 2 & 2 \\
\hline Calidad del producto & 3 & 1 & 3 \\
\hline Personal capacitado & 3 & 2 & 3 \\
\hline Posicionamiento & 4 & 2 & 1 \\
\hline Capacidad de abastecimiento & 3 & 2 & 1 \\
\hline Distribución a nivel nacional & 2 & 3 & 2 \\
\hline Desarrollo de nuevos productos & 1 & 3 & 3 \\
\hline
\end{tabular}


Entrevista a profundidad con especialista

\section{F1: Entrevistador}

F2: Entrevistado

\section{F1: ¿Cuál es su profesión?}

F2: Ingeniero civil

F1: ¿A qué se dedica actualmente?

F2: Construcción de edificaciones

F1: Cuál es su opinión de la empresa eternit, específicamente de su línea de fibrocemento

F2 Solución práctica e innovadora como material de construcción.

F1: ¿Conoce el soporte técnico que brinda la marca eternit?

F2: No

F1: ¿Cuál es su opinión acerca del fibrocemento como reemplazo de los materiales de construcción tradicionales?

F2: Mejor acabado y de fácil instalación

F1: ¿Cuales considera usted que son las principales debilidades del fibrocemento?

F2: La logística es su despacho

F1: De los siguientes factores críticos, ¿cómo calificaría usted su importancia? Considerar otorgarles un valor del 0 al 5, donde 0 significaría nada importantes y 5 , extremadamente importantes.

\begin{tabular}{|l|c|}
\hline FACTORES CRITICOS DE & \\
ÉXITO & PUNTAJE \\
\hline Fabricación Local & 4 \\
\hline Marca reconocida & 4 \\
\hline Know How de la Empresa & 3 \\
\hline Precio & 4 \\
\hline Participación de mercado & 4 \\
\hline Costos de producción & 3 \\
\hline Calidad del producto & 3 \\
\hline Personal capacitado & 4 \\
\hline Posicionamiento & 4 \\
\hline Capacidad de abastecimiento & 3 \\
\hline Distribución a nivel nacional & 4 \\
\hline Desarrollo de nuevos productos & 3 \\
\hline
\end{tabular}


F1: Según su opinión, cual seria la calificación que le daría a cada una de estas empresas en los siguientes factores de éxito, considerando la siguiente escala:

\section{1- Gran debilidad}

\section{2- Debilidad menor}

\section{3- Fuerza menor}

\section{4- Gran fortaleza.}

\begin{tabular}{|c|c|c|c|}
\hline \multirow{3}{*}{$\begin{array}{l}\text { FACTORES CRITICOS DE } \\
\text { ÉXITO }\end{array}$} & \multicolumn{3}{|c|}{ EMPRESA } \\
\hline & Eternit & Volcán & Plycem \\
\hline & Calif. & Calif. & Calif. \\
\hline Fabricación Local & 3 & 1 & 1 \\
\hline Marca reconocida & 4 & 3 & 3 \\
\hline Know How de la Empresa & 4 & 3 & 3 \\
\hline Precio & 3 & 3 & 3 \\
\hline Participación de mercado & 3 & 3 & 1 \\
\hline Costos de producción & 2 & 2 & 2 \\
\hline Calidad del producto & 4 & 2 & 2 \\
\hline Personal capacitado & 4 & 2 & 3 \\
\hline Posicionamiento & 3 & 2 & 2 \\
\hline Capacidad de abastecimiento & 4 & 2 & 2 \\
\hline Distribución a nivel nacional & 2 & 3 & 1 \\
\hline Desarrollo de nuevos productos & 2 & 2 & 4 \\
\hline
\end{tabular}


Entrevista a profundidad con especialista

\section{F1: Entrevistador}

F2: Entrevistado

\section{F1: ¿Cuál es su profesión?}

F2: Ingeniero civil

F1: ¿A qué se dedica actualmente?

F2: Construcción de edificaciones

F1: Cuál es su opinión de la empresa eternit, específicamente de su línea de fibrocemento

F2 Son prácticos y muy buenos productos

F1: ¿Conoce el soporte técnico que brinda la marca eternit?

F2: Sí

F1: ¿Cuál es su opinión acerca del fibrocemento como reemplazo de los materiales de construcción tradicionales?

F2: Las planchas de eternit lo reemplazo en los muros ligeros, lo compararia con el Drywall. Ya son mas resistentes ante la humedad

F1: ¿Cuales considera usted que son las principales debilidades del fibrocemento?

F2: Cuando uso pintura directo al fibrocemento no me queda muy bien como acabado... Tengo que empastarlo antes como 2 a 3 veces para que agarre un mismo nivel.

F1: De los siguientes factores críticos, ¿cómo calificaría usted su importancia? Considerar otorgarles un valor del 0 al 5, donde 0 significaría nada importantes y 5 , extremadamente importantes.

\begin{tabular}{|l|c|}
\hline FACTORES CRITICOS DE & PUNTAJE \\
ÉXITO & 4 \\
\hline Fabricación Local & 3 \\
\hline Marca reconocida & 4 \\
\hline Know How de la Empresa & 3 \\
\hline Precio & 4 \\
\hline Participación de mercado & 2 \\
\hline Costos de producción & 3 \\
\hline Calidad del producto & 3 \\
\hline Personal capacitado & 3 \\
\hline Posicionamiento & 2 \\
\hline Capacidad de abastecimiento & 3 \\
\hline Distribución a nivel nacional & 2 \\
\hline Desarrollo de nuevos productos & \\
\hline
\end{tabular}


F1: Según su opinión, cual seria la calificación que le daría a cada una de estas empresas en los siguientes factores de éxito, considerando la siguiente escala:

\section{1- Gran debilidad}

\section{2- Debilidad menor}

\section{3- Fuerza menor}

\section{4- Gran fortaleza.}

\begin{tabular}{|c|c|c|c|}
\hline \multirow{3}{*}{$\begin{array}{l}\text { FACTORES CRITICOS DE } \\
\text { ÉXITO }\end{array}$} & \multicolumn{3}{|c|}{ EMPRESA } \\
\hline & Eternit & Volcán & Plycem \\
\hline & Calif. & Calif. & Calif. \\
\hline Fabricación Local & 4 & 1 & 2 \\
\hline Marca reconocida & 3 & 3 & 3 \\
\hline Know How de la Empresa & 4 & 3 & 3 \\
\hline Precio & 3 & 3 & 2 \\
\hline Participación de mercado & 4 & 1 & 1 \\
\hline Costos de producción & 2 & 1 & 1 \\
\hline Calidad del producto & 3 & 3 & 3 \\
\hline Personal capacitado & 3 & 3 & 3 \\
\hline Posicionamiento & 4 & 2 & 2 \\
\hline Capacidad de abastecimiento & 4 & 2 & 1 \\
\hline Distribución a nivel nacional & 1 & 1 & 1 \\
\hline Desarrollo de nuevos productos & 2 & 2 & 4 \\
\hline
\end{tabular}


Entrevista a profundidad con especialista

\section{F1: Entrevistador}

F2: Entrevistado

\section{F1: ¿Cuál es su profesión?}

F2: Ingeniero civil

F1: ¿A qué se dedica actualmente?

F2: Docente tiempo completo

F1: Cuál es su opinión de la empresa eternit, específicamente de su línea de fibrocemento

F2 Buena opción y calidad de materiales

F1: ¿Conoce el soporte técnico que brinda la marca eternit?

F2: Sí

F1: ¿Cuál es su opinión acerca del fibrocemento como reemplazo de los materiales de construcción tradicionales?

F2: Una opción más eficiente y estética

F1: ¿Cuales considera usted que son las principales debilidades del fibrocemento?

F2: Su poco conocimiento en su uso como separadores de espacios

F1: De los siguientes factores críticos, ¿cómo calificaría usted su importancia?

Considerar otorgarles un valor del 0 al 5, donde 0 significaría nada importantes y 5 , extremadamente importantes.

\begin{tabular}{|l|c|}
\hline FACTORES CRITICOS DE & \\
ÉXITO & PUNTAJE \\
\hline Fabricación Local & 4 \\
\hline Marca reconocida & 4 \\
\hline Know How de la Empresa & 4 \\
\hline Precio & 4 \\
\hline Participación de mercado & 3 \\
\hline Costos de producción & 3 \\
\hline Calidad del producto & 2 \\
\hline Personal capacitado & 3 \\
\hline Posicionamiento & 3 \\
\hline Capacidad de abastecimiento & 4 \\
\hline Distribución a nivel nacional & 2 \\
\hline Desarrollo de nuevos productos & 2 \\
\hline
\end{tabular}


F1: Según su opinión, cual seria la calificación que le daría a cada una de estas empresas en los siguientes factores de éxito, considerando la siguiente escala:

\section{1- Gran debilidad}

\section{2- Debilidad menor}

\section{3- Fuerza menor}

\section{4- Gran fortaleza}

\begin{tabular}{|l|c|c|c|}
\hline \multirow{2}{*}{$\begin{array}{l}\text { FACTORES CRITICOS DE } \\
\text { EXITO }\end{array}$} & \multicolumn{3}{|c|}{ EMPRESA } \\
\cline { 2 - 4 } & Eternit & \multicolumn{1}{c|}{ Volcán } & Plycem \\
\cline { 2 - 4 } Calif. & Calif. & Calif. \\
\hline Marca reconocida & 4 & 1 & 1 \\
\hline Know How de la Empresa & 4 & 3 & 3 \\
\hline Precio & 4 & 2 & 4 \\
\hline Participación de mercado & 3 & 3 & 3 \\
\hline Costos de producción & 2 & 1 & 2 \\
\hline Calidad del producto & 3 & 3 & 3 \\
\hline Personal capacitado & 3 & 3 & 3 \\
\hline Posicionamiento & 3 & 2 & 1 \\
\hline Capacidad de abastecimiento & 4 & 1 & 2 \\
\hline Distribución a nivel nacional & 2 & 3 & 2 \\
\hline Desarrollo de nuevos productos & 2 & 3 & 4 \\
\hline
\end{tabular}


Entrevista a profundidad con especialista

\section{F1: Entrevistador}

F2: Entrevistado

F1: ¿Cuál es su profesión?

F2: Ingeniero civil

F1: ¿A qué se dedica actualmente?

F2: Construcción

F1: Cuál es su opinión de la empresa eternit, específicamente de su línea de fibrocemento

F2 Buen material

F1: ¿Conoce el soporte técnico que brinda la marca eternit?

F2: No

F1: ¿Cuál es su opinión acerca del fibrocemento como reemplazo de los materiales de construcción tradicionales?

F2: Es optativo y tiene la ventaja en rendimiento

F1: ¿Cuales considera usted que son las principales debilidades del fibrocemento?

F2: Contacto con la intemperie, Humedad a pesar de contar con planchas RH

F1: De los siguientes factores críticos, ¿cómo calificaría usted su importancia? Considerar otorgarles un valor del 0 al 5, donde 0 significaría nada importantes y 5 , extremadamente importantes.

\begin{tabular}{|l|c|}
\hline FACTORES CRITICOS DE & PUNTAJE \\
ÉXITO & 4 \\
\hline Fabricación Local & 4 \\
\hline Marca reconocida & 4 \\
\hline Know How de la Empresa & 4 \\
\hline Precio & 3 \\
\hline Participación de mercado & 3 \\
\hline Costos de producción & 2 \\
\hline Calidad del producto & 3 \\
\hline Personal capacitado & 3 \\
\hline Posicionamiento & 4 \\
\hline Capacidad de abastecimiento & 2 \\
\hline Distribución a nivel nacional & 2 \\
\hline Desarrollo de nuevos productos & \\
\hline
\end{tabular}


F1: Según su opinión, cual seria la calificación que le daría a cada una de estas empresas en los siguientes factores de éxito, considerando la siguiente escala:

\section{1- Gran debilidad}

\section{2- Debilidad menor}

\section{3- Fuerza menor}

\section{4- Gran fortaleza.}

\begin{tabular}{|l|c|c|c|}
\hline \multirow{2}{*}{\begin{tabular}{|} 
FACTORES CRITICOS DE \\
ÉXITO
\end{tabular}} & \multicolumn{3}{|c|}{ EMPRESA } \\
\cline { 2 - 4 } & Eternit & \multicolumn{1}{|c|}{ Volcán } & Plycem \\
\cline { 2 - 4 } & Calif. & Calif. & Calif. \\
\hline Fabricación Local & 3 & 2 & 1 \\
\hline Marca reconocida & 3 & 2 & 3 \\
\hline Know How de la Empresa & 4 & 3 & 3 \\
\hline Precio & 4 & 3 & 3 \\
\hline Participación de mercado & 4 & 3 & 1 \\
\hline Costos de producción & 1 & 2 & 1 \\
\hline Calidad del producto & 4 & 3 & 3 \\
\hline Personal capacitado & 4 & 3 & 2 \\
\hline Posicionamiento & 3 & 2 & 2 \\
\hline Capacidad de abastecimiento & 3 & 2 & 2 \\
\hline Distribución a nivel nacional & 2 & 2 & 1 \\
\hline Desarrollo de nuevos productos & 2 & 3 & 4 \\
\hline
\end{tabular}



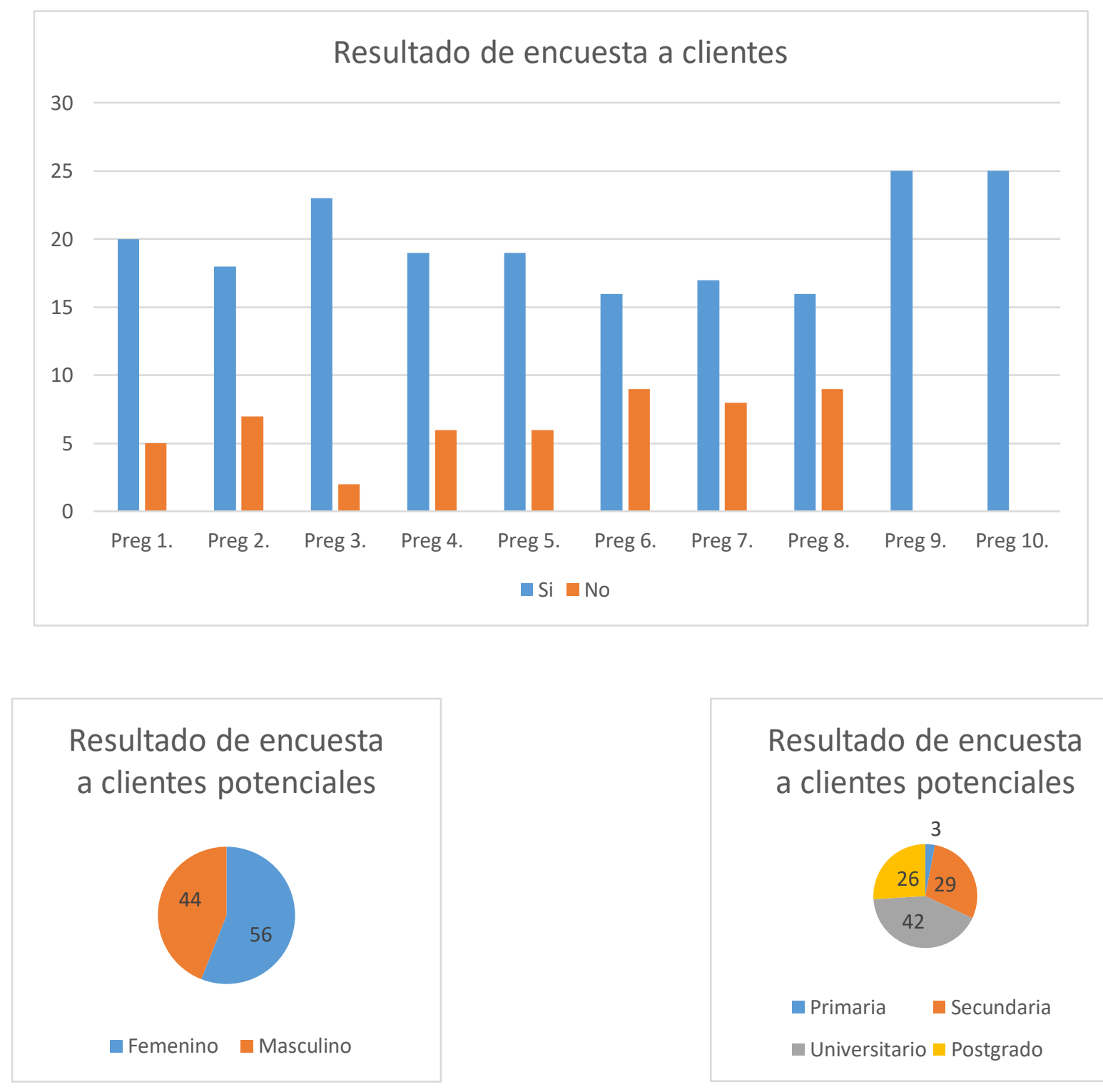

Resultado de encuesta a clientes potenciales

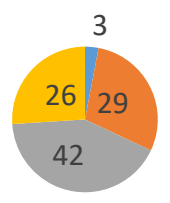
- Primaria
- Secundaria
n Universitario - Postgrado 

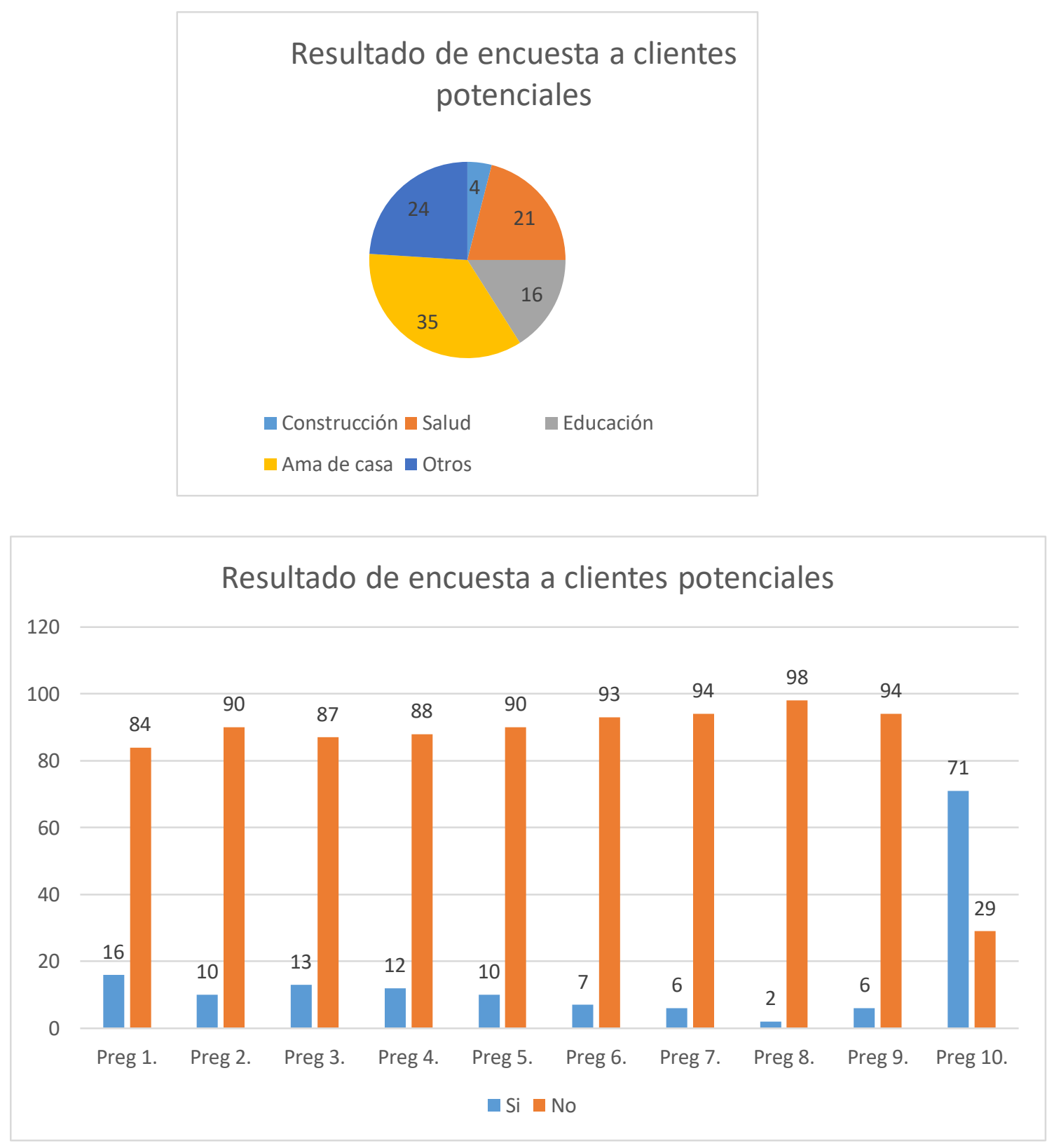
Anexo 9

\begin{tabular}{|c|c|c|c|c|c|c|c|c|c|c|c|c|c|}
\hline FABRICA PERUANA ETERNIT S.A. & & & & & & & & $12.99 \%$ & 37.07 & & & & \\
\hline \multicolumn{5}{|c|}{ ESTADOS FINANCIEROS |Individual | Anual al 31 de Diciembre del 2016 ( en miles de NUEVOS SOLES ) } & & & & & 3.37 & $1.42237 \%$ & & & \\
\hline & & & & & & & & & & & & & \\
\hline & & & & $2.50 \%$ & $2.50 \%$ & $2.50 \%$ & $2.50 \%$ & $2.50 \%$ & $2.50 \%$ & Proyeccion & de la empresa, tasa de & crecimiento & \\
\hline CUENTA & 2,015 & 2,016 & 2,017 & 2018 & 2019 & 2020 & 2021 & 2022 & 2023 & & & & \\
\hline Ingresos de Actividades Ordinarias & 259,485 & 236,929 & 248,775 & 254,994 & 261,369 & 267,903 & 274,601 & 281,466 & 288,503 & proyectado & en funcion a proyeccion & $n$ de ventas desde & e 1991 al 2024 \\
\hline Costo de Ventas & $-185,627$ & $-159,339$ & 169,971 & 171,393 & 172,678 & 173,814 & 174,783 & 175,572 & 176,162 & & & & \\
\hline \multirow[t]{2}{*}{ Ganancia (Pérdida) Bruta } & 73,858 & 77,590 & 78,804 & 83,602 & 88,691 & 94,090 & 99,818 & 105,894 & 112,340 & ratio de utili & lidad mayor eficiencia m & 1ejora a $3.5 \%$ & \\
\hline & & $30.61 \%$ & $31.68 \%$ & $32.79 \%$ & $33.93 \%$ & $35.12 \%$ & $36.35 \%$ & $37.62 \%$ & $38.94 \%$ & & & & \\
\hline Gastos de Ventas y Distribución & $-20,323$ & $-22,046$ & $-22,619$ & $-23,207$ & $-23,811$ & $-24,430$ & $-25,065$ & $-25,717$ & $-26,385$ & crecimiento & to por inflacion $2.6 \%$ & & \\
\hline Gastos de Administración & $-25,979$ & $-24,256$ & $-24,887$ & $-25,534$ & $-26,198$ & $-26,879$ & $-27,578$ & $-28,295$ & $-29,030$ & crecimiento & to por inflacion $2.6 \%$ & & \\
\hline Otros Ingresos Operativos & 534 & - & & & & & & & & & & & \\
\hline Otras Ganancias (Pérdidas) & $-2,790$ & -837 & $-1,777$ & $-1,821$ & $-1,867$ & $-1,913$ & $-1,961$ & $-2,010$ & $-2,061$ & se mantiene & en en $\%$ de las ventas & & \\
\hline \multirow[t]{2}{*}{ Ganancia (Pérdida) Operativa } & 25,300 & 30,451 & 29,522 & 33,039 & 36,816 & 40,868 & 45,214 & 49,872 & 54,864 & $19.02 \%$ & & & \\
\hline & & & & - & - & - & & - & - & & & & \\
\hline Gastos Financieros & $-6,141$ & $-6,720$ & $-6,472$ & $-6,634$ & $-6,799$ & $-6,969$ & $-7,144$ & $-7,322$ & $-7,505$ & se mantiene & en en $\%$ de las ventas & & \\
\hline Ganancia (Pérdida) por Deterioro de Valor & 2,665 & $-1,734$ & 367 & 376 & 386 & 395 & 405 & 415 & 426 & se mantiene & en en $\%$ de las ventas & & \\
\hline \multirow[t]{2}{*}{ Ganancia (Pérdida) antes de Impuestos } & 21,824 & 21,997 & 23,417 & 26,782 & 30,402 & 34,294 & 38,475 & 42,966 & 47,785 & & & & \\
\hline & & & - & - & - & - & - & - & - & & & & \\
\hline Ingreso (Gasto) por Impuesto & $-11,029$ & $-12,172$ & $-11,677$ & $-11,969$ & $-12,268$ & $-12,575$ & $-12,889$ & $-13,212$ & $-13,542$ & & & & \\
\hline Ganancia (Pérdida) Neta de Operaciones & 10,795 & 9,825 & 11,740 & 14,813 & 18,134 & 21,719 & 25,586 & 29,754 & 34,243 & & & & \\
\hline & & & & & & & & & & & & & \\
\hline & & & & & & & & & & & & & \\
\hline \multicolumn{14}{|l|}{ ANALISIS VERTICAL } \\
\hline \multicolumn{14}{|l|}{ FABRICA PERUANA ETERNIT S.A. } \\
\hline ESTADOS FINANCIEROS || |ndividual | Anual & ciembre de & (en miles $\mathrm{d}$ & EOS SOLES ) & & & & & & & & & & \\
\hline
\end{tabular}




\begin{tabular}{|c|c|c|c|c|c|}
\hline CUENTA & 2,015 & Var. \% & 2,016 & & Promedio \\
\hline Ingresos de Actividades Ordinarias & 259,485 & $100.00 \%$ & 236,929 & $100.00 \%$ & $100.00 \%$ \\
\hline Costo de Ventas & $-185,627$ & $-71.54 \%$ & $-159,339$ & $-67.25 \%$ & $-69.39 \%$ \\
\hline Ganancia (Pérdida) Bruta & 73,858 & $28.46 \%$ & 77,590 & $32.75 \%$ & $30.61 \%$ \\
\hline & & & & & \\
\hline Gastos de Ventas y Distribución & $-20,323$ & $-7.83 \%$ & $-22,046$ & $-9.30 \%$ & $-8.57 \%$ \\
\hline Gastos de Administración & $-25,979$ & $-10.01 \%$ & $-24,256$ & $-10.24 \%$ & $-10.12 \%$ \\
\hline Otros Ingresos Operativos & 534 & $0.21 \%$ & - & $0.00 \%$ & $0.10 \%$ \\
\hline Otras Ganancias (Pérdidas) & $-2,790$ & $-1.08 \%$ & -837 & $-0.35 \%$ & $-0.71 \%$ \\
\hline Ganancia (Pérdida) Operativa & 25,300 & $9.75 \%$ & 30,451 & $12.85 \%$ & $11.30 \%$ \\
\hline & & & & & \\
\hline Gastos Financieros & $-6,141$ & $-2.37 \%$ & $-6,720$ & $-2.84 \%$ & $-2.60 \%$ \\
\hline Ganancia (Pérdida) por Deterioro de Valor & 2,665 & $1.03 \%$ & $-1,734$ & $-0.73 \%$ & $0.15 \%$ \\
\hline Ganancia (Pérdida) antes de Impuestos & 21,824 & $8.41 \%$ & 21,997 & $9.28 \%$ & $8.85 \%$ \\
\hline & & & & & \\
\hline Ingreso (Gasto) por Impuesto & $-11,029$ & $-4.25 \%$ & $-12,172$ & $-5.14 \%$ & $-4.69 \%$ \\
\hline Ganancia (Pérdida) Neta de Operaciones & 10,795 & $4.16 \%$ & 9,825 & $4.15 \%$ & $4.15 \%$ \\
\hline & & & & & \\
\hline & & & & & \\
\hline
\end{tabular}




\begin{tabular}{|c|c|c|c|c|}
\hline \multicolumn{5}{|l|}{ Analisis Horizontal } \\
\hline FABRICA PERUANA ETERNIT S.A. & & & & \\
\hline \multicolumn{5}{|c|}{ ESTADOS FINANCIEROS |Individual | Anual al 31 de Diciembre del 2016 ( en miles de NUEVOS SOLES ) } \\
\hline & & & & \\
\hline \multirow[b]{2}{*}{ CUENTA } & & & & \\
\hline & 2,015 & 2,016 & Var. & $\%$ \\
\hline Ingresos de Actividades Ordinarias & 259,485 & 236,929 & $-22,556$ & $-8.69 \%$ \\
\hline Costo de Ventas & $-185,627$ & $-159,339$ & 26,288 & $-14.16 \%$ \\
\hline Ganancia (Pérdida) Bruta & 73,858 & 77,590 & 3,732 & $5.05 \%$ \\
\hline & & & & \\
\hline Gastos de Ventas y Distribución & $-20,323$ & $-22,046$ & $-1,723$ & $8.48 \%$ \\
\hline Gastos de Administración & $-25,979$ & $-24,256$ & 1,723 & $-6.63 \%$ \\
\hline Otros Ingresos Operativos & 534 & - & -534 & $-100.00 \%$ \\
\hline Otras Ganancias (Pérdidas) & $-2,790$ & -837 & 1,953 & $-70.00 \%$ \\
\hline Ganancia (Pérdida) Operativa & 25,300 & 30,451 & 5,151 & $20.36 \%$ \\
\hline & & & & \\
\hline Gastos Financieros & $-6,141$ & $-6,720$ & -579 & $9.43 \%$ \\
\hline Ganancia (Pérdida) por Deterioro de Valor & 2,665 & $-1,734$ & $-4,399$ & $-165.07 \%$ \\
\hline Ganancia (Pérdida) antes de Impuestos & 21,824 & 21,997 & 173 & $0.79 \%$ \\
\hline & & & & \\
\hline Ingreso (Gasto) por Impuesto & $-11,029$ & $-12,172$ & $-1,143$ & $10.36 \%$ \\
\hline Ganancia (Pérdida) Neta de Operaciones & 10,795 & 9,825 & -970 & $-8.99 \%$ \\
\hline & & & & \\
\hline & & & & \\
\hline
\end{tabular}


Anexo 10

Índices Financieros 2015-2016

Evaluación Índices Financieros Eternit

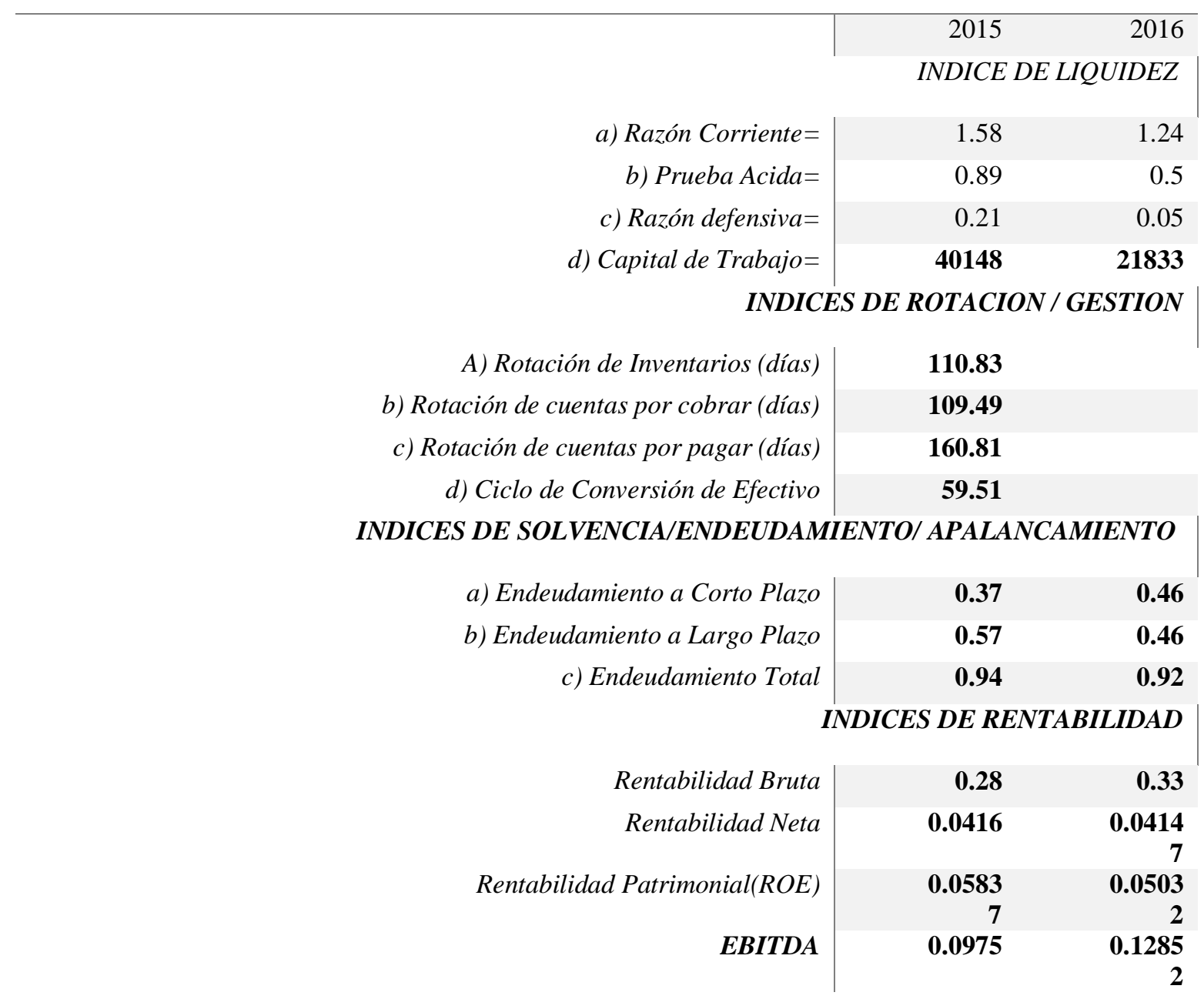

